ROMANIAN ACADEMY

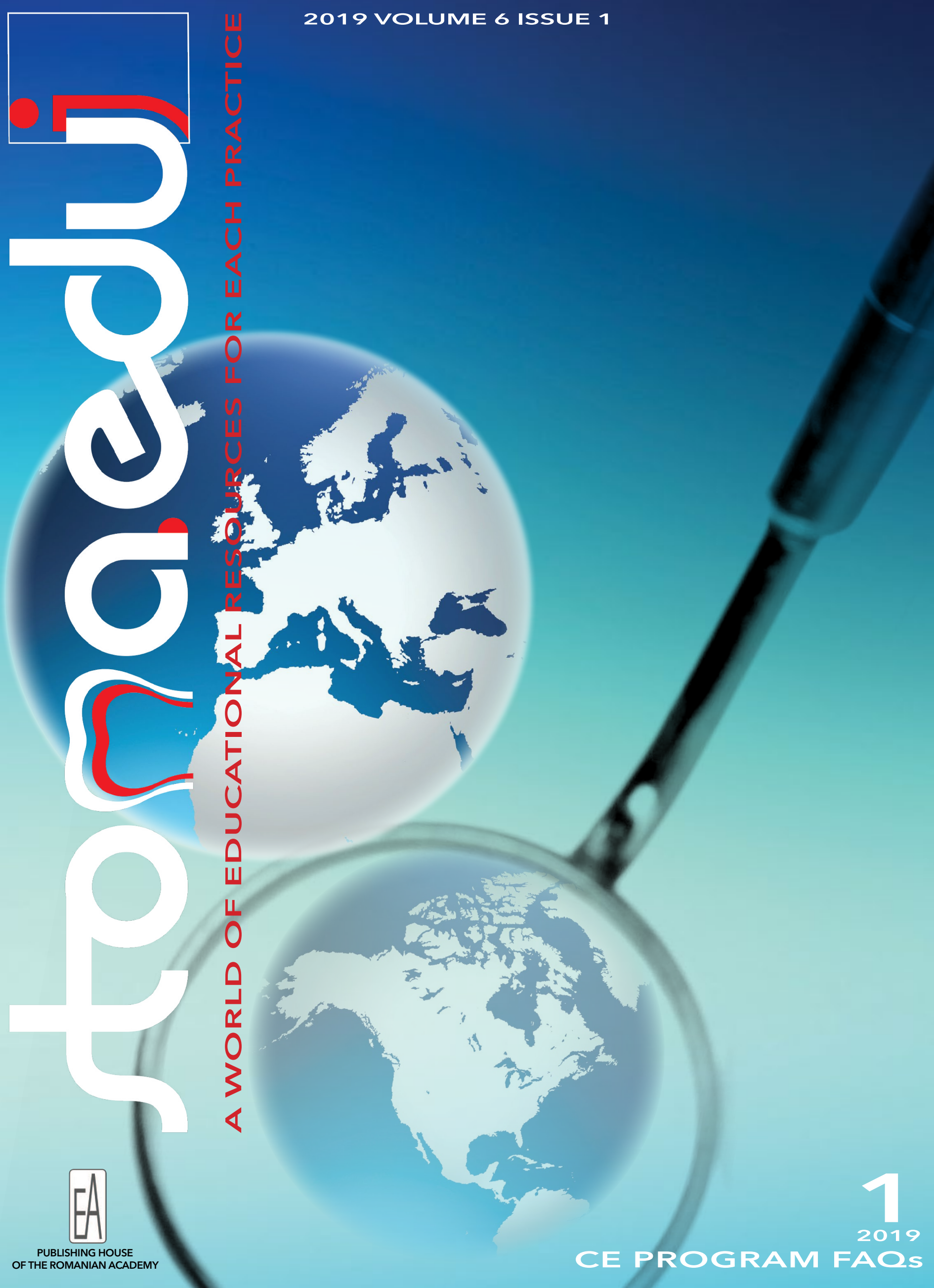




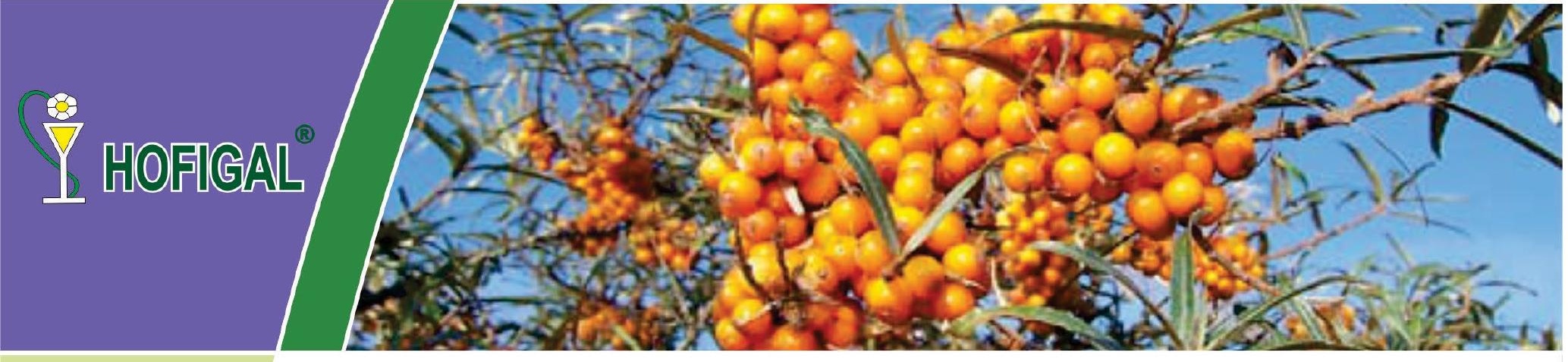

\section{Hofident $Q_{10}$}

Product presentation: Solution for oral hygiene.

Composition (INCI): aqua/water, alcohol, Capsella Bursa Pastoris extract, Plantago Lanceolata extract, Chamomilla Recutita extract, Achillea Millefolium extract, Aesculus Hippocastanum extract, Mentha Piperita extract, Ubiquinone.

Action: The product has antiseptic, healing, hemostatic, anti-inflammatory aєtion, it acts as a antioxidant, detoxifier, deodorant. It is strongly recommended in gingivitis, stomatitis, thrush, compression pain causedby dental prostheses, after tooth extraction, in case of nipple lesion, bleeding gums, mouth and gum ulcers.

Recommendations: It delays dental plaque formation, it prevents bad odour and provides daily mouth hygiene.

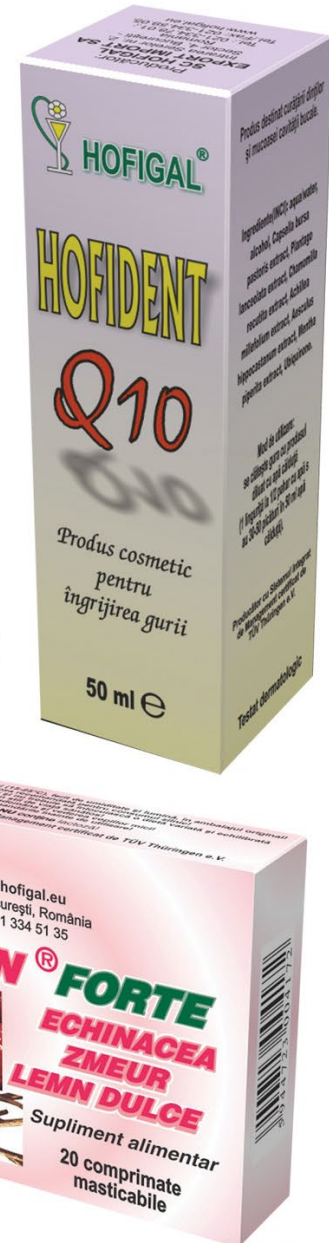

\section{Hoflmun ${ }^{\oplus}$ FORTE}

Product presentation:

Chewable tablets to stimulate the immune system

Composition: Each chewable tablet contains raspberry fruit extract (Rubii idaei fructus), Echinacea extract (Echinacea purpurea), concentrated extract of licorice root (Glycyrrhiza radix), magnesium ascorbate and excipients.

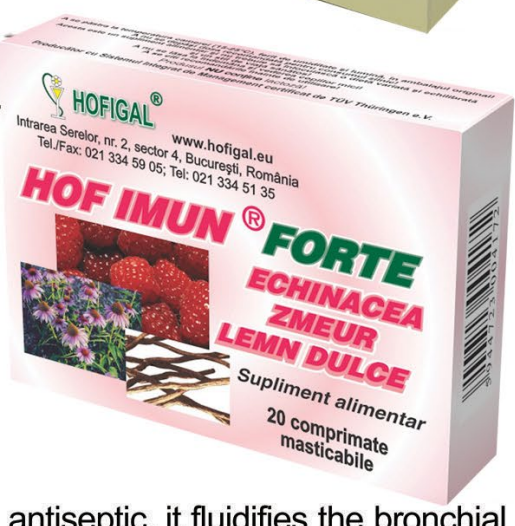

Action:It stimulates the immune system, it is antiinflammatory, antiviral, antiseptic, it fluidifies the bronchial and pharyngeal secretions, antioxidant, cardioprotective, vasoprotective, it has antineoplastic antileukimic action, (due to the ellagic acid), it contributes to wound healing, fortifies and remineralizes (it regulates the potassium balance), it has antiulcer effects and is an overall body tonic.

Recommendations: to supplement the diet with nutrients and bioactive substances in: acute and chronic infections of the upper airways (angina, pharyngitis, laryngitis, bronchitis), prophylactic during periods with increased risk of infection with influenza viruses, it has sweating effects in fever, in recurrent herpes episodes of mucocutaneous rash, frequent urinary tract infections, inflammatory urogenital processes; immunodepression after radiotherapy or chemotherapy, bacterial skin infections, psoriasis, neurodermitis, chronic cardiovascular diseases associated with hypercholesterolemia, adjuvant in the diet indicated in the treatment of gastroduodenal ulcers, tonic during periods of physical and mental strain, exhaustion.

\section{Bucoprotect gel}

\section{Product presentation: Gel for oral hygiene.}

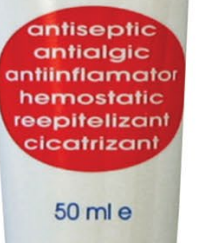

Composition (INCI): aqua, capsella bursa pastoris, calendula officinalis, achillea milefolium, hippophae rhamnoides, olea europea, hypericum perforatum, carbomer triethanolamine, collagen, foeniculum vulgare, mentha piperita, citrus amara.

Action: Antiseptic, anti-inflammatory, healing, stimulates the inside lining of the mouth and gums trophicity, reduces pain caused by specific oral uscupincipi ictiventur diseases (gingivitis, stomatitis, lesions of the prosthesis, thrush, periodontitis). 


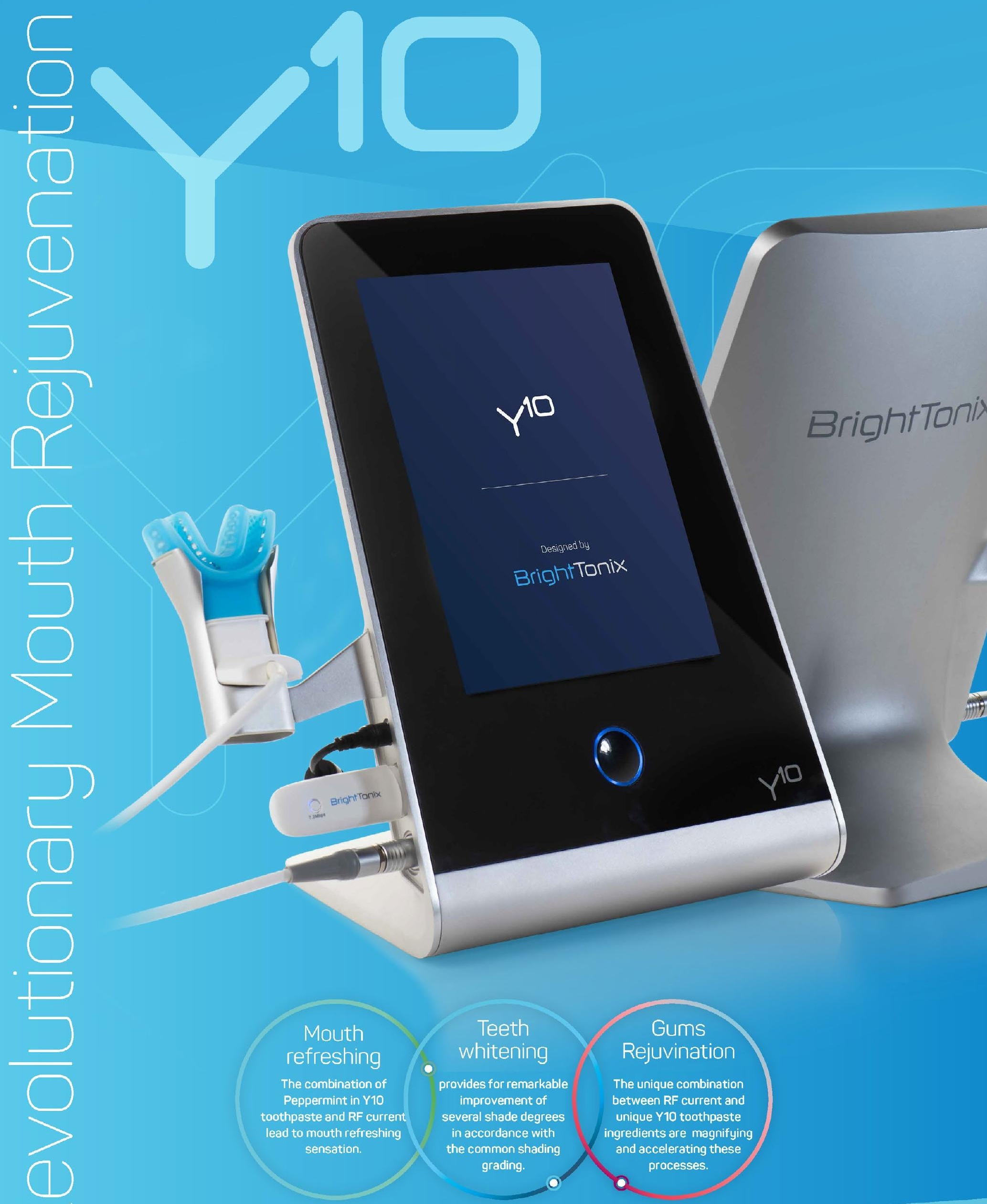




\section{Contents}

\section{stonaedij}

2019 Volume 6 Issue 1

Pages 1-80

ISSN (print) 2360-2406; ISSN (on-line) 2502-0285; ISSN-L 2360-2406

\section{EDITORIAL}

1 Continuing medical education in European dentistry

Hande Sar Sancaklı

3 The concept of complete dentistry

Peter E. Dawson

4 Transparency in peer review

Jean-François Roulet

\section{LETTERS}

5 Laudatio, to our beloved mentor, Professor Rudolf Slavicek Jean-Daniel Orthlieb

\section{CONTINUING EDUCATION ONLINE}

7 JADA CE Online

\section{ORIGINAL ARTICLES}

DENTAL MATERIALS: Effects of exposure time and exposure distance on the micro-

9 mechanical properties of light cured pit and fissure sealants

Maria Holroyd, Nicoleta Ilie

18

DENTAL MATERIALS: The effect of cleaning procedures on the bond strength of

ceramic surfaces contaminated with saliva and try-in paste

Luiz H. Gonzaga, Himanshu Arora, William C. Martin

ADHESIVE DENTISTRY: Influence of fluoride mouthwash containing

24 nanohydroxyapatite on the dentin interface of dire

Dayane Carvalho Ramos Salles de Oliveira, Livia Rodrigues de Menezes, Lúcia Trazzi Prieto,

Erick Kamiya Coppini, Luís Alexandre Maffei Sartini Paulillo, Gisele Damiana da Silveira Pereira

DENTAL EDUCATION: Oral health behaviour and awareness of young population in

Turkey

Görkem Sengez, Sina Saygılı, Mehmet Yıldız, Uğur Aksoy, Hande Șar Sancaklı

ORAL IMPLANTOLOGY: Immediate implant placement in fresh extraction sockets using

36 the open healing technique and tissue level implants

Alecsandru lonescu, Aliona Dodi, Vasileios Panagopoulos, Mihnea loan Nicolescu, Augustin Mihai, Gabriela Tănase
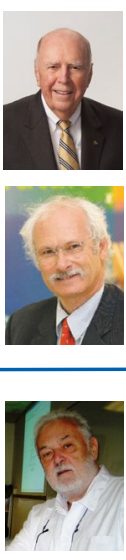


\section{REVIEW ARTICLES}

AESTETHIC DENTISTRY: Partial ceramic crowns. Esthetic and tissue conservative
restorations - Part II: Anterior teeth-laminate veneers
Gottfried Schmalz, Marianne Federlin

55 ORAL MEDICINE: Psychoneuroimmunology of oral diseases - A review

\section{DENTISTRY CONFERENCES}

67 Dentistry Conferences

\section{PRODUCT NEWS}

69 Adviser of dental industry quality products: IDS 2019

Florin - Eugen Constantinescu

\section{BOOK REVIEWS} Concepts in Oral Medicine - tractatio, concipio, documentatio. Volume I, II, III
Rudolf Slavicek 72 Oral Rehabilitation for Compromised and Elderly Patients

73 Esthetic and Restorative Dentistry

73 Material Selection and Technique Douglas A. Terry, Willi Geller

7 Diseases and Conditions in Dentistry

74 An Evidence-Based Reference Keyvan Moharamzadeh

7 Therapeutic Ultrasound in Dentistry

74 Applications for Dentofacial Repair, Regeneration, and Tissue Engineering Tarek El-Bialy, Eiji Tanaka, Dror Aizenbud

75 Application of the Neutral Zone in Prosthodontics

Joseph J. Massad, David R. Cagna, Charles J. Goodacre, Russell A. Wicks, Swati A. Ahuja 76 Imaging of the Temporomandibular Joint

\section{INSTRUCTIONS FOR AUTHORS}

78 Instructions for authors 
Editors-in-Chief

Jean-François Roulet

DDS, Habil, Prof hc, Dr hc, Professor

University of Florida, Gainesville, FL, USA

MD, DMD, PhD Professor and Chairman em.

Medical University of Vienna, Vienna, Austria

Marian-Vladimir Constantinescu

DDS, MSc, PhD, Professor

Th "Carol Davila" University of Medicine and Pharmacy, Bucharest, Romania Co-Editors-in-Chief (Americas)

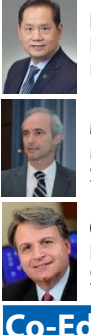

om-Lay Wang

DDS MSD PhD Professor

University of Michigan, Ann Arbor, MI, USA

\section{Mauro Marincola}

MD, DDS, Clinical Professor

State University of Cartagena, Cartagena, Colombia

George E. Romanos

DDS, PhD, DMD, Professo

Stony Brook University, Stony Brook, NY, USA

Co-Editors-in-Chief (Asia-Pacific)

Lakshman Perera Samaranayake

Hon DSC, FDSRCS (Edin), FDS RCPS (Glas), FRACDS, FRCPath (UK), BDS, DDS (Glas),

FHKCPath FCDSHK FHKAM (Pathology), FHKAM (Dental Surgery), Professor

University of Sharjah, Sharjah, United Arab Emirates

Hiroshi Ogawa

DDS, MDSC PhD Associate Professor

Niigata University, Niigata, Japan

Mahesh Verma

BDS, MDS, MBA, FAMS, FDSRCS (England), FDSRCPSG (Glasgow), FDSRCS (Edinburgh),

PhD (HC), Professor

Maulana Azad Institute of Dental Sciences, New Delhi, India Emeritus Editors-in-Chief

Peter E. Dawson

DDS, Founder Emeritus of The Dawson Academy

Saint Petersburg, FL, USA

Birte Melsen

DDS, Dr Odont, Professo

Aarhus University, Aarhus, Denmark

Alexandre Merse

DDS, PhD, Professor, Director of Studies

Geneva Institute of Medical Dentistry (GIMD), Versoix, Switzerland

$1 \times 1$

ciate Editors-in-Chief

Associate Editors-in-Chie

Complutense University of Madrid, Madrid, Spain

Noemí Bordoni, DDS, PhD, Director

Public Health Research Institute, University of Buenos Aires

Buenos Aires, Argentina

Radu Septimiu Câmpian, DMD, MD, Professor

Dean, "Iuliu Hațieganu" University of Medicine and Pharmacy

Cluj-Napoca, Cluj-Napoca, Romania

Sergiu Ciobanu, DDS, PhD, Professor, Dean

"Nicolae Testemitanu" State Medical and Pharmaceutical

University Chişinău, Chişinău, Moldova

Francois Duret, DDS, DSO, PhD, MS, MD, PhD, Professor

Acad (ANCD) University of Montpellier, Montpellier, France

Michael Frank, DDS, PhD

ERO President Elect, President Dental Chamber Hess

Frankfurt am Main, Germany

Luigi M Gallo, PhD, Dr Eng, MEng

Professor and Chairman, University of Zürich, Zürich, Switzerland

Klaus Gotfredsen, DDS, PhD, Dr Odont

University of Copenhagen, Copenhagen, Denmark
Maria Greabu, MD, PhD

"Carol Davila" University of Medicine and Pharmacy Bucharest Bucharest, Romania

Peter Hermann, DMD, MSc, PhD, Professor and Head

Vice-Rector, Semmelweis University Budapest, Hungary Ecaterina Ionescu, DDS, PhD, Professor, Vice-Rector

"Carol Davila" University of Medicine and Pharmacy Bucharest Bucharest, Romania

Amid I Ismail, BDS, MPH, MBA, Dr Ph, Dean

Temple University, Philadelphia, PA, USA

Vjekoslav Jerolimov, DDS, PhD, Acad (CASA)

University of Zagreb, Zagreb, Croatia

Veronica Mercuț, DMD, PhD, Professor, Dean

University of Medicine and Pharmacy Craiova, Dolj, Romania

Georg B. Meyer, DMD, PhD, Dr hc, Professor and Chairman

Ernst-Moritz-Arndt University, Greifswald, Germany

Takahiro Ono, DDS, PhD, Chief Professor

Niigata University, Niigata, Japan

Poul Erik Petersen, DDS, Dr Odont, BA, MSC, Professor

WHO Senior Consultant, University of Copenhagen

Copenhagen,Denmark
Deputy Editors-in-Chief

Adrian Bejan

Eng, PhD, J.A. Jones Distinguished Professor, Acad (AR)

Duke University, Durham, NC, USA

Constantin lonescu-Târgoviste

MD, PhD, Professor, Acad (AR)

abriel Octavian Lază

CPhys, PhD, Professor

"Vasile Alecsandri" University of Bacău, Bacău, România

Co-Editors-in-Chief (Europe)

Nicoletallie

Dipl-Eng, PhD, Professor

Ludwig-Maximilians-Universität München, München, Germany

Hande Şar Sancak

DDS, PhD, Associate Professo

FDI Regional CE Director Europe, Geneva-Cointrin, Switzerland

Constantinus Politis

MD, DDS, MM, MHA, PhD, Professor and Chairperson University of Leuven, Leuven, Belgium

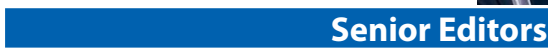

Senior Editors

Bruce Robert Donof

DMD, MD, Professor, Dean

Medicine Harvard University, Boston, MA, USA

Adrian Podoleanu

Eng, PhD Professor FInstP, FOSA FSPIE, Professor University of Kent, Canterbury, Kent, UK

Kasturi Warnakulasuriya OP(RCPA), FICD FILT, FMedSci, Professo King's College London, London, UK Emeritus Editors-in-Chief

Prathip Phantumvanit

DDS, MS, FRCDT, Professo Thammasat University, Bangkok, Thailand

Rudolf Slavicel

MD, DMD, Professor

Medical University of Vienna, Vienna, Austria

David Wray Pred (Edinburgh) F Med SC Professor Emeritus, Professo University of Glasgow, Glasgow, UK

Gottfried Schmalz, DDS, PhD, Drhc, Professor

Acad (Leopoldina), University of Regensburg

Regensburg, Germany

Anton Sculean, DMD, Drhc, MS, Professor

University of Bern, Bern, Switzerland

lgor Alexandrovici Shugailov, MD, PhD, Professor

Vice-Rector, "A.I. Evdokimov" Moscow State University of

Medicine and Stomatology, Moscow, Russia

Adam Stabholz, DDS, PhD, Professor, Head

The Hebrew University-Hadassah, Jerusalem, Israel

Zrinka Tarle, DMD, PhD, Professor, Dean

University of Zagreb, Zagreb, Croatia

Douglas A. Terry, DDS, PhD, Clinical Assistant Professor

University of Texas, Houston, TX, USA

Jacques Vanobbergen, MDS, PhD, Professor Em. Professor and Chairman

Gent University, Gent, Belgium

Yongsheng Zhou, DDS, PhD, Chair and Professor Associate

Dean, Peking University

Beijing, China
The Stomatology Edu Journal (Stoma Edu J), ISSN (printed) 23602406, ISSN (on-line) 2502-0285, ISSN-L 2360-2406, is a scientific magazine of the Romanian Association of Oral Rehabilitatio and Posturotherapy - ROPOSTURO, a partner of the FDI regular member, the Romanian Society of Stomatology - RSS (founded in 1923) under the aegis of The Romanian Academy.

\section{Editor Office}

Stomatology Edu Journal, 102-104 Mihai Eminescu st., $2^{\text {nd }}$ District, RO-020082 Bucharest, ROMANIA, Tel/Fax: +40314327930, e-mail: stomatology.edu@gmail.com, www.stomaeduj.com

Editors

Jean-François Roulet, Rolf Ewers, Marian-Vladimir Constantinescu

Managing Editor

Florin-Eugen Constantinescu

\section{ROPOSTURO}

Romanian Association of Oral Rehabilitation and Posturotherap 10, Ionel Perlea St., 1st District, R0-010209 Bucharest, Romania Tel: +4021314 1062, Fax: +4021312 1357

e-mail: roposturo@gmail.com,www.roposturo.stomaeduj.com

\section{Technical Editor}

Gabriel Octavian Lazar, Valentin Miroiu, Edgar Moraru

Project Editor

Irina-Adriana Beuran

Design Editor

Dragoș Georgian Guțoi

Cover by

Arch. Florin Adamescu

\section{Publisher Office}

Romanian Academy Publishing House, 13, Calea 13 Septembrie, 5th District, RO-050711 Bucharest, Romania, Tel: +40213188146, 40213188106, Fax: +40213182444

e-mail: edacad@ear.ro, www.ear.ro

Technical Editor

Doina Argeșanu

Editorial Assistant

Monica Stanciu

Computer Editing

Iolanda Povară

All the original content published is the sole responsibility of the authors. All the interviewed persons are responsible for their declaration and the advertisers are responsible for the information included in their commercials. 


\section{Associate Editors}

Rafael Benoliel, DDS, PhD, BDS, Professor, Associate Dean The State University of New Jersey Newark, NJ, USA Dana Cristina Bodnar, DDS, PhD, Professor

"Carol Davila" University of Medicine and Pharmacy Bucharest, Bucharest, Romania

Romeo Călărașu, MD, PhD, Professor, Acad (ASM) "Carol Davila" University of Medicine and Pharmacy Bucharest, Bucharest, Romania

Asja Čelebić, DDS, MSc, PhD, Professor

University of Zagreb, Zagreb, Croatia

Lola Giusti, DDS, CERT, Associate Professor

University of the Pacific, San Francisco, CA, USA

Galip Gürel, DDS, MS

Dentis Dental Clinic, Istanbul, Turkiye

Fawad Javed, BDS, PhD

University of Rochester, NY, USA

Joannis Katsoulis, DMD, PhD, MAS, Professor

University of Bern, Bern, Switzerland

Anastassia E Kossioni, DDS, PhD, Associate Professor

University of Athens, Athens, Greece

Luca Levrini, DDS, PhD, Professor

University of Insubria, Varese, Italy

Giorgio Lombardo, MD, DDS, Professo

University of Verona, Verona, Italy

Armelle Maniere-Ezvan, DDS, PhD, Professor, Dean

Nice Sophia-Antipolis University, Nice, France

Domenico Massironi, DDS, PhD

MSC Massironi Study Club, Melegnano (MI), Italy

Noshir R. Mehta, DMD, MDS, MS, Professor, Assoc. Dean

Tufts University, Boston, MA, USA

Marian Neguț, MD, PhD, Professor, Acad (ASM)

"Carol Davila" University of Medicine and Pharmacy

Bucharest, Bucharest, Romania

Jean-Daniel Orthlieb, DDS, PhD, Professor, Vice-Dean

Aix Marseille University, Marseille, France

Letizia Perillo, MD, MS, PhD, Professor, Head, Dean

University of Campania Luigi Vanvitelli, Naples, Italy

Paula Perlea, DDS, PhD, Professor, Dean

"Carol Davila" University of Medicine and Pharmacy

Bucharest, Bucharest, Romania

Chiarella Sforza, MD, PhD, Professor

University of Milan, Milan, Italy

Roman Šmucler, MD, PhD, Professor

Charles University Prague, Praque, Czech Republic

Roberto Carlo Spreafico, DM, DMD

Busto-Arsizio (MI), Italy

Jon B Suzuki, DDS, PhD, MBA, Professor, Associate Dean

Temple University, Philadelphia, PA, USA

\section{Editors}

Sorin Andrian, DDS, PhD, Professor and Chairman

"Gr. T. Popa" University of Medicine and Pharmacy lassi

lasi, Romania

Vasile Astărăstoae, MD, PhD, Professor

"Gr. T. Popa" University of Medicine and Pharmacy lași

\section{lasi, Romania}

Gabriela Băncescu, MD, PhD, Professo

"Carol Davila"University of Medicine and Pharmacy Bucharest Bucharest, Romania

Alexandru Dumitru Brezoescu, DDS, Chairma

Dentists'College, Bucharest, Bucharest, Romania

Octavian Buda, MD, PhD, Professor

"Carol Davila" University of Medicine and Pharmacy Bucharest Bucharest, Romania

Arnaldo Castellucci, DDS, PhD

Florence, Italy

Ingrida Čêma, DDS, PhD, Professor

Riga Stradins University, Riga, Latvia

Gabi Chaushu, DMD, MD Professor

Gabi Chaushu, DMD, MD, Professor

Rayleigh Ping-Ying Chiang, MD, MMS

Rayleigh Ping-Ying Chiang, MD, MMS

Taipei Veterans General Hospital, Taipe
Ioan Dănilă, DDS, PhD, Professor

"Gr. T. Popa" University of Medicine and Pharmacy lași
"Lan Danila, DDS, PhD, Professor

"Gr. T. Popa" Unive

lassi, Romania
Yuri Dekhtyar, Eng, Dr phys, Professor

Riga Technical University, Riga, Latvia

Valeriu Fala, DDS, PhD, MSc, Associate Professor

"Nicolae Testemițanu" State University of Medicine and Pharma

"Chişinău, Chişinău, Republic of Moldova

Daniela Aparecida Godoi Gonçalves, DDS, PhD, Professor

UNESP - Univ Est Paulista, Araraquara, Brazil

Martin D Gross, BDS, LDS, MSC, Associate Clinical Professor

Tel Aviv University, Tel Aviv, Israel

Emilian Hutu, DDS, PhD, Professor

"Carol Davila" University of Medicine and Pharmacy Bucharest

Bucharest, Romania

Andrei Cristian lonescu, DDS, PhD

University of Milan, Milan, Italy

Abdolreza Jamilian, DDS, PhD, Professor

Islamic Azad University, Tehran, Iran

Joanna Kempler, DDS, PhD, Associate Professor

University of Maryland, Baltimore, MD, USA

Amar Hassan Khamis, PhD, DEA, MSC, BSc, Professor

Mohammed Bin Rashid University of Medicine and Health

Sciences (MBRU), Dubai, UAE

Henriette Lerner, DDS, PhD

Baden-Baden, Germany

Paulo Ribeiro de Melo, DDS, PhD, Professor

University of Porto, Porto, Portugal
Annalisa Monaco, DDS, MSc, Associate Professor

University of L'Aquila, L'Aquila, Italy

Nina Mussurlieva, DDS, PhD, Professor

Medical University of Plovdiv, Plovdiv, Bulgaria

Radmila R. Obradović, DDS, PhD, Associate Professor

University of Nišs, Niš, Serbia

Sever Toma Popa, DDS, PhD, Professor

"Iuliu Hațieganu" University of Medicine and Pharmacy Cluj-Napoca Cluj-Napoca, Romanis

Mihaela Răescu, DDS, PhD, Professor

"Titu Maiorescu" University, Bucharest, Romania

lulia Romanova, DMS, PhD, Professor

Odessa National Medical University "ONMedU", Odessa, Ukrain

Mare Saag, DDS, PhD, Professor

University of Tartu, Tartu, Estonia

Fabio Savastano, MD, MOrth, Professor

University Jaume I Castellon, Castellon, Spain

Luc De Visschere, DDS, PhD, Professor

Gent University, Gent, Belgium

Constantin Marian Vârlan, DDS, PhD, Professor

"Carol Davila" University of Medicine and Pharmacy Bucharest

Bucharest, Romania

Irina Nicoleta Zetu, DDS, PhD, Professor

"Gr. T. Popa" University of Medicine and Pharmacy lași, lași, Romania Editorial Advisory Board

Marcus Oliver Ahlers, DDS, PD

Department of Operative Dentistry and Preventive Dentistry Center for Oral and Maxillofacial Surgery, University Medical Center

Hamburg-Eppendorf, Hamburg University Eppendorf

Hamburg, Germany

Cristina Maria Bortun, DDS, PhD, Professor and Head

Prosthetic Dentistry Technology Department

Faculty of Dental Medicine, "Victor Babeș" University of Medicine

and Pharmacy Timisoara, Timișoara, Romania

Bogdan Calenic, DDS, PhD, Associate Professor

Biochemistry Department, Faculty of Dental Medicine

"Carol Davila" University of Medicine and Pharmacy Bucharest Bucharest, Romania

Nardi Casap-Caspi, DDMD, MD, Professor and Head

Oral and Maxillofacial Surgery Department

Hadassah School of Dental Medicine

Hebrew University Hadassah Jerusalem, Jerusalem, Israe

Paulo G. Coelho, DDS, PhD, Professor

Hansjorg Wyss Department of Plastic Surgery

NYU Langone Health, NYU School of Medicine, New York University New York NY, USA

Daniel Edelhoff, CDT, DMD, PhD, Professor and Head

Department of Prosthodontics, Faculty of Medicine

Ludwig-Maximilians - München University, München, Germany

Claudia Maria de Felicio, MD, PhD, Professor

Orofacial Motricity Unit, Department of Ophthalmology and Otolaryngology, School of Medicine, Universidade de São Paulo (USP) Ribeirão Preto, Brazil

Dorjan Hysi, DMD, MsC, PhD, Associate Professor, Chair Conservative Dental Department, Faculty of Dental Medicine Tirana

University of Medicine Tirana, Tirana, Albania

Heinz Kniha DDS, MD, PhD, Associate Professor

Oral and Maxillofacial Surgery Department, Faculty of Medicine

Ludwig-Maximilians- München University, München, Germany

Rodica Luca, DDS, PhD, Professor

Pedodontics Department, Faculty of Dental Medicine

"Carol Davila" University of Medicine and Pharmacy Bucharest Bucharest, Romania

Mariam Margvelashvili-Malament, DDS, MSC, PhD, Professor Department of Prosthodontics and Operative Dentistry, School of

Dental Medicine, Tufts University, Boston, MA, USA

Domenico Massironi, DDS

MEG - Master Educational Group, Melegnano (MI), Italy

Rodolfo Isaac Miralles Lozano, MD, PhD, Professor

Physiology and Biophysics Department, Institute of Biomedical

Sciences, Faculty of Medicine, University of Chile, Santiago, Chile

Mutlu Özcan, DDS, PhD, Professor, Head

Dental Biomaterials Unit, Clinic of Fixed and Removable

Prosthodontics and Dental Material Science, Center of Dental

Medicine (ZZM), University of Zürich, Zürich, Switzerland

Mariana Păcurar, DDS, PhD, Professor and Head,

Orthodontics and DentoFacial Orthopedics Department, Faculty of Dental Medicine, University of Medicine and Pharmacy Târgu Mureș Târgu Mures, Romania

Alexandru Eugen Petre, DDS, PhD, Professor

Department of Fixed Prosthodontics and Occlusology

"Carol Davila" University of Medicine and Pharmacy Bucharest Bucharest, Romanis

Sanda Mihaela Popescu, DDS, PhD, Professor and Head

Dental Rehabilitation and Medical Surgery Emergencies

Department, Faculty of Dental Medicine, University of Medicine and

Pharmacy of Craiova, Dolj, Romania

Elena Preoteasa, DDS, PhD, Professor and Head

Complete Denture Department, Faculty of Dental Medicine

"Carol Davila" University of Medicine and Pharmacy Bucharest

Bucharest, Romania

Alina Pürienè, BS, PhD, Dr habil, Professor

Periodontics Department, Institute of Odontology

Faculty of Medicine, Vilnius University, Vilnius, Lithuania

Stephen F. Rosenstiel, BDS, MSD, Professor and Chair Restorative and Prosthetic Dentistry, College of Dentistry The Ohio State University Columbus, Columbus, OH, USA

Martina Schmid-Schwap, DDS, PhD, Professor

Department of Prosthodontics, Bernhard Gottlieb

University of Dentistry, Medical University of Vienna, Vienna, Austria
Gregor Slavicek, DDS, PhD, Professor,

Steinbeis Transfer Institute of Biotechnology in Interdisciplinary Dentistry, Steinbeis University Berlin, Berlin, Germany

Marius Steigmann, DDS, PhD, Professor

Steigmann Implant Institute, Neckargemund, Germany

Gianluca Martino Tartaglia, DDS, PhD, Associate Professo

Function Martino Tartaglia, DDS, PD, Associace Professor

Anatomy of the Stomatognic Apparatus, Depart

Biomedical Sciences for Health, Faculty of Medicine

University of Milan, Milan la,

Bernard Touati, DDS, PhD, Assistant Professor

Prosthodontics Department, Faculty of Odontology, Paris V

University, Paris, France

Tamara Tserakhava, DDS, PhD, Professor and Chair

Department of Pediatric Dentistry, Dental Faculty, Belarusian State Medical University Minsk, Belarus

Sorin Uram-Tuculescu, DDS, PhD, Assistant Professor

Prosthodontics Department School of Dentistry

Virginia Commonwealth University Richmond, Richmond, VA, USA Reviewers-in-Chief

Stephen F. Rosenstiel, BDS, MSD, Professor Emeritus The Ohio State University Columbus, Columbus, OH, USA Mihaela Rodica Păuna, DDS, PhD, Professor

"Carol Davila" University of Medicine and Pharmacy Bucharest

Bucharest, Romania

Nissan Joseph, DMD, Associate Professor

Tel Aviv University, Tel Aviv, Israel

\section{Reviewers}

Petr Bartak, Prague, Czech Republi

Cristian Niky Cumpătă, Bucharest, Romania

Andrezza Lauria de Moura, São Paulo, Brazil

Nikolay Ishkitiev, Sofia, Bulgaria

Barbara Janssens, Gent, Belgium

John Kois, Seattle, WA, USA

Cinel Malita, Bucharest, Romania

Enrico Manca, Cagliari, Italy

Vlademir Margvelashvili, Tbilisi, Georgia

Costin Marinescu, München, Germany

Marina Meleșcanu-Imre, Bucharest, Romania

Joel Motta Júnior, Manaus, AM, Brazil

Joel Motta Junior, Manaus, AM, Brazil

Hazem Mourad, Qassim, Saudi Arabia

Paula Perlea, Bucharest, Romania

Nikola Petricevic, Zagreb, Croatia

Cristina Teodora Preoteasa, Bucharest, Romani

Robert Sabiniu Şerban, Bucharest, Romania

Elina Teodorescu, Bucharest, Romania

Mei-Qing Wang, Xi'an, China

English Language Editor-in-Chief

Roxana-Cristina Petcu, Phil, PhD, Professor

Faculty of Foreign Languages, University of Bucharest

Bucharest, Romania

English Language Editors

Valeria Clucerescu, Biol.

Niculina Smaranda Ion, Phil.

Honorary Statistical Advisers

Radu Burlacu, PhD, Bucharest, Romania

loan Opris, PhD, Associate Scientist, Miami, USA

\section{Book Reviewers}

Iulia Ciolachi, DMD, Bucharest, Romania

Florin-Eugen Constantinescu, DMD, PhD Student Bucharest, Romania

\section{Project Editor}

Irina-Adriana Beuran, DMD, PhD

Faculty of Dental Medicine "Carol Davila" University of Medicine and Pharmacy Bucharest, Bucharest, Romania

Indexing Databases
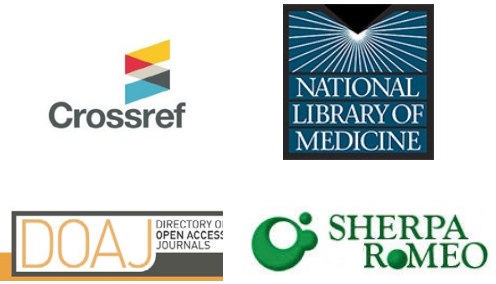

INFOBASE INDEX
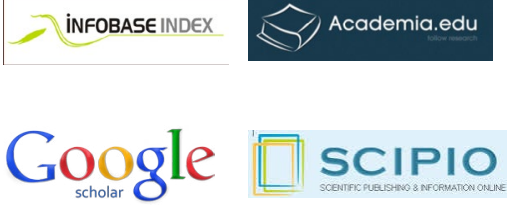


\section{Treatment Centers}

\section{Quality Beyond Reliability}

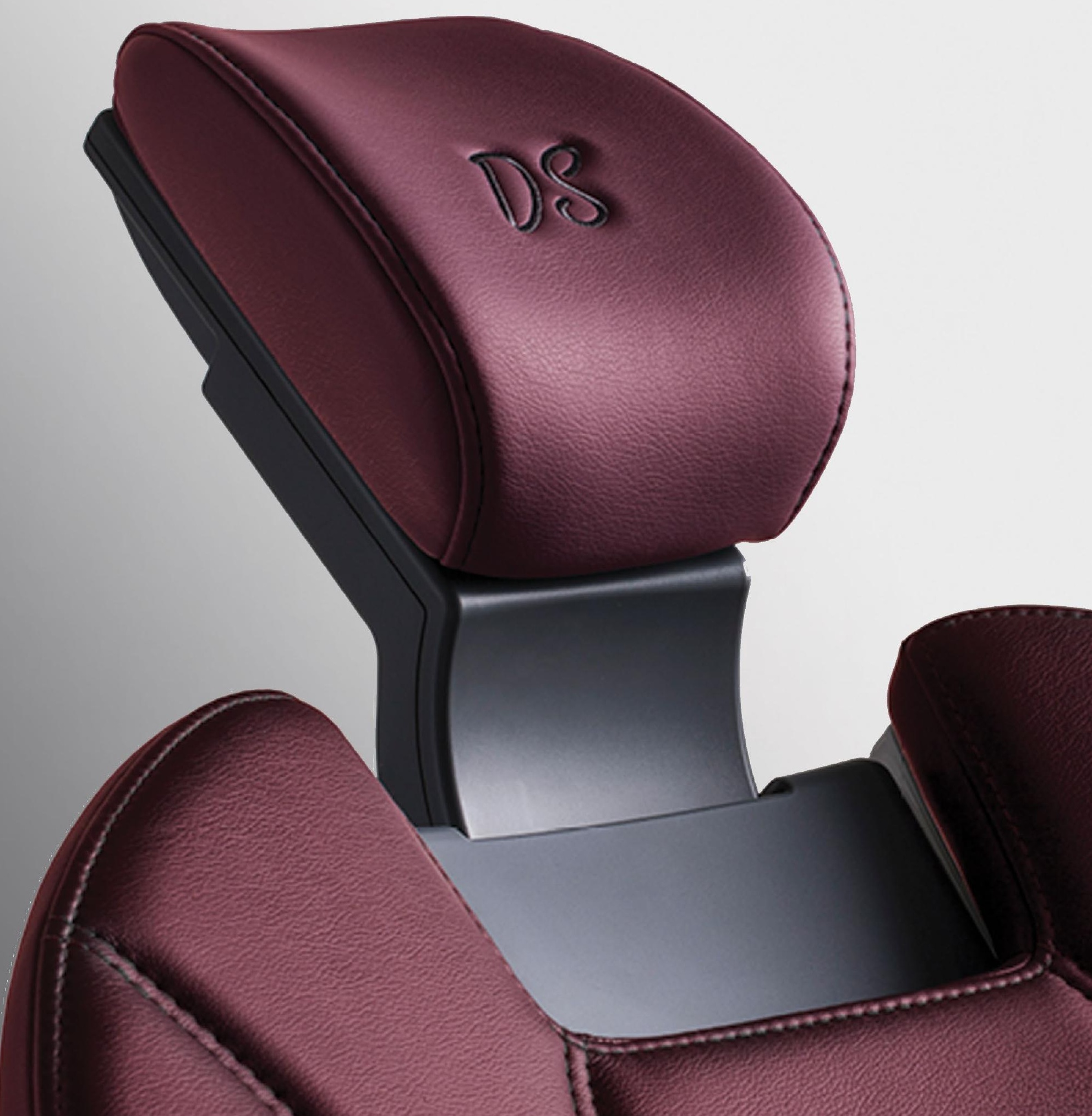




\title{
Continuing medical education in European dentistry
}

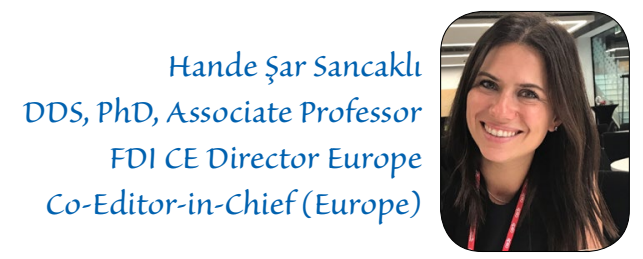

Dear readers,

As an FOI regular member, on October 19, 2018 the Romanian Society of Stomatology (RSS) received a notification on behalf of Enzo Bondioni, FOI Executive Director that the FOI Council appointed Assoc. Prof. Or. Hande şar Sancakll as CE Programme Director for Europe, as a replacement of Professor Alexandre Mersel. Her term of office started in September 2018 and will last until September 2020, with a possibility of renewal in September 2020.

As a member of the Editorial Board of the Stomatology Edu Journal, Assoc. Prof. Or. Hande Şar Sancakli co-ordinates the work of editors in the Central and Eastern European countries.

In order to correctly inform our readers, for the 2019 first issue of the Stomatology Edu Journal, we have formulated a series of questions that we have addressed to the new CE Programme Director for Europe, Assoc. Prof. Or. Hande Şar Sancakll so as to be able to better understand the activity of the ERO Working Group Continuing Medical Education in Dentistry.

\begin{abstract}
You are the new Director of the ERO Working Group - Continuing Medical Education in Dentistry. What are the goals you are considering?

Beside Chairing the FOI ERO Working Group - Continuing Medical Education in Dentistry since 2014, I have been appointed as the new FOI Continuing Education Director for Europe right after the FOI 2018 General Assembly in Buenos Aires. Taking over the responsibility of the CE programme directory successfully run by Prof. Dr. Alexandre Mersel, I will support our member NDAs' CE events for them to assume their responsibility to perform their role with respect to the continuing education of the dental profession. Beside supporting our members both by fundamental and clinical practice-based educational activities, I will highlight our motto "Leading the world into optimal oral health" as active representatives of FOl; we need to globally improve sustainable oral health so as to reach our target. And undoubtedly one of these targets is the intent to conduct research into the knowledge about the connection between oral and general health. Therefore besides clinical dental education, we shall be pointing out the vitality of the Continuing Medical Education for the advocacy of global health and raising awareness of the dental profession with respect to the relationship between oral health and general health; one of our program goals is to strongly support improving to way these priorities are addressed by organizing CE events among our NDAs.
\end{abstract}

\section{You attended the FOI Congress in Buenos Aires. How do you assess the quality of the papers presented?} What are the topics of interest to oral health specialists?

FOI WOC has a broad scope mainly addressing the general practitioners at global level. Aside from the researchbased institution's congresses, FOI WOC calls clinicians and academics to present their research and cases enabling the publication of the abstracts in the International Dental Journal (IOJ) which is the official peer-reviewed, SCIEindexed journal of FOI. Thus, all abstracts are peer-reviewed and qualified at a required scientific level. Generally, we have submissions under all clinical branches, both scientifically and clinically related abstracts and also prevention and public health-related subjects. However, concerning all the recent submissions most of them are related to clinical cases especially including novel materials and techniques used. 


\section{Why should oral health professionals in Europe attend the World Dental Congress?}

Beside a very rich scientific programme, in all our congresses we have "Meet the Expert" and "Hot topic" sessions which address top-attracted topics presented by the world-known distinguished peer lecturers that you can benefit from in your clinical and academic experience. Moreover, World Dental Congresses provide a great opportunity to network with the peers of the dental world. Many distinguished worldwide contributors, lecturers from all regions of the world can be seen as valuable resources for updating our professional knowledge and best-practices. Contributors also have chances to experience a possible collaboration for networking in today's dental world.

\section{What qualities will the Education Committee look for in the summaries presented at the World Dental Congress in San Francisco?}

As every year before, for 2019, we, the education Committee members will peer-review all the abstracts related to the required topics both at their scientific and clinically relevant base. All abstracts of the posters and oral presentations should be eligible by the journal and the congress publishing criteria.

\section{What is the added value of attending an international congress compared to national dental congresses?}

Within today's rapidly changing and evolving dentistry world, advancing new technologies and brand-new treatment approaches absolutely arises and at the same time requires an increase in the quality of the treatment and dentistry. Thus, we have to be up-to-date both on the knowledge basis and the contemporary path of our profession. Beside the above mentioned educational and academic opportunities, attending the world's largest and more wide scope dental congresses you will have the chance to attend one of the most significant dental exhibition taking place with FDI WOC. Meeting the leading major dental industry suppliers and dental companies, you can discover the innovative dental products and equipments for your clinical practice in today's fast-paced dental revolution.

\section{How do you think the Dental World Congress contributes to the dentists' continuing education?}

I can explain my comments addressing both academics and general practitioners. Researchers attending the congress have the chance to present their research or their clinical cases in front of distinguished experts of related clinical specialty and dental professionals all around the world. Beside that there is an opportunity to meet researchers and clinicians of the same or similar fields of interest allowing one to receive positive feedback and constructive criticism about their research. Moreover, the exchange of knowledge and ideas on the research field of interest will provide them with a possible future collaborations across the world.

What is your opinion about the fact that the FOI/ERO - WG Continuing Medical Education in Dentistry could evaluate and allocate CE points to some of Europe's print and online journals?

FOI ERO WG Continuing Medical Education has modified and re-established its vision during the last 5 years mostly on the progression of the medical-related education in dentistry to assist filling the gap between the basic medical and dental education especially in the continuing dental education programmes. Our priority undoubtedly should focus on supporting the educational activities specifically on the continuing medical education subjects. Concerning this aim, all our printed and online publications will surely serve and support the strengthening of our mission. As FOI and its European Regional Organisation - ERO, we highly appreciate all our member associations and countries' educational activities and publications serving as contributions to the continuing dental and medical education levels of European dentistry.

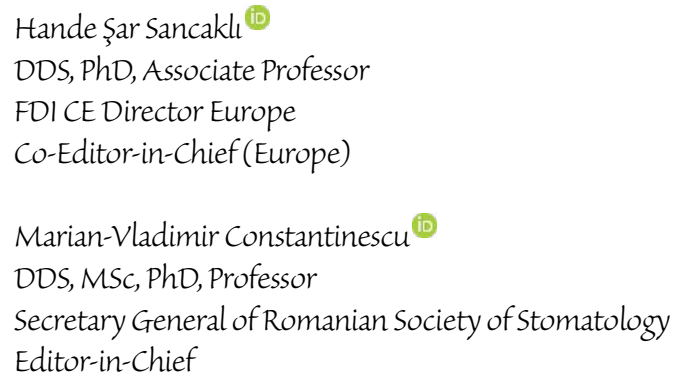

DOI: https://doi.org/10.25241/stomaeduj.2019.6(1).edit.1 


\section{The concept of complete dentistry}

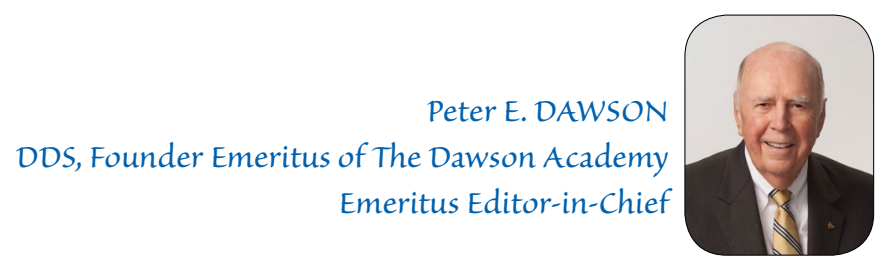

Dear readers,

There is an awakeninggoing on in dentistry today. The "tooth dentists" of yesterday are slowly but surely being transformed into physicians of the total masticatory system. And it is a transformation that is long past due.

Expanding the scope of dentistry in no way minimizes the importance of the teeth as a primary focus. It actually raises the bar for dentists to better understand why the interrelationship between the teeth and the rest of the masticatory system structures is so critical. A dentist who does not understand how important the relationship is between the teeth, the TMJs, and the total masticatory neuromusculature can be no better than a mediocre "tooth dentist". A practitioner who ignores the relationship of the airway to various types of dental malocclusions deprives patients of a potential life-changing treatment. If the relationship between occlusal disharmony and orofacial pain is ignored patients suffer needlessly. (And dentists fail to satisfy patients who are less than happy with their treatment results).

Teeth are made up primarily of neurogenic origin, and as such, they are sensors to the oral, facial and total masticatory system neuromusculature. Occluso-muscle disorders are the most common explanation for persistent problems seen in every dental office. Yet, they are routinely left undiagnosed or misdiagnosed by dentists who do not understand the exquisite interrelationship required for harmony within the gnathostomatic system.

Routine problems in every dental office such as sore teeth, fractured cusps, excessive wear problems and tooth hypermobility are all classified as occlusal diseases. Signs and symptoms that are the direct result of disharmony between the teeth and the position and condition of the TMJs are not just responsible for many toothaches. Occlusal disharmony triggers an array of pain symptoms that often include tension headaches and pain in the head, face or in the region of the jaw joints. Diagnosis and treatment of such disorders properly falls as a responsibility of complete dentists. There is no other medical specialist with the necessary training to accept this responsibility.

If the importance of functional harmony within the masticatory system is understood as a major factor for diagnosis and treatment in every dental office, one is left to wonder why functional occlusion has not been given a more important position in the training of dental school graduates. It is past time to correct this shortcoming in dental education.

Sincerely yours,

P.E. Dawson

Emeritus Editor-in-Chief

NOTE: "The Complete Dentist Manual" by Peter Dawson and John Cranham addresses the current shortcomings in dental practice and also outlines practical approaches for elevating the level of patient care. Instructions are simplified for easy understanding and the entire manual is profusely illustrated in color. It is available through Amazon Books. 


\section{Transparency in peer review}

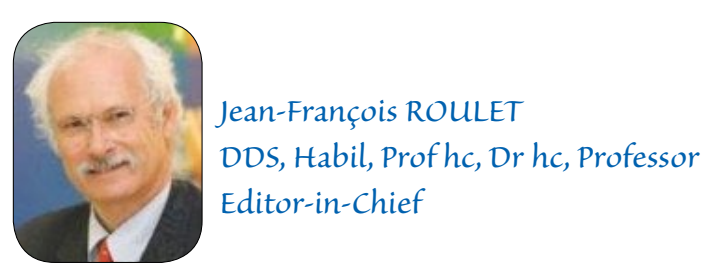

Dear readers, Dear authors,

Review is something that can have all shades of grey, even black. The black ones are allegedly reviewed, unfortunately a practice that can be observed in the literature. I can read "peer reviewed" published papers where I wonder if anybody with a functioning brain has ever read it. In the grey area, you find things as if copied from an advertisement: "Reduce the editorial time by proactively inviting the articles reviewed via our tools and reports" or "...article reports for language, plagiarism, reference accuracy \& actuality will also help you to review the articles". This sounds as if machines were doing the review.

My question is whether this software has the finesse of your trade. The next version is the editor's review. An editor may be excellent in picking up flawed language or unprecise diction. But again, no editor may be that smart and knowledgeable in order to pick scientific errors in a very specialized area of dentistry. Therefore, we rely on peer review, which means that the editor has a list of potential reviewers that are actively working on the specialty of the manuscript that needs to be reviewed. The backside of this approach is that the more qualified and specialized such a person is, the busier he/she usually is. Consequently, it has become a real pain to find good reviewers, willing to read and evaluate a manuscript in a relatively short time. In order to improve the peer review process, we decided to do a major investment and purchase the Manuscript Manager (www.manuscriptmanager.com). I can proudly announce that the Issue Stomatology Edu Journal 2019; 6 (1) is the first issue that was produced with manuscripts that were processed with the Manuscript Manager.

Once a manuscript is submitted by an author, the editor is automatically warned by an e-mail, which reduces the waiting time to be processed. The editor gets all the files in the original for the initial formal assessment. Then based on the content of the manuscript, the editor can select from a databank of specialized reviewers the best for the given manuscript. In the reviewer databank the qualification as well as the review history is visible on a click. Once selected, the potential reviewers are linked to the manuscript, while in the background the system compiles a pdf file for the reviewers. The editor can now create a priority list for the selected reviewers and invite the two most prominent ones for the review. With another click, an e-mail is created to invite the reviewer and the PDF file is automatically attached. The powerful thing about the Manuscript Manager is that it can be programmed to remind the invited reviewers if they did not answer or if they are late with submitting the review. Furthermore, the system switches automatically to the next reviewer on the list, if some time limits established for the reviewers are exceeded. By doing this we do not unnecessarily waste some time. Once two reviews are returned, again the editor gets an e-mail "decision required. If a revision is needed, which is most often the case, usually, if the authors follow the instructions to create a table with the reviewers' comments, the author' reaction and actions, the editor is then able to come up with a decision, which follows the mechanisms described above. On top of this, the system automatically keeps a log book of the events. The editor can exactly follow every step of the process and follow all e-mails exchanged as well. Thus, we get the guarantee that the peer review was done well and we also have transparency.

Summa summarum, with this outstanding tool we can serve the readers better with quality checked manuscripts and the authors with a transparent procedure. If needed, we can document the process for every single manuscript, which is important to position the Stomatology Edu Journal on a high scientific level.

Sincerely yours,

$J$-FRoulet ${ }^{(1)}$

Editor-in-Chief

DOI: https://doi.org/10.25241/stomaeduj.2019.6(1).edit.3 


\section{Laudatio, to our beloved mentor, Professor Rudolf Slavicek}

Rudolf Slavicek, a mentor of "modern gnathology" worldwide stays active in postgraduate education. His first scientific formation as a medical doctor (Doctor of Medicine in 1954) was followed by numerous others: his education in dentistry (certified in 1957), his post-graduation in Restorative Dentistry and Prosthetics (1958), in Orthodontics (1958-1960), but also by his passion for anatomy, anthropology, and biomechanics. This extremely broad knowledge was acquired in Vienna, Austria between 1946 (year of his baccalaureate) and 1960. On this solid foundation, he would build a professional career extraordinarily rich in innovations.

Between 1960 and 1975 he completed his knowledge by reading and meeting the great international authors in the field of oral dysfunctions. For instance, he worked with Arne G. Lauritzen, Harry C. Lundeen ... Along his private dental practice in Vienna, he developed a career as a professor-researcher during which he would demonstrate that the association between broad culture, intelligence, and willingness to share, generates extremely creative

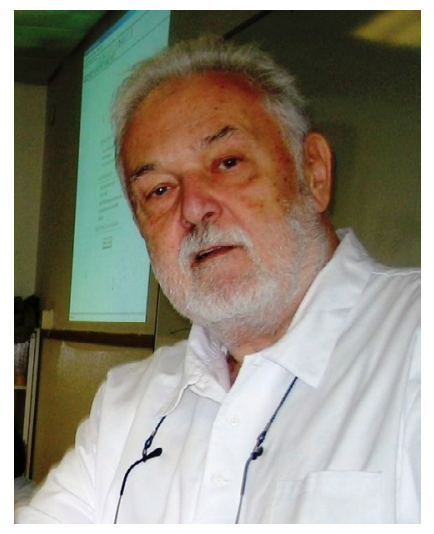
results that will significantly influence the dentistry of the late twentieth century.

\section{The scientist}

Among many publications and innovations, some major topics can be highlighted:

\section{- From anterior guidance to mandibular control}

In 1982, Rudolf slavicek presented a very extensive research work combining morphological, cephalometric, and axiographic analyses. He obtained his PhO habilitation and published his work in a first book entitled "Die funktionellen Determinanten des Kauorgans", Verlag Zahnärtzlich-Medizinisches Schriftum München -1984. He studied the angles of the guiding inclination of the maxillary teeth. From this work on, he would largely improve the concept of canine guidance by inventing sequential guidance, functional freedom angle, retrusive control. He is the one who proposes to replace the term anterior guide by the term anterior control.

\section{- Cephalometry}

As early as the 1980s, he developed the concept of occlusal analysis superimposing cephalometric, axiographic and occlusal data following the same axis-orbital reference plane to combine sagittal condylar inclination and the inclination of the occlusal plane inclination and calculate cusp inclinations. This concept is materialized in CADIAS software.

\section{- Articulator}

At the same time, Rudolf slavicek collaborated with a new company in Munich (SAM) to develop an articulator between semi and fully adaptable. The SAM Articulator incorporates curvilinear condylar boxes and curvilinear Bennett inserts. Later he developed a new concept of condylar articulator guidance based on a hinge-axis concept which was materialized in the Reference articulator system (Gamma, Klosterneuburg Austria).

\footnotetext{
- Axiography

It is due to the simplification of axiography that Rudolf slavicek is known internationally. This simplification was possible based on his work together with mathematician Peter Lugner on axio-pantographic principles. Originating in George G. Campion (1902), Gysi, Lee, Lundeen, SAM's axiograph system records condylar translations by eliminating condylar rotations. Rudolfslavicek was then able to develop a method of diagnostic analysis of intracapsular TMJ disorders. In the 90s, the mechanical axiographic would evolve with the
} 
development of the electronic condylography (CADIAX) developed by the Gamma company managed by his son Christian Slavicek.

\section{- Cybernetic}

As a mature scientist, having dominated the mechanical aspects, Rudolf slavicek was able to gain depth and integrate his occlusofunctional concept into the broader framework of the patient's global organism. This is materialized in the cybernetic concept of the masticatory organ published in his book "Das Kauorgan", "The Masticatory Organ" published in 2002. Consequently, Rudolf slavicek is an resolute advocate of intra- and interdisciplinary dentistry.

Recently, Professor Slavicek published a new three-part book, "Concepts in Oral Medicine" (2016) which presents many facts and documentation on the treatment of patient cases along the lines of the Vienna School of Interdisciplinary Dentistry (VieSID). In 2008, he was appointed to a new peer-reviewed journal, International Journal of Stomatology \& Occlusion Medicine (IJSOM), as a motivator and promoter for colleagues around the world, to publish their work as a forum for communication and discussion. He published hundreds of articles. He has been lecturing around the world since the 1970s. His research and articles set the standard for clinical studies in dentistry.

\section{The teacher}

His career as a member of the academia began in 1975 as an assistant at the Vienna Institute of Medicine. As of 1978, he was an Associate Professor, Head of the Prosthodontic Department at the Dental School of the University of Vienna. Since 1987, he has been Professor and Director of Fixed and Removable Prosthodontic Department, and between 1992 and 1997 he was Dean of the Dental Faculty of Vienna. He would leave the university in 1998 by inviting all his close colleagues to Vienna in a memorable farewell seminar. Yet, it was not an end, but a new beginning for a new teaching career at the Danube University in Krems. He founded the Center for Diagnosis and Therapy of Craniomandibular Functional Disorders in Vienna and he became Head of the Center for Interdisciplinary Dentistry at the Danube University, where he initiated a specialist master in oral functions-dysfunctions, as Professor Emeritus at the Danube University - Krems. His scientific research on TMJ dysfunctions (condylography), combined with cephalometrics, provides the articulator and clinical diagnosis which is unique in the world. He is the founder and mentor of the Vienna School of Interdisciplinary Dentistry in Vienna (VieSID). For many years, the training programs offered by ViesIO have been followed by a large number of colleagues from many countries around the world. He has created a real "Vienna School" in dentistry. At the same time, in 2006 he created, first in Krems and then in Vienna, the famous "Summer School" where every year, in July, his alumni meet; the fourteenth session is scheduled for July 2019. This event, currently gathering about 300 participants from 4 continents, has become a cult event of an impressive scientific level in the warm atmosphere of a real family.

\section{The man}

We know nothing about Rudolf slavicek if we miss to highlight his human qualities beside his scientific level as he skillfully combines these two facets. When you have seen Rudolf slavicek speak to his patients, teach his students, talk to his colleagues, lead an event, interact with his family members, have a smiling face for all people, you could understand the charisma that he emanates. His empathy, his attention to the others, the simplicity that he demonstrates towards everybody impress you forever. This is the indisputable mark of the great ones.

Jean-Daniel ORTHLIEB, DOS, PhO, Professor Chairperson, Vice-Dean Department of Function-Dysfunction, Imaging, Biomaterials Faculty of Odontology, Aix Marseille University, Marseille, France 


\section{stonacdij}

Stoma Edu J. 2019;6(1):11

From The Journal of the American Dental Association

JADA ONLINE CE EXAMS

http://jada.ada.org/ce/home

http://jada.ada.org/ceworksheets

March 2019

Sereen Kattan, BDS, MS, FRCD(C), Su-Min Lee, DDS, MS, DScD, Elliot V. Hersh, DMD, MS, PhD,

Bekir Karabucak, DMD, MS

DO BUFFERED LOCAL ANESTHETICS PROVIDE MORE SUCCESSFUL ANESTHESIA THAN NONBUFFERED SOLUTIONS IN PATIENTS WITH PULPALLY INVOLVED TEETH REQUIRING DENTAL THERAPY?

A systematic review

J Am Dent Assoc. 2019 Mar;150(3):165-177. doi: 10.1016/j.adaj.2018.11.007

This article has an accompanying online continuing education activity available at:

http://jada.ada.org/ce/home.

DOI: https://doi.org/10.1016/j.adaj.2018.11.007

Copyright $\odot 2019$ American Dental Association. Published by Elsevier Inc. All rights reserved

https://doi.org/10.1016/j.adaj.2018.11.007

https://jada.ada.org/article/S0002-8177(18)30786-4/fulltext 


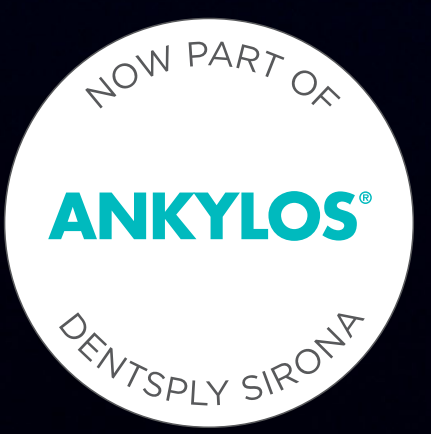

Ankylos ${ }^{\oplus}$

\section{The secret behind excellent anterior esthetics}

When you replace missing anterior teeth, the esthetics simply have to be excellent. That calls for your expertise and Ankylos, an implant system whose TissueCare concept allows for subcrestal placement. Together with the micro-rough surface, this helps bone to form up onto the implant shoulders, which maintains the soft tissue. Finally, the horizontal offset of the implant shoulders promotes both hard and soft tissue stability.

All this creates optimal conditions for long-term hard and soft tissue maintenance, with minimal need for additional augmentation. And the final esthetics is simply stunning.

Excellence without exception.

Ankylos by Dentsply Sirona Implants.

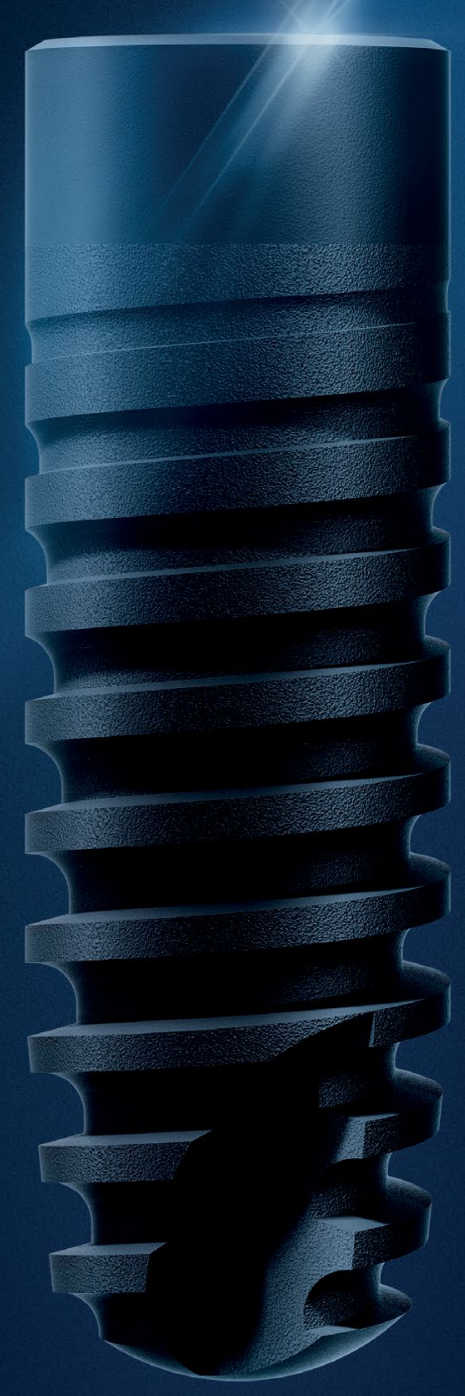




\title{
EFFECTS OF EXPOSURE TIME AND EXPOSURE DISTANCE ON THE MICRO-MECHANICAL PROPERTIES OF LIGHT CURED PIT AND FISSURE SEALANTS
}

\author{
Maria Holroyd ${ }^{1 a}$, Nicoleta llie $^{16 *(10)}$ \\ 'Department of Operative Dentistry and Periodontology, University Hospital, Ludwig-Maximilians University Munich, Goethestr. 70, D-80336 Munich, \\ Germany \\ ${ }^{a} D D S$, PhD Student \\ ${ }^{b}$ Dipl Eng, PhD, Professor
}

DOI: https://doi.org/10.25241/stomaeduj.2019.6(1).art.1

Introduction: The study aimed to perform comparative measurements on the effect of exposure time and exposure distance on the micro-mechanical properties Vickers hardness (HV) and indentation modulus (E) of light cured, resin-based pit and fissure sealants.

Material and Methods: Thirteen pit and fissure sealants were selected. Combinations of three clinically relevant exposure times $(10,20,40 \mathrm{~s})$ and two, fixed sample - light source exposure distances ( 4 and $7 \mathrm{~mm}$ ) were tested. The HV and E of each group $(n=6)$ were measured with an automatic hardness indenter. Data were analyzed by a multi-variant analysis and partial eta-squared $\left(\eta_{\mathrm{p}}{ }^{2}\right)$ statistic.

Results: The factor "material" had the most significant influence (significance level $a \leq$ 0.05 ) on the measured micro-mechanical properties $E$ and HV as shown by a $\eta^{2}$ statistic $\left(\eta_{p}^{2}=0.939\right.$ and 0.927 respectively). The factor "exposure time" had a significant but moderate influence on both material properties $E$ and $\mathrm{HV}\left(\mathrm{n}_{\mathrm{p}}{ }^{2}=0.297\right.$ and 0.084$)$ whereas a smaller but significant effect of the factor "exposure distance" was only observed for $E$ $\left(n_{p}^{2}=0.049\right)$.

Conclusions: Properties E and HV are strongly influenced by the type of sealant. On the other hand, the exposure distance had a low influence on these, whilst the exposure time had a greater influence. Exposure time and to a lesser extent exposure distance have a significant effect on the micro-mechanical properties of pit and fissure sealants.

Practical Implications: We conclude these findings indicate exposure time to be more significant when considering clinical application of these materials.

Keywords: Pit and fissure sealants; micro-mechanical properties; pediatric dentistry; dental materials; curing.

OPEN ACCESS This is
an Open Access article under
the CC BY-NC 4.0 license.
Peer-Reviewed
Article
Citation: Holroyd M, llie N. Effects
of exposure time and exposure
distance on the micro-mechanical
properties of light cured pit and
fissure sealants. Stoma Edu J.
2019;6(1):9-17
Received: January 21, 2019
Revised: February 12, 2019
Accepted: February 19, 2019
Published: February 21, 2019
Corresponding author:
Nicoleta llie, Dipl Eng, PhD,
Professor at the Department
of Operative Dentistry and
Periodontology, University Hospital,
Ludwig-Maximilians University
Munich Goethestr.70
D-80336 Munich, Germany
Phone: + +49-89-44005-9412
Fax: + 49-89--44005-9302
e-mail: nilie@dent.med.uni-
muenchen.de
Copyright: @ 2019 the Editorial
Council for the Stomatology Edu
Journal.

\section{Introduction}

Initial descriptions in the applicative use of pit and fissure sealants were published in the late 1960's [1] whilst retention rates of such sealants were evaluated in the 1980's, clearly demonstrating the benefits and effectiveness of the treatment [2-5]. In many cases the placement of pit and fissure sealant in a clinical setting is not clearly indicated. An America Dental Association (ADA) report published in 2008 [6] gave a number of recommendations to help dental practitioners with their decision making. This took into account not only the type of material, but also focused on placement techniques and emphasized the importance of periodical caries risk re-evaluation. How different pit and fissure sealant formulations performed in clinical retention studies has been analyzed by conducting a broad metaanalysis of published works [7]. This allowed two central statements to be drawn that conclude light polymerizing materials offer the better combination of performance in measures of five-year retention and practical ease of use in the clinical setting.

Modern, commercially available pit and fissure sealants come in a wide range of formulations which bear direct relevance in their application in the clinical setting [8]. For example, some sealants are transparent whilst others are opaque and have a distinctly different coloration to the tooth e.g. white. Indeed, it has been demonstrated in clinical studies that opaque sealants allow a more reliable clinical assessment of retention [9] whilst facilitating a significantly more accurate identification of sealant treated teeth [10]. Sealants also have a wide spread variability in the degree of filler content.

Sealant failure can typically be attributed to a number of factors that include multiple aspects of their clinical application to the tooth surface. For example, adequate preparations to ensure the exclusion of moisture (saliva) [11] or appropriate acid etching times that create favorable, sponge-like structures with greatly increased surface area [12] full stop. Such precautions and clinical diligence lead to increased micro-mechanical adhesion of the sealant, and reduced marginal fissures. Inappropriate control of occlusion to antagonists are also a source of sealant failure especially for materials that do not contain 

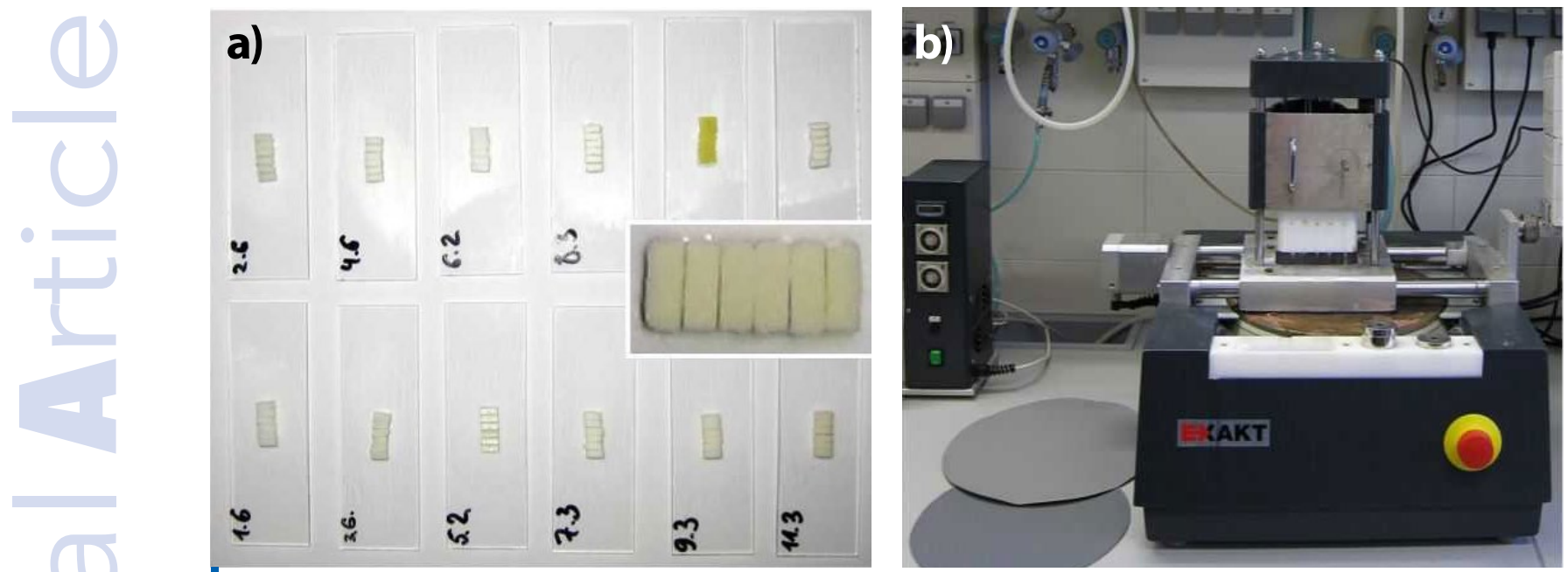

Figure 1. Preparation of fissure sealant samples for micro-mechanical measurements: a) specimen preparation for grinding; b) grinding procedure and device.

filler as these readily fail due to mechanical stress and abrasional forces $[13,14]$. Polymerization in resin based, light cured dental materials is an important factor that determines the quality, effectiveness and longevity of the clinical restorations [15] - indeed in this respect pit and fissure sealants are no different from their other material counterparts. Typically, polymerization will be affected by a number of aspects that are influenced by a range of interacting factors. These include, for example, the irradiance and spectral character of the light curing unit, material specific traits and formulation such as color, opacity, filler properties and monomer composition, the irradiation time and method such as a soft start polymerization program, absolute intensity level at the material surface, or pulsed light mode.

LED technology has established itself as the medium of choice in dental curing units and most contemporary devices use this type of light source. Typically, the peak emission is centered at a wavelength $(470 \mathrm{~nm})$ that has been selected for the optimal activation of camphor quinone [16]. Indeed, this is the most common photo-initiator substance employed in dental sealants. For an extensive review of dental photo-curing please refer to the publication by F. A. Rueggeberg [17]. The characteristics and efficiency of such devices was intensively investigated [18]. Interestingly for the purposes of this current study, based on the results published by Rencz et al. [18], the light curing unit Elipar Freelight 2 (3M ESPE) provided approximately 70 and $40 \%$ of the incident irradiance $(1400 \mathrm{~mW} /$ $\mathrm{cm}^{2}$ ) at an exposure distance of $4 \mathrm{~mm}$ and $7 \mathrm{~mm}$ respectively. These values correspond to ca. 1000 $\mathrm{mW} / \mathrm{cm}^{2}$ at the $4 \mathrm{~mm}$ geometry and $600 \mathrm{~mW} / \mathrm{cm}^{2}$ at the $7 \mathrm{~mm}$ distances employed in the present study. An irradiance of $1000 \mathrm{~mW} / \mathrm{cm}^{2}$ is a value that has been previously identified as a suggested upper limit for the polymerization of resin-based composites (RBCs). This is in part due to the photochemistry of the activator where conversion to the excited state is not the rate limiting process, rather its conversion and reaction (or decay) is kinetically limited. In this case increasing irradiance levels lead to its rapid saturation [19]. Furthermore, high irradiance levels $\left(>1000 \mathrm{~mW} / \mathrm{cm}^{2}\right)$ have been shown to have a detrimental effect on micromechanical properties of light cured materials. Current hypothetical models suggest that if the period between attaining the gelpoint and the initiation of polymerization is too short, internal stress build-up is not allowed to dissipate by a process of material "flow" [20]. Interestingly, earlier research suggested that irradiation time and irradiance level follow a simple reciprocal association $[21,22]$. This lead to the assumption that exposure times of less than $5 \mathrm{~s}$ are adequate to produce a cured material with optimal micro-mechanical properties. However, in the literature it is argued that such a relationship is a too simplified model to describe observed material and chemical behavior under such conditions [19,21]. Given that, for other materials of this class, the degree of cure as a function of the exposure time or exposure distance between the curing unit light guide exit aperture and sample has an influence on their material properties, we chose in the current study to quantify how typical micromechanical properties vary with exposure time and exposure distance. For this purpose, a selection of thirteen commercially available pit and fissure sealants were chosen (refer to Table 1 for details) and investigated. Two exposure distances were selected of $4 \mathrm{~mm}$ and $7 \mathrm{~mm}$ to simulate clinical conditions. 4 $\mathrm{mm}$ was chosen to represent a typical distance that is achieved when the aperture of the curing unit rests upon the cusps of the molar tooth. The $7 \mathrm{~mm}$ position represents a no contact position when the curing unit aperture is held above, but close to the tooth. The following null hypothesis was proposed and tested: Firstly, (a) that increasing the exposure distance between the light guide aperture of the curing unit and the sample surface would not affect the micro-mechanical properties. Secondly, (b) that an increased exposure time would have no influence on the micro-mechanical properties attained and thirdly (c) that the material employed does not influence the micro-mechanical characteristics.

\section{Materials and Methods}

Thirteen resin-based pit and fissure sealants (refer to Table 1 for details) were investigated by assessing the micro-mechanical properties by varying irradiation 
Table 1. Summary of the dental pit and fissure sealants compared in this study (Manufactures specifications).

\begin{tabular}{|c|c|c|c|}
\hline Brand & $\begin{array}{l}\text { Manufacturer } \\
\text { (LOT Nr.) }\end{array}$ & Composition & Curing \\
\hline Clinpro & $\begin{array}{l}\text { 3M ESPE } \\
\text { (N333694) }\end{array}$ & $\begin{array}{l}\text { Matrix: Bis-GMA/TEGDMA } \\
\text { Filler: } \mathrm{n} / \mathrm{a} \\
\text { Fluorid: Yes } \\
\text { Light yellow }\end{array}$ & Light \\
\hline Delton & $\begin{array}{l}\text { Dentsply } \\
(111003)\end{array}$ & $\begin{array}{l}\text { Matrix: } \mathrm{n} / \mathrm{a} \\
\text { Filler: Siliciumdioxide } \\
\text { Fluorid: No } \\
\text { (White) }\end{array}$ & Light \\
\hline Delton FS+ & $\begin{array}{l}\text { Dentsply } \\
(100218)\end{array}$ & $\begin{array}{c}\text { Matrix: Bis-GMA/TEGDMA } \\
\text { Filler: } 53 \% \text { wt. Barium-Aluminium-F-Br-Silica-Glass } \\
\text { Fluorid: No } \\
\text { (White) }\end{array}$ & Light \\
\hline Dyract-seal & $\begin{array}{c}\text { Dentsply } \\
\text { (0908001309) }\end{array}$ & $\begin{array}{c}\text { Matrix: PENTA/ DMAEMA/ DEGDMA } \\
\text { Filler: St-Al-FI-Silica Glas } \\
\text { Fluorid: Yes } \\
\text { (White) }\end{array}$ & $\begin{array}{l}\text { Light/ Chemical } \\
\text { (Compomer) }\end{array}$ \\
\hline $\begin{array}{l}\text { Embrace } \\
\text { Wetbond }\end{array}$ & $\begin{array}{l}\text { Pulpdent } \\
(100218)\end{array}$ & $\begin{array}{c}\text { Matrix: Urethandimethacrylate } \\
\text { Filler: } 43 \% \text { wt. Mixture of hydrophilic and } \\
\text { hydrophobic materials } \\
\text { Fluorid: Yes } \\
\text { (Yellow/white) }\end{array}$ & Light \\
\hline Fissurit-F & $\begin{array}{c}\text { Voco } \\
(1012227)\end{array}$ & $\begin{array}{c}\text { Matrix: Bis-GMA, UDMA } \\
\text { Filler: } 9.5 \% \text { wt. Siliciumdioxide } \\
\text { Fluorid:Yes } \\
\text { (White) }\end{array}$ & Light \\
\hline Grandio Seal & $\begin{array}{c}\text { Voco } \\
(1024382)\end{array}$ & $\begin{array}{l}\text { Matrix: Bis-GMA, TEGDMA } \\
\text { Filler: } 70 \% \text { wt. } \\
\text { Fluorid: Yes } \\
\text { (Yellow/while) }\end{array}$ & Light \\
\hline Helioseal & $\begin{array}{l}\text { Ivoclar Vivadent } \\
\quad \text { (P46901) }\end{array}$ & $\begin{array}{l}\text { Matrix: Bis-GMA, TEGDMA } \\
\text { Filler: } n / a \\
\text { Fluorid: No } \\
\text { (White) }\end{array}$ & Light \\
\hline Helioseal Clear & $\begin{array}{l}\text { Ivoclar Vivadent } \\
\quad \text { (P83091) }\end{array}$ & $\begin{array}{l}\text { Matrix: Bis-GMA, TEGDMA } \\
\text { Filler: } \mathrm{n} / \mathrm{a} \\
\text { Fluorid: No } \\
\text { (Transparent) }\end{array}$ & Light \\
\hline Helioseal F & $\begin{array}{l}\text { Ivoclar Vivadent } \\
\quad(\mathrm{P} 60584)\end{array}$ & $\begin{array}{c}\text { Matrix: Bis-GMA, TEGDMA, UDMA } \\
\text { Filler: } 20 \% \text { wt. F-silica-glass, } \\
21.5 \% \text { wt. Silica } \\
\text { Fluorid: Yes } \\
\text { (White) }\end{array}$ & Light \\
\hline Ionosit Seal & $\begin{array}{c}\text { DMG } \\
(635691)\end{array}$ & $\begin{array}{l}\text { Matrix: } n / a \\
\text { Filler: Ionomerglass } \\
\text { Fluorid: Yes } \\
\text { (White) }\end{array}$ & $\begin{array}{l}\text { Light / Chemical } \\
\text { (Compomer) }\end{array}$ \\
\hline Teethmate F1 & $\begin{array}{l}\text { Kuraray } \\
(00118 C)\end{array}$ & $\begin{array}{c}\text { Matrix: Methacryloyloxydecyldihydrogenphosphate } \\
\text { Filler: }<10 \% \mathrm{wt} \text {. } \\
\text { Fluorid: Yes } \\
\text { (Transparent) }\end{array}$ & Light \\
\hline $\begin{array}{l}\text { Ultraseal XT } \\
\text { plus }\end{array}$ & $\begin{array}{l}\text { Ultradent } \\
\text { (B4S8F) }\end{array}$ & $\begin{array}{l}\text { Matrix: Bis-GMA, Diurethandimethacrylate } \\
\text { Filler: } 58 \% \text { wt. } \\
\text { Fluorid: Yes } \\
\text { (White) }\end{array}$ & Light \\
\hline
\end{tabular}

Abbreviations: BisGMA - Bisphenol A dimethacrylate, BisEMA - Bisphenol A polyetheylene glycol diether dimethacrylate, UDMA - Urethane dimethacrylate, TEGDMA - triethyleneglycol dimethacrylate, PENTA - Dipentaerythritol penta acrylate monophosphate, DEGDMA - Diethylene Glycol Dimethacrylate, DMAEMA - N,N-Dimethylaminoethyl Methacrylate 
time $(10,20$, or 40 s) and spacing between the specimen and the curing unit light guide aperture ( $4 \mathrm{~mm}$ and $7 \mathrm{~mm}$ ). The sealants were chosen to form a representative selection of the commercially available types and compositions currently on the market.

The irradiance of the tested curing units was determined previously [18] by means of a calibrated fiber optic spectrally resolving radiometer equipped with an integrating sphere (S2000, Ocean Optics, USA) by considering the dimension differences between the curing unit tip and the sample. Irradiances passed through a round screen with an inner diameter of $4 \mathrm{~mm}$ (= dimension of cured samples) positioned at the center of the curing unit tip was thus calculated. At the present curing conditions the irradiance amounted $1000 \mathrm{~mW} / \mathrm{cm}^{2}$ at an exposure distance of $4 \mathrm{~mm}$ and $512 \mathrm{~mW} / \mathrm{cm}^{2}$ at an exposure distance of $7 \mathrm{~mm}$. Transferred to radiant exposure values (= Irradiance $x$ exposure time), the amount of light received by the materials at an exposure distance of $4 \mathrm{~mm}$ was $10.0 \mathrm{~J} / \mathrm{cm}^{2}, 20.0 \mathrm{~J} /$ $\mathrm{cm}^{2}$, and $40.0 \mathrm{~J} / \mathrm{cm}^{2}$ and $5.15 \mathrm{~J} / \mathrm{cm}^{2}, 10.3 \mathrm{~J} / \mathrm{cm}^{2}$ and $20.61 \mathrm{~J} / \mathrm{cm}^{2}$ at a distance of $7 \mathrm{~mm}$.

\subsection{Universal hardness measurement}

Samples from each sealant material were generated using a rod-shaped mold of $2 \times 5 \mathrm{~mm}$ and $2 \mathrm{~mm}$ depth (Fig 1). The sealant was bulk filled directly into the mold and the sample was immediately cured. The upper and lower surface was covered with a transparent matrix strip to ensure reproducible, smooth flat surfaces in the resulting samples. Two custom made adaptors were used to vary the spacing between the curing unit (Elipar Freelight 2, 3M ESPE, ca. $1,400 \mathrm{~mW} / \mathrm{cm}^{2}$, peak wavelength $460 \mathrm{~nm}$, serial \# 939820013826) light guide aperture (diameter 8 $\mathrm{mm}$ ) and the sample mold at a fixed distance of 4 $\mathrm{mm}$ and $7 \mathrm{~mm}$. For each product, exposure time (10, $20,40 \mathrm{~s})$ and exposure distance $(4 \mathrm{~mm}$ and $7 \mathrm{~mm}$ ) six samples were produced $(n=6)$. After curing the sample was immediately removed from the mold, the upper irradiated surface marked, then stored for $24 \mathrm{hrs}$ at high humidity (distilled water, $37^{\circ} \mathrm{C}$ ). Prior to measurement each sample was fixed to a glass slide and mounted in an automatic grinding machine (EXAKT 400CS Micro Grinding System EXAKT Technologies, Inc. OK, USA). Specimens were wet-ground with silicon carbide sand paper (grit size p2500 and p4000, LECO Corporation, USA) and polished with a diamond suspension (mean grain size: $1 \mu \mathrm{m}$ ) to remove the oxygen inhibited surface layer. Therefore, the grinding process was controlled electronically, comprising a pre-grinding of $100 \mu \mathrm{m}$ with the abrasive paper p2500 followed by additionally $100 \mu \mathrm{m}$ with $\mathrm{p} 4000$. The following polishing process lasted 2-3 minutes, until the surface was shiny. All measurements of HV and $E$ were performed using an automatic hardness indenter (Fischer-scope H100C, Fischer GmbH, Germany). Five measurements were made on each of the six samples per material and condition (total of 30 measurement positions per condition, 6 conditions per material, 13 materials $=2340$ measurements). The measurement positions were randomly selected and inspected
Table 2. Summary of the influence of factors material, exposure distance and exposure time on the micro-mechanical properties indentation modulus (E) and Vickers Hardness (HV). All values are $\eta_{p}{ }^{2^{*}}$.

\begin{tabular}{lcc}
\hline \multicolumn{1}{c}{ Factor } & E & HV \\
\hline Material & 0.939 & 0.927 \\
Exposure Distance & 0.049 & $\ldots$ \\
Exposure Time & 0.297 & 0.084 \\
\hline
\end{tabular}

* Only statistically significant $(a \leq 0.05)$ values are shown for each property. The higher the value of $\eta_{p}{ }^{2}$, the greater the influence of the selected factor on the measured property.

Table 3. Summary of the influence of factors exposure distance and exposure time on the micro-mechanical properties indentation modulus $(E)$ and Vickers Hardness (HV) for each material tested. All values are $\eta_{p}^{2^{*}}$.

\begin{tabular}{ccccc}
\hline & \multicolumn{2}{c}{$\begin{array}{c}\text { Exposure distance } \\
\eta_{p}{ }^{2}\end{array}$} & \multicolumn{2}{c}{ Exposure time $\mathbf{\eta}_{\mathrm{p}}{ }^{2}$} \\
\cline { 2 - 5 } Material & E & HV & E & HV \\
\hline Delton FS+ & 0.570 & 0.517 & $\ldots$ & 0.294 \\
Ultra Seal XT+ & 0.196 & 0.189 & 0.272 & $\ldots$ \\
Embrace & 0.218 & & 0.280 & 0.348 \\
Wetbond & & & & \\
Helioseal & $\ldots$ & $\ldots$ & 0.656 & 0.581 \\
Helioseal Clear & 0.513 & 0.432 & 0.289 & $\ldots$ \\
Helioseal F & $\ldots$ & $\ldots$ & 0.426 & $\ldots$ \\
Fissurit-F & $\ldots$ & 0.137 & 0.598 & 0.565 \\
Grandio Seal & 0.387 & $\ldots$ & 0.836 & $\ldots$ \\
Clinpro & $\ldots$ & $\ldots$ & 0.376 & 0.266 \\
Teethmate F1 & 0.588 & 0.311 & 0.740 & 0.783 \\
Delton & 0.184 & $\ldots$ & 0.496 & 0.213 \\
Dyract-Seal & 0.163 & $\ldots$ & 0.370 & $\ldots$ \\
lonosit-seal & $\ldots$ & $\ldots$ & 0.815 & 0.486 \\
\hline
\end{tabular}

* Only statistically significant $(a \leq 0.05)$ values are shown for each property. The higher the value of $\eta_{p}^{2}$, the greater the influence of the selected factor on the measured property.

with a microscope to ensure no air bubbles were present. The test load cycle was applied at a constant average velocity increasing from $0.4-500 \mathrm{mN}$, held constant at $500 \mathrm{mN}$ for $5 \mathrm{~s}$ and subsequently decreasing from $500-0.4 \mathrm{mN}$. During this cycle the load and penetration depth of the diamond indenter (square pyramid, angle of opposing faces at apex = $136^{\circ}$ ) were continuously monitored to follow the load-unload hysteresis.

Universal hardness is defined as the applied test force divided by the apparent area of indentation. A conversion factor between universal hardness and Vickers hardness was calculated and implemented into the software from a multiplicity of measurements stored in a database supplied by the manufacturer. In doing so, the results were documented in the more familiar Vickers hardness units. The indentation modulus (E) was calculated from the slope of the tangent to the indentationdepth curve at maximum force.

\subsection{Statistical analysis}

The results were assessed using a Generalized Linear 
Model (GLM). A multi-variant analysis was performed for the factors "material", "exposure distance" and "exposure time" and partial eta-squared $\left(\eta_{p}{ }^{2}\right)$ values determined (significance level $a \leq 0.05$ ). In addition for each material the factors "exposure distance" and "exposure time" were assessed using a uni-variant analysis with a $\eta_{p}^{2}$ statistic.

\section{Results}

For each material we measured the micro-mechanical properties HV and E for each exposure time (10, 20, $40 \mathrm{~s})$ and exposure distance (4 \& $7 \mathrm{~mm}$ ). The results of these tests are detailed in Tables 2-4.

The influence of the parameters "material", "exposure time", and "exposure distance" were analyzed statistically and compared using a GLM with multivariant analysis performed allowing partial eta squared $\left(n_{p}{ }^{2}\right)$ values to be determined (see Table 2 for summary of values). The significance levels of these factors were all $a \leq 0.05$, indicating that the null hypothesis - that no effect on micromechanical properties E and HV would be observed - could be rejected for all parameters with the exception of the values for exposure distance. The greatest influence on the measured micro-mechanical properties was displayed by the parameter "material" across all properties measured (consistently the highest values of $\eta_{p}{ }^{2}$ ). A significant effect of the "exposure time" was seen in both of the measured parameters - in order of descending magnitude E, HV. For the parameter "exposure distance" a statistical significance was observed in one of the two parameters - namely $\mathrm{E}$.

A detailed summary of all the statistical results on a material by material basis can be seen in Table 3. It details both of the measured parameters ( $E$ and HV) per material for both the factors exposure distance and exposure time. The table clearly shows that exposure time has a significant and higher effect than exposure distance in most analyzed materials. The detailed results of the measurements of $E$ and $H V$ values for all material and conditions are summarized as mean values from 6 samples tested at five different positions (Table 4). The measured $E$ values ranged from $2.34 \mathrm{GPa}$ (Embrace Wetbond at $20 \mathrm{~s}$ and $7 \mathrm{~mm}$ ) at the lower end to $9.70 \mathrm{GPa}$ (Grandio Seal at $40 \mathrm{~s}$ and $4 \mathrm{~mm}$ ) at the upper across all experimental parameters and materials. For HV the span of values ranged from $11.28 \mathrm{~N} / \mathrm{mm}^{2}$ (Embrace Wetbond, at 20 $\mathrm{s}$ and $7 \mathrm{~mm}$ ) for the lowest to $71.20 \mathrm{~N} / \mathrm{mm}^{2}$ (Grandio Seal, at $10 \mathrm{~s}$ and $4 \mathrm{~mm}$ ) for the highest.

Closely examining $E$ and comparing the $10 \mathrm{~s}$ and $40 \mathrm{~s}$ values at both the $4 \mathrm{~mm}$ and $7 \mathrm{~mm}$ exposure distances reveals that the average difference is $0.5 \mathrm{GPa}$ at 4 $\mathrm{mm}$ and $1.04 \mathrm{GPa}$ at $7 \mathrm{~mm}$. A similar inspection of the values for $\mathrm{HV}$ reveals that typically the values are reduced with increasing exposure time with few exceptions - only 2 or 4 of the materials showed an increase at either $4 \mathrm{~mm}$ or $7 \mathrm{~mm}$ exposure distances respectively.

\section{Discussion}

For this study we selected a representative cross section of thirteen commercially available pit and fissure sealants (see Table 1 for details). We investigated their micro-mechanical properties with respect to parameters clinically relevant to light activated curing. All experiments were executed using an automatic hardness indenter and micromechanical parameters determined from cured samples from each sealant material prepared under controlled laboratory conditions. We tested whether the three factors "material", "exposure time" and "exposure distance" had any significant influence on the micro-mechanical properties of the sealants.

The optical properties of the material in question play a role in the way in which curing light propagates through the sealant, both initially and as the polymerization reaction progresses. In fact, the results of this research clearly indicated that, not surprisingly, the material has the most profound effect on the measured micro-mechanical values. However, the relationship appears to be complex and it is difficult to see a direct correlation between the material composition and the $\mathrm{E} \& \mathrm{HV}$ values in the materials tested - with some exceptions - for example Grandio Seal has the highest level of filler content consistent and returns the highest HV of any tested material. The results of our present study indicate that, regardless of the material, increasing the exposure time leads in general to a small but significant increase in the $E$ values. Interestingly we found that for HV values the exposure distance had no significant effect, whereas exposure time did albeit less so than for $E$. Based on previous findings [18], the difference in irradiance between the 4 and $7 \mathrm{~mm}$ positions is on the order of approximately 400 $\mathrm{mW} / \mathrm{cm}^{2}$ lower at the more elevated position for the hand-held curing device employed in the current study. A simple conversion of the irradiance values $\left(\mathrm{mW} / \mathrm{cm}^{2}\right)$ employed in this study to examine the total energy equivalents delivered per $\mathrm{cm}^{2}$ (radiant exposure, $\mathrm{J} / \mathrm{cm}^{2}$ ) shows that approximately the same total "dose" of light energy was applied under the following conditions: $4 \mathrm{~mm} 10 \mathrm{~s}\left(10 \mathrm{~J} / \mathrm{cm}^{2}\right) \approx 7$ $\mathrm{mm} 20 \mathrm{~s}\left(10.3 \mathrm{~J} / \mathrm{cm}^{2}\right)$ and $4 \mathrm{~mm} 20 \mathrm{~s}\left(20 \mathrm{~J} / \mathrm{cm}^{2}\right) \approx 7$ $\mathrm{mm} 40 \mathrm{~s}\left(20.6 \mathrm{~J} / \mathrm{cm}^{2}\right)$. Previous findings on the exact same group of sealant materials with the same set of variables [23] revealed that for a given sealant material the degree of cure after 5 minutes was more strongly influenced by the exposure time rather than the exposure distance. The rates of curing, reached a maximum after ca. 5 seconds and remained constant for ca. $15 \mathrm{~s}$ before slowing to exhaustion (unpublished observations). Minor differences in the final degree of the cure were typically observed for each material. In the current study, a similar observation can be made on a per material basis respect to the $E$ and $H V$ values. Thus, at face value it would appear that the energy dose, when equivalent, leads to similar micromechanical properties for a given material. However, this applies, only for the materials Embrace, Teethmate F and Delton. Previous investigations with the degree of cure measurements also revealed similar findings in this respect [23]. Thus, it would seem for a given material that if the total amount of energy supplied is constant then similar micromechanical properties and degree of cure are observed. This is despite variations in the 
Table4. Summary of the results showing the measurements of micro-mechanical properties indentation modulus (E) andVickers Hardness (HV) for each material tested for each exposure distance and exposure time. All values are the mean of measurements on 6 samples (for each sample 5 positions were tested) for each material and condition. The standard deviation is indicated in brackets.

\begin{tabular}{|c|c|c|c|c|c|c|}
\hline Material & & Time (s) & E 4 mm (GPa) & E 7 mm (GPa) & HV 4 mm (N/mm²) & HV $7 \mathrm{~mm}\left(\mathrm{~N} / \mathrm{mm}^{2}\right)$ \\
\hline \multirow{3}{*}{ Delton FS+ } & \multirow{3}{*}{0} & 10 & $7.35(0.72)$ & $6.30(0.54)$ & $49.39(3.51)$ & $45.65(4.15)$ \\
\hline & & 20 & $7.90(0.45)$ & $6.07(1.03)$ & $48.46(3.46)$ & 37.71 (5.74) \\
\hline & & 40 & $7.42(0.36)$ & $6.34(0.40)$ & $45.95(1.63)$ & $39.58(2.05)$ \\
\hline \multirow{3}{*}{ Ultra Seal XT } & \multirow{3}{*}{0} & 10 & $6.46(1.84)$ & $6.26(1.21)$ & $39.89(11.55)$ & $39.50(8.22)$ \\
\hline & & 20 & $6.22(0.78)$ & $8.88(0.53)$ & $35.02(4.34)$ & $49.33(2.91)$ \\
\hline & & 40 & $7.57(1.32)$ & $8.72(1.77)$ & $42.02(6.80)$ & $48.73(9.52)$ \\
\hline \multirow{3}{*}{ Embrace } & \multirow{3}{*}{0} & 10 & $2.86(0.18)$ & $2.80(0.25)$ & $15.51(2.55)$ & $14.20(1.99)$ \\
\hline & & 20 & $2.82(0.21)$ & $2.34(0.24)$ & $13.52(1.16)$ & $11.28(1.10)$ \\
\hline & & 40 & $2.79(0.14)$ & $2.77(0.12)$ & $13.00(0.64)$ & $13.65(0.60)$ \\
\hline \multirow{3}{*}{ Helioseal } & \multirow{3}{*}{0} & 10 & $3.18(0.17)$ & $2.74(0.43)$ & $26.43(3.33)$ & $29.17(3.03)$ \\
\hline & & 20 & $3.55(0.05)$ & $3.47(0.16)$ & $23.59(0.41)$ & $23.70(1.76)$ \\
\hline & & 40 & $3.45(0.09)$ & $3.59(0.09)$ & $22.39(0.67)$ & $23.42(0.14)$ \\
\hline \multirow{3}{*}{ Helioseal Clear } & \multirow{3}{*}{0} & 10 & $3.74(0.05)$ & $3.36(0.08)$ & $25.60(1.32)$ & $21.47(1.44)$ \\
\hline & & 20 & $3.63(0.15)$ & $3.57(0.10)$ & $23.83(1.64)$ & $22.56(1.32)$ \\
\hline & & 40 & $3.75(0.73)$ & $3.63(0.11)$ & $24.53(0.77)$ & $23.69(1.17)$ \\
\hline \multirow{3}{*}{ Helioseal F } & \multirow{3}{*}{ ? } & 10 & $4.88(0.29)$ & $4.28(0.44)$ & $27.86(3.39)$ & $27.38(4.46)$ \\
\hline & & 20 & $5.04(0.25)$ & $5.23(0.24)$ & $25.90(1.96)$ & $27.38(2.28)$ \\
\hline & & 40 & $4.98(0.36)$ & $5.23(0.31)$ & $24.94(3.21)$ & $27.38(2.85)$ \\
\hline \multirow{3}{*}{ Fissurit F } & \multirow{3}{*}{0} & 10 & $3.78(0.81)$ & $3.18(0.41)$ & $32.43(5.41)$ & 38.74 (3.84) \\
\hline & & 20 & $4.40(0.05)$ & $4.21(0.05)$ & $29.87(0.24)$ & $29.90(0.83)$ \\
\hline & & 40 & $4.40(0.07)$ & $4.42(0.07)$ & $29.40(0.43)$ & $29.05(0.55)$ \\
\hline \multirow{3}{*}{ Grandio Seal } & \multirow{3}{*}{$?$} & 10 & $8.12(0.66)$ & $6.39(0.58)$ & $71.20(9.02)$ & $67.82(16.99)$ \\
\hline & & 20 & $9.61(0.28)$ & $9.42(0.60)$ & $67.40(2.94)$ & 71.07 (5.92) \\
\hline & & 40 & $9.70(0.51)$ & $9.36(0.40)$ & $65.65(4.43)$ & 63.25 (4.44) \\
\hline \multirow{3}{*}{ Clinpro } & \multirow{3}{*}{0} & 10 & $3.84(0.09)$ & $3.80(0.05)$ & $24.13(0.52)$ & $23.91(0.96)$ \\
\hline & & 20 & $3.98(0.13)$ & $3.92(0.05)$ & $25.25(0.33)$ & $24.58(0.50)$ \\
\hline & & 40 & $3.95(0.09)$ & $3.89(0.04)$ & 24.04 (1.15) & $24.15(0.64)$ \\
\hline \multirow{3}{*}{ Teethmate F1 } & \multirow{3}{*}{$\stackrel{0}{0}$} & 10 & $3.50(0.04)$ & $3.05(0.23)$ & $26.32(0.77)$ & $34.70(3.44)$ \\
\hline & & 20 & $3.66(0.05)$ & $3.53(0.04)$ & $25.67(0.28)$ & $24.05(1.32)$ \\
\hline & & 40 & $3.67(0.04)$ & $3.57(0.06)$ & $25.33(0.11)$ & $24.26(0.36)$ \\
\hline \multirow{3}{*}{ Delton } & \multirow{3}{*}{0} & 10 & $3.52(0.17)$ & $3.15(0.52)$ & $28.67(0.70)$ & 31.40 (8.99) \\
\hline & & 20 & $3.90(0.14)$ & $3.59(0.12)$ & $27.51(0.59)$ & 27.79 (1.07) \\
\hline & & 40 & $3.81(0.11)$ & $3.87(0.64)$ & $25.76(0.87)$ & $25.62(0.83)$ \\
\hline \multirow{3}{*}{ Dyract Seal } & \multirow{3}{*}{0} & 10 & $4.80(0.40)$ & $3.06(0.34)$ & $31.47(2.18)$ & $22.91(1.84)$ \\
\hline & & 20 & $3.85(0.18)$ & $4.10(0.29)$ & $22.91(2.47)$ & $26.97(2.53)$ \\
\hline & & 40 & $4.31(0.41)$ & $4.81(0.68)$ & $25.18(2.60)$ & $28.61(4.56)$ \\
\hline \multirow{3}{*}{ Ionosit Seal } & ○ & 10 & $4.49(0.29)$ & $4.74(0.17)$ & $33.55(0.99)$ & $38.43(2.88)$ \\
\hline & \multirow{2}{*}{0} & 20 & $5.29(0.19)$ & $5.07(0.19)$ & $31.45(2.30)$ & $33.46(1.35)$ \\
\hline & & 40 & $5.71(0.10)$ & $5.31(0.18)$ & $34.14(1.16)$ & $31.01(1.65)$ \\
\hline
\end{tabular}

Material composition codes:
with filler
without filler
with Fluoride
- without Fluoride Compomers 
way in which this energy is delivered (exposure time or exposure distance) under controlled laboratory conditions. In contrast, in the materials Delton FS+, Ultra Seal XT+ and Dyract-Seal, both parameters HV and E evidenced significant higher values when at a comparable radiant exposure, the exposure time was higher $(p<0.001)$. The statement above applies only for the lower radiant exposure $\left(10 \mathrm{~J} / \mathrm{cm}^{2}\right)$ in Helioseal and Helioseal Clear, while at a higher radiant exposure $\left(20 \mathrm{~J} / \mathrm{cm}^{2}\right)$ values were statistical similar. For materials Helioseal F, Fissurit-F, Grandio Seal, Clinpro and lonosit the above afirmations are valid only for the property $E$, while HV was similar within one radiant exposure. The effect of similar radiant exposure at different curing time or exposure distance is thus material dependent and cannot be related to the filler content. Moreover, in the clinical situation other factors, such as patient compliance, choice and handling of the equipment, lead to a recommendation to optimize such parameters for the chosen material. Interestingly, research into the efficiency of light activated polymerization has shown that this may reach saturation such that higher intensities or exposure times no longer have any effect on the material properties [19].

Furthermore, it has been suggested that too high light levels have a number of detrimental effects on the polymerization reaction. The creation of the excited state of the photo-initiator species reaches saturation as the kinetics of its decay and conversion are essentially rate limiting. Hence, it takes time for a partial steady state to be reached in which the photo-initiator can either be converted to a radical initiator or recycled to its ground state. Too high rates of initiator production can lead to increased probabilities of mutual annihilation that result in reduced polymer chain length. Hence, this reduces network formation within the curing material leading to poorer mechanical properties. Thus, longer exposures to high intensity light sources may be counterproductive in this respect. It might also be speculated that the light transmission characteristics of the materials change during the process of polymerization and that such modifications can also account for or contribute to these observations. In composite materials a significant contribution to this is assigned to the differences in the refractive index of the individual components and the way that this relationship changes during the course of polymerization and curing of the resin-based matrix [24]. In work previously published [23] we have investigated how the degree of cure (DC) after a 5-minute time course varies with the same set of experimental parameters and materials described here. Again, as in the current study the factor material had the most significant influence on DC, but a comparative correlation between filler content and DC, for example, does not reveal a distinct pattern. Thus, this would suggest that for a given sealant material brand an optimized curing protocol should be followed. In respect to the clinical function of pit and fissure sealants, the more important aspect is the ability to form a tight seal and plug between tooth and resin without any gap that might provide a niche to bacteria. Hence, material shrinkage and adhesion to the target are more important than absolute hardness for example. Typically, filled resins have a higher viscosity and a different characteristic in their ability to flow into and penetrate narrow spaces which may have an influence on retention rates [25]. However, the filler has another significant influence on these sealants. Typically, filled sealants are more resistant to abrasion meaning that not only occlusal control but also occlusal adjustment must be routinely employed when applying a filled sealant [13]. Potentially, this makes the process more time consuming whilst it also excludes unqualified auxiliaries from preforming the task.

This probably leads to a significant impact on the number patients treated in some localities. In general checking for occlusion anomalies is very important in pit and fissures treatments of this type, as the materials are generally not formulated to withstand high biting forces and potentially fail. For the unfilled sealants the situation is more forgiving and poor occlusal adjustment, although highly undesirable, is probably short lived as local occlusion anomalies are quickly worn within 24-48 hours [26] (provided the sealant is not lost completely or partially during this period!). Of course, successful sealant application is more than just materials science. In part the skill and knowledge of the practitioner paired with the appropriate application protocol are just as paramount in this respect [6].

\section{Conclusions}

The presented data allow rejecting all specified null hypothesis. It can therefore be concluded that:

- Micromechanical properties are significantly influenced be the factor "material". On the other hand "exposure time" has inverse effects on $E$ and HV and "exposure distance" only a minor effect on $E$.

- Within the bounds of this study exposure time has a more significant effect on micromechanical properties in comparison to exposure distance.

- On the basis of these findings under comparable clinical conditions a curing time of at least $20 \mathrm{~s}$ at $4 \mathrm{~mm}$ is probably to be recommended for the majority of the tested materials, providing clinical conditions are comparable to those in the described study.

- Material has the most significant effect on the measured properties. This suggests that for a given sealant brand individually optimized curing protocols need to be employed.

\section{Author Contributions}

$\mathrm{NI}$ : designed the study, provided the infrastructure (devices, materials), developed the measurement methods, supervised the experiment, performed statistics, drafted and critically revised the manuscript. $\mathrm{MH}$ : performed the measurements, 
collected data, and wrote the manuscript.

\section{Acknowledgments \\ Not applicable.}

\section{References}

1. Cueto El, Buonocore MG. Sealing of pits and fissures with an adhesive resin: its use in caries prevention. $J$ Am Dent Assoc. 1967;75(1):121-128.

[Full text links] [PubMed] Google Scholar Scopus

2. Rock WP, Anderson RJ. A review of published fissure sealant trials using multiple regression analysis. J Dent. 1982;10(1):3943.

[Full text links] [PubMed] Google Scholar Scopus

3. Llodra JC, Bravo M, Delgado-Rodriguez M, et al. Factors influencing the effectiveness of sealants--a meta-analysis. Community Dent Oral Epidemiol. 1993;21(5):261-268.

[Full text links] [PubMed] Google Scholar Scopus

4. Mejare I, Lingstrom P, Petersson LG, et al. Caries-preventive effect of fissure sealants: a systematic review. Acta Odontol Scand. 2003;61(6):321-330.

[PubMed] Google Scholar Scopus

5. Ahovuo-Saloranta A, Forss H, Walsh T, et al. Pit and fissure sealants for preventing dental decay in permanent teeth. Cochrane Database Syst Rev. 2017;7:CD001830. [CrossRef] [PubMed] Google Scholar Scopus

6. Beauchamp J, Caufield PW, Crall JJ, et al. Evidence-based clinical recommendations for the use of pit-and-fissure sealants: a report of the American Dental Association Council on Scientific Affairs. J Am Dent Assoc. 2008;139(3):257-268. [Full text links] [PubMed] Google Scholar Scopus

7. Kuhnisch J, Mansmann U, Heinrich-Weltzien R, Hickel R. Longevity of materials for pit and fissure sealing-results from a meta-analysis. Dent Mater. 2012;28(3):298-303.

[CrossRef] [PubMed] Google Scholar Scopus

8. Simonsen RJ, Neal RC. A review of the clinical application and performance of pit and fissure sealants. Aust Dent J. 2011;56 Suppl 1:45-58.

[CrossRef] [PubMed] Google Scholar Scopus

9. Simonsen RJ. Retention and effectiveness of dental sealant after 15 years. J Am Dent Assoc. 1991;122(10):34-42. [Full text links] [PubMed] Google Scholar Scopus

10. Rock WP, Potts AJ, Marchment MD, et al. The visibility of clear and opaque fissure sealants. Br Dent J. 1989;167(11):395-396. [PubMed] Google Scholar Scopus

11. Johnson WW, Armanazi Y, Sharp H. Sealant leakage with and without isolation. J Tenn Dent Assoc. 1997;77(1):32-34. [PubMed] Google Scholar Scopus

12. Beauchamp J, Caufield PW, Crall J, et al. Evidence-based clinical recommendations for the use of pit-and-fissure sealants: a report of the American Dental Association Council on Scientific Affairs. Dent Clin North Am. 2009;53(1):131-147. [CrossRef] [PubMed] Google Scholar Scopus
13. Stach DJ, Hatch RA, Tilliss TS, Cross-Poline GN. Change in occlusal height resulting from placement of pit and fissure sealants. J Prosthet Dent. 1992;68(5):750-753. [Full text links] [PubMed] Google Scholar Scopus

14. Tilliss TS, Stach DJ, Hatch RA, Cross-Poline GN. Occlusal discrepancies after sealant therapy. J Prosthet Dent. 1992;68(2):223-228.

[Full text links] [PubMed] Google Scholar Scopus

15. Aravamudhan K, Floyd CJ, Rakowski D, et al. Light-emitting diode curing light irradiance and polymerization of resinbased composite. J Am Dent Assoc. 2006;137(2):213-223.

[Full text links] [PubMed] Google Scholar Scopus

16. Neumann MG, Miranda WG Jr, Schmitt CC, et al. Molar extinction coefficients and the photon absorption efficiency of dental photoinitiators and light curing units. J Dent. 2005;33(6):525-532

[CrossRef] [PubMed] Google Scholar Scopus

17. Rueggeberg FA. State-of-the-art: dental photocuring--a review. Dent Mater. 2011;27(1):39-52.

[CrossRef] [PubMed] Google Scholar Scopus

18. Rencz A, Hickel R, Ilie N. Curing efficiency of modern LED units. Clin Oral Investig. 2012;16(1):173-179. [CrossRef] [PubMed] Google Scholar Scopus

19. Ledwith A. Photoinitiation of polymerization. J App/ Chem 1977:49:431-41

20. Musanje L, Darvell BW. Polymerization of resin composite restorative materials: exposure reciprocity. Dent Mater. 2003;19(6):531-541

[Full text links] [PubMed] Google Scholar Scopus

21. Caughman WF, Rueggeberg FA, Curtis JW Jr. Clinical guidelines for photocuring restorative resins. J Am Dent Assoc. 1995;126(9):1280-1282, 1284, 1286.

[Full text links] [PubMed] Google Scholar Scopus

22. Rueggeberg FA, Jordan DM. Effect of light-tip distance on polymerization of resin composite. Int J Prosthodont. 1993;6(4):364-370.

[PubMed] Google Scholar Scopus

23. Holroyd M, llie N. Effects of exposure time and exposure distance on the degree of cure in light-activated pit and fissure sealants. J Dent. 2013;41(12):1222-1228. [CrossRef] [PubMed] Google Scholar Scopus

24. Shortall AC, Palin WM, Burtscher P. Refractive index mismatch and monomer reactivity influence composite curing depth. $J$ Dent Res. 2008;87(1):84-88. [CrossRef] [PubMed] Google Scholar Scopus

25. Hatibovic-Kofman S, Wright GZ, Braverman I. Microleakage of sealants after conventional, bur, and air-abrasion preparation of pits and fissures. Pediatr Dent. 1998;20(3):173-176 [PubMed] Google Scholar Scopus

26. Handelman SL, Buonocore MG, Heseck DJ. A preliminary report on the effect of fissure sealant on bacteria in dental caries. J Prosthet Dent. 1972;27(4):390-392. [Full text links] [PubMed] Google Scholar Scopus

\section{Maria HOLROYD \\ DDS, PhD Student \\ Department of Operative / Restorative Dentistry, Periodontology \& Pedodontics Faculty of Medicine , Ludwig-Maximillians University of Munich Munich, Germany}

Maria Holroyd attended the Ludwig-Maximillians-University in Munich where she took her graduation examinations and qualified as a dentist in 2012. Since then she has worked as a dental practitioner and is currently finalizing her dissertation in the department of Operative / Restorative Dentistry, Periodontology \& Pedodontics in Munich to obtain her medical doctorate. 


\section{0uestions}

\section{The Following statements are valid for commercially available pit and fissure sealants:}

Da. Opaque sealants allow a more reliable clinical assessment of retention;

b. Only transparent ones are recommended, based on esthetical considerations;

ac. No filler content is identified;

$\square$ d. Only a universal, transparent shade is available.

\section{Pit and fissure sealants are subdivided with respect to following particularities:}

口a. Pit and fissure sealants are a unitary material category, with less difference among individual materials;

ab. Presence of filler, Fluoride, chemical composition;

ac. Low and fast curing materials;

d. Amount of light they need for polymerization.

\section{It has been observed in pit and fissure sealants that:}

a. Exposure distance had a low influence on their mechanical properties;

b. Exposure time has a low influence on their mechanical properties;

ac. The properties of the materials are not influenced by the way they are curing;

$\square d$. The filler content and not the amount of light the materials receive is important.

\section{What is clinically recommended for pit and fissure sealants?}

Da. Optimized curing protocols need to be employed, but a curing time of at least $20 \mathrm{~s}$ is recommended for the majority of the tested materials;

b. 5 s of curing are considered sufficient, particularly in non-cooperative children;

ac. A curing time of at least $60 \mathrm{~s}$;

$\square d$. The exposure time has no influence on the final properties.

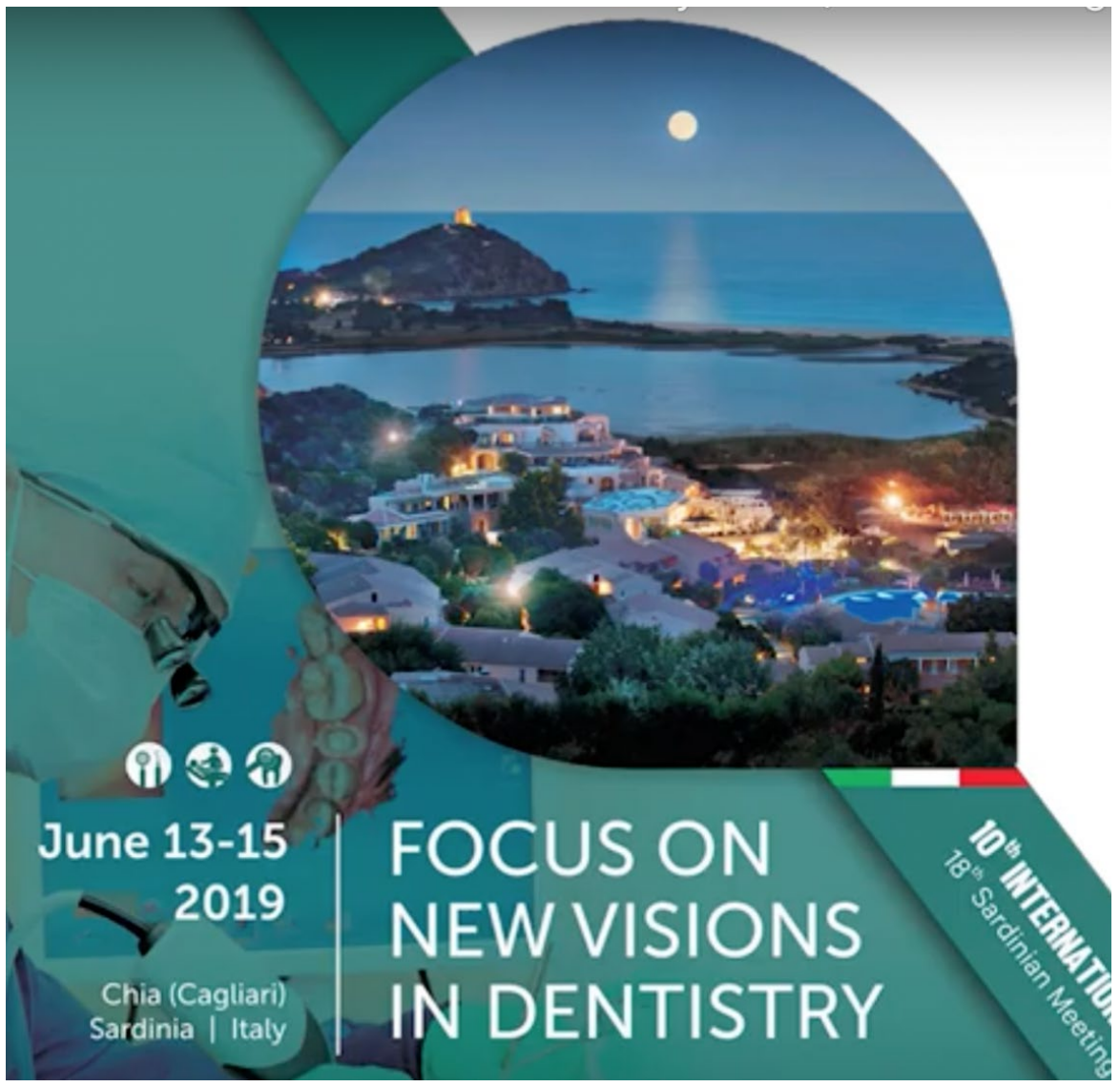

http://congressaio.it/programma.php 


\title{
THE EFFECT OF CLEANING PROCEDURES ON THE BOND STRENGTH OF CERAMIC SURFACES CONTAMINATED WITH SALIVA AND TRY-IN PASTE
}

\author{
Luiz H. Gonzaga ${ }^{1 a^{*}}$, Himanshu Arora ${ }^{1,2 b}$, William C. Martin"c \\ ${ }^{1}$ Center for Implant Dentistry, College of Dentistry, University of Florida, Gainesville, FL, USA \\ ${ }^{2}$ School of Dentistry and Oral Health, Griffith University, Gold Coast, Australia \\ ${ }^{a} D D S, M S$ \\ ${ }^{\mathrm{B} B D S}, \mathrm{MDS}, \mathrm{PhD}$ \\ 'DDS, MS, FACP
}

\begin{abstract}
DOI: https://doi.org/10.25241/stomaeduj.2019.6(1).art.2
Purpose of the study: To evaluate the effectiveness of different cleaning procedures on removing the saliva and try-in paste remnants from contaminated zirconia and lithium disilicate surfaces.

Material and Methods: Fifty samples of zirconia (IPS e.max ZirCAD) and 50 samples of lithium disilicate (IPS e.max CAD) were divided into 5 groups: Group 1 - No contamination with saliva and try-in paste (control); Group 2 - Contamination followed by rinsing with water; Group 3 - Contamination followed by cleaning with $\mathrm{NaOCL} 7 \%$ for 30 seconds; Group 4 - Contamination followed by cleaning with $\mathrm{H}_{3} \mathrm{PO}_{4} 35 \%$ for 30 seconds; Group 5 - Contamination followed by cleaning with Ivoclean for 30 seconds. Zirconium oxide cylinders were luted to the samples using Multilink Implant cement. After being stored for 24 hours in a deionized water bath at $37^{\circ} \mathrm{C}$, the samples were subjected to shear forces at a crosshead speed of $0.5 \mathrm{~mm} / \mathrm{min}$. ANOVA and Tukey's post-hoc test were used for statistical analysis.

Results: No significant differences were observed between various groups for zirconia samples with all cleaning protocols showing shear bond strengths similar to the control groups. Group 4 showed significant improvement in shear bond strength when compared to control $(p<0.05)$ for lithium disilicate samples.

Conclusions: Within the limitations of this study it could be said that the application of phosphoric acid for 30 seconds is effective to clean lithium disilicate samples contaminated with saliva and try-in paste.

Keywords: Bond strength; contamination; saliva; zirconia; lithium disilicate.
\end{abstract}

\section{Introduction}

The pursuit for restorations that mimic nature is more evident than ever. Ceramics are widely used in dentistry due to their ability to mimic the optical characteristics of enamel and dentine as well as for their biocompatibility and chemical durability [1]. The development of all-ceramic restorations and evolution of luting agents are making cementation of dental restorations stronger and more predictable [2]. At the same time a myriad of combinations between material and cement options make a simple task more complex, with diverse steps. The achievement of good bonding is sometimes essential for the survival and an all-ceramic restoration because high retention, better marginal adaptation. The achievement of proper bonding is essential for the survival of an all-ceramic restoration, as a result of a precise marginal adaptation associated with adequate bonding cementation, which prevents microleakage, and increase fracture resistance of the restored tooth and the restoration $[3,4]$.

Superior physical properties, biocompatibility, and esthetics have made zirconium oxide ceramics (zirconia) a popular high-strength ceramic coping and framework material [5]. Reliable bonding of zirconia ceramic was reportedly obtained by mechanical retention and chemical bonding of luting cement to the ceramic substrate [4]. Zirconia's acid resistance makes it unresponsive to common etching and silanization procedures, which makes establishing a strong and stable bond to resin luting agents a clinically challenging protocol [6]. The risk of bond failure further intensifies with any contamination on the cementation surfaces and insufficient removal of the contaminants following intraoral try-in procedures [7-9]. Once a restoration is received from the laboratory, it undergoes an initial inspection by the dentist which is followed by a series of events including, removal of temporary restoration, cleaning of the cavity/prepared tooth, try-in of the restoration (usually pretreated in the lab), cleaning the restoration after try-in and bonding of the restoration. While the majority of the bonding process is controlled by the practitioner, laboratory technicians perform some of the steps, like etching or abrasive particles blasting, which are described as pretreatment of the restoration. Those restorations with enhanced surface for bonding will then be tried in and sometimes adjusted by the clinician. During the try-in phase, the restoration comes in contact with saliva, blood, and/or try-in pastes. This process can lead to contamination of 


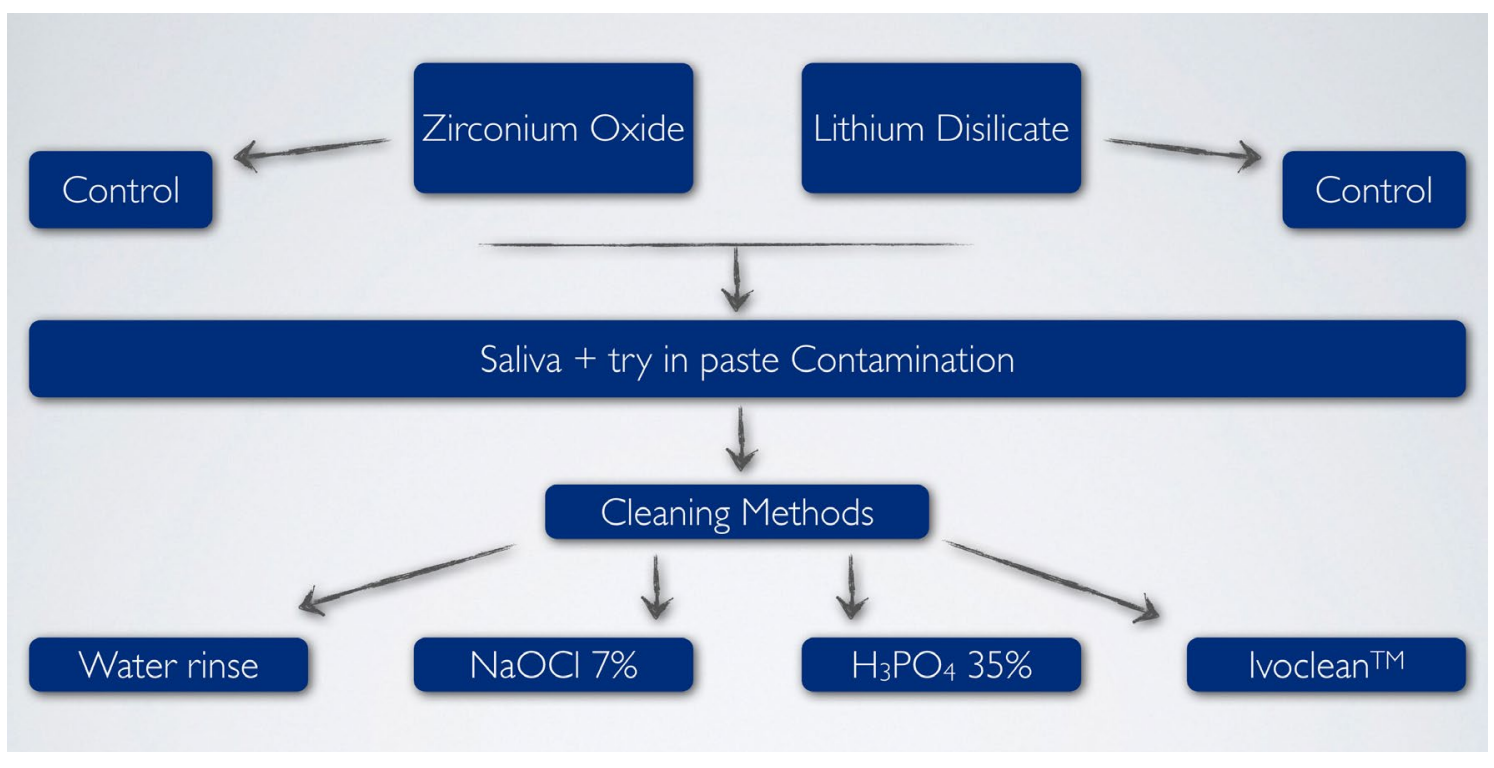

I Figure 1. Experimental design.

the internal surface of the restoration which could eventually compromise the bonding process during the seating of the restoration [6,7,9-11]. Some of the commonly used decontamination methods for restoration surfaces include scrubbing the surface with acetone, application of $37 \%$ phosphoric acid, immersing in $96 \%$ isopropanol, cleaning with $70 \%$ ethanol, airborne-particle abrasion, application of $2 \%$ chlorhexidine, or $5 \%$ sodium hypochlorite and water rinsing $[10,12,13]$. In addition to these products, a universal cleaning agent (Ivoclean; Ivoclar Vivadent AG, Schaan, Liechtenstein) is also available for the extraoral cleaning of ceramic and metal restorations. It is a non-toxic cleaning agent consisting of an alkaline suspension of zirconium dioxide particles, which tend to absorb and bond to phosphate contaminants and helps in surface decontamination $[7,12,14]$. Although, the effect of various cleaning agents/solutions on decontamination of saliva affected all ceramic restorations has been evaluated $[7,9,10,14-21]$, there is no clear protocol on the use of these agents. Also, the available literature is still inconclusive on the decontamination protocol for all ceramic restorations contaminated by both saliva and try-in pastes [11]. Therefore, the purpose of this bench study was to evaluate the bond strength of a resin-based cement to two commercial materials used for all ceramic restorations, IPS e.max ZirCAD and IPS e.max CAD after the contamination with saliva and try in paste and subsequent cleaning with $35 \%$ phosphoric acid or universal cleaning agent, or $7 \%$ Sodium Hypochlorite or simple water rinse. The null hypothesis was that there will be no difference in the bond strength between the resin cement and the ceramic materials after decontamination of the ceramic materials with the four methods used.

\section{Materials and Methods}

The experimental design is shown in Fig. 1. Ten samples for each group were fabricated as follows. IPS e.max ZirCAD (yttrium-stabilized zirconium oxide, Ivoclar Vivadent AG, Schaan, Liechtenstein)

blocks were sectioned to create $10 \times 15 \times 3 \mathrm{~mm}$ samples IsoMet 1000 Buehler) at 150 RPM with Cool 3 cutting fluid lubricant (Buehler, Lake Bluff, IL, USA). The samples were later sintered using a Sintramat (Ivoclar Vivadent AG, Schaan, Liechtenstein) sintering oven. The samples were placed in the firing saggar with sintering beads. The saggar was loaded to the firing chamber at room temperature. The $\mathrm{P} 1$ program was used and the sintering was done automatically for 8 hours with a maximum temperature of $1500^{\circ} \mathrm{C}$. The furnace could only be opened after the temperature dropped below $97^{\circ} \mathrm{C}$. After removal the saggar was allowed to cool to room temperature. IPS e.max CAD lithium metasilicate blocks (Ivoclar Vivadent AG, Schaan, Liechtenstein) were sectioned to create $10 \times 15 \times 3 \mathrm{~mm}$ samples. The samples were crystalized according to the manufacture instructions using the Programat P500 furnace (Ivoclar Vivadent AG, Schaan, Liechtenstein). The samples were placed in the furnace using a firing plate without any glaze application since the idea was to simulate the intaglio of the restoration. For crystallization, Sintramat's preloaded program for e.max CAD was used without altering any parameters. After crystallization, all samples were embedded in auto-polymerized acrylic resin (Acratray Blue, Zahn Dental, NY, USA) using an Ultradent 15-hole mold leaving one of the surfaces exposed. The exposed surface was ground with a silicon carbide paper in a polishing station with abundant water cooling to 240 grit size. For the zirconium oxide ceramic, the test surfaces were blasted with aluminum oxide 50 microns at 1 bar. The lithium disilicate ceramic samples were etched for 20 seconds with a $5 \%$ hydrofluoric acid gel (IPS ceramic Etching Gel, Ivoclar Vivadent AG, Schaan, Liechtenstein), rinsed with a water spray for 20 seconds and thoroughly dried with compressed air. One group with 10 samples for each material was not contaminated before bonding. Unstimulated human saliva was collected from one of the researchers that had withdrawn for eating or drinking one-hour prior the collection. Saliva and try-in paste (Variolink II tryin paste, Ivoclar Vivadent AG, Schaan, Liechtenstein) 


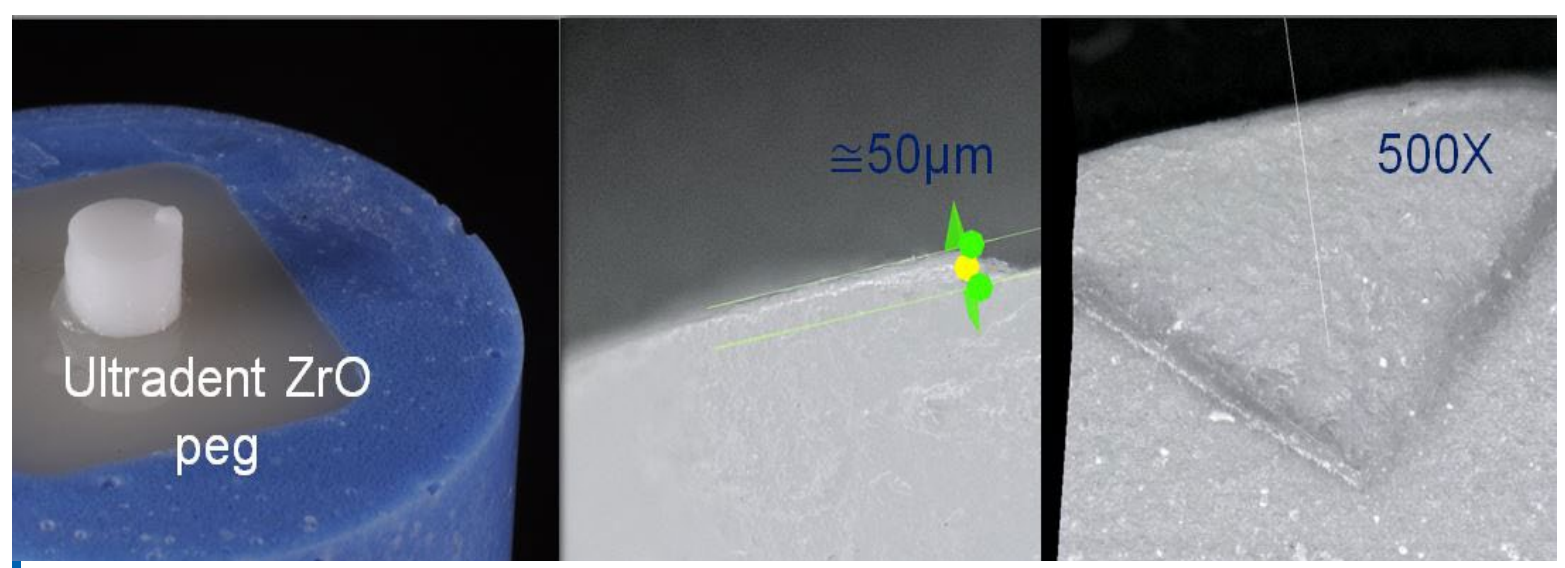

Figure 2. Test set-up for evaluation of shear bond strength.

were applied to the samples. A plastic disc was used to apply pressure over the samples to simulate a crown try-in. After the contamination with saliva and try-in paste all test samples were rinsed with water for 20 seconds and air-dried.

The samples were divided in 5 groups with 10 samples each for both materials, e.max ZirCAD (EMZ) and e.max CAD (EMC):

Group 1 (control group) - No contamination before bonding

Test groups - Saliva/try-in paste contamination with different cleaning methods:

Group 2: Water rinse

Group 3: Water rinse + Cleaning with NaOCL 7\% for 30 seconds followed by air-water rinse

Group 4: Water rinse + Cleaning with $\mathrm{H}_{3} \mathrm{PO}_{4} 35 \%$ for 30 seconds followed by air-water rinse

Group 5: Water rinse + Cleaning with Ivoclean for 30 seconds followed by air-water rinse

Zirconium oxide cylinders (Ultradent, UT, USA) designed with four $50 \mu \mathrm{m}$ pegs (Fig. 2) that defined the thickness of the cement layer were cemented to the samples. The Zirconium oxide cylinders were blasted with aluminum oxide 50 microns at 1 bar and a primer was applied (Zirconia Bond I, Signum). All the samples were treated with an all-purpose primer for 60 seconds (Monobond Plus, Ivoclar Vivadent AG, Schaan, Liechtenstein) prior to the cementation with Multilink Implant cement (Ivoclar Vivadent AG, Schaan, Liechtenstein) without light activation.

After cementation, the samples were placed in a deionized water bath at $37^{\circ} \mathrm{C}$ for $24 \mathrm{~h}$ hours after which they were subjected to shear forces using an Ultradent jig at a crosshead speed of $0.5 \mathrm{~mm} / \mathrm{min}$ with a universal testing machine (Instron, Norwood, MA, USA) to test for bond strength (Fig. 2). The mode of failure (cohesive, adhesive, or mixed) was examined under an optical microscope with 100x and 300x magnification (Keyence VHX-700F series). For the statistical analysis, ANOVA and Tukey's post hoc tests were used to find differences between the cleaning methods with the help of SAS software. The statistical significance was set at $p<0.05$.

\section{Results}

The shear bond strengths for the EMZ samples are shown in Table 1 and Fig. 3. The difference between various groups was not statistically significant $(p=$
Table 1. Shear bond strengths (MPa) for a max. ZirCAD (EMZ) samples.

\begin{tabular}{lcc}
\hline & Mean & Standard Deviation \\
\hline Control & 7.36 & 6.48 \\
EMZ-W & 9.96 & 6.62 \\
EMZ-HC & 8.14 & 5.31 \\
EMZ-PA & 12.95 & 7.96 \\
EMZ-IC & 9.10 & 5.30 \\
\hline
\end{tabular}

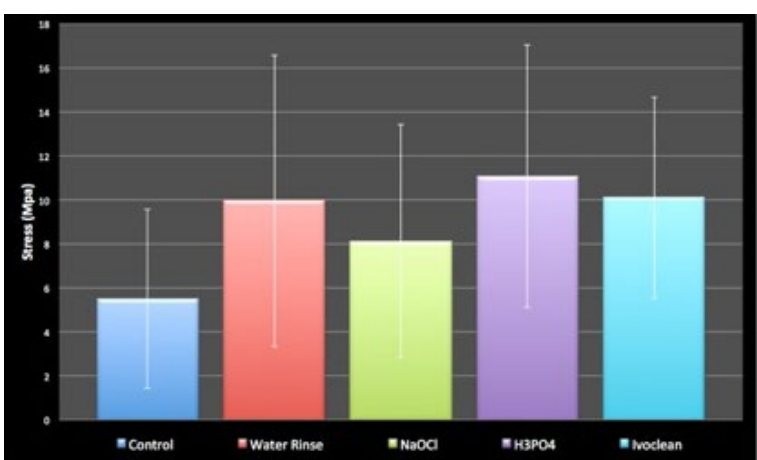

Figure 3. Shear bond strength values for IPS e.max ZirCAD samples for test and control groups.

I Table 2. Shear bond strengths (MPa) for EMC samples.

\begin{tabular}{lcc}
\hline & Mean & Standard Deviation \\
\hline Control & 4.65 & 3.72 \\
EMC-W & 6.78 & 5.30 \\
EMC-HC & 7.99 & 5.60 \\
EMC-PA & 12.28 & 7.22 \\
EMC-IC & 9.45 & 5.96 \\
\hline
\end{tabular}

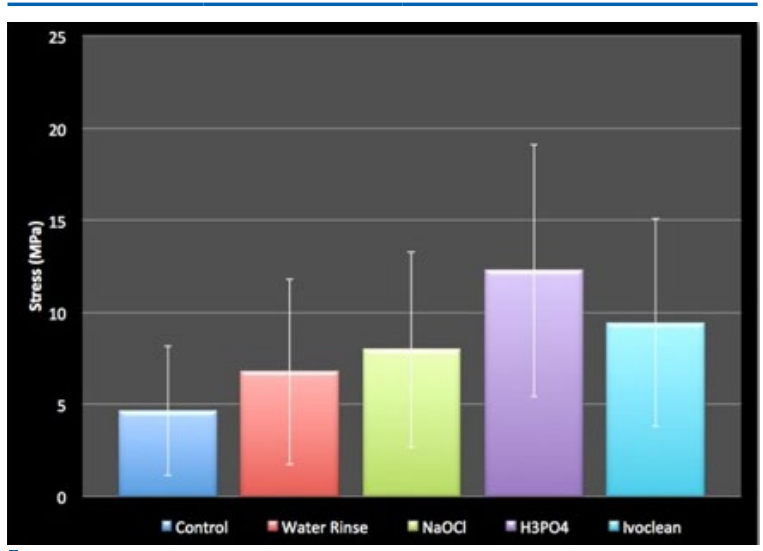

Iigure 4. Shear bond strength values for IPS e.max CAD samples for test and control groups. 

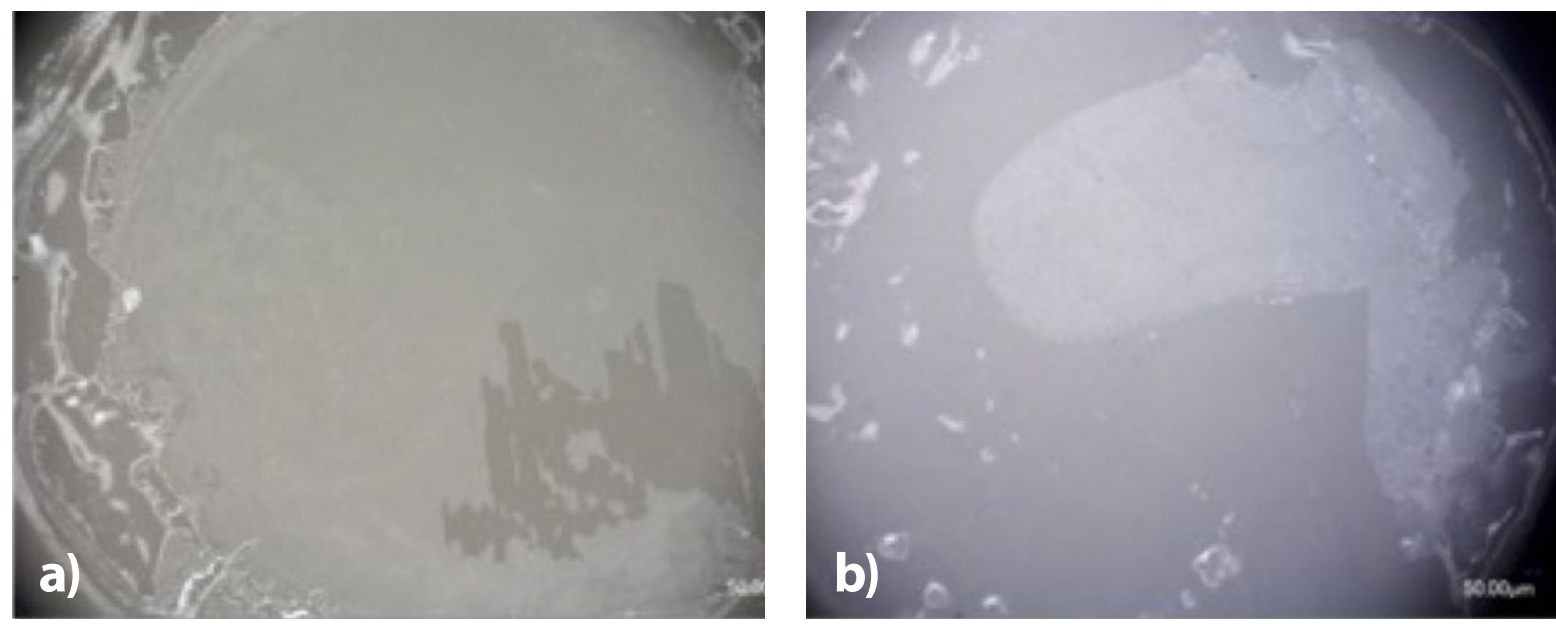

I Figure 5. Microscopic evaluation of failure modes: a) Failure at test ceramic surface; b) Adhesive failure

c) Failure at the peg interface.
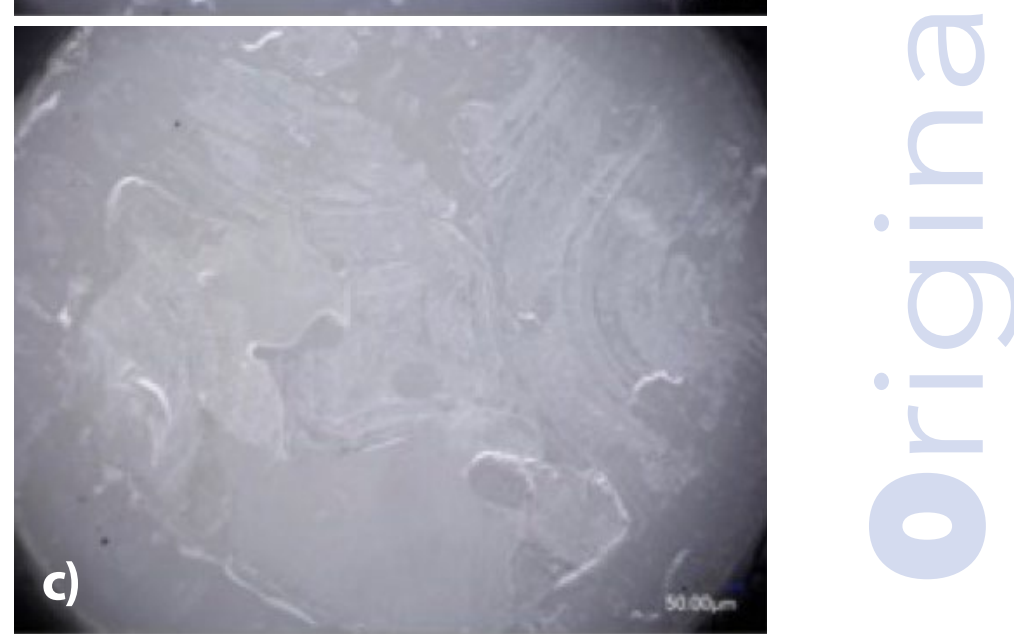

0.419). The shear bond strengths for the EMC samples are shown in Table 2 and Fig. 4.

Group 4 showed the highest shear bond strength. The initial analysis showed statical differences in between the treatment groups $(p=0.028)$.

The Tukey's test confirmed that only the difference between the control and the $\mathrm{H}_{3} \mathrm{PO}_{4}$ means were significantly different $(\mathrm{p}<0.05)$.

The microscopic analysis failed to find any cohesive failures in the test ceramic or the pegs (Fig. 5).

Mixed failures in the tested ceramic interface (63\%); mixed failures with adhesive failures in both side (34\%); mixed failures predominant in the peg interface (3\%).

\section{Discussion}

The present study evaluated the shear bond strengths of saliva and try-in paste contaminated lithium disilicate and zirconia samples subjected to different cleaning regimes. All the cleaning regimens employed in this study showed positive effects on the shear bond strength values. The treatment with phosphoric acid showed the highest values which were significantly better than control for the lithium disilicate samples $(p<0.05)$. The advancement in bonding technology is probably the great contributor for the high success of ceramic restorations, but the technique can be very sensitive. Salivary contamination comes into play when the restorations are tried-in for fit intraorally. The saliva

proteins can be absorbed on the tooth surface as well as the restorative materials [12]. It has been reported previously that the elimination of this saliva or try-in paste contamination is essential to improve the longterm durable ceramic bonding $[8,9,18]$.

All the cleaning methods used in the current study were able to eliminate the negative effects of saliva and try-in paste contamination on zirconia as measured with shear bond strengths. Ivoclean and sodium hypochlorite have been shown to be effective in removing the effects of salivary contamination on zirconia in previous studies $[7,16,18,20]$. Zirconia has a strong adsorption potential to the salivary phosphoproteins which leads to contamination when it comes in contact with saliva [16]. Ivoclean consists of zirconia particles, which, when brought in contact with contaminated zirconia, help absorb the phosphoproteins from its surface, which are then washed away during subsequent rinsing [20,22].

Interestingly, cleaning the zirconia surface with phosphoric acid showed not higher bond strength than control uncontaminated surfaces in this study. It has been reported previously that phosphoric acid successfully removes carbon-based contaminants but may leave a residue of phosphor-based contaminants on the zirconia surface [23]. These phosphor-based contaminants compete with the binding sites on the primer and lead to reduce bond strengths for saliva contaminated samples [16]. On the other hand, phosphoric acid proved to be an effective cleaning agent for zirconia samples contaminated with a 
combination of saliva and dental stone or saliva alone [23]. The values observed with phosphoric acid in our study could be due to the duration of time of its application, which was 30 seconds as compared to 60 seconds in the previous study [16], which could have minimized the phosphor-based contaminant residue on the zirconia surface. Nonetheless, this finding needs further exploration in future studies. Cleaning with phosphoric acid showed a significant improvement in shear bond strength when compared to uncontaminated control lithium disilicate samples. This finding is similar to the results from previous studies [11,14]. Klosa et al. tested the effect of various cleaning agents of lithium disilicate samples contaminated with saliva and silicone disclosing paste [14]. The authors found that both hydrofluoric acid and phosphoric acid were significantly better in improving bond strengths for saliva contaminated samples, although only hydrofluoric acid was able to achieve significantly higher bond strengths with saliva and silicone paste contamination. Interestingly, the samples were only visually inspected after silicone paste contamination and not cleaned with air/water which might have led to the abovementioned results. Nonetheless, the significantly higher bond strengths observed with phosphoric acid in our study shows that it is an effective way to clean lithium disilicate samples contaminated with saliva and try-in paste.

No cohesive failures were observed in this study. All the failures were mixed with a majority of them being either on the test ceramic interface or mixed adhesive failures on both sides suggesting that shear stresses were applied on the adhesive interface. More detailed results could have been observed with the use scanning electron microscopy at a higher magnification as compared to the low magnification of optical microscopy used in this study.

This study used shear bond strength as a measure of effectiveness of various cleaning agents on ceramic samples contaminated with saliva and try-in paste. Both shear and tensile bond strength values have been used in the literature to measure ceramicresin bond $[7,14,6,20,24]$. For a test to measure the bond strength values between an adherent and a substrate accurately, it is crucial that the bonding interface should be the most stressed region, regardless of the test methodology being employed [16]. Although, the microtensile test allows better specimen alignment and a more homogeneous stress distribution, during cutting procedures the adhesive joint may suffer from early debonding, yielding to high numbers of pretest failures, especially with a zirconia substrate [25]. Shear tests have been criticized for the development of nonhomogeneous stress distributions in the bonded interface, but they can be helpful in ranking materials or systems rapidly which could then be tested with more sophisticated methods. For high strength materials like zirconia, specimen preparation for microtensile test could result in more premature failures and defects in the bonded interface [25]. Therefore, SBS seems to be the choice for such specimens and was used for analysis in the present study.

The shear bond strength values observed in the current study are comparatively lower when compared to some studies $[7,16,21,23]$ and comparable to others [18]. Some of the differences in the numbers could be accounted due to different materials used for bonding the ceramic surfaces. Another reason could be the slight diameter mismatch between the pegs which were bonded to the ceramic samples and the notch inside the head of the shear tool on the testing machine as shown in Fig. 2. This could have led to excessive forces on the pegs during the shear test resulting in the observed lower values.

\section{Conclusion}

Within the limitations of the study the following inference could be made:

The cleaning methods used in the current study were able to improve the bond strengths of saliva and try-in paste contaminated zirconia samples to be comparable to the samples without contamination. Treatment with phosphoric acid was able to significantly increase the bond strength of lithium disilicate samples contaminated with saliva and tryin paste.

\section{Author Contributions}

LG:Idea, experimental design, performed the experiment, wrote initial manuscript. HA: wrote final manuscript, proofread manuscript, WM: contribution with literature review, discussion and proofread manuscript.

\section{Acknowledgement}

The authors thank Ivoclar Vivadent for donating the materials.

\section{References}

1. Kelly JR, Benetti P. Ceramic materials in dentistry: historical evolution and current practice. Aust Dent J. 2011;56 Supp 1:84-96.

[CrossRef] [PubMed] Google Scholar Scopus

2. Conrad HJ, Seong WJ, Pesun IJ. Current ceramic materials and systems with clinical recommendations: a systematic review. J Prosthet Dent. 2007;98(5):389-404.

[CrossRef] [PubMed] Google Scholar Scopus

3. Addison O, Marquis PM, Fleming GJ. Quantifying the strength of a resin-coated dental ceramic. J Dent Res. 2008;87(6):542-547. [CrossRef] [PubMed] Google Scholar Scopus

4. Blatz MB, Sadan A, Kern M. Resin-ceramic bonding: a review of the literature. J Prosthet Dent. 2003;89(3):268-274. [CrossRef] [PubMed] Google Scholar Scopus

5. Denry I, Kelly JR. State of the art of zirconia for dental applications. Dent Mater. 2008;24(3):299-307. [CrossRef] [PubMed] Google Scholar Scopus

6. Blatz MB, Chiche G, Holst S, Sadan A. Influence of surface treatment and simulated aging on bond strengths of luting agents to zirconia. Quintessence Int. 2007;38(9):745-753. PubMed] Google Scholar Scopus

7. Aladag A, Elter B, Comlekoglu E, et al. Effect of different cleaning regimens on the adhesion of resin to salivacontaminated ceramics. J Prosthodont. 2015;24(2):136-145. [CrossRef] [PubMed] Google Scholar Scopus

8. Quaas AC, Yang B, Kern M. Panavia F 2.0 bonding to contaminated zirconia ceramic after different cleaning procedures. Dent Mater. 2007;23(4):506-512. [CrossRef] [PubMed] Google Scholar Scopus

9. Yang B, Wolfart S, Scharnberg M, et al. Influence of contamination on zirconia ceramic bonding. J Dent Res. 2007;86(8):749-753.

[CrossRef] [PubMed] Google Scholar Scopus 
10. Nejatidanesh F, Savabi O, Savabi G, Razavi M. Effect of cleaning methods on retentive values of saliva-contaminated implant-supported zirconia copings. Clin Oral Implants Res. 2018;29(5):530-536

[CrossRef] [PubMed] Google Scholar Scopus

11. Prata RA, de Oliveira VP, de Menezes FC, et al. Effect of 'Try-in' paste removal method on bond strength to lithium disilicate ceramic. J Dent. 2011;39(12):863-870.

[CrossRef] [PubMed] Google Scholar Scopus

12. Yang B, Lange-Jansen HC, Scharnberg M, et al. Influence of saliva contamination on zirconia ceramic bonding. Dent Mater. 2008;24(4):508-513.

[CrossRef] [PubMed] Google Scholar Scopus

13. Aboushelib MN, Kleverlaan CJ, Feilzer AJ. Microtensile bond strength of different components of core veneered all-ceramic restorations. Part Il: Zirconia veneering ceramics. Dent Mater. 2006;22(9):857-863.

[CrossRef] [PubMed] Google Scholar Scopus

14. Klosa K, Wolfart S, Lehmann F, et al. The effect of storage conditions, contamination modes and cleaning procedures on the resin bond strength to lithium disilicate ceramic. J Adhes Dent. 2009;11(2):127-135.

[PubMed] Google Scholar Scopus

15. Borges ALS, Posritong S, Özcan M, et al. Can cleansing regimens effectively eliminate saliva contamination from lithium disilicate ceramic surface? Eur J Prosthodont Restor Dent. 2017;25(1):9-14

[PubMed] Google Scholar Scopus

16. Feitosa SA, Patel D, Borges AL, et al. Effect of cleansing methods on saliva-contaminated zirconia - an evaluation of resin bond durability. Oper Dent. 2015;40(2):163-171 [CrossRef] [PubMed] Google Scholar Scopus

17. Irmak O, Yaman BC, Orhan EO, et al. Influence of cleaning methods on bond strength to saliva contaminated zirconia. $J$ Esthet Restor Dent. 2018;30(6):551-556.

[CrossRef] [PubMed] Google Scholar Scopus
18. Kim DH, Son JS, Jeong $\mathrm{SH}$, et al. Efficacy of various cleaning solutions on saliva-contaminated zirconia for improved resin bonding. J Adv Prosthodont. 2015;7(2):85-92. [Free PMC Article] [CrossRef] [PubMed] Google Scholar Scopus

19. Pitta J, Branco TC, Portugal J. Effect of saliva contamination and artificial aging on different primer/cement systems bonded to zirconia. J Prosthet Dent. 2018;119(5):833-839. [CrossRef] [PubMed] Google Scholar Scopus

20. Takahashi A, Takagaki T, Wada T, et al. The effect of different cleaning agents on saliva contamination for bonding performance of zirconia ceramics. Dent Mater J. 2018;37(5):734-739.

[CrossRef] [PubMed] Google Scholar Scopus

21. Yoshida K. Influence of cleaning methods on resin bonding to saliva-contaminated zirconia. J Esthet Restor Dent. 2018;30(3):259-264 [CrossRef] [PubMed] Google Scholar Scopus

22. Ishii R, Tsujimoto A, Takamizawa T, et al. Influence of surface treatment of contaminated zirconia on surface free energy and resin cement bonding. Dent Mater J. 2015;34(1):91-97. [CrossRef] [PubMed] Google Scholar Scopus

23. Phark JH, Duarte S Jr, Kahn H, et al. Influence of contamination and cleaning on bond strength to modified zirconia. Dent Mater 2009:25(12):1541-1550. [CrossRef] [PubMed] Google Scholar Scopus

24. Kato T, Masuda Y, Nakamura N, Yoshida A. Association between changes in cortical and jaw motor activities during sleep. Journal of Oral Biosciences. 2012;54(1):5-10. Google Scholar Scopus

25. Valandro LF, Özcan M, Amaral R, et al. Effect of testing methods on the bond strength of resin to zirconia-alumina ceramic: microtensile versus shear test. Dent Mater J. 2008;27(6):849-855

[Full text links] [PubMed] Google Scholar Scopus

\section{Luiz H. GONZAGA}

DDS, MS, Clinical Assistant Professor Department of Oral \& Maxillofacial Surgery, Center for Implant Dentistry College of Dentistry, University of Florida Gainesville, FL, USA

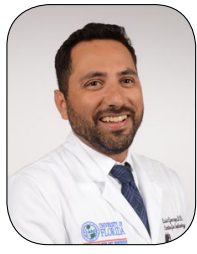

Dr. Luiz H. Gonzaga, DDS, MS graduated from the Catholic University of Brasilia College of Dentistry in 2004. After working in private practice and taking perio/implants CE courses for one year he was accepted for the Implant/Periodontic specialty training graduating in 2009. Dr. Gonzaga was awarded with the ITI scholarship in 2009 and completed his OMFS fellowship the next year. He completed a residency program and Masters in Prosthodontics from the University of Florida in 2014. Currently he is a Clinical Assistant Professor at the University of Florida Center for Implant Dentistry. Dr. Gonzaga is an ITI speaker and Fellow of the International Team for Implantology, a member of the American College of Prosthodontics, and the Academy of Osseointegration.

\section{0ugestions}

\section{What percentage of Hydrofluoric acid was used to etch Lithium Disilicate samples?}
ㅁ. 3.5\%;
口b. $5 \%$;
口c. 7\%;
口c. 9.5\%;

\section{Which try-in paste was used?}
口a. Duolink;
ab. Variolink;
口c. Panavia;
ad. Multilink.

3. How long was Ivoclean applied for?

口a. 30 seconds;

ab. 20 seconds;

ac. 15 seconds;

ad. 10 seconds.

\section{How long were samples placed in deionized bath?}

a. 6 hours;

ab. 12 hours;

ac. 24 hours;

ad. 1 week. 


\title{
INFLUENCE OF FLUORIDE MOUTHWASH CONTAINING NANOHYDROXYAPATITE ON THE DENTIN INTERFACE OF DIRECT RESTORATIONS: A RANDOMIZED CONTROLLED CROSSOVER IN SITUSTUDY
}

\author{
Dayane Carvalho Ramos Salles de Oliveira ${ }^{1 a^{*}}$ (D) $^{\text {, Livia Rodrigues de Menezes }}{ }^{2 \mathrm{C}}{ }^{(\mathbb{D})}$, Lúcia Trazzi Prieto ${ }^{1 \mathrm{a}}$ (D)

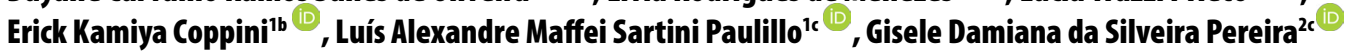 \\ 'Department of Restorative Dentistry, Piracicaba Dental School, State University of Campinas, Piracicaba, SP, Brazil \\ ${ }^{2}$ Federal University of Rio de Janeiro, Rio de Janeiro, RJ, Brazil \\ aPhD, Assistant Professor \\ ${ }^{\mathrm{bPhD}}$ \\ PhD, Associate Professor
}

ABSTRACT

DOI: https://doi.org/10.25241/stomaeduj.2019.6(1).art.3

Introduction: To evaluate the influence of a fluoride mouthwash containing nanohydroxyapatite on the dentin bonding interface microhardness of direct resin composite restorations in situ.

Methodology: Forty human premolars were sectioned and restored with a three-step adhesive system or a self-etch adhesive system and a conventional resin-based composite. After the initial microhardness measurements on the samples' dentin interface, the restored samples were fixed in acrylic palate appliances for an in situ experiment. Ten volunteers participated in a randomized double-blinded crossover study using the palate appliances and a placebo fluoride mouthwash for one week, one-week wash-out, and one-week fluoride mouthwash containing nanohydroxyapatite. The final microhardness measurements were evaluated, and data were analyzed by ANOVA and Tukey's test submitted for multiple comparisons ( $a=0.05 ; 0.8$ power).

Results: There were statistically significant differences between the mouthwash treatments with both adhesive systems tested $(p<0.001)$. The nanohydroxyapatite used in the mouthwash was an influencing factor on the dentin interface microhardness of resin composite restorations.

Conclusion: The fluoride mouthwash containing the nanohydroxyapatite was able to increase the dentin microhardness of the direct resin composite restorations regardless of the adhesive system used.

Keywords: Dental materials; composite resins; dental adhesive; mouthwashes.

OPEN ACCESS This is an Open
Access article under the CC BY-NC
4.0 license.
Citation: de Oliveira DCRS, de Menezes LR,
Prieto LT, Coppini EK, Sartini Paulillo LAM,
da Silveira Pereira GD. Influence of fluoride
mouthwash containing nanohydroxyapatite
on the dentin interface of direct restorations:
a randomized controlled crossover in situ
study. Stoma Edu J.2019;;6(1):24-28
Received: February 09, 2019
Revised: February 28, 2019
Accepted: March 18, 2019
Published: March 19, 2019
*Corresponding author:
Dayane C.R.S. de Oliveira
Department of Restorative Dentistry,
Piracicaba Dental School
State University of Campinas, 901, Limeira
Ave.SP-13414-903 Piracicaba, Brazil
Tel/ Fax: +55 (019) 2106-5341
e-mail: dayoli87@gmail.com
Copyright: $\odot 2019$ the Editorial Council
for the Stomatology Edu Journal.

\section{Introduction}

Dental enamel etching increases the surface energy, which facilitates the penetration of the adhesive system and the adhesion to this substrate[1]. Adhesion to the enamel substrate is more efficient than to the dentin substrate since it is composed of an inorganic matrix, while dentin presents a more significant amount of organic matrix composed mainly of collagen and water [2]. Moisture control, maintenance of the permeable collagen to the adhesive system penetration, and demineralization of acid etching are essential factors to improve the transition zone, called the hybrid layer [3], which is the primary mechanism of adhesion to the dentin substrate [4]. Several factors can influence the hybrid layer development. When moisture control is performed incorrectly, the penetration of the monomers into the demineralized dentin is incomplete, resulting in failure areas. This increases the risk of nanoleakage through the pores present in the adhesive interface of this defective hybrid layer. It can cause postoperative sensitivity and reduce the longevity of the direct restorations $[5,6]$. The presence of failure areas on the adhesive interface enables the infiltration of various harmful agents, as well as oral fluids, to infiltrate these gaps. Therefore, ions, such as calcium and fluoride, present in saliva or solutions used as mouthwashes [4] can also penetrate and fill the micro porosity present in the hybrid layer, thus decreasing its permeability [8-10]. It becomes evident that evaluating whether or not the use of mineralizing agents allows adducing within the hybrid layer of ions that can fill the nanopores present in the dentin interface is essential. Thus, this study assessed the influence of a fluoride mouthwash containing nanohydroxyapatite on the dentin bonding interface microhardness of direct resin composite restorations. The null hypothesis was that the use of the fluoride mouthwash containing nanohydroxyapatite will not influence the dentin interface microhardness of direct resin composite resin restorations.

\section{Methodology}

\subsection{Ethical aspects}

This in situ, double-blinded, single center, randomized controlled crossover study was authorized by the 


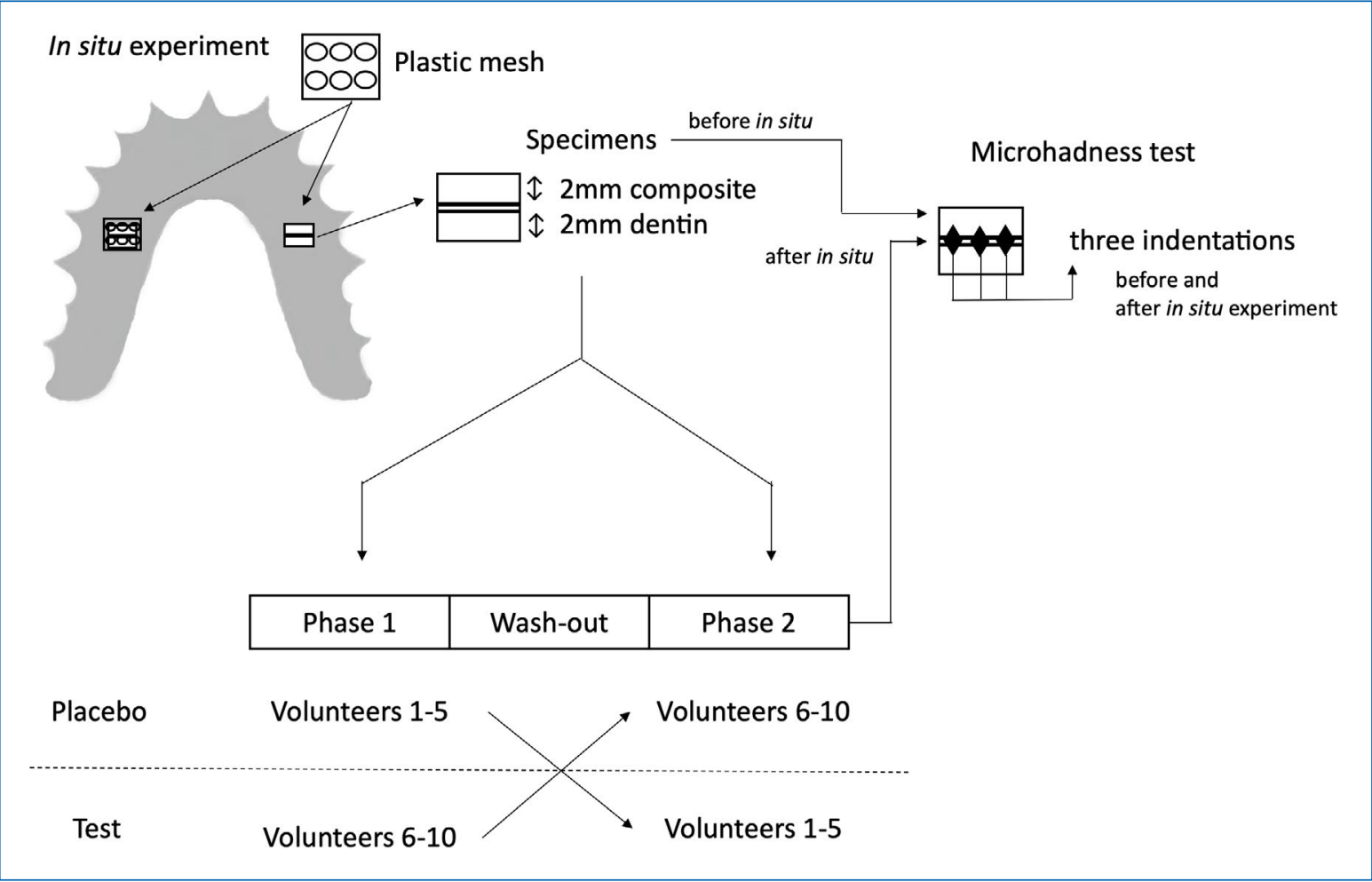

I Figure 1. Flow diagram with a systematic illustration of the crossover in situ model and experimental design.

local Institutional Ethics Committee of the Piracicaba Dental School, Piracicaba, SP, Brazil (protocol \#149/2012). A written informed consent was obtained from all volunteers in the study. Volunteers had the right to withdraw from the study at any time and for any reason without prejudice.

\subsection{Preparation of the specimens}

Forty human premolars recently extracted because of orthodontic reasons were donated to this study. The teeth were stored for $24 \mathrm{~h}$ in a $0.1 \%$ thymol solution at $37^{\circ} \mathrm{C}$, then stored in distilled water until the beginning of the study. The coronal portion was separated from the root through a straight section on the long axis of the tooth using a metallographic precision cutter (Isomet 1000, Buehler Ltd., Buff Lake, IL, USA) with a diamond saw under constant irrigation. To obtain a flat dentin surface, the occlusal surfaces were ground with sandpaper silicon carbide ( $\mathrm{SiC}$ \#320 and \#400 in a metallographic polisher sander cooled with water. Then, $4 \times 4 \mathrm{~mm}$ dentin blocks were obtained with $2 \mathrm{~mm}$ of thickness. After an ultrasound bath to remove the sander debris, the standardization of the smear layer was performed on the dentin flat by manually rubbing with SiC wet sandpaper \#1000 and \#1200 for 15 s per sandpaper grit. The dentin blocks were kept in $100 \%$ relative humidity at $37^{\circ} \mathrm{C}$. This study used the total etching technique with a three-step adhesive system (Scotchbond Multi-Purpose Plus, 3M ESPE, St. Paul, MN, USA) and a self-etch adhesive system (Clearfill SE Bond, Kuraray, Tokyo, Japan) with a nanofilled resin composite (Filtek Z350 XT, 3M ESPE, St. Paul, MN, USA). All clinical and laboratory steps were performed at the Restorative Department of Piracicaba Dental School,
UNICAMP, Piracicaba, SP, Brazil. For the three-step adhesive system, the excess water was removed by capillary action with an absorbent paper. The dentin etching was performed with $35 \%$ phosphoric acid for $15 \mathrm{~s}$, followed by rinsing with abundant water for $30 \mathrm{~s}$. The moisture was controlled with a moist cotton ball. Both adhesive systems were used according to the manufacturers' instructions with a microbrush and light cured for $20 \mathrm{~s}$ with a LED light source (Radii, SDI, Victoria, Australia). The restoration was carried out with a single $2 \mathrm{~mm}$ increment of the resin composite in a $4 \times 4 \mathrm{~mm}$ acetate pattern to standardize the direct restorations, and then light-cured for $20 \mathrm{~s}$. All samples were stored in $100 \%$ relative humidity at $37^{\circ} \mathrm{C}$ for $24 \mathrm{~h}$.

\subsection{In situ study}

This in situ, double-blinded, single center, randomized controlled crossover study was carried out for three weeks, including a one-week fluoride nanohydroxyapatite-free phase, a one-week washout period and a one-week fluoride nanohydroxyapatiteactive phase. A total of 10 adult volunteers (mean age $23.3 \pm 2.3 \mathrm{yrs} ; 5$ females and 5 males) were recruited in the Piracicaba Dental School, UNICAMP, Piracicaba, SP, Brazil and in the Dental School of the Federal University of Rio de Janeiro, Rio de Janeiro, RJ, Brazil. All volunteers had confirmed satisfactory oral health, did not use any medication, did not have any systemic disease or pregnancy, and did not use any mouthwash or toothpaste except as provided for the research. In this study, all volunteers completed the study, no participants were excluded or withdrawn from the study. Impressions of all the volunteers' mouths were made to obtain a model to make a palate acrylic 
I Table 1. Means (standard deviations) values for microhadness test (KHN).

\begin{tabular}{lcc}
\hline \multicolumn{1}{c}{ Experimental Group } & \multicolumn{2}{c}{ Microhardness } \\
\cline { 2 - 3 } & \multicolumn{1}{c}{ Initial } & Final \\
\hline Clearfill SE (+ testing mouthwash) & $42.59(0.5) \mathrm{Ba}$ & $44.33(0.6) \mathrm{Aa}$ \\
Clearfill SE (+ placebo mouthwash) & $41.29(0.5) \mathrm{Aa}$ & $40.4(1.0) \mathrm{Ab}$ \\
ScotchBond MP (+ testing mouthwash) & $42.15(0.4) \mathrm{Bb}$ & $45.42(0.6) \mathrm{Aa}$ \\
ScotchBond MP (+ placebo mouthwash) & $39.66(0.6) \mathrm{Aab}$ & $40.35(0.5) \mathrm{Ab}$ \\
\hline
\end{tabular}

${ }^{*}$ Means followed by different capital letters in the same line and small letters in the same column were significantly different $(p<0.05)$.

appliance for the upper arch. In each plate two cavity sites were fabricated where the specimens were fixed. All sites were positioned posterior to the incisive papillae to avoid contact between the tongue and the specimens. Every site had a $4.5 \times 4.5 \mathrm{~mm}$ uniform gap with $4 \mathrm{~mm}$ in depth covered by a plastic mesh to allow free contact of the saliva with the specimens, but protection from mechanical disturbance. New specimens were inserted into the appliance before phase 2 . The specimens were randomly assorted and allocated into two groups: experimental or placebo. A systematic illustration of the crossover in situ model and the experimental design can be observed in Fig. 1. In the first week half of the volunteers were randomly allocated to use the fluoride mouthwash containing nanohydroxyapatite, while the other half to use the placebo fluoride mouthwash containing no nanohydroxyapatite. After the second week "wash-out" to neutralize the fluoride agent and the microhardness readings, the groups were reversed and conducted as described in the first week. The volunteers who used the placebo fluoride mouthwash in the first week used the tested mouthwash in the second week and vice versa. The study products and tested materials were provided as coded packages labeled with participants number and study period. None of the volunteers, in situ study instructors or in situ study monitors that were participating in the study knew the type of group (placebo or test) being tested until all procedures were finalized. The in situ study coordinators were responsible for blinding all participants and labeling the study products and tested materials. The mouthwashes used in the study were prepared by FGM Produtos Odontológicos (89219-501 Joinville, SC, Brasil). The placebo fluoride mouthwashes were produced with the same color, viscosity and taste compared to the tested mouthwash. The placebo mouthwash and the tested one contained the same components, including the fluoride and the potassium nitrate, but only the tested mouthwash contained the nanohydroxyapatite, as in the Desensibilize Nano $P$ (FGM Produtos Odontológicos, 89219-501 Joinville, SC, Brasil). The volunteers were instructed to swish $20 \mathrm{~mL}$ of the mouthwash around their mouth for thirty seconds then spit it out with no rinsing. The volunteers were also instructed to use it twice a day, every day, after brushing and flossing their teeth in the morning and at night. All volunteers were instructed to brush their teeth using the same toothpaste containing no fluoride during all study. The volunteers should wear the appliance for more than $20 \mathrm{~h}$ per day, removing it only while eating or brushing. The volunteers were instructed to rinse off their appliance and store it in artificial saliva while not in use.

\subsection{Microhardness readings (KHN)}

The Knoop Microhardness of the dentin interface (illustrated in Fig. 1) was examined using a microhardness tester (HMV-2, Shimadzu, Kyoto, Japan) with a $50 \mathrm{~g}$ load for $15 \mathrm{~s}$ in three equally spaced points on each sample. A blinded trained operator performed all the microhardness measurements before and after the crossover in situ experiment. The microhardness of each sample was taken from the arithmetic mean of the three readings.

\subsection{Statistical analyses}

The sample size was calculated according to a pilot test to provide a power of 0.8. The power was calculated according to power analysis. The data were subjected to ANOVA and Tukey's test with a limit of $5 \%$ probability of making decisions.

\section{Results}

ANOVA showed a significant difference between the tested groups (placebo/tested mouthwash $x$ time) $(p<0.001)$. Mean values taken from Tukey's test are shown in Table 1. As could be observed, the nanohydroxyapatite used in the mouthwash was an influencing factor on the dentin interface microhardness of resin composite restorations. The fluoride mouthwash containing the nanohydroxyapatite managed to increase the dentin interface microhardness of direct resin composite restorations regardless of the adhesive system used, while the placebo fluoride mouthwash solution containing no nanohydroxyapatite had no influence on dentin interface microhardness.

\section{Discussion}

The present study clinically investigated the influence of a fluoride mouthwash containing nanohydroxyapatite on the dentin bonding interface microhardness of direct resin composite restorations in situ. There are several in vitro studies showing 
possible effects of mouthwashes in composite restorations overtime [11-14]. However, there is no consensus about this topic, and the reason for this is that different mouthwashes contain different components. The crossover in situ model allowed to access the real effects in the oral cavity. Moreover, the use of the same fluoride mouthwash composition varying only theaddition ornot of nanohydroxyapatite, allowed to access the real influence of the different mineralizing agents on the dentin bond interface of composite restorations. The null hypothesis that the use of the fluoride mouthwash containing nanohydroxyapatite would not influence the dentin interface microhardness of direct resin composite resin restorations was rejected. This occurred since the final microhardness values were statistically different between the fluoride mouthwash containing nanohydroxyapatite and the placebo fluoride mouthwash containing no nanohydroxyapatite, regardless of the adhesive system tested. The mineralizing agents had been tested to reduce the failure areas of the adhesive interface, hindering the infiltration of harmful agents. Calcium and fluoride have been described in the literature as being able to fill the microporosity present in the hybrid layer, decreasing its permeability [7-10]. As observed in this study, the fluoride mouthwash containing nanohydroxyapatite managed to influence the dentin microhardness showing a possible ability to fill the microporosity present in the dentin interface. However, due to the similar mean values of the initial and final microhardness, it is presumed that despite the capability of the fluoride to penetrate the hybrid layer, it could have been lixiviated from the hybrid layer during the in situ study, not contributing to filling the microporosities present in the dentin interface. The microporosities in the dentin interface occurs due to the incorrect or incomplete penetration of the adhesive monomers into the demineralized dentin, resulting in failure areas within the hybrid layer. These failures within the hybrid layer increase the risk of micro or nanoleakage through the pores present in the adhesive interface, reducing the longevity of the restoration [5-6]. However, the same way oral fluids can infiltrate through these failures, other substances such as calcium and fluoride, present in the saliva or solutions used as mouthwashes [4] could also penetrate and fill the microporosity present in the hybrid layer, thus decreasing its permeability [8-10], and possibly increasing the longevity of composite restorations. As observed in this study, despite fluoride having been described in the literature as being able to fill the microporosity present in the hybrid layer [7-10], the conventional fluoride mouthwash solution (placebo) was not able to increase the initial microhardness much as the fluoride mouthwash containing nanohydroxiapatite. As a limitation of this study, the effects of the fluoride mouthwashes containing nanohydroxyapatite or not were evaluated in situ for only one week. Thus, further clinical studies should be performed to further evaluate the clinical performance of these different treatments using mouthwashes and their real effects in the long term. By all means, the addition of nanohydroxyapatite seems to increase the efficiency of fluoride with regard to mineralization. The remineralizing formula containing nanostructured calcium phosphate, organized in the crystalline form of hydroxyapatite allows the releasing of calcium and phosphate ions to the demineralized surface of the tooth, which can be reorganized in the form of hydroxyapatite, fluorapatite or calcium fluoride, as well as to occlude the dentinal tubules. Moreover, the hydroxyapatite crystals are highly stable and more resistant to acidic challenges when compared to amorphous calcium phosphates, explaining the increased efficiency of the tested formula containing nanohydroxyapatite in comparison to the fluoride placebo formula. Thus, with the limitations of this crossover in situ study, it was possible to conclude that the fluoride mouthwash containing nanohydroxyapatite managed to increase the dentin microhardness of direct resin composite restorations regardless of the adhesive system used within one week. On the other hand, the conventional fluoride mouthwash solution had no influence on dentin microhardness within one week.

\section{Authors contribution}

DO/LM: Experimental design, crossover in situ study coordinator, statistical analysis, manuscript writing, manuscript proofreading. LTP: Experimental design, blinded in situ study clinical instructor, manuscript proofreading. EK: Experimental design, blinded technical microhardness tester, manuscript proofreading. GP/LMP: Experimental design, in situ study clinical monitor, manuscript proofreading.

\section{Acknowledgments}

This study thanks FGM for preparing and donating the mouthwashes used in this study. DO is a Post-Doctoral Researcher at the Sao Paulo Research Foundation (FAPESP grant \#2016/05823-3 and \#2017/22161-7).

The authors declare no potential conflict of interest concerning the authorship or the publication of this article.

\section{References}

1. Buonocore MG. A simple method of increasing the adhesion of acrylic filling materials to enamel surfaces. J Dent Res. 1955;34(6):834-853.

[CrossRef] [PubMed] Google Scholar Scopus

2. Perdigão J. New Concepts in dental adhesion. Northwest Dent. 2000;79(4):29-33.

[PubMed] Google Scholar Scopus

3. Nakabayashi N, Kojima K, Masuhara E. The promotion of adhesion by the infiltration of monomers into tooth substrates. J Biomed Mater Res. 1982;16:265-273. [CrossRef] [PubMed] Google Scholar Scopus

4. Nakabayashi N. The hibrid layer: A resin-dentin composite. Proc Finn Dent Soc. 1992;8(1): 322-329. [PubMed] Google Scholar 
5. Frankenberger R, Perdigão J, Rosa BT, Lopes M. No-bottle vs multi-bottle dentin adhesives - a Microtensile bond strength and morphological study. Dent Mater. 2011;17:373-380. [Full text links] [PubMed] Google Scholar

6. Lopes GC, Marson FC, Vieira LC, et al. Composite bond strength to enamel with self-etching primers. Oper Dent. 2004;29(4):424-9.

[PubMed] Google Scholar Scopus

7. Lenz H. Ultrastructure of the tooth in respect of mineralization, demineralization and remineralization. Int Dent J. 1967:17(4): 693-708.

8. Akimoto N, Yokovama G, Ohmori K, et al. Remineralization across the resin-dentin interface: in vivo evaluation with nanoindentation measurements, EDS, and SEM. Quintessence Int. 2001;32(7):561-570.

[PubMed] Google Scholar Scopus

9. Perdigão J, Van Meerbeek B, Lopes MM, Ambrose WW. The effect of re-wetting agent on dentin bonding. Dent Mater. 1999;15(4):282-95.

[Full text links] [PubMed] Google Scholar Scopus

10. Watanabe I, Nakabayashi N, Pashley DH. Bonding to ground dentin by a phenyl-P self-etching primer. J Dent Res.
1994;73(6):1212-1220.

[CrossRef] [PubMed] Google Scholar Scopus

11. Ajami AA, Bahari M, Oskoee SS, et al. Effect of three different mouthrinses o microleakage of composite resin restoration with two adhesive systems after bleaching with $10 \%$ carbamide peroxide. J Contemp Dent Pract. 2012;1(13):16-22. Google Scholar

12. Wilde MG, Delfino CS, Sassi JF, et al. Influence of $0.05 \%$ sodium fluoride solutions on microhardness of resinmodified glass ionomer cements. J Mater Sci Med. 2006;17(9):869-873.

[CrossRef] [PubMed] Google Scholar Scopus

13. Yap AU, Tan BW, Tay LC, et al. Effect of mouthrinses on microhardness and wear of composite and compomer restoratives. Oper Dent. 2003;28(6):740;746.

[PubMed] Google Scholar Scopus

14. Gurdal P, Akdeniz BG, Hakan Sen B. The effects of mouthrinses on microhardness and colour stability of aesthetic restorative materials. J Oral Rehabil. 2002;29(9):895901.

[Full text links] [PubMed] Google Scholar Scopus

\section{Dayane C. R. S. de OLIVEIRA \\ DDS, MS, PhD, Assistant Professor Department of Restorative Dentistry Piracicaba Dental School State University of Campinas Piracicaba, SP, Brazil}

Dayane C. R. S. de Oliveira, DDS, MS, PhD, is a post-doc fellow of the Department of Restorative Dentistry at Piracicaba Dental School, State University of Campinas (UNICAMP), in Brazil. Dr. Oliveira is a young researcher that contributed to 6 textbook chapters, authored 7 patents and is the recipient of many awards in her area of expertise. Her areas of interest include esthetic dentistry, color science and biomaterials development and characterization.

\section{0uestions}

\section{Based on the results in this study, fluoride mouthwashes:}

$\square$ a. Are capable of increasing microhardness of dentin interface of composite restorations; $\square$ b. Are not capable of increasing microhardness of dentin interface of composite restorations; ac. Are not necessarily capable of increasing microhardness of dentin interface of composite restorations depending on composition;

$\square$ d. None of the above.

\section{Based on the results in this study, fluoride mouthwashes containing nanohydroxyapatite:}

口a. Are capable of increasing microhardness of dentin interface of composite restorations;

b. Are not capable of increasing microhardness of dentin interface of composite restorations;

ac. Have similar performance compared to conventional fluoride mouthwashes;

$\square$ d. None of the above.

\section{Based on the discussion section, which statement is true:}

$\square$ a. Fluoride mouthwashes not containing nanohydroxyapatite might be capable of infiltrating in the hybrid layer and forming amorphous calcium phosphates; but it is probably dissolved and lixiviated over time; $\square$ b. Fluoride mouthwashes not containing nanohydroxyapatite do not contribute to filling the microporosities present in the dentin interface over time;

c. Fluoride mouthwashes containing nanohydroxyapatite are capable of infiltrating in the hybrid layer, and forming highly stable hydroxyapatite crystals;

$\square$ d. All of the above.

\section{Based on the discussion section, which statement is not true:}

$\square$ a. The primary limitation of this study was follow-up time which does not allow the authors to extrapolate the results in regard the longevity of the composite restorations;

b. Literature demonstrate the immediate results of fluoride agents, however, this study demonstrated that these results can be modified over time;

ac. This study demonstrated that increasing the longevity of the composite restorations might be possible using fluoride agents associated with nanohydroxyapatite, however further studies are necessary;

$\square$ d. None of the above. 


\title{
ORAL HEALTH BEHAVIOUR AND AWARENESS OF YOUNG POPULATION IN TURKEY
}

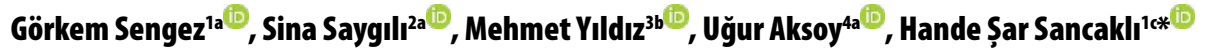 \\ 'Department of Restorative Dentistry, Faculty of Dentistry, Istanbul University, 34093, Çapa-Fatih, Istanbul, Turkey \\ 2Department of Prosthodontics, Faculty of Dentistry, Istanbul University, 34093, Çapa-Fatih, Istanbul, Turkey, \\ ${ }^{3}$ Department of Dental Services, Faculty of Dentistry, Toros University, 33140, Yenişehir, Mersin, Turkey \\ ${ }^{4}$ Department of Endodontics, Faculty of Dentistry, Istanbul University, 34093, Çapa-Fatih, Istanbul, Turkey
}

aDDS, PhD, Researcher

${ }^{b} D D S$

'DDS, PhD, Associate Professor

Introduction: Transition from adolescence to adulthood is an important episode in life since it determines a person's long-time health behavior and their tendency to carry chronic diseases. The present study aims to assess oral health behavior and awareness of the young population in Turkey.

Methodology: A sample of 2,740 students (1309 male, 1431 female) from 5 different universities studying 10 different degree subjects completed a questionnaire related to their oral health behavior. Age, gender and degree subjects were also recorded. The data were analyzed using SPSS 21.0.

Results: $66.6 \%$ of the students brushed their teeth twice or more times daily. The brushing frequency of students studying different degree subjects is significantly different $(p<0.01)$. Dental students have the highest brushing frequency whereas sports students have the lowest. $38 \%$ of the participants indicated that they use mouthwash; however, only $21.2 \%$ used it daily. $21.2 \%$ of the participants visit a dentist once or twice per year. $50.9 \%$ of the participants experience bleeding while brushing. Only $28.8 \%$ had regular scaling and polishing. $22.6 \%$ of the participants smoke, while $18.8 \%$ stated that they have halitosis.

Conclusion: The present study indicated that oral health behavior of young population needs to be further improved. Therefore, oral health education programs should be initiated to emphasize the importance of oral hygiene.

Keywords: Oral hygiene; health attitude; health education; health risk behaviors; toothbrushing.

\section{Introduction}

As one of the world's leading authority on oral health, theWorld Dental Federation (FDI) identifies dental caries and periodontal diseases among the most common and crucial global oral health burdens [1]. Scientific evidence shows a significant relationship between oral health and general health. Non-communicable diseases such as cancer, diabetes, respiratory, cardiovascular and oral diseases share mutual risk factors. The possibility of having systemic diseases increase in the presence of periodontitis, or vice versa $[2,3]$. VanWormer et al. stated that participants with poor oral hygiene have higher cardiovascular disease risk than those who have good oral health [4].

Prevention of oral diseases is the most efficient approach to ensure oral health. The primary etiologic factor of periodontal diseases is microbial plaque; therefore, they can mostly be prevented by plaque control. The most common way to remove plaque is tooth brushing and flossing as they avoid plaque accumulation on teeth and gums. Plaque elimination also contributes to the prevention of caries $[5,6]$. It is known that people who adopted the habit of brushing their teeth at least twice a day have less dental caries compared to others. Apart from the toothbrush, oral hygiene aids such as interdental brush, tongue cleanser, chewing gum and mouthwash can be used in oral healthcare regimen [7].

Consistent health behavior is established at the early stages of human life, with the help of the parents, teachers and caretakers [8,9]. At the age of the transition from childhood to adulthood, a teenager's routines and habits are likely to be challenged since they experience independence for the first time and carry more responsibilities. During their university years students encounter new experiences, stress, social pressure and busyness. Oral and general hygiene habits can become less important with the intrusion of all these factors $[8,10]$.

Through the review of the related literature, there are some studies which observe the oral health behavior of young population around the world. Different findings were reported depending on cultural beliefs, financial situation and education strategies [10-12]. There are 
only a few studies investigated the oral health behavior of Turkish university students. This study aims to determine the oral health habits of university students from five different universities and ten different departments [13-15].

The hypothesis of the present study is that there would be slight differences on the evaluation of oral health awareness level of the current young generation considering their awareness and tendency regarding the oral health care behavior.

\section{Material and Methods}

This study was conducted at five university campuses in different cities of Turkey, which were Gazi University (Ankara), Istanbul University (Istanbul), Abant Izzet Baysal University (Bolu), Ege University (Izmir) and Kocaeli University (Kocaeli). Universities from different cities with a high average student count were selected in order to represent the situation in different areas of Turkey with an adequate number of subjects. The student numbers at the respective campuses were 21270 for Gazi University, 6171 for Istanbul University, 21568 for Abant Izzet Baysal University, 27439 for Ege University and 23951 for Kocaeli University. Participation was voluntary and anonymous.

On World Oral Health Day (March $20^{\text {th }}, 2012$ ), desks were set by volunteer dental students in a popular area of the campuses. The volunteers were prepared during a 2 hour-training by a professor from their universities before the event. On the day of the event, the students were invited to participate in the study. They were informed about the study and signed a consent form if they agreed to participate. 3150 students were asked, 2740 agreed to participate. The participation rate was $87 \%$. After completing the survey, the participants were given an oral health education lecture. The study included 2740 undergraduate students (1309 male, 1431 female) enrolled in different faculties which were Sports, Dentistry, Pharmacy, Science, Nursing, Economics, Engineering, Teaching, Humanities and Social Sciences and Medicine.

As reviewed in similar studies, an 11-item questionnaire was designed and validated through a pilot survey before. The questions were designed to evaluate oral health habits and awareness of the students enrolled in different faculties. Age, gender, degree subject were also recorded. Participants were asked to fill out the self-administered questionnaire (Fig. 1). They received an explanation of how to fill in. The questionnaires were collected immediately after they were filled and volunteer dental students gave participants an oral care education lecture.

\subsection{Statistical Analysis}

The data obtained were organized into Microsoft Excel (Microsoft Inc., USA) and analyzed statistically using SPSS 21.0 software (IBM Inc., USA). The standard descriptive methods were applied to determine the characteristics of the sample. Each data set was tested for normality with the Kolmogorov-Smirnov test. Categorical variables between groups were compared by the Pearson's chi-square test. The confidence interval was set to $95 \%$ and p-values less than 0.05 were considered statistically significant.

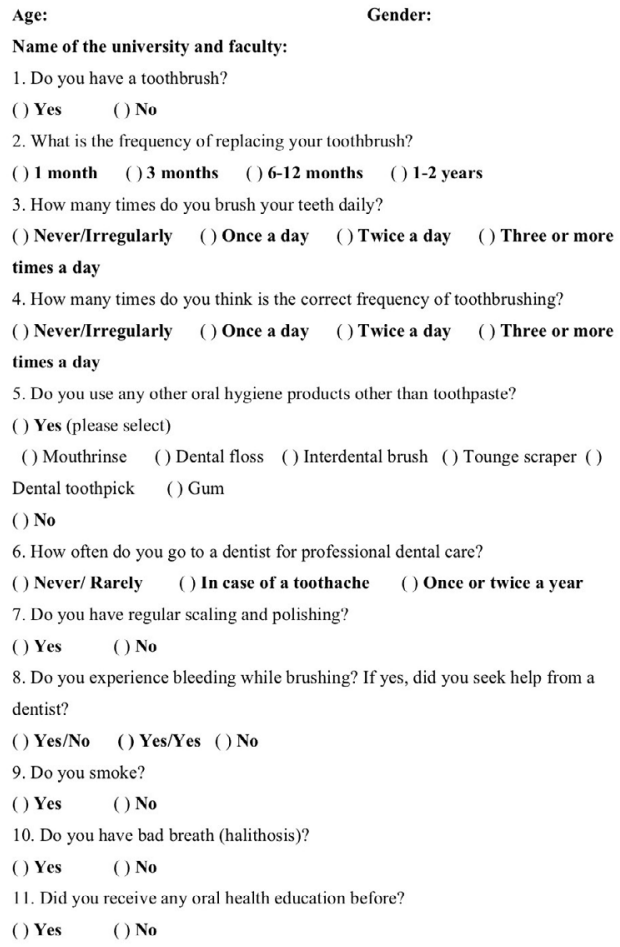

Figure 1. Sample of the questionnaire used in the present study.

I Table 1. Distribution of students by university, gender, age and degree subject.

\begin{tabular}{lccc}
\hline Characteristics & $\mathbf{n}$ & $\%$ & Mean \\
\hline City & & & \\
Ankara & 275 & 10 \\
Istanbul & 574 & 20.9 \\
Bolu & 569 & 20.8 & \\
Izmir & 638 & 23.3 \\
Kocaeli & 684 & 25 & \\
Gender & & \\
Male & 1309 & 47.7 \\
Female & 1431 & 52.3 \\
Age & & \\
Degree Subject & & \\
Sports & 68 & 2.5 \\
Dentistry & 92 & 3.4 \\
Pharmacy & 33 & 1.2 \\
Science & 246 & 9.0 \\
Nursing & 55 & 2.0 \\
Economics & 114 & 4.2 \\
Engineering & 461 & 16.8 \\
Teaching & 536 & 19.6 \\
Social Sciences & 559 & 20.4 \\
Medicine & 576 & 21.0 \\
\hline
\end{tabular}

\section{Results}

The answers of the students according to degree subject were given in Table $2.52,8 \%$ of the participants changed 
I Table 2. Frequency of toothbrushing, use of oral hygiene aids, smoking, receiving oral health education before and belief of the correct frequency of toothbrushing

\begin{tabular}{|c|c|c|c|c|c|c|c|c|c|c|c|c|c|c|}
\hline & \multicolumn{5}{|c|}{ Frequency of Toothbrushing } & \multicolumn{2}{|c|}{ Oral Hygiene Aids } & \multicolumn{2}{|c|}{ Smoking } & \multicolumn{2}{|c|}{ Oral Health Education } & \multicolumn{3}{|c|}{ Belief of the Correct Frequency of TB } \\
\hline & Never & $\begin{array}{c}\text { Once a } \\
\text { day }\end{array}$ & $\begin{array}{c}\text { Twice a } \\
\text { day }\end{array}$ & $\begin{array}{c}\text { Thricea } \\
\text { day/more }\end{array}$ & $\begin{array}{c}\text { After each } \\
\text { meal }\end{array}$ & Yes & No & Yes & No & Yes & No & $\begin{array}{c}\text { Once a } \\
\text { day }\end{array}$ & $\begin{array}{c}\text { Twice a } \\
\text { day }\end{array}$ & $\begin{array}{c}\text { Thrice a } \\
\text { day/more }\end{array}$ \\
\hline Sports & $3(4.4)$ & $28(41.2)$ & $29(42.6)$ & $7(10.3)$ & $1(1.5)$ & $66(97.1)$ & $2(2.9)$ & $23(33.8)$ & $45(66.2)$ & $34(50)$ & $34(50)$ & $4(5.9)$ & $39(57.4)$ & $25(36.8)$ \\
\hline Dentistry & $4(4.3)$ & $16(17.4)$ & $62(67.4)$ & $10(10.9)$ & $0(0)$ & $92(100)$ & $0(0)$ & $25(27.2)$ & $67(72.8)$ & $47(51.1)$ & $45(48.9)$ & $2(2.2)$ & $57(64)$ & $30(33.7)$ \\
\hline Pharmacy & $3(9.1)$ & $7(21.2)$ & $20(60.6)$ & $2(6.1)$ & $1(3)$ & $33(100)$ & $0(0)$ & $9(27.3)$ & $24(72.7)$ & $17(51.5)$ & $16(48.5)$ & $3(9.1)$ & $18(54.5)$ & $12(36.4)$ \\
\hline Science & $7(2.8)$ & $72(29.3)$ & $136(55.3)$ & $27(11)$ & $4(1.6)$ & $241(98)$ & $5(2)$ & $50(20.3)$ & $196(79.7)$ & $135(54.9)$ & $111(45.1)$ & $18(7.4)$ & $113(46.3)$ & $113(46.3)$ \\
\hline Nursing & $1(1.8)$ & $23(41.8)$ & $29(52.7)$ & $1(1.8)$ & $1(1.8)$ & $55(100)$ & $0(0)$ & $11(20)$ & $44(80)$ & $27(49.1)$ & $28(50.9)$ & $6(10.9)$ & $25(45.5)$ & $24(43.6)$ \\
\hline Economics & $10(8.8)$ & $29(25.4)$ & $67(58.8)$ & $8(7)$ & $0(0)$ & $111(97.4)$ & $3(2.6)$ & $23(20.2)$ & $91(79.8)$ & $52(45.6)$ & $62(54.4)$ & $10(8.9)$ & $58(51.8)$ & $44(39.3)$ \\
\hline Engineering & $24(5.2)$ & $136(29.5)$ & $253(54.9)$ & $38(8.2)$ & $10(2.2)$ & $450(97.6)$ & $11(2.4)$ & $117(25.4)$ & $344(74.6)$ & $226(49)$ & $235(51)$ & $33(7.3)$ & $233(51.2)$ & $189(41.5)$ \\
\hline Teaching & $35(6.5)$ & $137(25.6)$ & $322(60.1)$ & $35(6.5)$ & $7(1.3)$ & $508(94.8)$ & $28(5.2) \mathrm{a}$ & $110(20.5)$ & $426(79.5)$ & $250(46.6)$ & $286(53.4)$ & $27(5.1)$ & $255(47.9)$ & $250(47)$ \\
\hline Social Sciences & $29(5.2)$ & $148(26.5)$ & $327(58.5)$ & $50(8.9)$ & $5(0.9)$ & $554(99.1)$ & $5(0.9) b$ & $133(23.8)$ & $426(76.2)$ & $277(49.6)$ & $282(50.4)$ & $31(5.6)$ & $275(49.5)$ & $249(44.9)$ \\
\hline Medicine & $31(5.4)$ & $172(29.9)$ & $327(56.8)$ & $36(6.3)$ & $10(1.7)$ & 555 (96.4) & $21(3.6) \mathrm{a}$ & $118(20.5)$ & $458(79.5)$ & $353(61.3)$ & $223(38.7)$ & $30(5.3)$ & $329(57.7)$ & $211(37)$ \\
\hline $\mathbf{p}$ & & & 0.072 & & & 0.0 & & 0. & 162 & & & & 0.025 & \\
\hline
\end{tabular}

their toothbrush every 3 months, while $30,1 \%$ of them changed every $6-12$ months. About $28 \%$ of the students brushed their teeth once, $57.4 \%$ of them twice, $9.2 \%$ of them three times per day. $5.4 \%$ never or irregularly brushed their teeth. There is no significance between faculty and frequency of toothbrushing ( $p>0.05$ ). $54.4 \%$ of sports students, $79.4 \%$ of dentistry, $69.7 \%$ of pharmacy, $67.9 \%$ of science, $65.8 \%$ of economics, $65.3 \%$ of engineering, $67.9 \%$ of teaching, $68.3 \%$ of humanities and social sciences and $64.8 \%$ of medicine students brushed their teeth twice or more times daily.

$97.3 \%$ of the students used one or more oral care product other than toothpaste included mouthwash (38\%), gum (31.8\%), floss (26.5\%), tongue scraper (13.5\%), dental toothpick (6.4\%) and interdental brush (4.7\%). $72.8 \%$ of the participants never/irregularly used mouthwash, while $15.4 \%$ used once and $5.8 \%$ twice a day. There is a statistical significance between oral hygiene aids usage by students from different faculties. Table 3 presents the summary statistics for receiving oral health education (OHE) before.

Dental care visit is in relation with receiving oral health education $(p<0,01)$. Of those whom received $\mathrm{OHE}, 43.1 \%$ never visits a dentist, $33.6 \%$ visits in case of a toothache and $23.3 \%$ visits twice annualy. These percentages are statistically significant.

There is a statistical significance in the frequency of toothbrushing between OHE receivers and nonreceivers. $3.7 \%$ of the $\mathrm{OHE}$ receivers stated they never or irregularly brush their teeth while $7.1 \%$ non-receivers did the same. $60.2 \%$ of the OHE receivers and $54.4 \%$ of non-receivers brush their teeth twice a day. There is no significance in students who brush their teeth three times or more daily.

The students who experience halitosis is higher than students who did not receive OHE than those who received.

$28.8 \%$ of the students had regular scaling and polishing. In Table 4, the relationship between bleeding while tooth brushing and regular scaling/polishing were provided ( $p$ $<0.05)$. $15.8 \%$ of the subjects who had regular scaling (1-2 times/year) experienced bleeding during brushing while $35.2 \%$ of the ones who did not have regular scaling experienced the same problem. Among these students, only $16.8 \%$ sought help from a dentist.

Table 5 presents an overview of smoking habits among students. $77.4 \%$ of the students were nonsmokers and $22.6 \%$ of them were smokers. Brushing frequency among smokers and nonsmokers were statistically
Table 3. Percentages of oral-health education receivers and non-receivers of dentist visits, frequency of toothbrushing and halithosis.

\begin{tabular}{|c|c|c|c|}
\hline \multirow{2}{*}{$\begin{array}{l}\text { Dental Care } \\
\text { Visit }\end{array}$} & \multicolumn{2}{|c|}{ Oral Health Education } & \multirow{2}{*}{$\mathbf{p}$} \\
\hline & Yes & No & \\
\hline $\begin{array}{l}\text { Never/Rarely } \\
(n=1293)\end{array}$ & $\begin{array}{c}611 \\
(43.1 \%)^{*}\end{array}$ & $\begin{array}{c}682 \\
(51.6 \%)\end{array}$ & \multirow{3}{*}{$<0.001$} \\
\hline $\begin{array}{l}\text { In case of a } \\
\text { toothache } \\
(n=866)\end{array}$ & $\begin{array}{c}476 \\
(33.6 \%)^{*}\end{array}$ & $\begin{array}{c}390 \\
(29.5 \%)\end{array}$ & \\
\hline $\begin{array}{l}\text { Twice a year } \\
(n=580)\end{array}$ & $\begin{array}{c}330 \\
(23.3 \%)^{*}\end{array}$ & $\begin{array}{c}250 \\
(18.9 \%)\end{array}$ & \\
\hline \multicolumn{4}{|l|}{$\begin{array}{l}\text { Frequency of } \\
\text { toothbrushing }\end{array}$} \\
\hline $\begin{array}{c}\text { Never/ } \\
\text { Irregularly } \\
(\mathrm{n}=146)\end{array}$ & $\begin{array}{c}52 \\
(3.7 \%)^{*}\end{array}$ & $\begin{array}{c}94 \\
(7.1 \%)\end{array}$ & \multirow{4}{*}{$<0.001$} \\
\hline $\begin{array}{l}\text { Once daily } \\
(n=769)\end{array}$ & $\begin{array}{c}372 \\
(26.2 \%)^{*}\end{array}$ & $\begin{array}{c}397 \\
(30.0 \%)\end{array}$ & \\
\hline $\begin{array}{l}\text { Twice daily } \\
(n=1573)\end{array}$ & $\begin{array}{c}854 \\
(60.2 \%)^{*}\end{array}$ & $\begin{array}{c}719 \\
(54.4 \%)\end{array}$ & \\
\hline $\begin{array}{l}\text { Thrice or more } \\
\text { daily }(n=252)\end{array}$ & $\begin{array}{c}140 \\
(9.9 \%)\end{array}$ & $\begin{array}{c}112 \\
(8.5 \%)\end{array}$ & \\
\hline \multicolumn{4}{|l|}{ Halithosis } \\
\hline Yes $(n=516)$ & $\begin{array}{c}225 \\
(15.9 \%)\end{array}$ & $\begin{array}{c}291 \\
(22.0 \%)\end{array}$ & \multirow{2}{*}{$<0.001$} \\
\hline No $(n=2224)$ & $\begin{array}{c}1193 \\
(84.1 \%)\end{array}$ & $\begin{array}{c}1031 \\
(78.0 \%)\end{array}$ & \\
\hline
\end{tabular}

*Cells which cause signification

Table 4. Frequencies of bleeding during brushing.

\begin{tabular}{|c|c|c|c|c|}
\hline & & \multicolumn{2}{|c|}{$\begin{array}{l}\text { Bleeding during } \\
\text { brushing }\end{array}$} & \multirow[t]{2}{*}{ Total } \\
\hline & & Yes & No & \\
\hline \multirow{2}{*}{$\begin{array}{l}\text { Regular } \\
\text { Scaling \& } \\
\text { Polishing }\end{array}$} & Yes & $15.8 \%$ & $13.0 \%$ & $28.8 \%$ \\
\hline & No & $35.2 \%$ & $36.0 \%$ & $71.2 \%$ \\
\hline \multicolumn{2}{|c|}{ Total } & $51.0 \%$ & $49.0 \%$ & $100.0 \%$ \\
\hline
\end{tabular}

$<0.05$

Table 5. Brushing frequency of smokers and non-smokers.

\begin{tabular}{|c|c|c|c|c|}
\hline & & \multicolumn{2}{|c|}{ Smoking } & \multirow{2}{*}{ Total } \\
\hline & & Yes & No & \\
\hline \multirow{2}{*}{$\begin{array}{l}\text { Frequency of } \\
\text { Toothbrushing }\end{array}$} & $\begin{array}{l}1 \text { or } \\
\text { less }\end{array}$ & $7.2 \%$ & $15.4 \%$ & $22.6 \%$ \\
\hline & $\begin{array}{l}2 \text { or } \\
\text { more }\end{array}$ & $52.8 \%$ & $24.6 \%$ & $77.4 \%$ \\
\hline Total & & $60.0 \%$ & $40.0 \%$ & $100.0 \%$ \\
\hline
\end{tabular}


significant ( $p<0.01$ ). $13.1 \%$ of the smokers never or irregularly brushed, while only $3.1 \%$ of the nonsmokers did the same. In total, $82 \%$ of the non-smokers brushed twice daily, while $68.2 \%$ of the smokers did the same. Sports students evinced the highest smoking rate among students. Dental and pharmacy students followed. Nursing students evinced the lowest rate.

\section{Discussion}

Health behavior is defined as the activities undertaken by people in order to protect, promote or maintain health, and to prevent disease [16]. It can be determined by numbers of factors including education, beliefs, social environment (family, friends, opinion leaders), skills, financial situation and time [17]. Having an excellent oral health care routine which includes tooth brushing, use of dental floss and mouthwash, a balanced diet, frequent (ideally every six months) visits to the dentist will lead to a caries-free oral cavity $[18,19]$. According to previous studies poor dental behavior, diet and smoking are the risk factors of periodontal diseases $[20,21]$. The oral health behavior establishes the health condition of the oral cavity. Chronic oral conditions such as dental caries and periodontitis are common, yet preventable. During a person's lifetime, the progression of these conditions is induced by structural and behavioral factors [22].

Differing among different academic-based students, the hypothesis of the currents study that there would be slight differences on the evaluation of oral health awareness level of the current young generation considering their awareness and tendency regarding the oral health care behavior has been clearly accepted. In the literature review, while some researches evaluated the behavioral aspects of specific groups, no study has evaluated this much of a population in Turkey. The present study reveals that $33.4 \%$ of Turkish university students brush their teeth less than twice a day, which is below the recommended behavior [23]. This data are in accordance with the previous studies which investigates Turkish university students' dental care habits. Peltzer and Pengpid (2014), Kırtıloğlu and Yavuz (2006) and who reported $32 \%$ and $32.4 \%$ of the Turkish students show inadequate brushing respectively $[11,13]$. In the same study of Peltzer and Pengpid, it was also stated that Indian (52.2\%), Lebanese (35\%) and Nigerian $(79.1 \%)$ university students brush their teeth less than twice a day. Previous studies have shown that $92 \%$ of the university students brush their teeth twice or more times a day in Italy [24], and $85 \%$ of the $20-25$ Swedes brush their teeth once or twice a day [25]. 80\% of the university students in the USA are reported to brush their teeth twice or more daily [26]. Other studies conducted in UK and Norway $[27,28]$ have revealed high percentages of brushing twice a day whereas lower findings were reported in Lebanon and Kuwait $[12,29]$. A possible explanation for this discrepancy is that the industrialized and developing countries have significant differences concerning oral health behavior. It could be the reflection of cultural beliefs, education system and financial status $[11,30]$.

As shown in Table 3, the dental students brushing frequency is higher than the other departments, which was an expected outcome. This finding is higher than
Indian (54.4\%) and Iranian (57\%) dental students, but lower than Lithuanian dental students (92\%) [31-33]. In the latter study, $73.3 \%$ of the technology students brushed their teeth twice, which is higher than that of engineering students (65.3\%) in the present study. What is pleasing is that the habits of the students of the teaching department were relatively better than some of the other departments. Taking into consideration that these students will be the future role models for children, this is a good start that needs improvement. In a previous study, it was reported that $90.7 \%$ of the nursing students in Hong Kong brush at least twice a day [34]. Another study revealed that $61 \%$ of the nursing students in Jordan brush at least twice a day [35]. Oral health is known to be closely related to general health. As one of the primary healthcare professionals, nurses are expected to provide a good example to the patients and their community. They also have the task of informing the hospitalized patients or the public of oral health prevention in rural areas, where the number of dentists is relatively low. For this reason, oral health care courses should be given during nursing education [36]. Another critical finding was about the medical students' oral health. The frequency of tooth brushing of medical students is significantly lower than that of dental students. The medical students' frequency of tooth brushing is relatively lower than that of dental students. Medicine education is part of the undergraduate dental curriculum and supported by extensive study of human diseases. However, the involvement of dental subjects in the educational program of medical students is limited [37]. Loster and Likeman (2012) suggested that the basic dental knowledge of medical students will lead to stronger communication between dentists and medical doctors. This suggestion will further support the idea of oral health being a significant part of general health, and professionals of those fields should work together for a healthier community [38].

WHO states that $60-90 \%$ of the schoolchildren and almost $100 \%$ of the adults have dental cavities which indicate an epidemic situation worldwide [39]. Every 92 out of 100 people need treatment for dental caries in Turkey [36]. Visits to a dental professional regularly (once every six months) increase the likelihood of early diagnose of oral diseases [18]. Statistics about the oral health condition and frequency of dentist visits are relatively low in Turkey compared to the global average. $47 \%$ of the population have not visited a dentist in the last year, while $12.5 \%$ have never been to one. $51 \%$ of the patients visit a dentist only when they have a problem and only $\% 10$ visit a dentist for routine dental check-ups [37]. According to the present study results, $19.3 \%$ of the students visit the dentist regularly. The probable cause of this difference is that the oral health knowledge by the young population may be higher than by the general population in Turkey. This can be explained by the effect of college education and higher use of social media among the young population [40]. In reviewing the literature, it was found that $60 \%$ of the Korean dental hygiene students postpone visiting a dentist until they have a toothache, whereas only $1 \%$ of the US dental hygiene students agreed to this remark [36]. In another study, it was found that $41 \%$ of Japanese and only $3 \%$ of Finnish dental students have the same opinion [30]. A study including multiple 
countries found that $58.2 \%$ of university students rarely or never had gone for a dentist visit [11], which is higher than the present study (47.2\%). These results corroborate with the findings of Kawamura et al. (2002) who stated that the Asian way of dealing with the disease is different from the Western concepts and that they only seek professional help when home remedies are unsuccessful [36]. Also, there are other studies conducted in Arab countries like Saudi Arabia and Jordan in which the subjects tend to visit the dentist only if they have a problem or are in pain $[41,42]$. The thought of preventive care being unnecessary and financial status were the major obstacles preventing the subjects from visiting the dental office regularly.

Oral hygiene aids such as mouth rinse, floss and interdental brush should be used as complementary to tooth brushing in order to maintain a better plaque removal from interdental areas [18]. In the present study mouth rinse (38\%) and floss (26.5\%) are the most frequently used aids, while interdental brush $(4.7 \%)$ is the least common oral hygiene aids that the subjects have at home. However, only $21.2 \%$ of them use mouth rinse regularly. These results reflect those of Kırtıloğlu and Yavuz (2006) who also examined the frequency of regular use of antibacterial rinse (18.8\%) and interdental brush (1.6\%) in Turkish students [13]. Cultural belief has a strong relationship with oral hygiene habits. In a study conducted in Saudi Arabia, the use of miswak was found to be high among school children [43]. In a previous study, it was mentioned that $52 \%$ of the students use a toothpick daily, which is a low-cost interdental cleaning device used frequently in Turkey. However, the findings of the current study (6.4\%) do not support previous research. A possible explanation for this might be that the word 'dental toothpick' was used in the questionnaire which may confuse the subjects and prevent them from marking the option even if they use it.

Several reports have shown that $81 \%$ of the Turkish children did not have a regular tooth brushing habit. $72 \%$ of Turkish high school children needed oral health education [14]. The main objective of oral health education is to enhance knowledge which may lead to better oral health behavior [44]. According to the present study results $51.8 \%$ of the subjects had received oral health education. This is lower than another study made in Turkey (61\%) and higher than Lithuanian technology students [13,33]. Oral health education and preventive programs are vital in decreasing caries and periodontal diseases prevalence in children and the young population [13]. Studies have shown that teachers, family and peers have a more significant role than dentists in adopting oral health behavior in adolescents [15]. Oral health education given at school considered to be efficient since the school children are approached at an age when their habits are forming. Besides, such education may not only reach the children but their family and community members [45]. It was shown in a study by Eden et al. (2018) that correct brushing techniques education is more effective if given by teachers than dentists [46]. In the present study, only less than half of the teaching students (46.6\%) had received oral health education. It is important to emphasize more educating future teachers on oral health for a healthier community.
Another finding was that $22.6 \%$ of the university students are smokers and $82 \%$ of the non-smokers brush twice daily, while $68.2 \%$ of the smokers do the same. This finding indicates that poor oral health behavior (smoking) and the frequency of tooth brushing are associated, which is mostly consistent with the previous study findings $[11,12,31]$. Based on these findings, it is suggested that oral and general health promotion programs should be combined and encourage positive health behavior in public [11]. Healthcare professionals have an essential role in smoking cessation $[47,48]$. However, in a study investigating the dentists' role in tobacco control it was suggested that $60 \%$ of the dentists do not routinely recommend the smokers to quit. Therefore, the education of dental students may emphasize more tobacco control of patients [49]. According to present study, Turkish dental and medical students' smoking rates are higher than Lithuanian dental students (12\%) and American medical students $(6.1 \%)$ but lower than that of Italian medical students (29.5\%) [33,50]. Previous studies indicated that non-smoking physicians are more successful at getting patients to quit smoking. Since healthcare professionals have a high impact on patients to establish positive health behavior, future interventions should aim to eliminate tobacco usage among the students [50].

Limitations of this study were the lack of socioeconomic status and background information of the participants. Another limitation is that dental health behavior was only assessed by self-report. This could lead to an optimistic view of the current situation since sometimes respondents tend to overestimate their actual health behaviors due to the social acceptability of their answers. Future studies may include a dental examination and socio-economic status related questions.

\section{Conclusion}

The findings of this study indicated that young Turkish generation sectioned from different parts of the country revealed low level of oral health awareness and behavioral routines; moreover, the overall aspect was found to be of a lesser extent when compared to high-income countries.

Regarding the data indicated there is an association between previous OHE and oral health behavior on which academic tendency plays a differentiating role in oral health behavior. Beside the primary oral health indicators, the risk factors threatening the oral health also needs to be enrolled on the awareness raising programmes. Thus, positive inclined health behavior adopted in the early adult phase of one's life would encourage the young population to adopt better health behavior.

\section{Author Contributions}

GS: planned and organized the study. wrote the manuscript. SS: collected and imported the data into the computer. MY: coordinated the volunteer students in different cities. UA: interpreted the data. HS: provided the critical revision and guidance. 


\section{Acknowledgement}

The authors would like to thank volunteer dental students in five different cities who have worked on the day of the study to distribute the questionnaires and give oral hygiene instructions to the participants.

\section{References}

1. FDI World Dental Federation. FDI policy statement on oral infection/inflammation as a risk factor for systemic diseases: Adopted by the FDI General Assembly: 30 August 2013-Istanbul, Turkey. Int Dent J. 2013;63(6):289-290. [CrossRef] [PubMed] Google Scholar(2)

2. Dörfer C, Benz C, Aida J, Campard G. The relationship of ora health with general health and NCDs: a brief review. Int Dent J. 2017;67 Suppl 2:14-18

[Full text links] [Free PMC Article] [PubMed] Google Scholar(7) Scopus(4)

3. Kanjirath PP, Kim SE, Inglehart MR. Diabetes and oral health: the importance of oral health-related behaviour. J Dent Hyg. 2011:85(4):264-272.

[PubMed] Google Scholar(28) Scopus(15)

4. VanWormer JJ, Acharya A, Greenlee RT, Nieto FJ. Oral hygiene and cardiometabolic disease risk in the survey of the health of Wisconsin. Community Dent Oral Epidemiol. 2013;41(4):374 384.

[Full text links] [PubMed] Google Scholar(7) Scopus(5)

5. Choo A, Delac DM, Messer LB. Oral hygiene measures and promotion: review and considerations. Aust Dent $J$ 2001:46(3):166-173.

[Full text links] [PubMed] Google Scholar(130) Scopus(52)

6. Marsh PD. Microbiology of dental plaque biofilms and their role in oral health and caries. Dent Clin North Am. 2010;54(3):441-454.

[Full text links] [Pubmed] Google Scholar(205) Scopus(61)

7. Gibson S, Williams S. Dental caries in pre-school children: associations with social class, toothbrushing habit and consumption of sugars and sugar-containing foods. Caries Res. 1999;33(2):101-113.

[Full text links] [PubMed] Google Scholar(355) Scopus(142)

8. Small M, Bailey-Davis L, Morgan N, Maggs J. Changes in eating and physical activity behaviours across seven semesters of college: living on or off campus matters. Health Educ Behav. 2013:40(4):435-441.

[Full text links] [PubMed] Google Scholar(141) Scopus(50)

9. Okada M, Kawamura M, Kaihara Y, et al. Influence of parents oral health behavior on oral health status of their school children: an exploratory study employing a causal modelling technique. Int J Paediatr Dent. 2002;12(2):101-108. [Full text links] [PubMed] Google Scholar(194) Scopus(46)

10. Crabtree R, Kirk A, Moore M, Abraham S. Oral health behaviors and perceptions among college students. Health Care Manag (Frederick). 2016;35(4):350-360.

[Full text links] [PubMed] Google Scholar(3) Scopus(46)

11. Peltzer K, Pengpid S. Oral health behavior and social and health factors in university students from 26 low, middle and high income countries. Int J Environ Res Public Health. 2014;11(12):12247-12260.

[Full text links] [PubMed] Google Scholar(7) Scopus(11)

12. Kassak KM, Dagher R, Doughan B. Oral hygiene and lifestyle correlates among new undergraduate university students in Lebanon. J Am Coll Health. 2001:50(1):15-20. [PubMed] Google Scholar(64) Scopus(18)

13. Kırtıloğlu T, Yavuz ÜS. An assessment of oral self-care in the student population of a Turkish university. Public Health. 2006;120(10):953-957.

[Full text links] [PubMed] Google Scholar(45) Scopus

14. Kulak-Özkan Y, Ozkan Y, Kazazoglu E, Arikan A. Denta caries prevalence, tooth brushing and periodontal status in 150 young people in Istanbul: a pilot study. Int Dent $J$. 2001:51(6):451-456

[Full text links] [PubMed] Google Scholar(50) Scopus(15)

15. Karadaş M, Tahan E, Köse O, Demirbuğa S. Evaluation of the frequency of tooth brushing in the 13-20 age group of Individuals and the relationship between oral hygiene and DMFT [Article in Turkish]. Turkiye Klinikleri J Dental Sci. 2014;20(3):177-181. Google Scholar(0)

16. Steptoe A, Wardle J, Vinck J, et al. Personality and attitudina correlates of healthy and unhealthy lifestyles in young adults. Psychol Health. 1994;9(5):331-343. [PubMed] Google Scholar(162) Scopus(71)

17. Park K. Park's textbook of preventive and social medicine. 18 ed. Jabalpur (M.P.), India: M/s. Banarsidas Bhanot; 2005. Google Scholar(2311)
18. Harris NO, Garcia-Godoy F. Primary preventive dentistry. 6th ed. Upper Saddle River (NJ), USA: Pearson Prentice Hall; 2004. 399-409.

Google Scholar(3)

19. Polk DE, Weyant RJ, Manz MC. Socioeconomic factors in adolescents' oral health: are they mediated by oral hygiene behaviors or preventive interventions? Community Dent Oral Epidemiol. 2010;38(1):1-9.

[Full text links] [PubMed] Google Scholar(96) Scopus(44)

20. Amarasena N, Ekanayaka AN, Herath L, Miyazaki H. Tobacco use and oral hygiene as risk indicators for periodontitis. Community Dent Oral Epidemiol. 2002;30(2):115-123. [Full text links] [PubMed] Google Scholar(127) Scopus(67)

21. Pihlstrom BL, Michalowicz BS, Johnson NW. Periodontal diseases. Lancet. 2005; 366(9499):1809-1820.

Google Scholar(2768) Scopus(1680)

22. Fisher-Owens SA, Gansky SA, Platt LJ, et al. Influences on children's oral health: a conceptual model. Pediatrics. 2007;120(3):e510-e520.

[Full text links] [PubMed] Google Scholar(443) Scopus

23. Davies RM, Davies GM, Ellwood RP, Kay EJ. Prevention. Part 4: Toothbrushing: what advice should be given to patients? $\mathrm{Br}$ Dent J. 2003;195(3):135-141. [Full text links] [PubMed] Google Scholar(7) Scopus

24. Rimondini L, Zolfanelli B, Bernardi F, Bez C. Self-preventive oral behavior in an Italian university student population. $J$ Clin Periodontol. 2001;28(3):207-211.

[Full text links] [PubMed] Google Scholar(109) Scopus

25. Stenberg $\mathrm{P}$, Håkansson J, Ákerman S. Attitudes to dental health and care among 20 to 25 -year-old Swedes: results from a questionnaire. Acta Odontol Scand. 2000;58(3):102106.

[Full text links] [PubMed] Google Scholar(67) Scopus(22)

26. Luebke TE, Driskell JA. A group of Midwestern university students needs to improve their oral hygiene and sugar/pop consumption habits. Nutr Res. 2010;30(1):27-31.

[Full text links] [PubMed] Google Scholar(12) Scopus(3)

27. Bradnock G, White DA, Nuttall NM, et al. Dental attitudes and behaviors in 1998 and implications for the future. Br Dent J. 2001;190(5):228-232.

[PubMed] Google Scholar(56) Scopus

28. Åstrøm AN, Samdal O. Time trends in oral health behaviors among Norwegian adolescents: 1985-97. Acta Odontol Scand. 2001;59(4):193-200.

[PubMed] Google Scholar(37) Scopus

29. Al-Ansari J, Honkala E, Honkala S. Oral health knowledge and behavior among male health sciences college students in Kuwait. BMC Oral Health. 2003:3(1):2.

[Full text links] [PubMed] Google Scholar(64) Scopus(35)

30. Kawamura M, Honkala E, Widström E, Komabayashi T. Cross-cultural differences of self-reported oral health behavior in Japanese and Finnish dental students. Int Dent J. 2000;50(1):46-50.

[Full text links] [PubMed] Google Scholar(121) Scopus(41)

31. Sharda AJ, Shetty S. A comparative study of oral health knowledge, attitude and behaviour of first and final year dental students of Udaipur city, Rajasthan, India. Int J Dent Hyg. 2008;6(4):347-353.

[Full text links] [PubMed] Google Scholar(72) Scopus(18)

32. Khami MR, Virtanen Jl, Jafarian M, Murtomaa H. Oral health behavior and its determinants amongst Iranian dental students. Eur J Dent Educ. 2007:11(1):42-47.

[Full text links] [PubMed] Google Scholar(81) Scopus

33. Pacauskiene IM, Smailiene D, Siudikienè J, et al. Self-reported oral health behavior and attitudes of dental and technology students in Lithuania. Stomatologija. 2014;16(2):65-71. [Full text links] [PubMed] Google Scholar(18) Scopus(5)

34. Chan JC, Chin LS. Oral health knowledge and psychological determinants of oral health behavior of nursing students. $J$ Health Psychol. 2017;22(1):79-88. [Full text links] [PubMed] Google Scholar(6) Scopus(2)

35. Alsrour SS, Nassrawin N, Al-Tawarah YM. Oral health knowledge, attitudes and behavior of nursing students at Mutah University (Jordan). Pakistan Oral Dent $J$. 2013;33(1):102-109. Google Scholar(8)

36. Kawamura M, Spadafora A, Kim KJ, Komabayashi T. Comparison of United States and Korean dental hygiene students using the Hiroshima university-dental behavioral inventory (HU-DBI). Int Dent J. 2002;52(3):156-162. [Full text links] [PubMed] Google Scholar(78) Scopus(28)

37. Kılınç G, Günay T. The knowledge level of the last year students of Dokuz Eylül University Faculty of Medicine about oral health. [Article in Turkish]. Dokuz Eylül Üniversitesi Tıp Fakültesi Dergisi. 2010;24(3):131-137. Google Scholar(10)

38. Loster BW, Likeman PR. Teaching of dentistry to medical students in English at the Jagiellonian University, Krakow, Poland. Eur J Dent Educ. 2012;16(1):1-2. [Full text links] [PubMed] Google Scholar(5) Scopus 
39. WHO - World Health Organization. Oral Health. Fact sheet no. 318, April. 2012. Available from www who.int/mediacentre/ factsheets/fs318/en/index.htm. Accessed on 17 January 2015

40. Gholami M, Pakdaman A, Montazeri A, et al. Assessment of periodontal knowledge following a mass media oral health promotion campaign: a population-based study. BMC Oral Health. 2014;14(31):1-7

[Full text links] [PubMed] Google Scholar(22) Scopus(11)

41. Quteish Taani DQ. Dental fear among young adult Saudian population. Int Dent J. 2001;51(2):62-66.

[Full text links] [PubMed] Google Scholar(74) Scopus

42. Taani DQ. Periodontal awareness and knowledge, and pattern of dental attendance among adults in Jordan. Int Dent J. 2002;52(2):94-98.

[Full text links] [PubMed] Google Scholar(91) Scopus(27)

43. Farsi JM, Farghaly MM, Farsi N. Oral health knowledge, attitude and behavior among Saudi school students in Jeddah city. J Dent. 2004;32(1):47-53.

[Full text links] [PubMed] Google Scholar(116) Scopus(38)

44. Nakre PD, Harikiran AG. Effectiveness of oral health education programs: a systematic review. J Int Soc Prev Community Dent. 2013;3(2):103-115.

[Full text links] [PubMed] Google Scholar(67)

45. Mota A, Oswal KC, Sajnani DA, Sajnani AK. Oral health knowledge, attitude, and approaches of pre-primary and primary school teachers in Mumbai, India. Scientifica (Cairo). 2016;2016:5967427.

[Full text links] [PubMed] Google Scholar(12) Scopus(1)
46. Eden E, Akyildiz M, Sönmez I. Comparison of two schoolbased oral health education programs in 9-year-old children. Int Q Community Health Educ. 2019;39(3):189-196. Google Scholar(3) Scopus

47. Stead LF, Buitrago D, Preciado N, et al. Physician advice for smoking cessation. Cochrane Database Syst Rev. 2013;(5):CD000165

[Full text links] [PubMed] Google Scholar(1305) Scopus(350)

48. Lim G, Park I, Park S, et al. Effectiveness of smoking cessation using motivational interviewing in patients consulting a pulmonologist. Tuberc Respir Dis (Seoul). 2014;76(6):276-283. [Full text links] [PubMed] Google Scholar(11) Scopus(4)

49. Tomar SL. Dentistry's role in tobacco control. J Am Dent Assoc 2001;132 Suppl:30S-35S.

[Full text links] [PubMed] Google Scholar(194) Scopus(96)

50. Armstrong GW, Veronese G, George PF, et al. Assessment of tobacco habits, attitudes, and education among medical students in the United States and Italy: a cross-sectional survey. J Prev Med Public Health. 2017;50(3):177-187. [Full text links] [PubMed] Google Scholar(5) Scopus(3)

\section{Görkem SENGEZ \\ DDS, PhD, Researcher \\ Department of Restorative Dentistry, Faculty of Dentistry Istanbul University Istanbul, Turkey}

Görkem Sengez, DDS, received her degree in dentistry in 2014 from the Istanbul University. Dr. Sengez is currently a PhD at the Department of Restorative Dentistry, Istanbul University, Istanbul, Turkey. She is a young researcher whose area of interest includes esthetic dentistry, shade matching and laminate veneers.

\section{Orestions}

\section{Which one is an important factor in developing health behaviors?}
a. Family;
b. Friends;
ac. Education;
ad. All.

\section{What is the most efficient approach to ensure oral health?}

$\square$ a. Toothbrushing twice a week;

b. Consuming sugary beverages;

c. Removing microbial plaque regularly;

$\square$ d. Smoking once a day.

\section{According to the results of this study, which students brush more frequently?}

$\square$ a. Medicine;

b. Dental

Dc. Sports;

ad. Science.

\section{Which one is among the most common chronic diseases globally?}

a. Sjögren Syndrome;

b. Dental caries;

ac. Tonge cancer;

d. Behcet's Disease. 


\title{
IMMEDIATE IMPLANT PLACEMENT IN FRESH EXTRACTION SOCKETS USING THE OPEN HEALING TECHNIQUE AND TISSUE LEVELIMPLANTS
}

\author{
Alecsandru lonescu ${ }^{1,2 a}$, Aliona Dodi'b ${ }^{10}$, Vasileios Panagopoulos ${ }^{10}$, Mihnea loan Nicolescu ${ }^{3,4 d^{*}}$, Augustin Mihai ${ }^{2 e}$, \\ Gabriela Tănase $^{2 f}$
}

\author{
${ }^{a}$ DDS, PhD student \\ ${ }^{\mathrm{b}} \mathrm{DDS}$ \\ 'DDS, MD, OMFS, PhD \\ ${ }^{\mathrm{d} D D S}, \mathrm{MD}$, OMFS, MSc, PhD, Lecturer \\ e DDS, PhD, Professor \\ 'DDS, PhD, Lecturer
}

'Aesthetics One Dental Center, Bucharest, Romania

${ }^{2}$ Implantology Division, Faculty of Dental Medicine, Carol Davila University of Medicine and Pharmacy, Bucharest, Romania

${ }^{3}$ Histology Division, Faculty of Dental Medicine, Carol Davila University of Medicine and Pharmacy, Bucharest, Romania

${ }^{4}$ Radiobiology Division, Victor Babes National Institute of Pathology, Bucharest, Romania

DOI: https://doi.org/10.25241/stomaeduj.2019.6(1).art.5

Introduction: Correctly managed, immediate implant placement into fresh extraction socket is a favorable treatment option in order to reduce the overall treatment time and to increase the patient's comfort and satisfaction.

Methodology: Atraumatic extractions $(\mathrm{N}=42)$ with socket preservation were performed in $n=40$ patients ( 0.74 sex ratio) followed by immediate placement of tissue level implants. Post extraction sockets were filled with either platelet-rich growth factors (PRGF) clots, or deproteinized bovine bone granules, or both; then covered by collagen resorbable membrane or cyanoacrylate and left exposed during healing. The pre-loading need for additional augmentation was assessed clinically and radiologically, using CBCT scans at $t=6$ months. The success and survival rate were evaluated by control CBCT scans at a 4 year follow-up.

Results: This analysis showed that "open healing" technique allowed uneventful healing and sufficient bone formation in combination with immediate placement of soft tissue level implants, a survival rate of $100 \%$ and a success rate of $95.2 \%$ at a $4 \mathrm{yr}$ follow-up. There were no significant differences regarding crestal bone level stability around the implants with the different augmentation materials.

Conclusion: Immediate placement of tissue level implants in fresh post extraction sockets using "open healing" approach can be favorable from both a clinical and radiological point of view considering the results at 4 years. In addition, soft-tissue problems associated with extensive flap mobilization and tension may be avoided and the 3D architecture of hard and soft tissues surrounding the implant may be maintained due to the tissue level implants design in accordance with the biological width when restored.

Keywords: Immediate implant placement; open healing; flapless; biological width.

OPEN ACCESS This is
an Open Access article under
the CC BY-NC 4.0 license.
Peer-Reviewed
Article
Citation: Ionescu A, Dodi A,
Panagopoulos V, Nicolescu Ml,
Mihai A, Tănase G. Immediate
implant placement in fresh
extraction sockets using the open
healing technique and tissue
level implants. Stoma Edu J.
2019;6(1):36-41.
Received: February 21, 2019
Revised: March 22, 2019
Accepted: March 26, 2019
Published: March 27, 2019
*Corresponding author:
Dr. Mihnea loan Nicolescu
Histology Division, "Carol Davila"
University of Medicine and
Pharmacy Bucharest, 8, Eroilor
Sanitari Blvd, District 5
R0-050474 Bucharest, Romania
Tel/Fax: +40722767260, e-mail:
mihnea.nicolescu@umfcd.ro
Copyright: $\odot 2019$ the
Editorial Council for the
Stomatology Edu Journal.

\section{Introduction}

Nowadays the first choice treatment option after extraction of failing teeth is represented either by immediate implant placement or by a socket preservation procedure [1,2]. Correctly managed, immediate implant placement into fresh extraction socket is a favorable treatment option in order to reduce the overall treatment time and to increase the patient's comfort and satisfaction [3]. Oral implantology has been intensively researched in basic as well as in clinical grounds [4]. In order to improve and accelerate healing of both hard and soft tissues after immediate implant placement, substitutes including growth factors and biomaterials have been traditionally employed and membranes were introduced to separate tissues [5]. It has been previously reported [6] that immediate implantation will not prevent resorption of the alveolar ridge. A recent systematic review analyzed the three-dimensional changes in bone tissue after immediate installation of a single implant in a fresh extraction socket, reaching a clear conclusion that bone remodeling occurs after tooth extraction even with immediate implant insertion [7]. One other recent systematic review described the effects of implants with different connections on the crestal bone level in relation with the surgical procedure after at least 12 months of functional loading. The conclusion was that platform-switched implants showed greater crestal bone preservation than non-platform-switched implants. There was no significant difference in the crestal bone loss with one- versus two-stage placement or the use of immediate versus delayed loading. Although there were statistically significant differences favoring immediate implant placement, as well as 
favorable outcomes for crestal bone level changes, the small differences may not be clinically relevant because of high heterogeneity among studies [8].

However, the use of immediate implantation techniques without raising a muco-periosteal flap, combined with a bone graft in the gap left between the implant and the post extraction socket walls, led to osseointegration accompanied by high stability of bone and the resulted soft tissue [7-9]. On the other hand, the use of tissue level implants is beneficial for the surrounding soft and hard tissues, especially when inserted with a flapless approach. Furthermore, the "open healing" technique used as an alternative ridge augmentation procedure, maintains a high stability of the crestal bone level as well as the architecture of the soft tissue after the healing period, with a good outcome even when resorptions of the buccal bone were present prior to extraction [10]. According to the literature, a classification system for management of molar extraction sockets is based upon the morphology of the septal bone and its influence on the implant's primary stability. Implants may be placed predictably into molar sockets when initial stability can be obtained within the septal bone, either entirely (Type A socket) or partially (Type B socket), or by engaging the walls at the periphery of the socket (Type $C$ socket). Otherwise, a delayed protocol should be utilized [11]. When it comes to monoradicular sites, especially in the esthetic zone, a simplified socket classification and repair technique was described: Type 1 - labial bone plate and associated soft tissues are completely intact; Type 2 - soft tissue is present, but a dehiscence osseous defect exists that is indicative of the partial or complete absence of the labial bone plate; Type 3 - midfacial recession defect is present, representing the loss of the labial bone plate and soft tissues [12]. A further classification of Type 2 socket defects where the soft tissue is present but a dehiscence osseous defect was later used to quantify the absence of the labial bone plate: Type $2 \mathrm{~A}$ - absence of the coronal one-third of labial bone plate of the extraction socket 5 to $6 \mathrm{~mm}$ from the free gingival margin; Type $2 \mathrm{~B}$ - absence of the middle to coronal two-thirds of the labial bone plate of the extraction socket approximately 7 to $9 \mathrm{~mm}$ from the free gingival margin; Type $2 \mathrm{C}$ - absence of the apical one-third of the labial bone plate of the extraction socket $10 \mathrm{~mm}$ or more from the free gingival margin [13].

This study shows the rationale behind immediate placement of a tissue level implant in the fresh extraction socket in conjunction with the "open healing" technique, showing not only the advantages of tooth extraction with minimal damage to the surrounding anatomic structures, but also how to maintain the implant surrounding hard and soft tissues threedimensional architecture, following the guidelines previously reported in the literature [14].

The aim of this retrospective analysis is to validate the protocol of immediate implant placement into fresh extraction sockets using open-healing approach and non-submerged (tissue-level) implants and to evaluate
I Table 1. Surgical site position.

A.

\begin{tabular}{lll}
\hline & Bone site & Number of Sites \\
\hline & Maxilla & $23(54.8 \%)$ \\
& Mandible & $19(45.2 \%)$ \\
\hline B. & & \\
\hline & Site region & Number of Sites \\
\hline & Anterior & $22(52.4 \%)$ \\
& Lateral & $20(47.6 \%)$ \\
\hline
\end{tabular}

the outcome of the surrounding bone at 12 and 24 month after loading.

\section{Materials and Methods}

This retrospective study evaluated patients treated between 2014-2018 in a private dental practice. The study protocol is in accordance with the Helsinki Declaration of 1975, revised in 2000 and was approved by the Ethics Committee. Every person involved in the study signed an informed consent. Patients with hopeless teeth with indication for extraction and implant therapy were recommended for the study. If primary stability could not be achieved or if the buccal bone plate was missing, such as there were no conditions to stabilize the implant in the healing phase, a delayed protocol was followed. The sites with indication for two stage approach were excluded from this study. There were 40 patients (sex ratio 0.74 ), with 42 surgical sites that met the conditions for immediate implant placement. After the teeth were extracted atraumatically, the extraction sockets were cleaned, and all granulation tissue was removed carefully.

We included surgical sites from the anterior and lateral regions of both maxilla and mandible (location frequency is detailed in Table $1-A, B)$. Both smokers (23.8\%) and non-smokers (76.2\%) were included in the study. Surgical interventions were performed according to our standard procedures. Tooth extraction was performed atraumatically, the roots where separated and extracted one by one in order to preserve the surrounding walls and interradicular septum. Of all the surgical sites, there were 2 sites that had two surrounding walls, 3 sites with three surrounding walls, the rest of the alveoli having all 4 surrounding walls. A tissue level implant was inserted into the neoalveolus created in the post extraction socket according to the initial 3D planning. Tissue level implants with similar Titanium alloy composition were used in all cases, 40 sites received standard $4.8 \mathrm{~mm}$ diameter platform conical implants (TRI Octa, TRI Dental Implants AG, Hünenberg, Switzerland) and 2 sites received wide neck $6.5 \mathrm{~mm}$ diameter platform cylindrical implants TissueLevel StandardPlus WN (Straumann AG, Basel, Switzerland).

Both implant types had a $1.8 \mathrm{~mm}$ high polished collar. The implants were placed having the polished collar at the same level with the cement-enamel junction (CEJ) level of adjacent teeth, with respect to the biological 
Table 2.Grafting material.

\begin{tabular}{ll}
\hline Grafting Material & Number of Sites \\
\hline Bio-Oss & $31(73.8 \%)$ \\
Copios & $7(16.7 \%)$ \\
Bio-Oss + PRGF & $3(7.1 \%)$ \\
No grafting material & $1(2.4 \%)$ \\
\hline
\end{tabular}

Table 3. Membrane type.

\begin{tabular}{ll}
\hline Membrane type & Number of Sites \\
\hline Histoacryl & $19(45.2 \%)$ \\
Bio-Gide & $18(42.9)$ \\
PRGF & $3(7.1 \%)$ \\
No membrane & $2(4.8 \%)$ \\
\hline
\end{tabular}

width protocol. The implant was installed in the septum in 4 sites, in other 3 sites the neoalveolus were created along the socket walls and in 35 sites new alveolae were created in another axis than the roots axis. In 2 of the sites in the molar region of the maxilla, internal lifting of the sinus membrane was performed in the same stage with implant insertion in the septum. No flap or deperiostation were performed in any of the 42 sites. The gaps of the alveolae where fulfilled either with deproteinized bovine bone granules (DBBO), with plasma rich in growth factors (PRGF) clots (Endoret - PRGF ${ }^{\circledR}$, BTI Biotechnology Institute, VitoriaGasteiz, Spain) mixed with DBBO or PRGF clots alone. The gaps were covered with a resorbable collagen membrane (RCM) or with a PRGF fibrine membrane. The membranes were stabilized with a PTFE continuous suture (Coreflon ${ }^{\circledR}$, Implacore Sp. z o.o. Poznań, Poland) that was applied to the free gingival margins. In caset the gap between the implant neck and the gingival margin was less than $4 \mathrm{~mm}$, a layer of cyanoacrylate was applied instead of the membrane and no suture was applied. There was one single site that neither received a graft material nor a membrane.

We used the following biomaterials: DBBO: Bio-Oss ${ }^{\circledR}$ (Geistlich Pharma, Wolhusen, Switzerland), Copios ${ }^{\circledR}$ (Zimmer Biomet Dental, Palm Beach Gardens, FL-USA) and RCM: Bio-Gide ${ }^{\circledast}$ (Geistlich Pharma, Wolhusen, Switzerland), Socket Repair Membrane ${ }^{\circledast}$ (Zimmer Biomet Dental, Palm Beach Gardens, FL-USA), Histoacryl ${ }^{\circledR}$ (B. Braun Medical, Melsungen, Germany) (Tables 2 and 3 ).

The patients received a specific scheme for control and follow up appointments. Clinical observations were made at 24 h, 48 h, 7 days and 14 days. The suture was removed after 21 days. Antibiotics were prescribed for prophylactic reason. Indications for cleaning and special care of the clinical sites were given. Painkillers and nonsteroidal anti-inflammatories were recommended just when needed. The suture removal took place after three weeks. In order to allow maturation of the bone and soft tissue, the sites were allowed to heal for at least six months before loading. We have chosen this aspect of the protocol based on previously success rate reported in the literature [15]. The case where no grafting material or membrane were used was planned to be loaded after three months, but the patient postponed the appointment until after six months due to personal reasons.

The CBCT scans were performed with the same investigation unit Cranex 3D (Soredex, Helsinki, Finland/ KaVo Dental Gmbh, Biberach, Germany) and analyzed with the OnDemand 3D software (CyberMed, Yuseonggu, Daejeon, Korea).

\section{Results}

During the observation period, a total of 41 patients with 43 surgical areas were treated with immediate implant placement in the post extraction site using the open-healing technique. One patient did not show up for prosthetic treatment, so we excluded him from the study. Therefore, the analysis included 42 surgical areas in 40 patients ( $42.5 \%$ male and $57.5 \%$ female). The nean patient age was $50.2 \pm 16.0$ years (aged $28-81$ years).

The clinical outcome was observed, checking parameters such as inflammation, swelling, pain and soft tissue secondary healing. The patients were scheduled at the specified time frame, 6 months before loading, for the CBCT scan in order to analyze the bone volume, crestal bone loss and the possibility of scheduling the implant loading procedures. All implants were loaded, using fixed single unit or multiunit cemented restorations, respecting the biological width protocol [16]. CBCT control scans were performed at 24 and 48 months follow-up. Success and survival rates were analyzed using the Buser criteria: (1) Absence of persistent subjective complaints, such as pain, foreign body sensation, and/or dysesthesia; (2) Absence of periimplant infection with suppuration; (3) Absence of mobility; (4) Absence of continuous radiolucency around the implant [17]. From the 42 sites, only 2 (two) cases needed additional surgery after clinical and CBCT observation at 6 months. Both sites were in the premolar area, one in the maxilla and one in the mandible, underwent the same procedure, using the exact same biomaterials (BioOss and BioGide). Both patients were suffering from the same systemic disease, Hepatitis, Type $C$ Virus. There was no relevant correlation with other factors. Of these 2 cases, one required additional bone augmentation procedure and the second one just a soft tissue remodeling procedure, yielding a survival rate of $100 \%$ and a success rate of $95.2 \%$ at the control time of 6 months after initial surgery. The CBCT scans showed a stable bone dimensions at 24 and 48 months followup intervals with a bone preservation of $98.9 \pm 0.7 \%$ and $98.1 \pm 0.9 \%$ compared with initial measurements. The results were analyzed and interpreted by the same clinician, in order to eliminate deviations. The bone parameters measured on CBCT scans showed stable results for all three bone levels mean values (buccal and oral bone plate height, and crest width - Table 4).

To sum up, the atraumatic extraction (Fig. 1) was followed by the tissue level implant insertion in the septum (Fig. 2). The "Open healing" technique is shown at one day, two days and three weeks in Fig. 3. Followups at one and three years (Fig. 4), as well as 4 years 
I Table 4.CBCT bone level measured parameters.

\begin{tabular}{llcccc}
\hline & & Mean & Std. Deviation & Minimum & Maximum \\
\hline \multirow{2}{*}{ Initial } & BP-height & 13.55 & 2.90 & 4.08 & 17.71 \\
& OP-height & 14.34 & 2.90 & 3.03 & 20.70 \\
\hline \multirow{2}{*}{ After loading } & BP-height & 13.73 & 1.74 & 10.70 & 17.17 \\
& OP-height & 14.26 & 1.87 & 8.97 & 18.99 \\
\hline \multirow{2}{*}{ loar after } & BP-height & 13.61 & 1.78 & 10.68 & 17.03 \\
\hline \multirow{2}{*}{$\begin{array}{l}\text { loading } \\
\text { loading }\end{array}$} & OP-height & 14.07 & 1.82 & 8.94 & 18.87 \\
\hline
\end{tabular}

$\mathrm{BP}=$ buccal bone plate, $\mathrm{OP}=$ oral bone plate. All measurements in $\mathrm{mm}$.

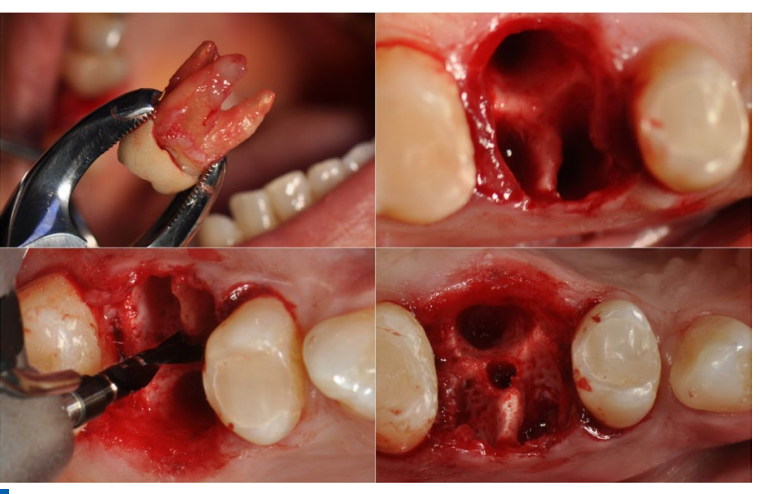

I Figure 1. Atraumatic extraction (a,b). Neoalveolus preparation in the $\operatorname{septum}(c, d)$.

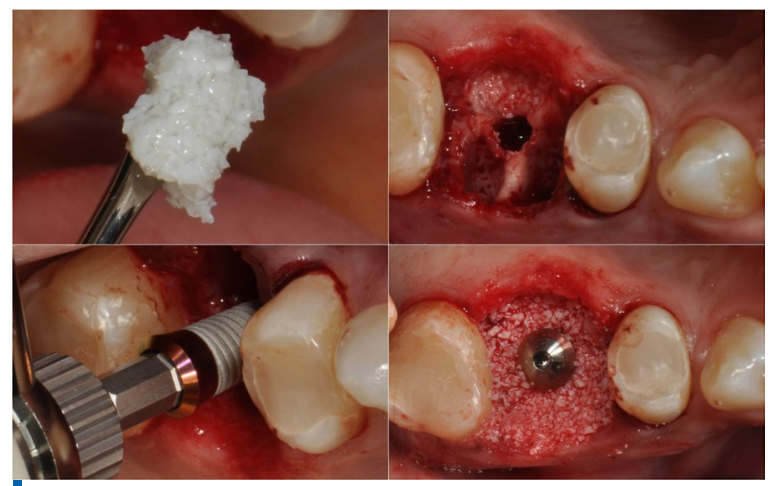

I Figure 2. Bovine bone granules filling the alveolae (a,b). Tissue level implant inserted in the septum $(c, d)$.

(Fig. 5) shape the picture of one of the cases that were successfully addressed using the protocol described in this study.

In our study, all implants obtained a good primary stability. The treatment was judged to be successful if implant loading was possible with no additional augmentation needed and implants were in place at the follow-up intervals, thus a success rate of $95.2 \%$. The survival rate after criteria described by Buser et al in 1997 was $100 \%$ [18].

\section{Discussions}

In order to facilitate the implant therapy, ridge resorption caused by tooth extraction should be limited or even eliminated. The evaluation of bone quality during treatment planning is mandatory

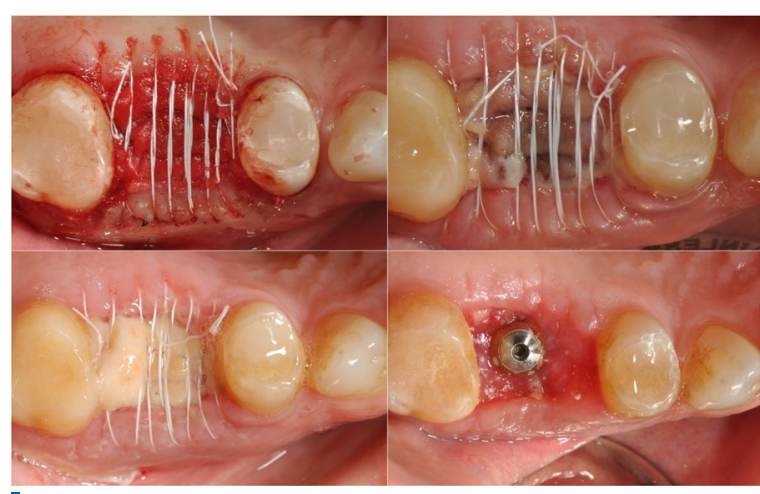

I Figure 3. Open healing. Resorbable collagen membrane stabilized by PTFE continuous suture (a). Healing at 24h (b), 48h (c) and 3 weeks (d).

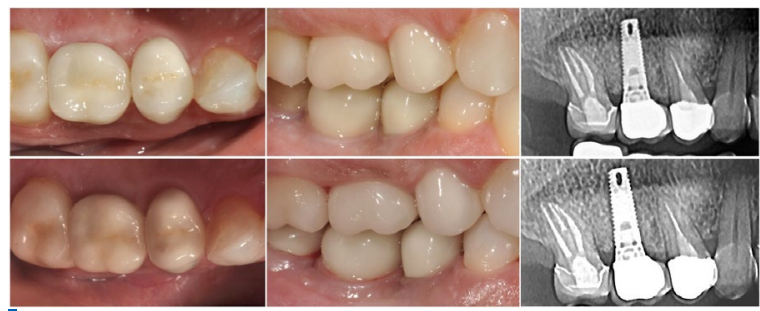

Figure 4. Follow-up at 12 months (clinical - $\mathrm{a}, \mathrm{b}$ and radiological $-\mathrm{c}$ ) and at 36 months (clinical - d,e and radiological $-f$ ).

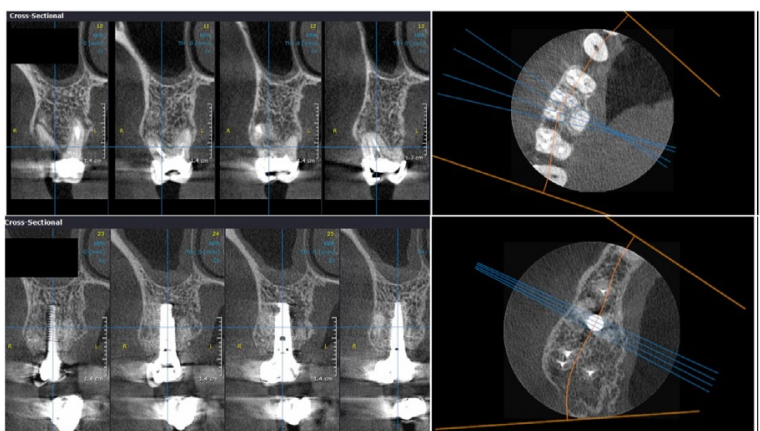

Figure 5. CBCT scan before surgery (up) and at 4 years follow up (down), showing implant position in the septum.

especially when immediate loading is intended. Positive results regarding the possible implant stability can lead to immediate implant insertion as the first choice clinical procedure instead of a delayed two-stage approach. Such a delayed-approach treatment sequence encompasses several steps over an extended period of time and appointments, not only for the practitioner, but also for the patient. Barone et al. [19] showed that regenerative techniques 
(GBR) were able to limit resorption of the alveolar crest after implant placement in a fresh extraction socket. On the contrary, Hsu et al. [20] demonstrated in an experimental study that the placement of implants and deproteinized bovine bone granules into fresh extraction sockets generates significant buccal bone loss as well as low osseointegration. Other clinical studies [21-23] used GBR techniques to fill the gap between bone and implant.

Our study showed that placing a bone graft into the residual gap around a post-extraction socket is helpful for limiting the amount of facial-palatal contour change from the FGM to more apical reference points. In a retrospective cohort study conducted by Tarnow et al. the conclusion stated was that all post-extraction implant placement without flap elevation demonstrated some negative contour change (facial collapse) relative to the adjacent contralateral control tooth. However, the change was minimal compared to previous studies where full periosteal flaps were elevated for ridge augmentation after teeth extraction. According to these authors, the key elements in preserving ridge contour are protection, containment and maintenance of the bone graft during the healing phase of treatment, which can extend from 4 to 6 months. A contoured healing abutment or provisional restoration were used to close the gap and keep the graft in place [24]. Alternatively, our concept is based on the tissue level emergency profile design that can seal the gap similarly to the contoured healing abutment. The advantage of our technique compared to the above-mentioned ones is that having the tissue level in place after the osseointegration period, there will be no trauma of the peri-implant tissues generated by the dismounting of the healing abutment or provisional crown and mounting the final prosthesis. When the tissue level implant's neck was not wide enough to close the space left, cyanoacrylate tissue glue was used to protect the bone graft [14]. In gaps that are larger than $4 \mathrm{~mm}$, a collagen resorbable membrane was placed over and stabilised with a continuous PTFE suture, according to the described "open healing" protocol. Although various studies have shown controversial results regarding the effect of secondary wound dehiscence occurring during healing when using suitable membrane materials, the protocol allows uneventful healing and sufficient bone formation. Also, soft-tissue problems associated with extensive flap mobilisation and tension may thus be avoided.

\section{Conclusion}

This retrospective study indicates that immediate implant placement into fresh extraction sockets using tissue level implants, suitable grafting materials and membranes with the "open healing" protocol allows uneventful healing, predictable aesthetic results and lower surgical trauma compared with conventional methods using flap techniques. Furthermore, the softtissue problems associated with flap mobilization and consecutive tension due to the wound closure are avoided. The clinical significance of the combination of the "open healing" technique, with immediate implant placement of a tissue level implant into a fresh extraction socket with partial or complete loss of the buccal bone plate has significant benefits for both the clinician and the patient: treatment procedures are reduced to fewer appointments, the overall time of the treatment is reduced and the tridimensional architecture of the soft and hard tissues is maintained, including the possibility of regenerating the buccal bone plate when missing. Further scientific studies need to be conducted to reinforce our clinical results.

\section{Author contributions}

All the authors participated in establishing the concept and protocol. Al, AD, VP performed the surgical procedures. MIN, AM, GT participated in data gathering, analysis and interpretation. All the authors participated in critically revising the manuscript.

\section{References}

1. Hämmerle $\mathrm{CH}$, Chen ST, Wilson JrTG. Consensus statements and recommended clinical procedures regarding the placement of implants in extraction sockets. Int JOral Maxillofac Implants. 2004; 19(Suppl):26-28.

[PubMed] Google Scholar Scopus

2. Hämmerle CH, Araújo MG, Simion M, Osteology Consensus Group 2011. Evidence-based knowledge on the biology and treatment of extraction sockets. Clin Oral Implants Res. 2012;23(Suppl 5):80-82.

[CrossRef] [PubMed] Google Scholar Scopus

3. Jung $\mathrm{RE}$, loannidis A, Hämmerle $\mathrm{CH}$, Thoma DS. Alveolar ridge preservation in the esthetic zone. Periodontology 2000. 2018;77(1):165-175.

[CrossRef] [PubMed] Google Scholar

4. Tomlin EM, Nelson SJ, Rossmann JA. Ridge preservation for implant therapy: a review of the literature. Open Dent J. 2014;16(8):66-76.

[CrossRef] [PubMed] Google Scholar Scopus

5. Sehgal M, Puri, L, Yadav S et al. Immediate Dental Implants Enriched with L-PRF in the Esthetic Zone. Case Rep Dent. 2018; 9867402.

[Free PMC Article] [CrossRef] [PubMed] Google Scholar Scopus

6. Botticelli D, Berglundh T, Lindhe J. Hard-tissue alterations following immediate implant placement in extraction sites. J Clin Periodontol. 2004;31(10):820-828

[CrossRef] [PubMed] Google Scholar Scopus

7. Denardi RJ, da Silva RD, Thomé G et al. Bone response after immediate placement of implants in the anterior maxilla: a systematic review. Oral Maxillofac Surg. 2019 Feb. [Full text links] [PubMed] Google Scholar Scopus

8. Mehta H, Shah S. Management of Buccal Gap and Resorption of Buccal Plate in Immediate Implant Placement: A Clinical Case Report. JInt Oral Health. 2015;7(Suppl 1):72-75. [Full text links] [PubMed] Google Scholar

9. Gotta SL, Reynolds MA, Saito H, Tarnow DP. Flapless post extraction socket implant placement, part 2: the effects of bone grafting and provisional restoration on peri-implant soft tissue height and thickness-a retrospective study. Int $J$ Periodontics Restorative Dent. 2015;35(6):803-809. Google Scholar

10. Ionescu A, Panagopoulos V, Taffet G. Open healing protocol as alternative ridge augmentation procedure in implant patients. Clinical Oral Implants Research. 2015;26:441.

11. Smith RB, Tarnow DP. Classification of molar extraction sites for immediate dental implant placement. Int JOral Maxillofac Implants. 2013 May-Jun;28(3):911-916.

[CrossRef] [PubMed] Google Scholar Scopus

12. Elian N, Cho S, Froum S et al. A simplified socket classification and repair technique. Pract Proced Aesthet Dent. 2007 Mar;19(2):99-104. [PubMed] Google Scholar Scopus

13. Chu SJ, Sarnachiaro GO, Hochman MN, Tarnow DP. Subclassification and Clinical Management of Extraction Sockets with Labial Dentoalveolar Dehiscence Defects. Compend Contin Educ Dent. 2015 Jul-Aug;36(7):516, 518-20, 522 passim. [PubMed] Google Scholar Scopus 
14. Taffet G. Open healing: a retrospective analysis. J Oral Science Rehabilitation. 2016; 2(4):16-25.

15. Botticelli D, Renzi A, Lindhe J, Berglundh T. Implants in fresh extraction sockets: a prospective 5-year follow-up clinical study. Clin Oral Implants Res. 2008;19(12):1226-1232. [CrossRef] [PubMed] Google Scholar Scopus

16. Taffet G. Implantate in der ästhetischen Zone Im Konflikt oder in Harmonie mit der ",biologischen Breite"? DGZI Impl J 2009;(7):48-53. Google Scholar

17. Buser $D$, Ingimarsson $S$, Dula K et al. Long-term stability of osseointegrated implants in augmented bone: a 5-year prospective study in partially edentulous patients. Int $J$ Periodontics Restorative Dent. 2002 Apr;22(2):109-117. [PubMed] Google Scholar Scopus

18. Buser D, Mericske-Stern R, Bernard JP et al. Long-term evaluation of non-submerged ITI implants. Part 1: 8-year life table analysis of a prospective multi-center study with 2359 implants. Clin Oral Implants Res. 1997;8(3):161-172.

[CrossRef] [PubMed] Google Scholar Scopus

19. Barone A, Ricci M, Calvo-Guirado JL et al. Bone remodelling after regenerative procedures around implants placed in fresh extraction sockets: an experimental study in Beagle dogs. Clin Oral Implants Res. 2011;22(10):1131-1137.

[CrossRef] [PubMed] Google Scholar Scopus

20. Hsu KM, Choi BH, Ko CY et al. Ridge alterations following immediate implant placement and the treatment of bone defects with Bio-Oss in an animal model. Clin Implant Dent Relat Res. 2012;14(5):690-695.

[CrossRef] [PubMed] Google Scholar Scopus

21. Cafiero C, Annibali S, Gherlone E et al. Immediate transmucosal implant placement in molar extraction sites: a 12-month prospective multicenter cohort study. Clin Oral Implants Res. 2008;19(5):476-482

[CrossRef] [PubMed] Google Scholar Scopus

22. Matarasso S, Salvi GE, lorio Siciliano V et al. Dimensional ridge alterations following immediate implant placement in molar extraction sites: a six-month prospective cohort study with surgical re-entry. Clin Oral Implants Res. 2009;20(10):1092-1098. [CrossRef] [PubMed] Google Scholar Scopus

23. Siciliano VI, Salvi GE, Matarasso S et al. Soft tissues healing at immediate transmucosal implants placed into molar extraction sites with buccal self-contained dehiscences. A 12-month controlled clinical trial. Clin Oral Implants Res. 2009;20(5):482-488. [CrossRef] [PubMed] Google Scholar Scopus

24. Tarnow DP, Chu SJ, Salama MA et al. Flapless postextraction socket implant placement in the esthetic zone: part 1. The effect of bone grafting and/or provisional restoration on facial-palatal ridge dimensional change-a retrospective cohort study. Int $J$ Periodontics Restorative Dent. 2014;34(3):323-331. [CrossRef] [PubMed] Google Scholar

\section{Alecsandru IONESCU \\ DDS, PhD Student \\ Aesthetics One Dental Center \\ Bucharest, Romania}

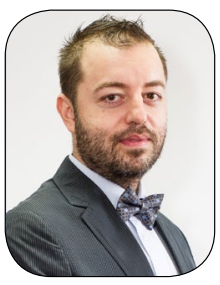

Dr. Alecsandru lonescu graduated from the Faculty of Dentistry, "Carol Davila” University of Medicine and Pharmacy Bucharest, Romania (2001). He is a member of the board of the Society for Esthetic Dentistry in Romania (SSER). He is also the co-founder of Quintessence International Romania and a founding member of the Romanian Society for Digital Dentistry. He is an active member of IADFE, ESCD, EAO and ICOI. Dr. lonescu's main lecturing topics focus on minimally invasive approaches in oral surgery and implantology. $\mathrm{He}$ is an international speaker, author of different articles and a co-author of the "Comprehensive Esthetic Dentistry", the first volume by Romanian authors published by Quintessence International in 2015, translated into Chinese in 2017. He works in Bucharest in his private clinic and training center "Aesthetics One".

\section{Drestions}

\section{In which situation is immediate implant placement possible?}

口a. When primary stability can be obtained;

ab. In type A socket;

c. In all socket types;

$\square d$. After all granulation tissue is removed and the alveolae are cleaned.

\section{Buser criteria for survival and success are:}

$\square$ a. Absence of any postoperative edema;

ab. Absence of mobility;

c. Absence of continuous radiolucency around the implant;

$\square$ d. Absence of periimplant infection with suppuration.

\section{The following is true about immediate implantation:}

$\square$ a. It reduces the overall treatment plan;

b. It stops the postextractional bone loss;

ac. It can be done in conjunction with the open healing technique;

$\square d$. The polished collar must be placed at the same level as the cement-enamel junction.

\section{To facilitate implant placement:}

口a. Tooth extraction must be atraumatic;

ab. Postextractional bone loss must be minimized;

ac. A mucoperiosteal flap should be raised;

$\square$ d. Additional augmentation should be performed. 


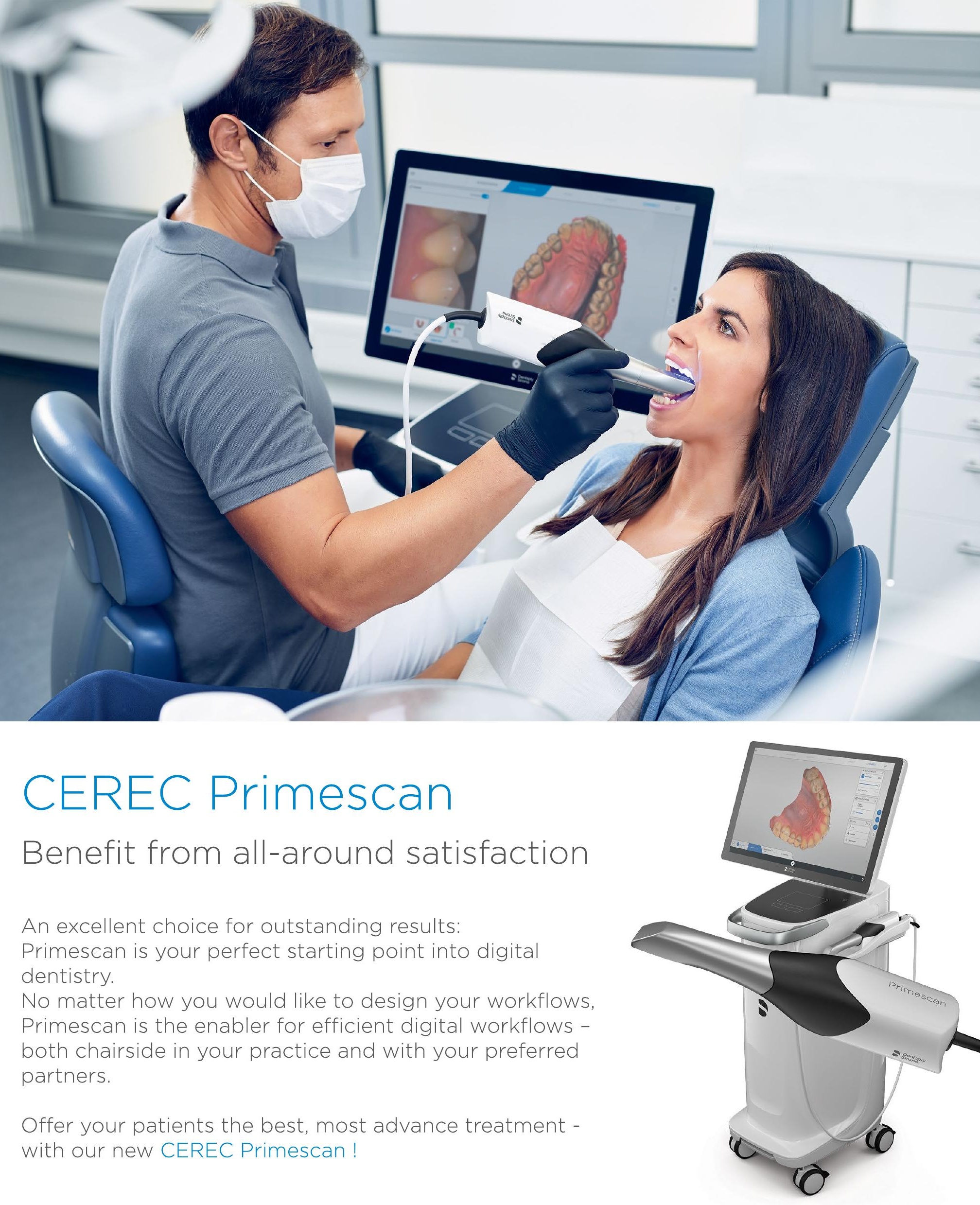

An excellent choice for outstanding results:

Primescan is your perfect starting point into digital dentistry.

No matter how you would like to design your workflows, Primescan is the enabler for efficient digital workflows both chairside in your practice and with your preferred partners.

Offer your patients the best, most advance treatment with our new CEREC Primescan! 
PARTIAL CERAMIC CROWNS. ESTHETICAND TISSUE CONSERVATIVE RESTORATIONSPART II:ANTERIOR TEETH - LAMINATE VENEERS

\author{
Gottfried Schmalz ${ }^{1,2, a^{*}(i)}$, Marianne Federlin ${ }^{1, b}$ \\ 'Department of Operative Dentistry and Periodontology, Medicine Faculty, University Hospital Regensburg, D-93052 Regensburg, Germany \\ ${ }^{2}$ Department of Periodontology, School of Dental Medicine (ZMK Bern), University of Bern, CH-3010 Bern, Switzerland
}

'DMD, PhD, Professor, Drhc mult.

bDMD, PhD, Professor

DOI: https://doi.org/10.25241/stomaeduj.2019.6(1).art.6

Background: For anterior teeth with large defects or for teeth which need major changes in color, shape or size, laminate veneers are a highly esthetic and comparatively tissue conservative treatment option within a large group of other therapeutic measures. The survival rates of laminate veneers are $>90 \%$ over 10 years and in the range of full coverage crowns. For patients with heavy bruxism and/or small clinical crowns the longevity may be reduced.

Objective: to review the main guidelines for dental treatment using laminate veneers.

Data Sources: dental literature (Web of Science, PubMed, Google Scholar) about laminate veneers between 1998 and 2019.

Study Selection: articles, reviews and textbooks about laminate veneers were selected to obtain the most relevant information.

Data Extraction: all data evidence-based about laminate veneers technique were extracted.

Data Synthesis: all data considered important and relevant for the laminate veneers technique were presented step by step in a coherent and concise way.

The conclusions were:

- Preparation should be as conservative as possible $(0.3-0.5 \mathrm{~mm}$ cervical-buccal reduction).

- Special methods for impression taking and for temporization should be applied.

- The ceramic material needs to have optimal esthetic properties including adequate translucency.

- The choice of the luting material is based on optimal bonding (etch \& rinse, SE). Solely light curing luting composite materials or flowable composites can be used for optimal and longlasting esthetics for ceramic thickness of up to $1 \mathrm{~mm}$.

- In order to protect the laminate veneers against parafunctional forces during night sleep a protective splint (night guard) is recommended.

Keywords: Laminate veneers; dental ceramic; esthetics; dental light curing; flowable composite resins.

\section{Introduction}

For anterior teeth with cavities extending into large parts of the buccal surface and potentially needing replacement of the incisal edge, the classical treatment method for many years has been a full coverage crown, either made of resin materials, ceramics, or combination of metals with (mainly) ceramics. In anterior teeth with smaller defects, major esthetic problems related to color, shape and size have also been reasons for full coverage of such teeth, consequently removing quite large amounts of sound tooth hard tissue [1]. However, for a number of years, adhesive technology has enlarged the spectrum of treatment options. Adhesively bonded resin-based composites can be used very successfully in many of such cases.

In more complicated cases, partial crown coverage of anterior teeth may be a treatment option, which has been successfully used in posterior teeth [2].
Fig. 1 shows a clinical case, where this technique has been applied. Such restorations are commonly named laminate veneers. They impress with optimal esthetics and require less removal of sound tooth tissue than full coverage crowns [1]. Part I of this article [2] focused on the restoration of posterior teeth with partial crowns, here our results over the recent 20 years and data from the literature with partial crowns in anterior teeth, i.e. laminate veneers are described. The objective of this article is to discuss whether this is a reliable treatment option, and to which critical points attention has to be paid in order to achieve a successful treatment outcome.

\section{Definition}

For anterior teeth, partial coverage (here mainly the buccal aspect) of the clinical crown by a restoration is also termed "laminate veneer". Some authors 


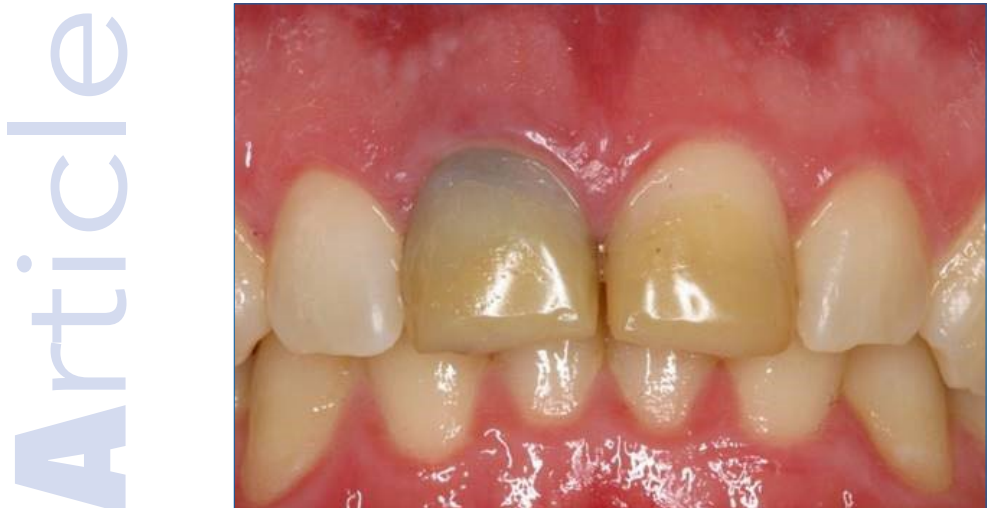

(a)

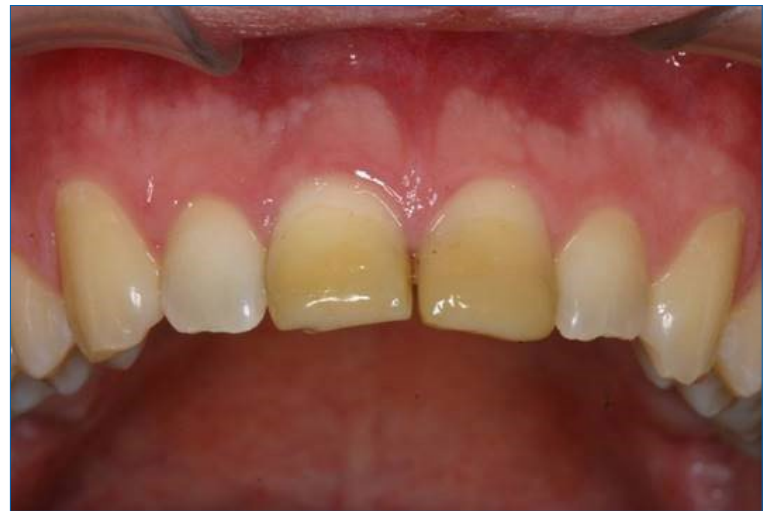

(c)

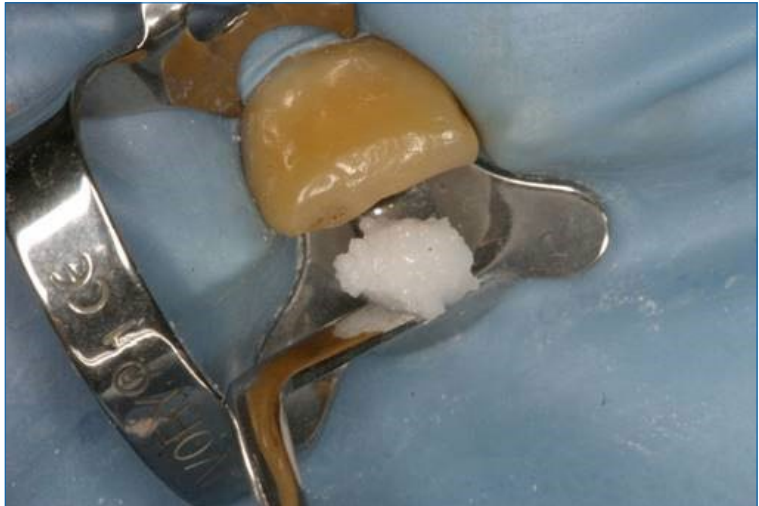

(b)

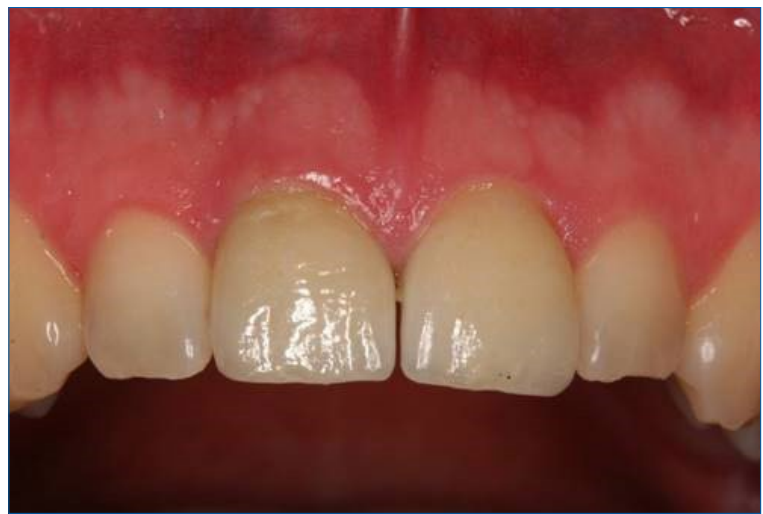

(d)

I Figure 1. Restoration of severely discolored teeth with extended composite resin restorations $(\mathrm{a})$; during and after internal bleaching $(\mathrm{b}, \mathrm{c})$; restored with two laminate veneers (d).

distinguish between (1) veneers with no or only a minor inclusion of the incisal edge and (2) anterior partial crowns with an extended inclusion of the lingual surfaces [3]. However, this subdivision appears somewhat academic and the terms partial crown in anterior teeth or laminate veneers are used synonymously in this review.

\section{Longevity}

A number of clinical studies on the longevity of laminate veneers have been published with varying observation times ranging from 40 months to more than 15 years. Similar to partial crowns in posterior teeth, the clinical survival rates of ceramic laminate veneers were rated to be very good and up to 40 months more than $93 \%$ of the restorations were still in situ [4]. As laminate veneers are also used in teeth with existing composite restorations, it was interesting to analyze if such restorations have a negative influence on the general outcome for laminate veneers. Interestingly, no statistically significant differences had been observed in this study [4] between cases with and without composite restoration being present. Slight marginal defects (16 of 87 veneers) and slight marginal discoloration at the margins were observed ( 12 of 87 veneers), but no secondary caries or endodontic complications [4]. However, in another clinical study increased marginal problems have been reported, when the ceramic margin was in contact with composite fillings [5]. On tetracycline-stained teeth $99 \%$ out of 546 ceramic veneers were in situ after up to 2.5 years [6]. Also, after longer observation periods (7-year Kaplan-Meier survival rate) in a prospective clinical study a retention rate between 97.6 and $100 \%$ was reported [7].

After 5 years, Aristidis et al. recorded the clinical performance of ceramic veneers (61 patients) concerning esthetics, marginal integrity, marginal discoloration, fracture rate, and patient satisfaction. In this study, $98.4 \%$ of the veneers were satisfactory without intervention and the patient satisfaction was very high [8]. After up to 20 years, laminate veneers made of silicate glass-ceramic had an estimated survival probability of $93.5 \%$ over 10 years. Significantly increased failure rates were associated with bruxism and non-vital teeth, and marginal discoloration was worse in patients who smoked [9]. In a prospective study over ten years, ceramic veneers maintained their esthetic appearance. None of the veneers were lost. The percentage of restorations that remained "clinically acceptable" (without need for intervention) significantly decreased from an average of $92 \%$ ( $95 \mathrm{Cl}: 90 \%$ to $94 \%$ ) at 5 years to $64 \%$ ( $95 \mathrm{Cl}: 51 \%$ to $77 \%$ ) at 10 years. Most of them could be repaired, only $4 \%$ needed replacement [5].

In another long-term study, the clinical performance of ceramic laminate veneers bonded to teeth prepared with the use of an additive mock-up and aesthetic pre-evaluative temporary technique (APT) was evaluated over a 12-year period. Briefly, with 


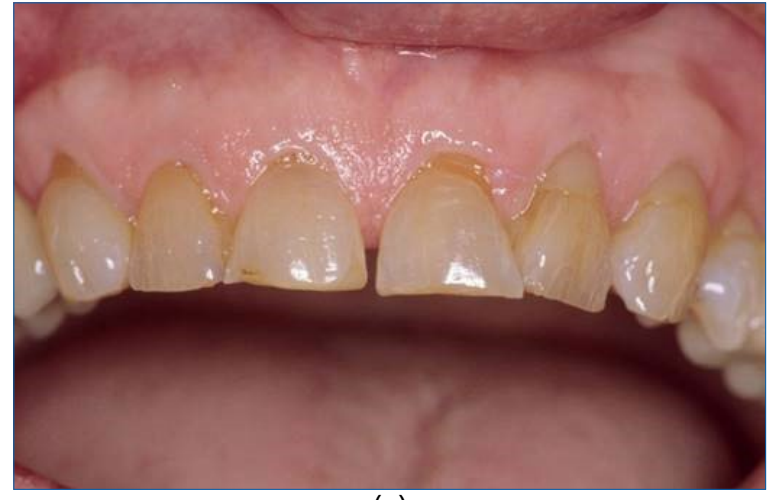

(a)

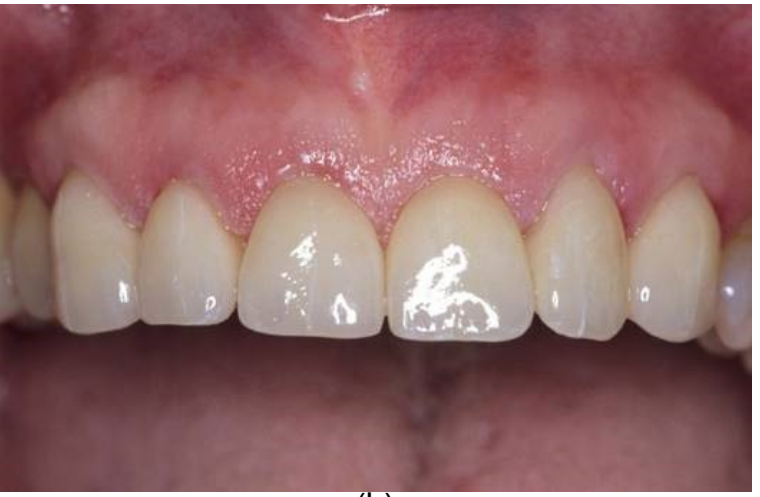

(b)

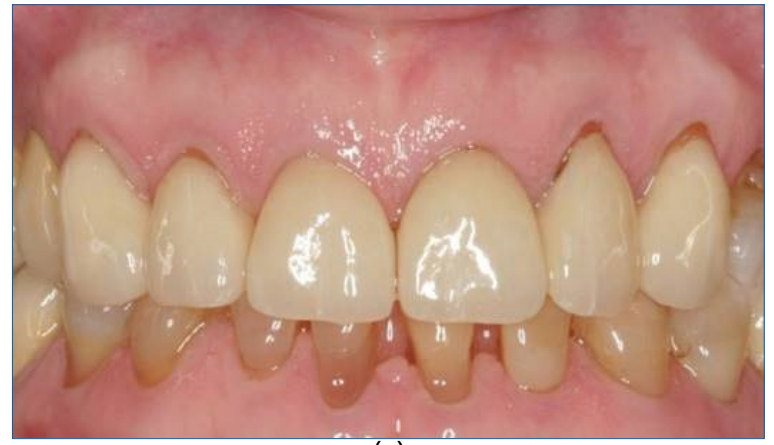

(c)

I Figure 2. Restoration of severely discolored and abraded teeth (a) with laminate veneers (b) and control after 15 years (c); slight marginal discolorations are visible.

the APT technique the dentist creates an immediate mock up from composite resin in the patient's mouth, in order to design the outline of the veneers together with the patient. Then, this is transferred to the technician who produces a silicone index for further treatment. The preparation is performed in conjunction with this index, allowing for a minimally invasive approach. Sixty-six patients were restored with 580 porcelain laminate veneers. The technique used for diagnosis, esthetic design, tooth preparation, and provisional restoration fabrication, was based on the APT protocol. Over $80 \%$ of tooth preparations were confined to the dental enamel. Over 12 years, 42 laminate veneers failed, but when the preparations were limited to the enamel, the failure rate resulting from debonding and microleakage decreased to $0 \%$. Ceramic laminate veneers presented a successful clinical performance in terms of marginal adaptation, discoloration, gingival recession, secondary caries, postoperative sensitivity, and satisfaction with restoration shade at the end of 12 years [10].

In a recent systematic review and meta-analysis, 13 publications have been included. The estimated overall cumulative survival rate was $89 \%$ (95\% Cl: $84 \%$ to $94 \%$ ) in a median follow-up period of 9 years. The estimated survival for glass-ceramic was 94\% (95\% Cl: $87 \%$ to $100 \%$ ), and for feldspathic porcelain veneers, $87 \%$ (95\% Cl: $82 \%$ to $93 \%)$. It was not possible to perform a meta-analysis of the influence of enamel/dentin preparation on failure rates. Fracture or chipping of the ceramic was the most frequent complication, providing evidence that ceramic veneers are a safe treatment option that preserves tooth structure [11]. Fig. 2 shows an exemplary case, where laminate veneers had been controlled after 15 years.

All these results are in the same order of magnitude as survival data reported for all ceramic full coverage crowns, e.g. $95.4 \%$ - $94.5 \%$ after 5 years (reinforced glass ceramic: Empress) [12] or $94.8 \%$ or more in situ after up to 10 years (Li-disilicate) $[13,14]$.

Problems may occur in teeth with small clinical crowns, when the size of the teeth shall be enlarged and the area for bonding becomes comparatively small. Heavy bruxism is generally considered to be a contraindication for laminate veneers [9], because strong horizontal forces (1) endanger the bond of the veneer to the tooth structure and (2) may lead to a fracture of thin incisal ceramic. Discoloration of the margins and wear of the luting material are also reported in the literature [5], especially for smokers [9]. The accuracy of fit with the aim of a small primary marginal gap, which has to be filled with the luting material, will reduce the wear. Furthermore, the correct choice and use of the luting material seems to be an important factor (see below). The above mentioned meta-analysis showed the following rates: debonding: $2 \%$ ( $95 \% \mathrm{Cl}: 1 \%$ to $4 \%)$; fracture/ chipping: $4 \%$ (95\% Cl: $3 \%$ to $6 \%$ ); secondary caries: $1 \%(95 \% \mathrm{Cl}: 0 \%$ to $3 \%)$; severe marginal discoloration: $2 \%$ (95\% Cl: $1 \%$ to $10 \%$ ); endodontic problems: $2 \%$ (95\% Cl: $1 \%$ to $3 \%$ ); and incisal coverage odds ratio: 1.25 (95\% Cl: 0.33 to 4.73) [11]. For non-vital teeth there is a slight chance for further discoloration after the application of laminate veneers, which was reported to result in minor esthetic problems [5].

Thus it can be concluded, that ceramic partial crowns/laminate veneers are a reliable treatment method in anterior teeth. They show survival rates, which are in the same order of magnitude as for full coverage crowns, but more sound tooth tissue is conserved. However, special techniques must be followed in order to keep failures at a minimum.

\section{Which Ceramic?}

In part I of this review the different ceramics available for ceramic partial crowns have been described and the reader is referred to this publication [2]. 
In anterior teeth, mechanical properties do not play such a great role as in posterior teeth; instead, esthetic considerations are of major concern. Esthetic properties are mainly related to the translucency of ceramics [15], which is defined as the extent to which light is diffused rather than reflected [16]. Extensive experiences exist with feldspathic ceramics and glass ceramic reinforced with leucite, less with (monolithic) lithium disilicate reinforced silicate ceramics, some of which are less transparent than glass ceramics [17]. Recently, translucent lithiumdisilicate ceramic with two levels of translucency has been marketed, a high and a low translucency material [16]. For full coverage crowns few clinical studies with (monolithic) lithium disilicate ceramics are available and they report positive results $[14,18]$; for laminate veneers, clinical data using this ceramic are scarce. Zirkonia ceramics are comparatively opaque and are presently not used for laminate veneers [19]. With newer polymer containing/-based materials, which have to be milled, little clinical experience with laminate veneers exists for the time being.

Which ceramic to select? Over the recent 25 years the authors used mainly leucite reinforced glass ceramics, which were pressed and then individualized. If the restorations are produced in a dental laboratory, an experienced technician and a close communication between dentist and technician are essential. It is advisable that the technician should be present when selecting the tooth color and designing the shape of the veneers. Finally, the color of the prepared tooth has to be taken into account.

\section{Which Preparation?}

\subsection{Ceramic thickness}

In contrast to posterior teeth, the thickness of the ceramic is not mainly determined by the masticatory forces, but by esthetics and the idea of tooth substance conservation [20]. The determination of the appropriate ceramic thickness has, nevertheless, to take biomechanical aspects into consideration, which, however, are different in the anterior region of the mouth compared to posterior teeth, which have been described in part I [2]. Obviously, fracture resistance of ceramic will depend, beside other factors, upon the ceramic thickness [21]. Recently, Costa et al. [1] performed in vitro studies using FEA (finite element analysis) comparing 0.3 and $0.8 \mathrm{~mm}$ thick lithium disilicate ceramic used for veneering human canines. They found that $0.8 \mathrm{~mm}$ thickness was associated with better stress distribution and lower tensile stress concentration than $0.3 \mathrm{~mm}$ thickness; thus the authors concluded that higher ceramic thickness may contribute to higher longevity, although the maximum stress values did not overcome the material's limit to failure. Furthermore, Stappert et al. [22] investigated the fracture behavior of veneer ceramic (leucite-reinforced glass-ceramic) of $0.5 \mathrm{~mm}$ thickness in preparations with and without different methods of incisal coverage. After dynamic loading simulating 5 years of service, a significantly higher number of palatal cracks was found in ceramic with an extended palatinal preparation design (see also Fig. 4). Such cracks were found in areas of maximum stress concentration in natural teeth [23] and the results are in line with FEA analyses from Magne and Douglas [24] showing highest stress concentrations at the extended palatinal chamfer areas. Therefore, if such a preparation design is chosen, ceramic thickness at the palatinal site should be increased (for leucitereinforced glass ceramic) to more than $0.5 \mathrm{~mm}$. In vitro studies have also shown that the fracture resistance of laminate veneers with $0.5-\mathrm{mm}$ preparation depth was greater than that of the $0.3-\mathrm{mm}$ and $1-\mathrm{mm}$ preparation depth [25], which, however, for the $1 \mathrm{~mm}$ thickness may have been due to the fact that the preparation mainly exposed dentin. It is generally accepted that the preparation should be kept - as much as clinically possible - to the enamel as bonding substrate and over-contour of the veneer should be avoided. On the other side, an adequate material thickness is needed for masking the discolored hard tooth tissues and to give the technician freedom for the esthetic design $[26,27]$. Form those and other studies it can be concluded that although a ceramic thickness of 0.3 $-0.5 \mathrm{~mm}$ has generally been recommended [26], it has to be adjusted to the individual clinical situation. Magne and Belser [20] have therefore recommended that in the cervical area the ceramic thickness should be $0.3-0.5 \mathrm{~mm}$, in the middle third around $0.7 \mathrm{~mm}$ and at the incisal coverage at least $1.5 \mathrm{~mm}$.

A completely different approach uses prefabricated veneers from ceramics (recently also from composite resins), which are adhesively luted to the unprepared or only slightly roughened enamel [28]. This is meant as a one visit, cost-effective alternative [28]. Reports on clinical outcome are scarce.

\subsection{Enamel vs. dentin}

As mentioned above, the bond strength of laminate veneers to enamel is generally regarded to be higher than that to dentin [29], although it depends on the adhesive system used. However, it has been recommended that the ideal preparation for laminate veneers should remain within enamel [30]. In a clinical study longevity of veneers with a preparation solely in enamel was better than in dentin, but the difference was not statistically significant [26]. A special problem is the extension into the cervical dentin for esthetic reasons. In vitro studies have shown that similarly favorable marginal adaptations of ceramic veneers to dentin and enamel can be achieved using high viscosity luting composites with their corresponding adhesive systems [31]. Cötert et al. however reported that a supragingival preparation had a significantly positive effect on the overall survival rate [26]. Furthermore, iso-or supragingival margins have a positive effect upon gingival health (Fig. 3). 


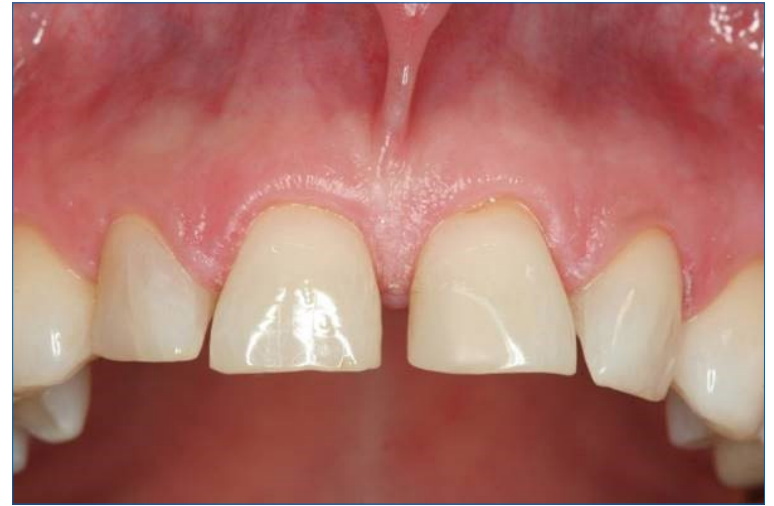

(a)

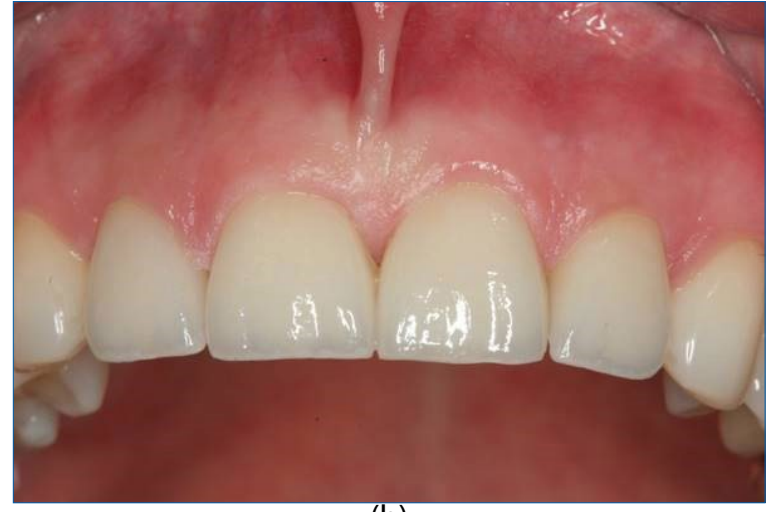

(b)

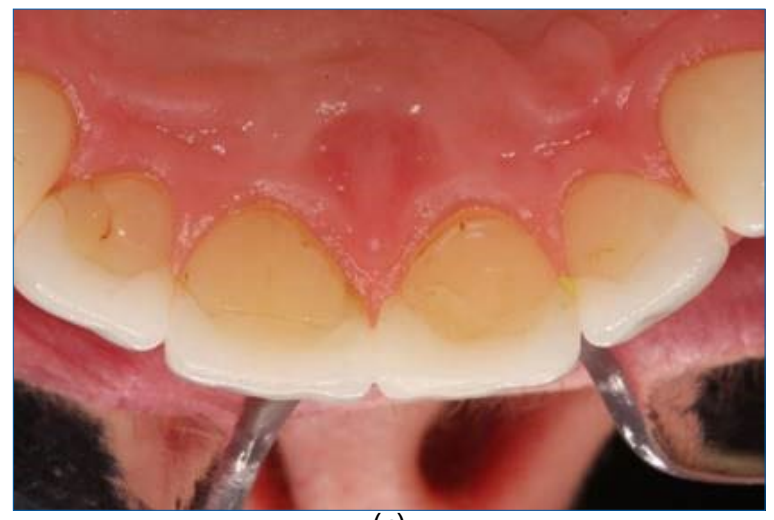

(c)

I Figure 3. Restoration of a diastema and increasing tooth size (a): Iso- or supragingival preparation leads to optimal healthy gingiva (b): view from buccal; (c): view from palatinal).

\subsection{Incisal coverage}

Both incisal coverage and non-coverage have been described in the literature (Fig. 4a-c) and the defect size primarily decides which preparation to choose. However, even if from this point of view an incisal overlapping is not necessary, an incisal overlapping has some clinical advantages. First of all, it may improve the mechanical properties of the laminate veneer [32] and it may result in better esthetics [27]. Finally it facilitates proper seating of veneers during luting. Cötert et al. reported that the overlapped incisal edge had a significantly positive effect on the overall clinical survival rate [26]. However, as a result of a meta-analysis of existing literature the estimated survival rate for laminate veneers with incisal coverage was reported to be $88 \%$ and $91 \%$

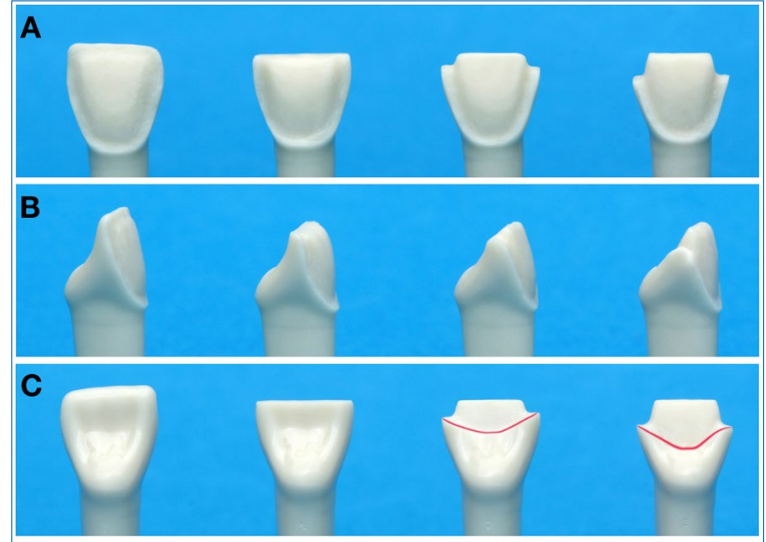

Figure 4. Preparation design (from left to right) without incisal coverage, with horizontal coverage and with coverage combined with a small or extended palatinal chamfer/shoulder;viewfrom(A):buccal,(B):approximal and (C): palatinal; palatinal chamfer is visualized by a line;

(Courtesy of Dr. F. Cieplik).

for those without incisal coverage [33]. In a more recent meta-analysis by Hong et al. [34] comprising 10 clinical studies, veneers with incisal coverage had a worse prognosis as compared to those without. However, the difference was not statistically significant. Apparently, horizontal mechanical forces which are directed to the incisal ceramic part are responsible for slightly lower survival rates of laminate veneers with incisal coverage. However, not only the thickness and the mechanical properties of the ceramic material play a role, but also the patient. Here, patients with a tendency to bruxism have been reported to have a higher failure rate [9]. This should be taken into account when planning the preparation. The incisal coverage may have different designs: a pure overlap by reducing the incisal part by about $2 \mathrm{~mm}$ or a further palatinal chamfer below the $2 \mathrm{~mm}$ reduction (see also Fig. 4).

Concerning marginal integrity and fracture resistance, no difference between the two designs has been reported in the literature [22,35], although one in vitro study indicated that deep palatinal chamfer or butt joint preparation will result in a stress concentration at the palatinal area and an increased ceramic thickness is recommended [22].

\subsection{Preparation Margins}

Proximal preparation design can be classified into "proximal chamfer" and "proximal slice" or "shoulder/ butt joint" type preparation. Chamfer type approximal preparations proved in one study to reveal higher clinical success rates [26]. The interproximal extension of the preparation shall comprise the anatomical equator so that the cavity margins are beyond the visible area. It is a matter of discussion, if the contact points shall be resolved or if the veneer margin can be located in the contact point area. According to classical concepts, contact point areas are difficult to clean and thus prone for secondary caries. On the other side, appropriate oral hygiene; e.g. using flosses, can prevent secondary caries at contact point areas (Fig. 5). Resolving the contact point offers more 


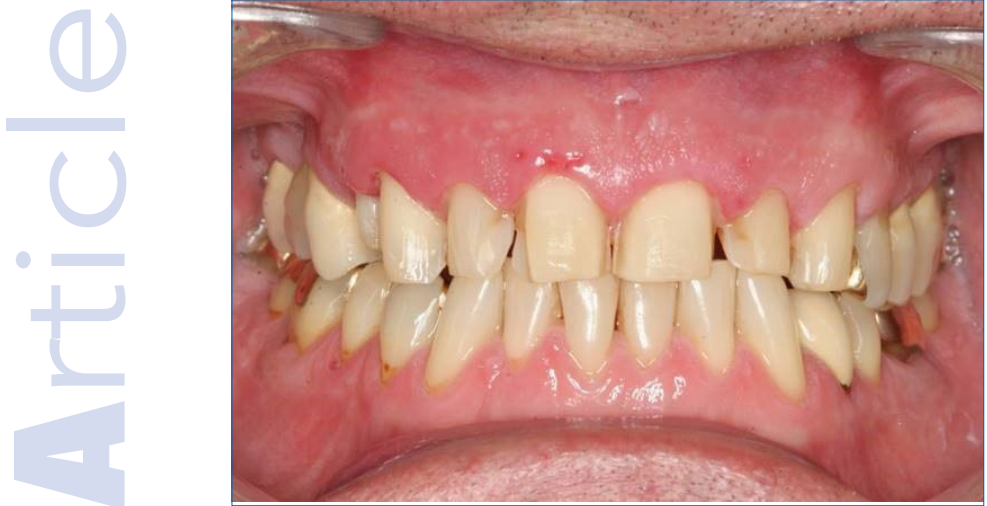

(a)

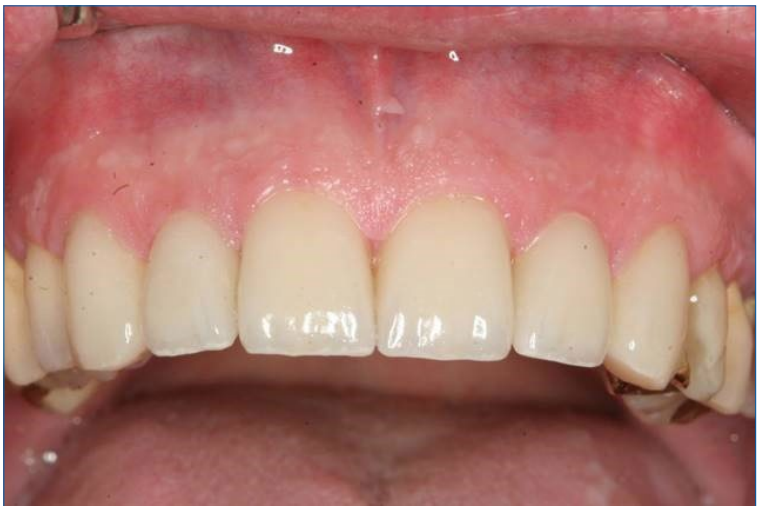

(b)

I Figure 5. Different preparations of the proximal area: (a) between 1.1 and 2.1 contact point was not resolved in order to save tooth structure; between 1.2 and 1.1 and between 2.1 and 2.2 the contact point was opened as a result of the tooth position of the lateral incisors; (b) final laminate veneer restorations.

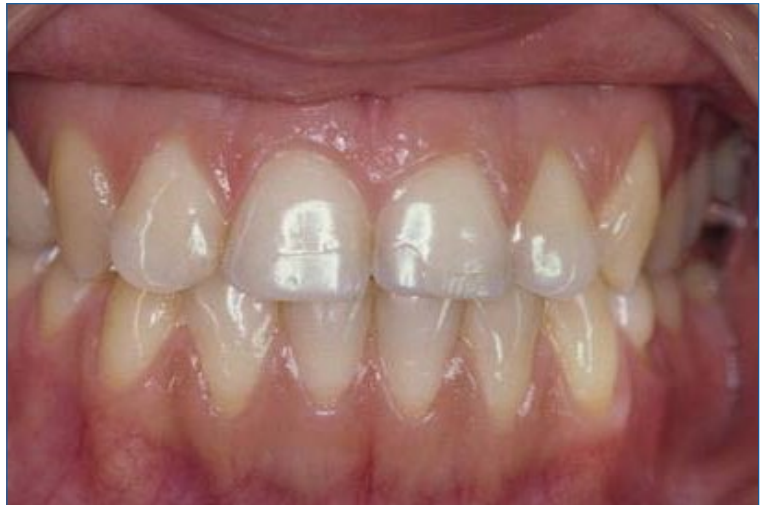

(a)

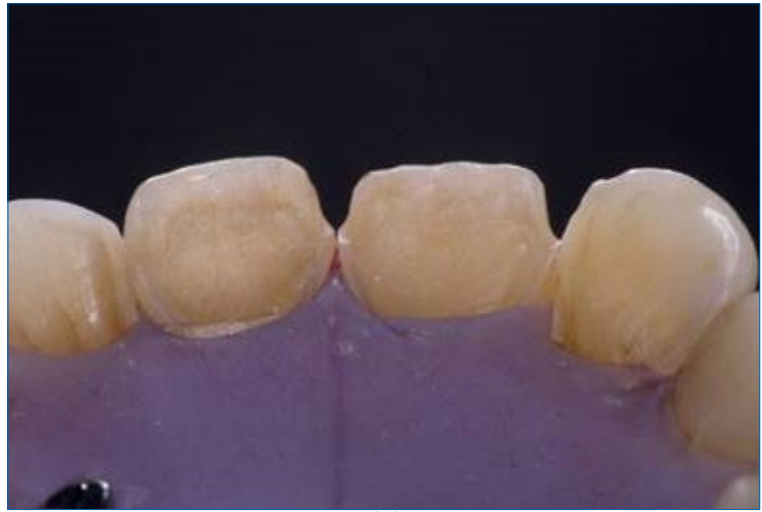

(c)

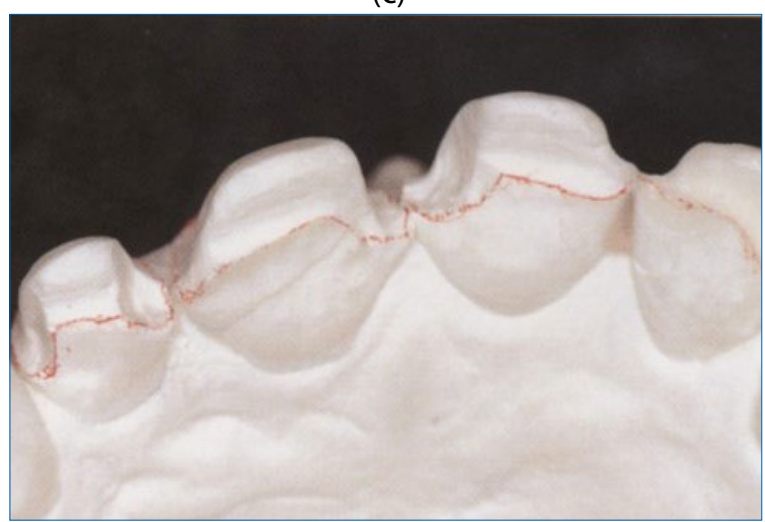

(e)

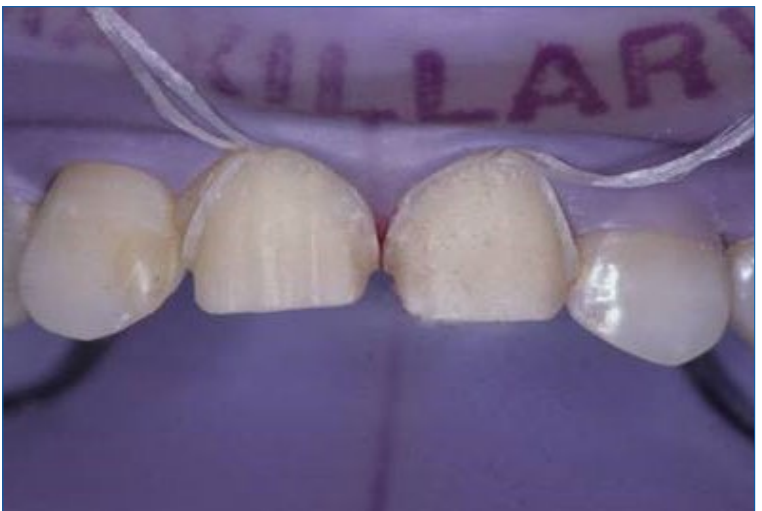

(b)

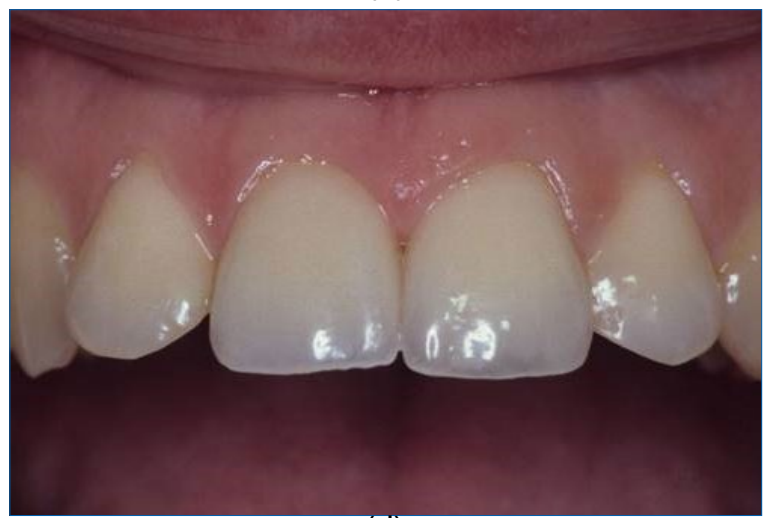

(d)

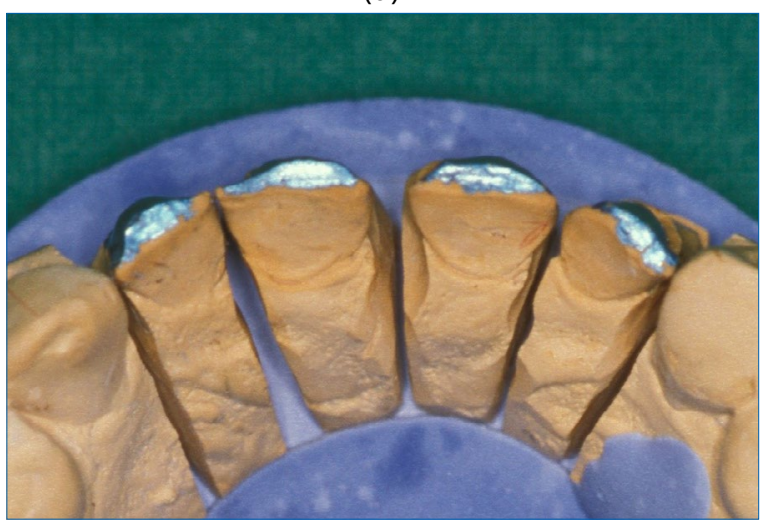

(f)

I Figure 6. Different preparations:(a): shoulder preparation with a palatinal chamfer before preparation; (b,c): preparations; (c,d): inserted veneers; (e): another case of a palatinal chamfer preparation; $(\mathrm{f})$ : or incisal reduction without a chamfer. 


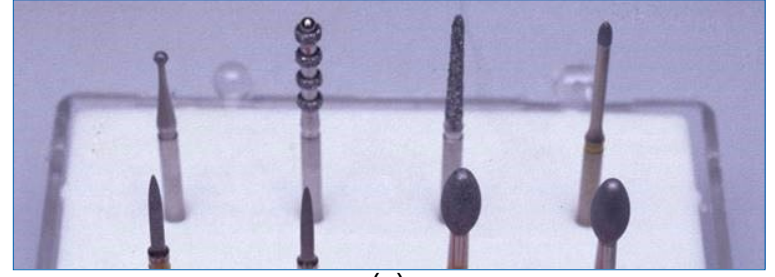

(a)

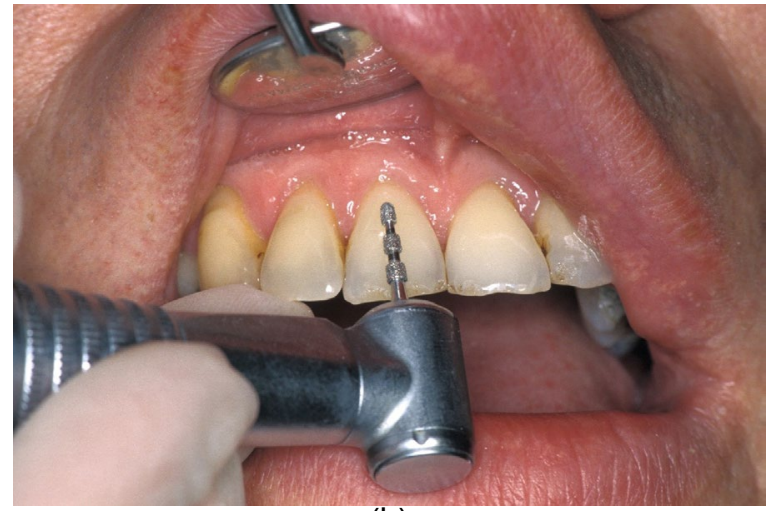

(b)

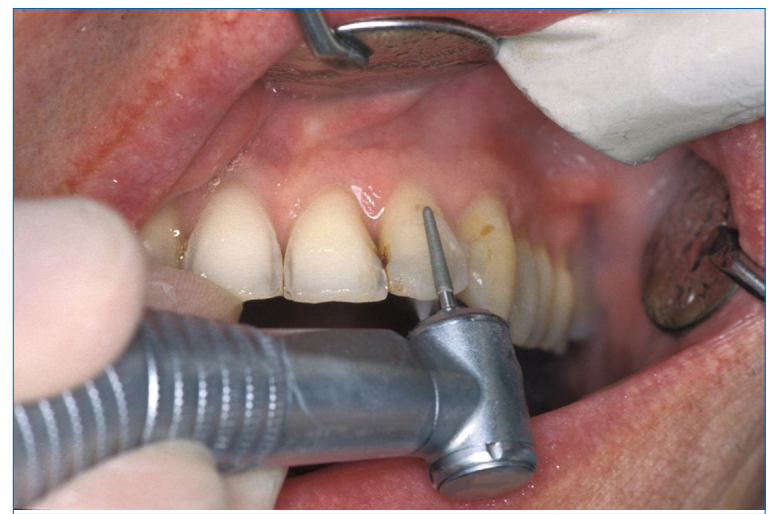

(c)

I Figure 7. Selected preparation instruments: (a): instrument kit; (b): Instrument for determination the preparation depth; (c): finishing the preparation to improve adhesion.

options for the esthetic design of the interproximal area and the closure of "black triangles [27]. Buccal preparation can be performed as a chamfer or as a shoulder/butt joint (Fig. 6). What is important is that the margin of the preparation is clearly visible/ detectable. Incisal overlapping of $2 \mathrm{~mm}$ with a palatinal chamfer preparation instead of a feathered incisal edge preparation are recommended by some authors $[26,36]$. According to a meta-analysis, a butt joint type preparation least affects the strength of the tooth and the chamfer preparation type is more susceptible to ceramic fractures [36].

\subsection{Existing composite restorations}

As has been lined out above, clinical studies indicated that the presence of composite resin restorations at the margins may influence the marginal quality [4]. However, data are inconclusive [4,5]. In an invitro study, the margins of luted veneers had the same morphological quality towards a composite resin restoration as compared to prepared enamel [37]. In any case, such fillings should be of optimal

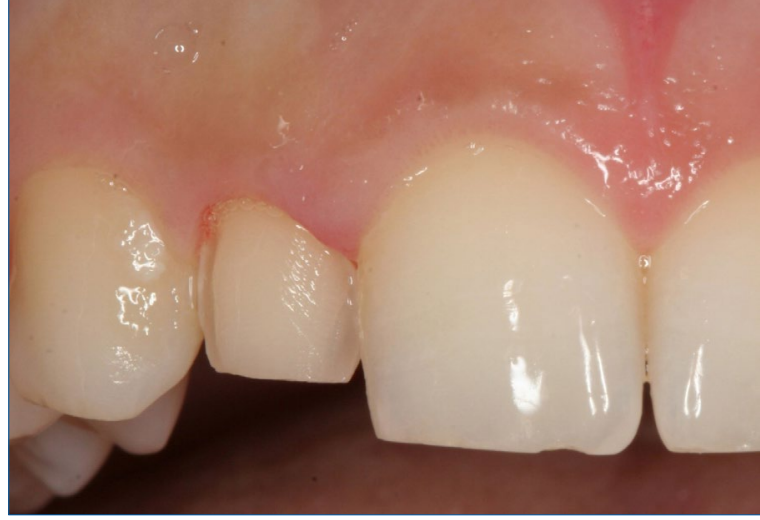

(a)

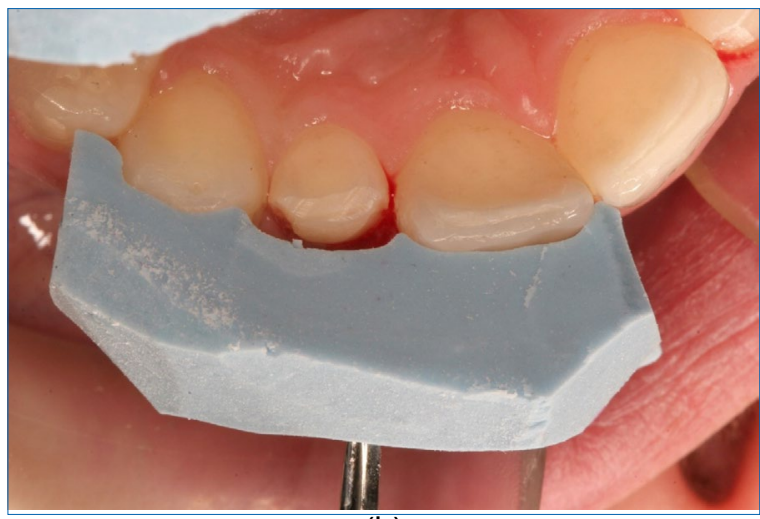

(b)

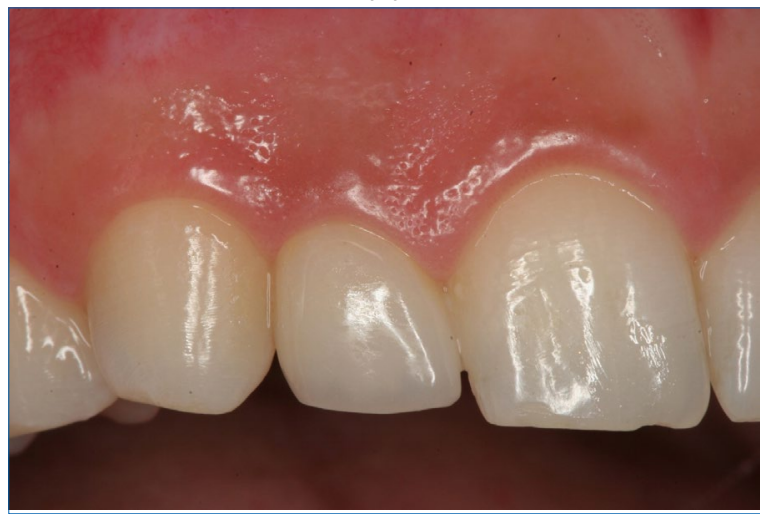

(c)

I Figure 8. Preparation for a laminate veneer on tooth 1.2 (a); ilicone index to control the preparation (b); final restoration (c).

quality and should be roughened. Some authors recommend acid etching to improve the cleaning effect and to roughen the exposed fillers [37].

\subsection{Preparation instruments/guides}

Special sets of preparation instruments are offered by industry (Fig. 7); A very helpful instrument is the one by which the maximum preparation depth can be defined. One way to control the preparation is to use a guide either made from orthodontic wire [38] or by an impression before the preparation (or from the mock up), which is reduced with a knife to the upper third of the tooth, which is being prepared (Fig. 8). Prepared tooth hard substance should be finished using a fine grid diamond (Fig. 7 c). From all information presented above on the preparation for laminate veneers it can be concluded that a preparation depth of $0.3-0.5$ $\mathrm{mm}$ iso- or slightly subgingival in the cervical area 


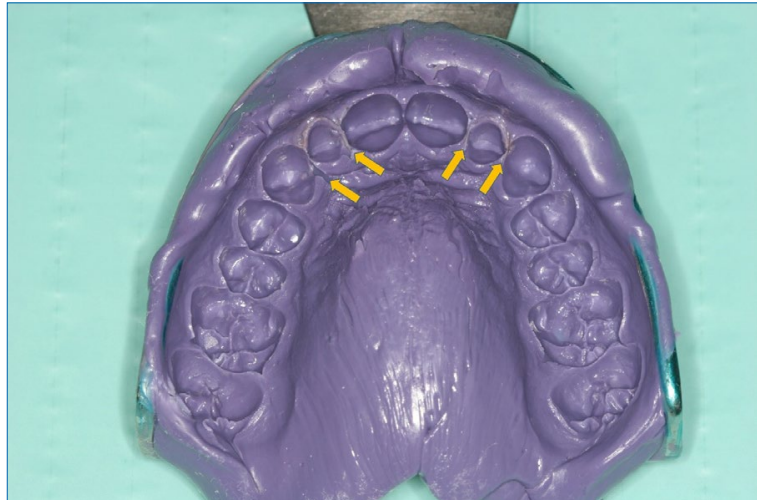

Figure 9. One-step impression for veneers on teeth 1.2 and 2.2 with foils separating contact points (arrows).

can be regarded as a general rule and thickness can vary from $0.3 \mathrm{~mm}$ in the cervical area to 1.5 or more in the incisal area; deviations are, however, possible and necessary in each individual case, e.g. due to tooth decay, extensive tooth discoloration or adjustment of alignment of teeth. Incisal coverage has a tendency to reduce longevity and here the patient situation (e.g. bruxism) should be taken into consideration and special measure like the application of a resin splint to be used as a night guard (see below) is highly recommended.

\section{Impression}

Basically, all routine impression techniques can be applied. However, especially if the contact points are not resolved, a one-step impression technique is advisable. It is helpful for the technician, if a small foil is placed in the contact point area during impression. Fig. 9 shows such an impression using a polyether impression material.

\section{Temporaries}

While temporaries for partial ceramic crowns for posterior teeth follow widely accepted techniques, temporaries for veneers in anterior teeth are challenging because generally little tooth substance has been removed. A classical method is that the teeth are prepared for veneers on a gypsum model and the dental technician produces such veneers according to the planned design/mock up. If more than one tooth has been prepared the temporaries are produced in one piece. They are then adjusted to the patient by relining with a flowable composite (Fig. 10). If more than one veneer is prepared, this relining will lead to a reasonable bond. If there are doubts, an adhesive can be used on a limited tooth area (spot etching). The use of a thermoforming sheet, which has been prepared on the mock up model and which is filled with a composite has also been recommended. However, meticulous occlusal adjustment in cases of incisal overlapping is necessary due to the thickness of the sheet material. Temporaries can be luted with non-eugenol

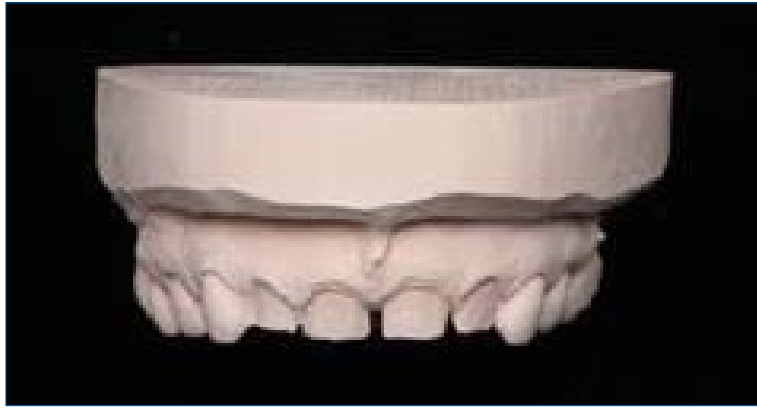

(a)

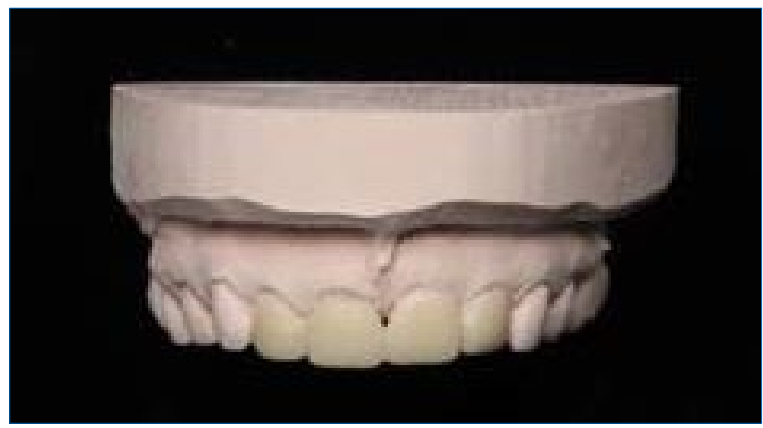

(b)

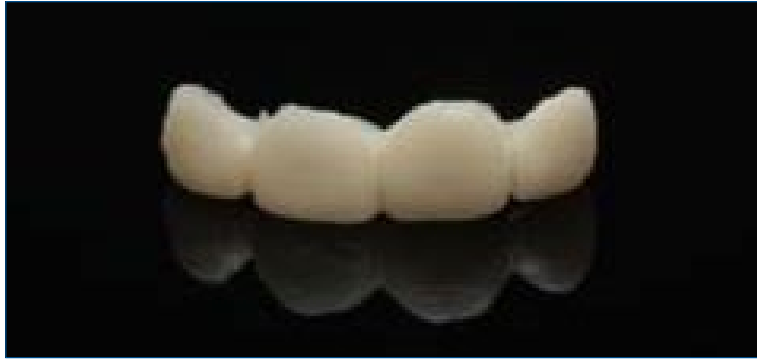

(c)

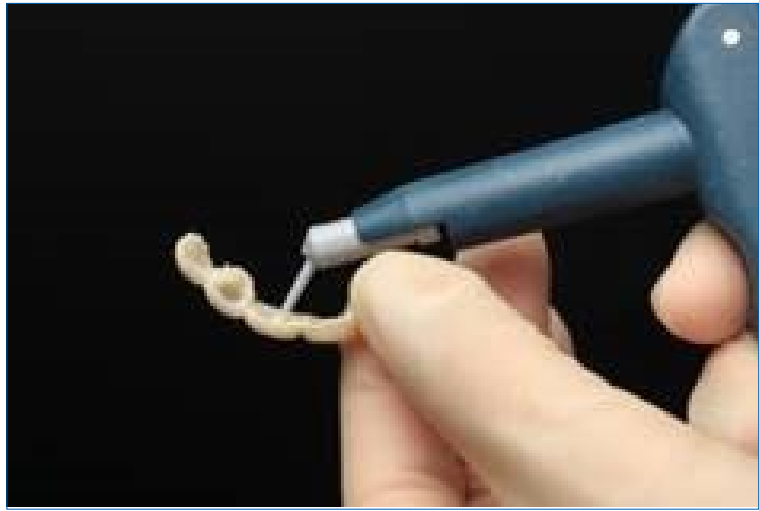

(d)

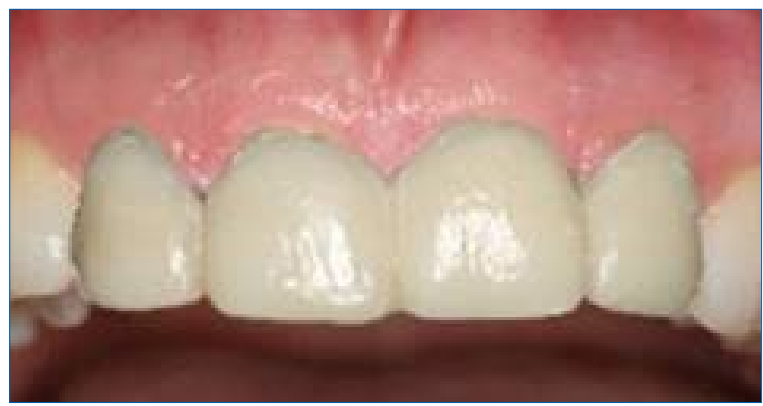

(e)

Figure 10. Temporaries: preparation on model (a); fabrication of temporaries on the model (b); temporaries polished (c); relining with a flowable composite (d); in situ (e). 
cements, whereas the postulated influence of eugenol upon the bond strength of adhesives is a matter of discussion [39]. Alternatively, water diluted polycarboxylate cement (Durelon) has been recommended.

\section{Which adhesive/ luting material? \\ 8.1. Adhesive technique}

Generally, laminate veneers must be luted using an adhesive technique and basically, the same materials and procedures can be used as for partial ceramic crowns in posterior teeth. However, there are some special points which have to be taken care of; optimal adhesion is of utmost importance as well as optimal and long-lasting esthetics. If the preparation is solely in the enamel, etch and rinse adhesives should be used, in other cases selective enamel etching using a universal dental adhesive (see below) is recommended.

\subsection{Dual curing or light curing only?}

For ceramic partial crowns in posterior teeth, generally dual curing luting composites are recommended [2].

However, especially for veneers, the use of purely light curing flowable composites was described, because a chemical initiating system used in the dual curing products was claimed to have a tendency for discoloration over time.

However, recently no difference was found in a clinical study related to color stability between a light cured resin composite and a dual curing luting material [40]. If veneers are luted with light curing only materials, the optimal quality of cure (polymerization) has to be guaranteed. In own in vitro studies on the curing of luting composites with and without chemical activation we could show that with highly transparent ceramics like leucite reinforced glass ceramics up to $2 \mathrm{~mm}$ ceramic thickness, composite luting materials can be sufficiently cured without additional chemical curing [17].

The time of light application should be at least twofold compared to the situation with an additional chemical activation. In a more recent in vitro study $1 \mathrm{~mm}$ thick specimens of a leucite reinforced glass ceramic and a lithium disilicate ceramic (slightly less translucent) were luted using composite resins with different shades with $1200 \mathrm{~mW} / \mathrm{cm}^{2}$ and an irradiation time of 20 seconds. The least opaque cements revealed the best mechanical data and there was no difference between the two ceramic materials [41].

In a clinical study, the delivery of laminate veneers using a direct restorative composite rather than a resin cement resulted in significantly less chipping and fractures, higher fracture strength in both accelerated fatigue and load-to-failure [42]. In a further clinical study with feldspathic laminate veneers over 7 years using a light cured composite resin for luting, a $90 \%$ retention rate was observed (patient as statistical unit) or $97.5 \%$ (veneer as statistical unit) [43].

Again, the irradiation time was doubled. Therefore, indeed this method can be recommended for luting veneers; the time of light application should, however, be doubled (see below).

\subsection{Universal adhesives}

Generally, it should be taken into account that the chemical activators of dual curing luting materials are acid-sensitive and that these luting materials should basically not be used together with self-etching adhesives. However, recently, new dental adhesives were marketed containing MDP as adhesive agent. These adhesives can be used together with an etchand-rinse, a self-etch and a selective etch approach. Details have been described in part I of this article [2]. They can also be used together with dual-curing luting materials. However, this is manufacturerspecific and the instructions for use must be carefully followed [2] and special dual cure activators may be required. For this group of newly introduced adhesives (Universal adhesives) positive results have been found in a clinical study for partial crowns in posterior teeth [44], but little data are reported so far for laminate veneers.

\subsection{Modification of color by luting material}

Basically, it is possible to use luting materials with different color and thus influence the color of the restoration (fine tuning). However, the potential of such a fine tuning is limited. If the color of the veneer does not match, the veneer should be corrected. Generally, a rather translucent luting material is recommended in order to optically link the veneer to the tooth structure. If it is attempted to fine-tune the color by the luting material, this must be checked before the actual luting step by using a try-in paste.

\subsection{Light curing}

Appropriate light curing is essential for the successful outcome of the treatment. General problems of light curing have been delineated in part I [2]. General recommendations for the delivered energy to the composite luting material vary between 16 and 25 $\mathrm{J} / \mathrm{cm}^{2}$.

As the translucency of the veneer/luting composite system is dependent on a large variety of factors [41], recommendations for a prolongation factor are associated with a certain degree of uncertainty.

However, in the literature prolongation factors of two to -three-fold are described, which would mean for a standard light curing unit with an irradiance of around $1000 \mathrm{~mW} / \mathrm{cm}^{2}$ an irradiation time of at least (!) 40 seconds. The light source must be placed directly on the ceramic. Recently, a number of dental material experts met in Oslo and worked on a consensus statement on 'Light Transmission Through Indirect Restorative Materials' and 'Bioactive 
Restorative Materials' [45].

Here are the most important facts:

$>$ There is an exponential decline in the amount of light that reaches the bottom of the restoration as its thickness increases;

$>$ to use the recommended adhesive - cement combinations, particularly when using self-etching universal adhesives together with dual-cure resin cements;

$>$ to recognize that resins that are solely light-cured must receive sufficient light, to check the thickness of the restoration, and to stay within the cement manufacturer's instructions for use;

$>$ to recognize that most "dual curing" resin materials benefit from receiving additional light exposure;

$>$ to recognize that doubling the exposure time will not compensate for the reduction in transmitted light if the thickness of the restorative material has doubled (e.g., from 1.0 to $2.0 \mathrm{~mm}$ ) [45].

\section{Step by Step laminate veneers checklist}

- Case selection/Prevention program: as has been lined out in part I for posterior teeth, also patients scheduled for laminate veneers must exercise an excellent oral hygiene because luting resins may enhance bacterial growth [46, 47]; smoking is discouraged as this increases marginal staining [9].

- Indication: e.g. cavities extending into large parts of the buccal surface and potentially needing replacement of the incisal edge, major esthetic problems related to color, shape, large size diastema or small corrections of dental malocclusions in the anterior part.

- Pretreatment: If teeth are heavily discolored; e.g. after endodontic treatment, bleaching of teeth (intracoronally or externally) is recommended well before the preparation for veneers (Fig. 1). As oxygen peroxide products are used for bleaching, clinicians should wait for at least 2 weeks after bleaching and before veneer treatment; during this time, residual oxygen, which may interfere with the resin setting reaction, can diffuse out of the tooth substances.

- Diagnostic wax up/mock-up: using composite resin, the effect of a veneer treatment can be simulated and the new size of the front teeth can be controlled together with the patient, e.g. concerning aesthetics and phonetics. An impression can be made and the technician can finalize the mock up and prepare a preparation guide.

- Check for existing restorations and replace if not optimal.

- Preparation: determine the preparation depths (e.g. $0.3-0.5 \mathrm{~mm}$ at the cervical buccal area) potentially using special preparation instruments (Fig. 7) and prepare the tooth preferably with a chamfer or a shoulder /butt joint. Use indexes made from mock-up models to control preparation (Fig. 8); use fine grid diamonds for finishing; for gingival retraction, use aluminum chloride chords.

- Impression: If contact points are not resolved, place thin foils at the contact point before (one phase) impression taking (Fig. 9).

- Final determination of the color and the shape of the veneers taking the color of the prepared tooth into consideration; this should preferably be done together with the technician in the dental practice.

- Temporaries: use individually prefabricated temporaries and fix them with a flowable composite resin (Fig. 10); alternatively, temporaries can be produced by filling a flowable composite into a splint, which has been produced on the mock-up model; or one can use an impression made from a mock-up model and fill it with an auto-polymerizing composite resin.

- Try-in of the restoration: remove all (!) remaining temporary cementation material from the tooth; cautiously adjust proximal contact points and occlusal surfaces avoiding any high pressure, because ceramic veneers are in this state highly prone to fractures. Use try-in pastes or petrolatum/glycerine in order to have optic connection between veneer and tooth, simulating the luting procedure and then control the color. Perfect color match must result from the veneer itself. Corrections of the color with the luting cement are generally not very efficient.

- Pretreatment of ceramic/tooth: Etching of ceramic, silanization and enamel/dentin pretreatment see part I [2].

- Luting composite: clean teeth thoroughly again, Ivoclean is a very useful substance; either dual curing cement or flowable composite can be used; in the latter case prolong the irradiation time as indicated by the manufacturer, as a rule of thumb two to three-fold compared to the situation without the ceramic veneer interposed. For the combination of self-etch/Universal adhesives and dual curing luting materials check with the manufacturer's instructions for use. If multiple veneers are to be luted (e.g. upper front), always lute two at a time, beginning with 1.1 and 2.1, then 1.2 and 2.2, etc. Coverage of the margins with glycerin gel before irradiation prevents the formation of a layer of low/non polymerized resins (oxygen inhibition layer).

- Resin splint: in order to protect laminate veneers - especially those with incisal coverage - against strong horizontal forces during bruxism during the night a resin splint (normally for the upper jaw) is recommended (Fig. 11).

\section{Authors contribution}

GS: Planning and writing the text. MF: Writing and proof reading the text.

\section{Acknowledgments}

No conflict of interest exists for any of the authors of the paper. 


\section{References}

1. Costa VLS, Tribst JPM, Uemura ES, et al. Influence of thickness and incisal extension of indirect veneers on the biomechanical behavior of maxillary canine teeth. Restor Dent Endod. 2018;43(4):e48.

[Free PMC Article][CrossRef] [PubMed] Google Scholar

2. Schmalz G, Federlin M. Partial Ceramic Crowns: Esthetic and Tissue Conservative Restorations - Part I: Posterior Teeth. Stoma Edu J. 2017;4(4):270-281.

3. Touati B, Miara P, Nathanson D. [Aesthetic Dentistry and Ceramic Restoration]. German edition: Schmalz G, Federlin M. München, Germany: Urban \& Fischer Verlag; 2001.

4. Gresnigt MM, KalkW, Ozcan M. Clinical longevity of ceramic laminate veneers bonded to teeth with and without existing composite restorations up to 40 months. Clin Oral Investig. 2013;17(3):823-832

[CrossRef][PubMed] Google Scholar Scopus

5. Peumans M, De Munck J, Fieuws S, et al. A prospective ten-year clinical trial of porcelain veneers. J Adhes Dent 2004;6(1):65-76.

[PubMed] Google Scholar Scopus

6. Chen JH, Shi CX, Wang M, Zhao SJ, Wang H. Clinical evaluation of 546 tetracycline-stained teeth treated with porcelain laminate veneers. J Dent. 2005;33(1):3-8. [CrossRef] [PubMed] Google Scholar Scopus

7. Guess PC, Selz CF, Voulgarakis A, et al. Prospective clinica study of press-ceramic overlap and full veneer restorations: 7-year results. Int J Prosthodont. 2014;27(4):355-358. [CrossRef] [PubMed] Google Scholar Scopus

8. Aristidis GA, Dimitra B. Five-year clinical performance of porcelain laminate veneers. Quintessence Int. 2002;33(3):185189.

$$
\text { [PubMed] Google Scholar Scopus }
$$

9. Beier US, Kapferer I, Burtscher D, Dumfahrt $\mathrm{H}$. Clinical performance of porcelain laminate veneers for up to 20 years. Int J Prosthodont. 2012;25(1):79-85. [PubMed] Google Scholar Scopus

10. Gurel G, Morimoto S, Calamita MA, et al. Clinical performance of porcelain laminate veneers: outcomes of the aesthetic pre-evaluative temporary (APT) technique. Int J Periodontics Restorative Dent. 2012;32(6):625-635 [PubMed] Google Scholar

11. Morimoto S, Albanesi RB, Sesma N, et al. Main Clinical Outcomes of Feldspathic Porcelain and Glass-Ceramic Laminate Veneers: A Systematic Review and Meta-Analysis of Survival and Complication Rates. Int J Prosthodont. 2016;29(1):38-49.

[CrossRef] [PubMed] Google Scholar Scopus

12. Pjetursson BE, Sailer I, Zwahlen M, Hammerle CH. A systematic review of the survival and complication rates of all-ceramic and metal-ceramic reconstructions after an observation period of at least 3 years. Part I: Single crowns. Clin Oral Implants Res. 2007;18 Suppl 3:73-85. [CrossRef] [PubMed] Google Scholar Scopus

13. Valenti M, Valenti A. Retrospective survival analysis of 261 lithium disilicate crowns in a private general practice. Quintessence Int. 2009:40(7):573-579.

[Full text links] [PubMed] Google Scholar Scopus

14. Gehrt M, Wolfart S, Rafai N, et al. Clinical results of lithiumdisilicate crowns after up to 9 years of service. Clin Oral Investig. 2013;17(1):275-284

[CrossRef] [PubMed] Google Scholar Scopus

15. Lawson NC, Burgess JO. Dental ceramics: a current review. Compend Contin Educ Dent. 2014;35(3):161-166; quiz 8 [PubMed] Google Scholar Scopus

16. Al Ben Ali A, Kang K, Finkelman MD, et al. The effect of variations in translucency and background on color differences in CAD/CAM lithium disilicate glass ceramics. J Prosthodont. 2014;23(3):213-220. [CrossRef] [PubMed] Google Scholar Scopus

17. Koch A, Kroeger M, Hartung M, et al. Influence of ceramic translucency on curing efficacy of different light-curing units. J Adhes Dent. 2007;9(5):449-462. [PubMed] Google Scholar Scopus

18. Kassardjian V, Varma S, Andiappan M, et al. A systematic review and meta analysis of the longevity of anterior and posterior all-ceramic crowns. J Dent. 2016;55:1-6. [CrossRef] [PubMed] Google Scholar Scopus

19. Manicone PF, Rossi lommetti P, Raffaelli L. An overview of zirconia ceramics: basic properties and clinical applications. $J$ Dent. 2007;35(11):819-826.

[CrossRef] [PubMed] Google Scholar Scopus

20. Magne P, Belser UC. Novel porcelain laminate preparation approach driven by a diagnostic mock-up. J Esthet Restor Dent. 2004;16(1):7-16; discussion 7-8.

[Full text links] [PubMed] Google Scholar Scopus

21. Ge C, Green CC, Sederstrom D, et al. Effect of porcelain and enamel thickness on porcelain veneer failure loads in vitro.
The Journal of prosthetic dentistry. 2014;111(5):380-387.

[CrossRef] [PubMed] Google Scholar Scopus

22. Stappert CF, Ozden U, Gerds T, Strub JR. Longevity and failure load of ceramic veneers with different preparation designs after exposure to masticatory simulation. The Journal of prosthetic dentistry. 2005;94(2):132-139.

[CrossRef] [PubMed] Google Scholar Scopus

23. Magne P, Versluis A, Douglas WH. Rationalization of incisor shape: experimental-numerical analysis. J Prosthet Dent. 1999;81(3):345-355

[Full text links] [PubMed] Google Scholar Scopus

24. Magne P, Douglas WH. Design optimization and evolution of bonded ceramics for the anterior dentition: a finite-element analysis. Quintessence Int. 1999;30(10):661-672. [PubMed] Google Scholar Scopus

25. Tugcu E, Vanlioglu B, Ozkan YK, Aslan YU. Marginal Adaptation and Fracture Resistance of Lithium Disilicate Laminate Veneers on Teeth with Different Preparation Depths. Int J Periodontics Restorative Dent. 2018;38(Suppl):s87-s95.

[Crossref] [PubMed] Google Scholar Scopus

26. Cotert HS, Dundar M, Ozturk B. The effect of various preparation designs on the survival of porcelain laminate veneers. J Adhes Dent. 2009;11(5):405-411.

[PubMed] Google Scholar Scopus

27. Edelhoff D, Prandtner O, Saeidi Pour R et al. Anterior restorations: The performance of ceramic veneers. Quintessence Int. 2018;49(2):89-101.

[Full text links] [PubMed] Google Scholar Scopus

28. Dietschi D. Prefabricated Veneers - An established technique is revisited with new technologies. Inside Dentistry. 2012;8(9):https://www.aegisdentalnetwork.com/id/2012/09/ prefabricated-veneers.

29. Ozturk E, Bolay S, Hickel R, Ilie N. Shear bond strength of porcelain laminate veneers to enamel, dentine and enameldentine complex bonded with different adhesive luting systems. J Dent. 2013;41(2):97-105. [CrossRef] [PubMed] Google Scholar Scopus

30. Burke FJ. Survival rates for porcelain laminate veneers with special reference to the effect of preparation in dentin: $a$ literature review. J Esthet Restor Dent. 2012;24(4):257-265. [CrossRef] [PubMed] Google Scholar Scopus

31. Christgau M, Friedl KH, Schmalz G, Resch U. Margina adaptation of heat-pressed glass-ceramic veneers to dentin in vitro. Oper Dent. 1999;24(3):137-146. [PubMed] Google Scholar Scopus

32. Chaiyabutr Y, Phillips KM, Ma PS, Chitswe K. Comparison of load-fatigue testing of ceramic veneers with two different preparation designs. Int J Prosthodont. 2009;22(6):573-575. [PubMed] Google Scholar Scopus

33. Albanesi RB, Pigozzo MN, Sesma N, et al. Incisal coverage or not in ceramic laminate veneers: A systematic review and meta-analysis. J Dent. 2016;52:1-7. [CrossRef] [PubMed] Google Scholar Scopus

34. Hong N, Yang H, Li J, et al. Effect of Preparation Designs on the Prognosis of Porcelain Laminate Veneers: A Systematic Review and Meta-Analysis. Oper Dent. 2017:42(6):E197-E213. [CrossRef] [PubMed] Google Scholar Scopus

35. Stappert CF, Ozden U, Att W, et al. Marginal accuracy of press-ceramic veneers influenced by preparation design and fatigue. Am J Dent. 2007;20(6):380-384. [PubMed] Google Scholar Scopus

36. da Costa DC, Coutinho M, de Sousa AS, Ennes JP. A metaanalysis of the most indicated preparation design for porcelain laminate veneers. J Adhes Dent. 2013;15(3):215-220. [Full text links] [PubMed] Google Scholar Scopus

37. Christgau M, Friedl KH, Schmalz G, Edelmann K. Marginal adaptation of heat-pressed glass-ceramic veneers to Class 3 composite restorations in vitro. Oper Dent. 1999;24(4):233-244. [PubMed] Google Scholar Scopus

38. Cho SH, Nagy WW. Labial reduction guide for laminate veneer preparation. The Journal of prosthetic dentistry. 2015;114(4):490-492.

[CrossRef] [PubMed] Google Scholar Scopus

39. Abo-Hamar SE, Federlin M, Hiller KA, et al. Effect of temporary cements on the bond strength of ceramic luted to dentin. Dent Mater. 2005:21(9):794-803.

[CrossRef] [PubMed] Google Scholar Scopus

40. Marchionatti AME, Wandscher VF, May MM et al. Color stability of ceramic laminate veneers cemented with light-polymerizing and dual-polymerizing luting agent: A split-mouth randomized clinical trial. J Prosthet Dent. 2017;118(5):604-610. [CrossRef] [PubMed] Google Scholar Scopus

41. Ozturk $E$, Chiang YC, Cosgun E et al. Effect of resin shades on opacity of ceramic veneers and polymerization efficiency through ceramics. J Dent. 2013;41 Suppl 5:e8-14. [CrossRef] [PubMed] Google Scholar Scopus

42. Gresnigt MMM, Ozcan M, Carvalho $M$ et al. Effect of luting agent on the load to failure and accelerated-fatigue 
resistance of lithium disilicate laminate veneers. Dent Mater. 2017;33(12):1392-1401.

[CrossRef] [PubMed] Google Scholar Scopus

43. D'Arcangelo C, De Angelis F, Vadini M, D'Amario M. Clinical evaluation on porcelain laminate veneers bonded with light-cured composite: results up to 7 years. Clin Oral Investig. 2012;16(4):1071-1079.

[CrossRef] [PubMed] Google Scholar Scopus

44. VogI V, Hiller KA, Buchalla W, et al. Controlled, prospective, randomized, clinical split-mouth evaluation of partial ceramic crowns luted with a new, universal adhesive system resin cement: results after 18 months. Clin Oral Investig. 2016;20(9):2481-2492.

[CrossRef] [PubMed] Google Scholar Scopus

45. Price RB, Roulet JF. The value of consensus conferences: peer review by 50 key opinion leaders! Stoma Edu J. 2018;5(4):202204.
46. Auschill TM, Arweiler NB, Brecx M, et al. The effect of dental restorative materials on dental biofilm. Eur J Oral SCi. 2002;110(1):48-53.

[Full text links] [PubMed] Google Scholar Scopus

47. Hansel C, Leyhausen G, Mai UE, Geurtsen W. Effects of various resin composite (co)monomers and extracts on two caries-associated micro-organisms in vitro. J Dent Res. 1998;77(1):60-67

[CrossRef] [PubMed] Google Scholar Scopus

\section{Gottfried SCHMALZ}

DMD, PhD, Professor Dr, Dr hc Department of Operative Dentistry and Periodontology Medicine Faculty, University Hospital Regensburg

Regensburg, Germany

Gottfried Schmalz, DDS, Dr med dent, PhD, is the former chair and current professor at the Department of Operative Dentistry and Periodontology, University of Regensburg, Germany. He is a member of many scientific organizations and has won numerous awards, e.g. the Distinguished Scientist Award of the IADR and the Award of Excellence of the European Federation for Conservative Dentistry. He is the editor of the book 'Biocompatibility of Dental Materials'; he has authored 5 books and more than 260 publications listed in PubMed.

He has been Editor-in-Chief of "Clinical Oral Investigations", since 1996 and Honorary Editor since 2016. Since 2016 he is chairman of ISO (International Organization of Standardization) Technical Committee 106: Dentistry.

His main scientific interests are material/tissue interactions, oral tissue regeneration and ceramic restorations.

\section{Orestions}

\section{Which is the most important factor for reduced longevity of laminate veneers?}

a. Extensive bruxism;

b. Patients older than 60 years;

ac. Teeth with endodontic pretreatment;

ad. Smoking.

\section{When is an incisal coverage for a veneer preparation recommended?}

$\square$ a. For patients with insufficient oral hygiene;

ab. For smokers;

$\square c$. For aesthetic reasons;

$\square$ d. In young patients (younger than 20 years).

\section{Preparation depth for laminate veneers is determined by}

口a. Patients 'demands;

b. Presence of composite restorations;

ac. Size of defect, tooth discoloration and adjustment of teeth alignment;

$\square d$. Size of the tooth.

\section{Luting of ceramic veneers can be done using}

$\square$ a. Always light curing only composite resins;

b. Light curing only composite resins together with a transparent ceramics up to $1 \mathrm{~mm}$ thickness;

$\square c$. Generally self etch adhesives with dual curing composite luting materials;

d. Light curing only composite resins together with transparent ceramics of up to $0.3 \mathrm{~mm}$ thickness. 


\author{
Matej Par $^{1 \mathbf{1}^{*}(1)}$,Zrinka Tarle ${ }^{1 \mathbf{b}^{*}(1)}$
}

'Department of Endodontics and Restorative Dentistry, School of Dental Medicine, University of Zagreb, Zagreb, Croatia

'DMD, PhD, Postdoctoral Researcher

bDMD, PhD, Professor, Dean

DOI: https://doi.org/10.25241/stomaeduj.2019.6(1).art.7

Background: Various oral stimuli that are perceived by the brain as stressful can trigger patterns of neurological activity which then directly influence immune and endocrine response.

Objective: To analyze the psycho-neuro-endocrine-immunological interactions involved in oral diseases and conditions.

Data sources: Web of Science, PubMed, Google Scholar were databases researched for peer review articles in indexed journals.

Study selection: A literature search limited to peer-reviewed articles in indexed journals published before January 2019 was performed using specific keywords. 107 articles were selected.

Data extraction: The aspects related to psycho-neuro-immune interactions relevant for dental practitioners were synthesized and presented in the form of narrative review. Oral diseases and conditions in which psychological factors act through neurological, endocrine and immunological mechanisms are discussed. The following clinical entities were included: periodontitis, oral lichen planus, recurrent aphthous stomatitis, temporomandibular disorders, herpes labialis, burning mouth syndrome, and atypical odontalgia. Additionally, the role of psycho-neuro-immunological factors on bacterial adherence and oral microbiome is briefly discussed.

Data synthesis: Various oral diseases and conditions of multifactorial etiology can be influenced by psycho-neuro-immunological interactions. In daily practice, clinicians should be aware of the interplay between mental and general health and consider addressing psychological disturbances as a supplement for conventional treatment modalities. Recognizing these interactions should help to better understand the relationship between mental and physical health.

Keywords: Periodontitis; Lichen planus, oral; Stomatitis, aphthous; Temporomandibular joint disorders; Herpes labialis.

\begin{tabular}{|c|}
\hline $\begin{array}{l}\text { OPEN ACCESS This } \\
\text { is an 0pen Access article } \\
\text { under the CC BY-NC } 4.0 \\
\text { license. }\end{array}$ \\
\hline $\begin{array}{l}f_{\text {Article }}^{\text {Peer-Reviewed }} \\
\text { Aris }\end{array}$ \\
\hline $\begin{array}{l}\text { Citation: Par M, Tarle Z. } \\
\text { Psychoneuro-immunology of } \\
\text { oral diseases - a review. } \\
\text { Stoma Edu J. 2019;6(1):55-65 }\end{array}$ \\
\hline $\begin{array}{l}\text { Received: March 14, } 2019 \\
\text { Revised: March 21, } 2019 \\
\text { Accepted: March 27, } 2019 \\
\text { Published: March 28, } 2019\end{array}$ \\
\hline $\begin{array}{l}\text { *Corresponding author: } \\
\text { Dr. Matej Par, DMD, PhD } \\
\text { Gunduliceva 5, Department of } \\
\text { Endodontics and Restorative } \\
\text { Dentistry, School of Dental } \\
\text { Medicine, University of Zagreb, } \\
\text { Zagreb, Croatia } \\
\text { Tel.: + } 3851 \text { 480 2203, Fax: } \\
\text { +3851 4802 203, e-mail: } \\
\text { mpar@inet.hr }\end{array}$ \\
\hline $\begin{array}{l}\text { Copyright: } \odot 2019 \text { the } \\
\text { Editorial Council for the } \\
\text { Stomatology Edu Journal. }\end{array}$ \\
\hline
\end{tabular}

\section{Introduction}

Psychoneuroimmunology is an interdisciplinary field which represents the convergence of psychology, neuroscience, endocrinology, and immunology. Various stimuli that are perceived by the brain as stressful can trigger patterns of neurological activity which then directly influence immune and endocrine response. Since many cells of the nervous, immune, and endocrine systems share common signaling pathways, these systems do not act as isolated functional units, but instead interact with each other to yield an integrated response. By recognizing these interactions, psychoneuroimmunology helps to better understand the relationship between mental and physical health. The idea of the interplay between psychological factors and physical health is not new - its origins can be traced back to Galen, who in the year 200 presented the observation that melancholic women are more susceptible to breast cancer than sanguine women [1]. Almost two millennia later, contemporary studies have collected a great deal of experimental data and clinical evidence which support the hypothesis that stress-induced immunosuppression, stressinduced inflammation, and various subtle changes in the regulation of the endocrine and immune system caused by psychological factors can modify the course of different diseases. This review is focused on the diseases affected by psycho-neuroimmunological factors which occur in the oral cavity.

\section{Methodology}

A literature search limited to peer-reviewed articles in indexed journals published before January 2019 (1983-2018) which were identified by searching the Web of Science, PubMed (Medline) and Google Scholar using the following keywords: (psychoneuroimmunology OR psychological OR psychiatric OR mental health OR stress OR depression OR cortisol OR hypothalamic-pituitary-adrenal) AND (oral OR dental OR dentistry OR periodontitis OR oral lichen planus $O R$ recurrent aphthous stomatitis OR temporomandibular disorders OR herpes OR burning mouth syndrome OR atypical odontalgia OR eating disorders OR microbiome). The aspects 
Table 1. Systematic division of the cited articles according to the discussed topics.

\begin{tabular}{lc}
\hline Topic & Reference No. \\
\hline Periodontitis & $2-40$ \\
Oral lichen planus & $41-54$ \\
Recurrent aphthous stomatitis & $55-62$ \\
Temporomandibular disorders & $63-82$ \\
Herpes labialis & $83-87$ \\
Burning mouth syndrome & 88,89 \\
Atypical odontalgia & 90 \\
Eating disorders & $91-97$ \\
Oral microbiome & $4,98-107$ \\
\hline
\end{tabular}

of psycho-neuro-immune interactions relevant for dental practitioners were synthesized and presented in the form of a narrative review.

\section{Results}

Oral diseases and conditions in which psychological factors act through neurological, endocrine and immunological mechanisms are discussed. The following clinical entities were included: periodontitis, oral lichen planus, recurrent aphthous stomatitis, temporomandibular disorders, herpes labialis, burning mouth syndrome, and atypical odontalgia. Additionally, the role of psycho-neuroimmunological factors on bacterial adherence and oral microbiome is briefly discussed. The systematic division of referenced articles regarding individual topics is presented in Table 1.

\subsection{Periodontitis}

Periodontitis is an inflammatory disease which progressively damages periodontal tissues, eventually leading to tooth loss. Although periodontitis is clearly associated with the presence of certain microbial species, it cannot be regarded as a classical infective disease because the damage to periodontal tissues results from an inappropriate inflammatory reaction and not from the destructive action of the microbes alone [2]. The pathophysiology of periodontitis is thus related to a complex interplay between the microbial challenge and host immune response [3], while the differences in immunological reactivity and susceptibility to periodontal destruction between individual persons are determined genetically. These differences explain why the presence of a certain microbial community can cause an aggressive disease in some individuals, whereas in others the same microbial species may not trigger any destructive reaction. Additionally, it is still unclear whether the bacterial strains found in active periodontal pockets truly initiate the disease or these strains simply prefer the new environment created by pocket formation and active inflammation, without an active role in its initiation and perpetuation [4]. The effect of periodontitis on systemic health has been extensively studied and many connections with illnesses of remote organs have been hypothesized [5, 6]. Many of these connections have also been supported by evidence, although to varying extents. Rather compelling evidence exists for the association of periodontitis with cardiovascular disease [7] and diabetes mellitus [8]. Obstetric complications, respiratory diseases, chronic kidney disease, and cancer have also been linked to periodontitis [9-12]. Two major mechanisms of systemic action involve (I) invasion of periodontal pockets bacteria, leading to bacteremia and dissemination of living bacteria or products of their decomposition; and (II) excessive production of long-range pro-inflammatory cytokines, resulting in their elevated systemic levels. The latter mechanism clearly represents an immuno-endocrine response, while the former mechanism is also immunologicallymediated since the presence of bacterial antigens in the bloodstream causes a cross-reactive immunological response which then leads to the destruction of host tissues [5]. The relationship between periodontitis and systemic health is often bidirectional: a complex immuno-endocrine response initiated by the microbiome in periodontal pockets modulates various systemic conditions, while the impaired systemic health, in turn, affects the progress of periodontal disease. For example, elevated levels of pro-inflammatory cytokines due to periodontitis can increase insulin resistance, while the resulting hyperglycemia and formation of glycosylation end products enhance the destructive potential of periodontitis [13]. Without going further into detailed descriptions of the pathophysiology of periodontitis and the related systemic conditions, it is evident that many of the interactions stem from the underlying dysregulation of the immune system and can be affected by psycho-neurological factors. Although the psycho-neurological influence on the complex interactions between periodontitis and systemic diseases currently remain unexplored, the psycho-neurological aspects of periodontitis itself have been well documented. Clinical observations and epidemiological studies have indicated that stress [14], depression [15], and inadequate coping behaviors [16] are related to the onset and progression of periodontitis. Psychological factors have long been known to present a risk factor for acute necrotizing ulcerative gingivitis and periodontitis - these aggressive forms were the first to be related to psychological factors about 50 years ago [17-20]. A systematic review from the year 2013 analyzed 14 studies and showed that 8 studies identified a positive relation between psychosocial factors and periodontitis, 4 studies identified a positive relation between some characteristics of psychological factors and periodontal disease, whereas only 2 studies were unable to identify any 
relation [19]. Contrary to early beliefs that stress response mediated through catecholamines and cortisol is primarily immunosuppressive, the immune system may be affected by psychological stress in both directions. This happens because the individual cell or tissue reaction to elevated levels of stress hormones depends on the presence or absence of particular receptors [21]. Short-term stress appears to suppress cellular immunity, whereas chronic stress leads to a more comprehensive dysregulation of the immune system, affecting both cellular and humoral immunity [15]. Psychological status was found to correlate with salivary levels of cortisol and $\beta$-endorphin, which were in turn identified as determinants for tooth loss due to periodontal disease [22]. Depression has also been associated with increased risk and severity of periodontitis. Various psychometric factors, such as depression and anxiety scores, subjective well-being, somatic complaints, quality of life, and introversion have been correlated with periodontitis [23]. Traumatic life events such as the loss of a spouse, as well as the personality trait of exercising extreme external control were shown to increase the risk for severe periodontitis [24]. Stress-related depression and exhaustion have been associated with increased levels of cortisol and IL- 6 in the gingival crevicular fluid, as well as higher levels of gingival inflammation and plaque accumulation [25]. Women on long-term sick leave for depression had more severe periodontitis and elevated levels of IL- 6 in gingival crevicular fluid compared to healthy controls [26]. Patients with rapidly progressing periodontitis presented significantly higher depression and loneliness scores compared to patients with chronic adult periodontitis and healthy controls [27]. Depression was associated with a more extensive periodontal breakdown [28]. Psychosocial measures of stress and depression associated with financial strain were shown to be significant risk indicators for severity of periodontitis in adults [16]. The effectiveness of coping behavior has also been identified as a modulating factor for periodontitis in patients exposed to psychological stress. Adequate coping behaviors, such as problem-based coping were shown to reduce the stress-associated risk [16]. Conversely, patients with inadequate coping techniques (passive coping) were shown to be at greater risk for severe periodontitis [29]. Ineffective coping was also associated with poorer responses to nonsurgical periodontal treatment, whereas patients with active coping had less severe forms of disease and better treatment outcomes [30]. Although psychological factors have been identified as risk factors for periodontitis in multiple studies, rigorous analyses highlight the issue of heterogeneity of study designs, methodology and assessment criteria, thus claiming that it is not yet possible to regard psychological stress as a definitive risk factor [19,21].
In any case, a relation between psychological factors and periodontal health has been repeatedly observed. In studies on the relation between stress and periodontitis, it is generally difficult to distinguish between the contribution of stressrelated behavioral factors (poor oral hygiene, poor nutrition, smoking, and generally neglected health) from exclusively psychoneuroimmunological stressrelated factors which directly affect the progress of the disease, without a behavioral intermediary [15]. The psycho-neuro-immunological mechanism is evidenced by the role of cortisol and other stressrelated hormones. In an experimentally induced periodontitis in rats which had genetically different responsiveness of the hypothalamic-pituitaryadrenal axis, the high-responding rats developed more severe periodontal disease. Additionally, they showed elevated corticosterone blood levels due to a local inflammatory response induced by experimentally enhancing the accumulation of subgingival microbiome, indicating a positive feedback loop between the hypothalamic-pituitaryadrenal axis activation and local periodontal inflammation [31]. In a rat model of depression induced by olfactory bulbectomy, the role of psychoneuro-endocrine factors has been demonstrated by a decreased expression of glucocorticoid receptors in the hippocampus, different response to injected lipopolysaccharide and more extensive periodontal bone loss in depressive animals [32]. The association between cortisol and periodontitis has also been observed in humans; patients undergoing stressful life events had higher cortisol levels and more severe periodontitis [33]. Other studies have confirmed that hyperactivation of the hypothalamic-pituitaryadrenal axis and the resulting increase in cortisol level was positively related to the extent and severity of periodontitis [34]. Psychological stress, depression, and salivary cortisol levels were found to be positively correlated with the extent of periodontal destruction, independent of the level of oral hygiene [35]. In addition to cortisol, levels of another stressrelated hormone whose secretion is regulated by corticotrophin, dehydroepiandrosterone, were also related to the extent and severity of periodontitis, adding to the evidence for the role of hypothalamicpituitary-adrenal axis hyperactivation in the pathogenesis of periodontitis [36]. The outcome of periodontal treatment can be negatively affected by stressful life events [37], occupational stress [38], and clinical depression [39], indicating that psychoneuro-immunological factors play a role in wound healing and recovery following an invasive treatment. From a clinical standpoint, these findings indicate that routine periodontal treatments may benefit from an adjunctive stress-management therapy which would comprise the assessment of patient's stress levels and their ability to cope with stress, followed by implementation of stress- 
reduction protocols [40]. Similarly, addressing depression in patients with periodontitis may help to alleviate the course of periodontitis through immunologic and behavioral changes conducive of periodontal healing [35].

\subsection{Oral lichen planus}

Oral lichen planus is a chronic inflammatory disorder which clinically manifests on the oral mucosa as multiple bilateral papular, reticular, erythematous, and erosive lesions. Besides the significant negative effect on the quality of life due to its chronic course, oral lichen planus lesions have a potential for malignant transformation at an overall frequency of $0.3-3 \%$ [41]. Although the etiology of oral lichen planus is unclear, the underlying pathophysiology has been known to involve a dysregulated T-cell immune response to an induced antigenic change in the oral mucosa. The hypothesized etiologic factors which have the potential to induce that antigenic change include dental amalgam, non-steroid antiinflammatory drugs, and hepatitis C virus [41].

The association of oral lichen planus with psychological stress has generally been acknowledged and reported in multiple studies [42-45]; however, the causal relationship is less clear since chronic discomfort due to persistent lesions may itself act as a stressing factor [46]. An interesting approach for evaluating a possible etiological role of psychosocial stressors on oral lichen planus was employed in a double-controlled study which involved healthy individuals as a negative control and patients with burning mouth syndrome, atypical facial pain, and myofascial pain dysfunction syndrome as a positive control [45]. That study found significantly higher stress, anxiety, and depression levels in oral lichen planus patients and positive control compared to the general population, whereas no significant differences were found between the oral lichen planus patients and the positive control group. These results have led the investigators to hypothesize that psychological disturbances in susceptible persons may indeed play a causative role in the pathophysiology of oral lichen planus, probably by acting as a starting point for the initiation of autoimmune reactions.

In a study which assessed the psychiatric status of 56 patients with clinically and histologically verified oral lichen planus, $52 \%$ of patients were diagnosed with mental disturbances (12 patients with slight, 3 with moderate, and 14 with severe disturbances); that percentage was significantly higher than in healthy participants in the control group and the general population [42]. In a study on anxiety, depression, and stress in patients with oral lichen planus, no differences were found between the acute and remission stage, while patients diagnosed with oral lichen planus reported encountering stressful life events more frequently and received higher scores on anxiety and depression tests compared to healthy controls [43]. Higher sensitivity to stress perception and reduced capability of coping with stress was also observed [44]. A study evaluating psychological personality profiles of patients with oral lichen planus found significantly higher scores for hypochondriasis, depression, and hysteria compared with controls, whereas the scores at other clinical scales (psychopathic deviate, paranoia, psychasthenia, schizophrenia, and hypomania) were not different from controls [47]. In that study, a two-fold increase in serum cortisol levels was found between patients with erosive lesions and controls, whereas patients with reticular lesions had similar cortisol levels as controls. Elevated plasma cortisol levels were also found to be associated with more aggressive erosive lesions in another study [48], suggesting that cortisol levels may be predictive of the severity of the disease. Cortisol levels were positively correlated with scores on clinical scales for hysteria, hypochondriasis, and depression [47]. Conversely, a study on diurnal cortisol production reported that patients with oral lichen planus had decreased salivary cortisol production in the morning hours compared with healthy controls [44]. Despite some inconsistencies in the studies of cortisol levels, the findings indicate that oral lichen planus may be related to the dysregulation of the hypothalamic-pituitary-adrenal axis triggered by psychological factors. Considering the autoimmune background of oral lichen planus, additional evidence for the role of neuro-immune crosstalk for the systemic immune response is the finding that bilateral transection of glossopharyngeal nerves can attenuate the dose-dependent febrile response to injection of lipopolysaccharide or IL-1- $\beta$ into the soft palate of rats [49]. This demonstrates that the communication between the central nervous system and the immune system is not exclusively mediated by cytokines and other humoral pathways, but instead requires a local neural route linked to the site at which the antigen was administered. The common treatment for oral lichen planus is symptomatic and involves topical, intralesional, and systemic administration of corticosteroids, while other immunosuppressive agents (cyclosporine and tacrolimus) or retinoids can also be used in more severe cases [46]. Although the disease can be successfully controlled by these medications in most cases, the effects of the treatment are usually transient and the side effects of long-term treatment may outweigh the benefits. Addressing the psychical health as a possible adjunctive therapy in treating oral lichen planus has been suggested decades ago $[42,47,50]$, however, no studies evaluating the effectiveness of this approach have been published up to date. A multidisciplinary approach to the treatment of oral lichen planus could be beneficial because the psychological well-being of patients 
with oral lichen planus can be severely affected by the disease itself. Psychological support may help in breaking the vicious circle formed by the disease that is both causing and being perpetuated by impaired psychological status [51]. Oral microbiome in patients with oral lichen planus has been shown to be altered in comparison to healthy controls [52]. Also, different colonization patterns were observed at the sites of oral mucosa affected by lesions compared to healthy control sites within the same patient [53]. However, it has not yet been clarified if the dysbiosis associated with oral lichen planus has some causative role, for example by invading the epithelial barrier and modifying the immune response [54]. Alternatively, the dysbiosis may simply be an epiphenomenon due to the changed oral environment, without having an active role in the immunopathology of oral lichen planus.

\subsection{Recurrent aphthous stomatitis}

Recurrent aphthous stomatitis (RAS) is a chronic disease of unclear etiopathogenesis, characterized by a recurrent onset of solitary or multiple painful ulcerations and erosions appearing predominantly on unattached oral mucosa. Clinical characterization distinguishes three main types of oral lesions: minor, major and herpetiform. The disease is considered to be caused by a hyper-reactive immune response, which is influenced by genetic predisposition and modulated by a multitude of factors, some of which include: viral and bacterial infections, nutritional deficiencies, food allergies, psychological stress, mechanical trauma, and hormonal imbalance [55]. The exacerbation of RAS is often related to psychological stress. Higher anxiety levels coupled with elevated cortisol levels in plasma and saliva have been associated with RAS [56]. Exposure to stressful situations and conditions appears to be more important for the onset of RAS than personality profiles and stable psychological traits [57]. However, some evidence exists that trait anxiety may be a predisposing factor for RAS [58]. A study in which 160 RAS patients were followed by weekly phone surveys over 1 year found a significant association of stressful life events and exacerbations of RAS, while a stronger association was found for psychological than physical stressors [59]. However, no association of stressful life events with the duration of RAS episodes was identified in that study. There are also reports of no association of RAS with alterations in cortisol levels [60] and psychological factors (stress and depression) [61], which is in line with the complex and multifactorial etiology of RAS. Frequent exacerbations of painful RAS lesions interfere with normal daily activities and negatively affect the quality of life [62]. The psychological consequences may then influence the course of disease thus forming a vicious circle in a similar manner as mentioned for oral lichen planus. Since the conventional treatment for RAS is symptomatic and ineffective in the long-term, a supportive psychotherapy may be beneficial for alleviating the discomfort that RAS patients experience [56].

\subsection{Temporomandibular disorders}

Temporomandibular disorders (TMD) encompass several clusters of symptoms involving chronic pain in the temporomandibular joint and masticatory muscles, limitations in the range of mandibular movement and sounds occurring during movements. Pain can be spontaneous or triggered by mandibular movement or palpation of the masticatory muscles. The etiology of TMD remains poorly understood and involves psychological, behavioral and environmental factors. TMD usually presents no observable organic pathology and shares many features with other chronic pain conditions. TMD is often comorbid with other chronic pain conditions, such as fibromyalgia, headaches, spinal pain, and back pain [63]. Although it causes significant distress to affected patients, TMD is self-limiting and usually does not lead to a progressive structural or functional deterioration [64]. Being predominantly a functional rather than structural disorder, TMD appears more as a symptom than a disease.

The inseparable interplay between psychological stress and the experience of pain is biologically based on the fact that most of the molecules which regulate the stress response are the same as those involved in pain modulation [65]. As in other chronic pain conditions, psychological factors are generally implicated in the occurrence of TMD, with the involvement of the hypothalamicpituitary-adrenal axis, as well as the serotoninergic and opioid system [66]. In addition to the psychoneuro-immunological dysregulation, the symptoms can be aggravated by hyperactivity of masticatory muscles which often accompanies TMD. However, the stress-induced parafunctional activities are not necessarily related to muscle pain and [67] and thus cannot be regarded as the primary source of TMD symptoms. This is supported by a study evaluating the association of masticatory muscle pain and nocturnal electromyography activity with psychological factors demonstrating that muscle pain is more related to psychological stress than to parafunctional activity [68].

Studies have indicated that patients with TMD tend to present higher levels of anxiety [69], depression and somatization [70]. Stress and emotional distress have also been shown to be associated with TMD pain, as well as muscular tension and parafunctional habits which can independently contribute to the painful experience [71]. TMD patients showed higher electromyographic activity during experimentally induced stress compared to patients with other chronic painful conditions (e.g. chronic back pain) and healthy controls [72]. 
Subjects with maladaptive coping were at greater risk for TMD pain than the subjects with adaptive coping [73]. A prospective cohort study of 171 healthy female volunteers identified the first-onset TMD in $8.8 \%$ of the participants over the course of 3 years and demonstrated a high predictive value of depression, perceived stress, and mood for the onset of TMD [74]. Some of the TMD patients showed cortisol hypersecretion in response to stress, which could be regarded as a biological predisposition to TMD [75]. However, the excessive cortisol secretion may represent a response to a painful stimulus, as evidenced in a study which showed that cortisol hypersecretion occurred mostly while the subjects were awake, i.e. aware of pain [76].

Sleep disorders may also be implicated in the pathophysiology of TMD through increasing central sensitivity to pain, but also by being associated with muscular parafunctions leading to myofascial pain [77]. The relation between sleep bruxism and TMD is unclear, as it has been shown that not all patients with parafunctional habits develop myofascial pain [78]. The cause and effect relation between sleep disorders and related parafunctions of masticatory muscles are difficult to establish since sleep disorders are commonly accompanied by depression and other psychological disturbances which may independently influence TMD symptoms [79].

The usual symptomatic treatment of TMD involves the use of orthopedic appliances which are intended to improve the biomechanics of temporomandibular joint thus reducing muscle activity and joint loading, while simultaneously increasing patient awareness of parafunctional habits [80]. Due to multifactorial etiology of TMD, a multidisciplinary treatment approach encompassing physiotherapy, biofeedback, and cognitive behavioral therapy seems reasonable [81]. Therapeutic modalities targeting psychological factors may be beneficial for reducing painful symptoms and functional limitations; however, the level of evidence for their effectiveness is currently low [82]. In any case, it appears that combined treatment modalities can be more effective and yield longer-lasting results than the conventional treatment which employs orthopedic appliances alone [81]. Also, as in other chronic pain conditions, the TMD pain can in many patients be mitigated by antidepressants regardless of their possible comorbidity with depressive disorder [66].

\subsection{Herpes labialis}

Most individuals have been exposed to herpes simplex virus through their lifetime, as evidenced by the presence of antibodies in up to $90 \%$ of the general population. About $75 \%$ of the general population is affected by clinically evident herpes labialis at some time in life [83]. After a primary infection on skin or mucosa, herpes simplex virus establishes a latent infection in ganglionic neurons which can be reactivated under conditions of impaired immune surveillance, thus causing a recurrent infection. The potential of psychological stress to exacerbate the recurrence of herpes virus infection has been well documented and various factors such as short-term stress, stressful life events, dysphoria, anxiety, anger, and negative mood were associated with viral reactivation at both oral and genital sites [84]. Since cellular immunity plays an important role in maintaining the infection in a latent stage, an exacerbation is considered to occur when the cellular immune response is impaired due to the stress-induced imbalance in the secretion of catecholamines, glucocorticoids, and pro-inflammatory cytokines (IL-1, IL-6, and TNF) [85]. For example, it has been demonstrated that adrenaline and glucocorticoids can be used to experimentally induce herpes simplex virus reactivation in animal models [86]. A longitudinal study which evaluated daily mood states and weekly levels in neuroendocrine markers found that the number of natural killer cells and serum levels of adrenaline were associated with herpes labialis exacerbations [83]. Additionally, that study found that adrenaline levels were positively correlated to scores of affect intensity. Although the role of psychoneuroimmunological interaction in the recurrent herpes infections has been well confirmed, it remains difficult to quantify psychological stress and its etiological significance for the onset of the disease [87].

\subsection{Burning mouth syndrome}

Burning mouth syndrome is a chronic pain condition of unknown etiology, usually characterized by burning or stinging sensation coupled with a subjective feeling of dryness and altered taste. Besides sensory disorders, clinically no oral lesions or other objective signs can be identified. The condition is usually associated with a number of psychological factors, leading some authors to refer to it as psychostomatodynia [88]. Higher levels of neuroticism, anxiety, depression, exposure to stressful life events have been associated with the syndrome and the involvement of some personality disorders as well as cortisol dysregulation have been hypothesized [89]. The treatment should aim at identifying and treating underlying psychological disturbances.

\subsection{Atypical odontalgia}

Atypical odontalgia is persistent idiopathic pain which mimics toothache but lacks any identifiable organic cause. It may occur at a healed extraction site or in a healthy, restored or endodontically treated tooth which presents with no evidence of pathology on clinical or radiographic examination. Etiopathogenesis of atypical odontalgia is unclear and the involvement of psychogenic and neuropathic 
factors has been proposed, although the primary cause remains unclear and thus no causal treatment exists [90].

The symptomatic treatment is generally difficult and unsuccessful, usually leading to unnecessary extractions of multiple teeth due to patients' persistent requests for treatment driven by persistent pain. Thus psychological factors need to be thoroughly considered in patients with atypical odontalgia in order to avoid irreversible iatrogenic damage.

3.8. Eating disorders: anorexia and bulimia nervosa Eating disorders which are characterized by restricted food intake (anorexia nervosa) or purging behavior by means of induced vomiting or laxative use (bulimia nervosa) are psychiatric disorders of unclear etiology with probable involvement of serotoninergic dysregulation in the brain [91]. Frequent exposure of dental hard tissues to gastric acid due to vomiting can lead to cumulative demineralization and extensive erosions on enamel and dentin. The resulting defects usually require comprehensive restorative or prosthodontic treatment. Eating disorders are associated with elevated levels of pro-inflammatory cytokines such as TNF- $a$ and IL-6, indicating a psycho-neuroimmune interplay [92,93].

Also, eating disorders are related to psychological stress and inadequate coping behaviors and are often comorbid with other psychiatric disturbances such as anxiety and depression, with a probable bidirectional interaction [94]. The acute phase of anorexia nervosa has been associated with increased levels of salivary cortisol, secretory immunoglobulin- $A$, and alpha-amylase, reflecting dysregulation of hypothalamic-pituitary-adrenal axis [95]. Some patients with bulimia nervosa have shown changes in the enzymatic activity of proteases, collagenase, and pepsin in resting and simulated saliva, which contributes to the progression of dental erosions [96]. Gut microbiome can also play a role in the regulation of food intake. For example, bacterial metabolic products such as short-chain fatty acids exert a neuroactive effect which affects the host appetite, possibly playing a role in the pathophysiology of eating disorders [97].

\subsection{The role of the oral microbiome}

Besides the gut and the skin, as two sites of the human body that are most heavily populated by microbes, the oral cavity is also an important habitat for 500-1000 bacterial species [4, 98, 99]. The discrepancy in the number of species which is encountered in the literature stems from the fact that approximately half of the bacterial species found in the mouth cannot be cultured under laboratory conditions [100]. Most of the species present can be regarded as commensal, while some are symbiotic (e.g. ammonia-producing species which elevate oral $\mathrm{pH}$ values) and pathogenic (e.g. acidogenic species which cause tooth caries through demineralization of dental hard tissues).

In fact, two most frequent diseases in the oral cavity, i.e. caries and periodontitis, are caused by complex changes in the microbial community, rather than by infection with a specific pathogen [101]. Especially in the case of periodontitis, well-known shifts of microbial ecology in favor of specific bacterial species are associated with the destructiveness of the disease. Healthy periodontal tissues express a lowgrade controlled inflammation which represents the host response to periodontal microbiome, whereas the transition towards destructive inflammation occurs in susceptible individuals when the microbial dysbiosis occurs [102].

The primary local beneficial effect of the commensal microbiome is the inhibition of colonization of the oral cavity by pathogenic species, the so-called colonization resistance [103]. Disbalances of the commensal microbiome can lead to opportunistic infections by Candida spp. or Staphylococcus aureus, which are commonly seen as a side-effect of antimicrobial therapy. Oral microbiome also has some systemic effects, as exemplified by its role in the metabolism of nitrates. Nitrate is secreted into the saliva (about $25 \%$ of the total ingested amount) and reduced by oral bacteria into nitrite which is then absorbed through gastric mucosa and converted into nitric oxide. Nitric oxide has an important role in regulating vasodilatation and maintaining blood pressure homeostasis. For example, orally ingested nitrates in the form of food supplements help to reduce blood pressure by exploiting this mechanism [104]. It is clear that the oral microbiome plays a complex role in both local and systemic health, whereas its imbalances reach beyond a straightforward infective disease caused by a single pathogen. However, the effects of psycho-neuroimmunological factors on the oral microbiome and the consequences of that interaction on systemic health have not been extensively studied. Considering the better-established links of psycho-neuro-immunological factors with the gut microbiome, it is plausible that a similar interplay may occur in the oral cavity. If the link is to be established and mechanisms elucidated, the oral microbiome could be altered by using probiotics in a manner similar to what is now commonly accepted for gut microbiome [105]. In such a scenario, modifying the oral microbiome could aid in mitigating the course of periodontal destruction through two major mechanisms: (I) inhibition of microbial adhesion, colonization, growth, and biofilm formation; and (II) altering the destructive host response involving inhibition of pro-inflammatory pathways and inflammation-induced enzymes [106]. 


\subsubsection{Bacterial adherence}

Psychoneuroimmunological factors have been shown to affect the adherence of oral and non-oral microorganisms: experimentally induced stress was shown to increase saliva-mediated adherence of S. sanguis, S. gordonii, and H. pylori, whereas the co-adherence of $C$. albicans with S. gordonii was decreased [107]. These results suggest that stress-induced changes in salivary composition may predispose oral mucosa to various diseases associated with changes in the oral microbiome.

\section{Limitations of the current analysis}

Due to the scarcity of published research on psychoneuroimmunological interactions related to oral diseases, the data from available literature are summarized in the form of a narrative review. A qualitative approach was used without attempting to address a specific research question, therefore the presentation limited to the general overview of the current state of research.

\section{Conclusion}

Various oral diseases and conditions of multifactorial etiology can be influenced by psycho-neuroimmunological interactions. Due to complex and insufficiently elucidated etiopathology of these conditions, it is difficult to isolate and quantify the significance of psychological factors. Further research should attempt to investigate intricate interactions of a number of psychological, neurological, endocrine, and immunological factors, as well as their impact on the onset and progress of oral diseases.

Also, the potential benefit of psychological support for alleviating the course of oral diseases needs to be assessed. In daily practice, clinicians should be aware of the interplay between mental and general health and consider addressing psychological disturbances as a supplement for conventional treatment modalities.

\section{Author Contributions}

MP: wrote the manuscript. ZT: critically revised the manuscript.

\section{Conflict of interest statement}

The authors declare no conflict of interest.

\section{References}

1. Connor TJ, Leonard BE. Depression, stress and immunological activation: the role of cytokines in depressive disorders. Life Sci. 1998;62(7):583-606

[CrossRef] [PubMed] Google Scholar Scopus

2. Laine ML, Moustakis V, Koumakis L, et al. Modeling susceptibility to periodontitis. J Dent Res. 2013;92(1):45-50.
[CrossRef] [PubMed] Google Scholar Scopus

3. Sanz M Quirynen M. Advances in the aetiology of periodontitis. Group A consensus report of the 5th European Workshop in Periodontology. J Clin Periodontol. 2005;32(Suppl 6):54-56. [CrossRef] [PubMed] Google Scholar Scopus

4. WadeWG. The oral microbiome in health and disease. Pharmacol Res. 2013;69(1):137-143.

[CrossRef] [PubMed] Google Scholar Scopus

5. Seymour GJ, Ford PJ, Cullinan MP, et al. Relationship between periodontal infections and systemic disease. Clin Microbiol Infect. 2007(13 (Suppl 4)):3-10.

[Free PMC Article] [CrossRef] [PubMed] Google Scholar Scopus

6. Garcia R, Henshaw MM, Krall EA. Relationship between periodontal disease and systemic health. Periodontol. 2000 2001;25:21-36.

[CrossRef] [PubMed] Google Scholar Scopus

7. Tonetti MS, Van Dyke TE. Periodontitis and atherosclerotic cardiovascular disease: consensus report of the Joint EFP/ AAPWorkshop on Periodontitis and Systemic Diseases. Periodontol. 2013;84(4-s):S24-S29.

[CrossRef] [PubMed] Google Scholar Scopus

8. Lalla E, Papapanou PN. Diabetes mellitus and periodontitis: a tale of two common interrelated diseases. Nat Rev Endocrinol 2011;7(12):738-748

[CrossRef] [PubMed] Google Scholar Scopus

9. Cardoso EM, Reis C, Manzanares-Cespedes MC. Chronic periodontitis, inflammatory cytokines, and interrelationship with other chronic diseases. Postgrad Med. 2018;130(1):98-104 [CrossRef] [PubMed] Google Scholar Scopus

10. Fisher MA, Taylor GW, Shelton BJ, et al. Periodontal disease and other nontraditional risk factors for CKD. Am J Kidney Dis. 2008;51(1):45-52.

[CrossRef] [PubMed] Google Scholar Scopus

11. Michalowicz BS, Gustafsson A, Thumbigere-Math V, et al. The effects of periodontal treatment on pregnancy outcomes. J Clin Periodontol. 2013;40 Suppl 14:S195-208.

[CrossRef][PubMed] Google Scholar Scopus

12. Tezal M, Sullivan MA, Reid ME, et al. Chronic periodontitis and the risk of tongue cancer. Arch Otolaryngol Head Neck Surg. 2007; 133(5):450-454

[Full text links] [PubMed] Google Scholar Scopus

13. Kim J, Amar S. Periodontal disease and systemic conditions: a bidirectional relationship. Odontology. 2006;94(1):10-21.

[CrossRef] [PubMed] Google Scholar Scopus

14. Reners M, Brecx M. Stress and periodontal disease. Int J Dent Hyg. 2007;5(4):199-204

[CrossRef] [PubMed] Google Scholar Scopus

15. Warren KR, Postolache TT, Groer ME, et al. Role of chronic stress and depression in periodontal diseases. Periodontol. 2000 2014;61(1):127-138 [CrossRef] [PubMed] Google Scholar Scopus

16. Genco RJ, Ho AW, Grossi SG, et al. Relationship of stress, distress and inadequate coping behaviors to periodontal disease. $J$ Periodontol. 1999:70(7):711-723.

[CrossRef] [PubMed] Google Scholar Scopus

17. Green LW, Tryon WW, Marks B, et al. Periodontal disease as a function of life events stress. J Human Stress. 1986;12(1):32-36. [CrossRef] [PubMed] Google Scholar Scopus

18. Shannon IL, Kilgore WG, O'Leary TJ. Stres as a predisposing factor in necrotizing ulcerative gingivitis. J Periodontol. 1969;40(4):240242.

[Full text links] [PubMed] Google Scholar Scopus

19. Peruzzo DC, Benatti BB, Ambrosano GM, et al. A systematic review of stress and psychological factors as possible risk factors for periodontal disease. J Periodontol. 2007;78(8):1491-1504. [CrossRef] [PubMed] Google Scholar Scopus

20. Page RC, Altman LC, Ebersole JL, et al. Rapidly progressive periodontitis. A distinct clinical condition. J Periodontol. 1983;54(4):197-209.

[CrossRef] [PubMed] Google Scholar Scopus

21. LeResche L, Dworkin SF. The role of stress in inflammatory disease, including periodontal disease: review of concepts and current findings. Periodontol. 2000 2002;30:91-103. [CrossRef] [PubMed] Google Scholar Scopus

22. Rai B, Kaur J, Anand SC, et al. Salivary stress markers, stress, and periodontitis: a pilot study. J Periodontol. 2011;82(2):287-292 [CrossRef] [PubMed] Google Scholar Scopus

23. Saletu A, Pirker-Fruhauf $\mathrm{H}$, Saletu F, et al. Controlled clinical and psychometric studies on the relation between periodontitis and depressive mood. JClin Periodontol. 2005;32(12):1219-1225. [CrossRef] [PubMed] Google Scholar Scopus

24. Hugoson A, Ljungquist B, BreivikT. The relationship of some negative events and psychological factors to periodontal disease in an adult Swedish population 50 to 80 years of age. $J$ Clin Periodontol. 2002:29(3):247-253.

[CrossRef] [PubMed] Google Scholar Scopus

25. Johannsen A, Rylander G, Soder B, et al. Dental plaque, gingival inflammation, and elevated levels of interleukin- 6 and cortisol in gingival crevicular fluid from women with stress-related depression and exhaustion. J Periodontol. 2006;77(8):1403-1409. 
[CrossRef] [PubMed] Google Scholar Scopus

26. Johannsen A, Rydmark I, Soder B, et al. Gingival inflammation, increased periodontal pocket depth and elevated interleukin- 6 in gingival crevicular fluid of depressed women on long-term sick leave. J Periodontal Res. 2007;42(6):546-552. [CrossRef] [PubMed] Google Scholar Scopus

27. Monteiro da Silva AM, Oakley DA, Newman HN, et al. Psychosocial factors and adult onset rapidly progressive periodontitis. J Clin Periodontol. 1996;23(8):789-794. [CrossRef] [PubMed] Google Scholar Scopus

28. Moss ME, Beck JD, Kaplan BH, et al. Exploratory Case-Control Analysis of Psychosocial Factors and Adult Periodontitis. $J$ Periodontol. 1996;67 (Suppl 10S):1060-1069. [CrossRef] [PubMed] Google Scholar Scopus

29. Wimmer G, Janda M, Wieselmann-Penkner K, et al. Coping with stress: its influence on periodontal disease. J Periodontol. 2002;73(11):1343-1351.

[CrossRef] [PubMed] Google Scholar Scopus

30. Wimmer G, Köhldorfer G, Mischak I, et al. Coping with stress: its influence on periodontal therapy. J Periodontol. 2005;76(1):9098. [CrossRef] [PubMed] Google Scholar Scopus

31. BreivikT, Thrane PS, Gjermo P, et al. Hypothalamic-pituitaryadrenal axis activation by experimental periodontal disease in rats J Periodontal Res. 2001·36(5):295-300.

[CrossRef] [PubMed] Google Scholar Scopus

32. Breivik T, Gundersen Y, Myhrer T, et al. Enhanced susceptibility to periodontitis in an animal model of depression: reversed by chronic treatment with the anti-depressant tianeptine. J Clin Periodontol. 2006;33(7):469-477.

[CrossRef] [PubMed] Google Scholar Scopus

33. Genco RJ, Ho AW, Kopman J, et al. Models to evaluate the role of stress in periodontal disease. Ann Periodontol. 1998;3(1):288-302 [Full text links] [PubMed] Google Scholar Scopus

34. Hilgert JB, Hugo FN, Bandeira DR, et al. Stress, cortisol, and periodontitis in a population aged 50 years and over. J Dent Res. 2006;85(4):324-328.

[CrossRef] [PubMed] Google Scholar Scopus

35. Rosania AE, Low KG, McCormick CM, et al. Stress, depression, cortisol, and periodontal disease. J Periodontol. 2009;80(2):260266.

[CrossRef] [PubMed] Google Scholar Scopus

36. Ishisaka A Ansai T, Soh l, et al. Association of salivary levels of cortisol and dehydroepiandrosterone with periodontitis in olde Japanese adults. J Periodontol. 2007;78(9):1767-1773. [CrossRef] [PubMed] Google Scholar Scopus

37. Kamma JJ, Baehni PC. Five-year maintenance follow-up of earlyonset periodontitis patients. J Clin Periodontol. 2003;30(6):562 572

[CrossRef] [PubMed] Google Scholar Scopus

38. Linden GJ, Mullally BH, Freeman R. Stress and the progression of periodontal disease. J Clin Periodontol. 1996;23(7):675-680. [CrossRef] [PubMed] Google Scholar Scopus

39. Elter JR, White BA, Gaynes BN, et al. Relationship of clinica depression to periodontal treatment outcome. J Periodontol. 2002;73(4):441-449.

[CrossRef] [PubMed] Google Scholar Scopus

40. Boyapati L, Wang HL. The role of stress in periodontal disease and wound healing. Periodontol. 2000 2007;44:195-210. [CrossRef] [PubMed] Google Scholar Scopus

41. Mollaoglu N. Oral lichen planus: a review. BrJ Oral Maxillofac Surg. 2000;38(4):370-377.

[Full text links] [PubMed] Google Scholar Scopus

42. Hampf BG, Malmström MJ, Aalberg VA, et al. Psychiatric disturbance in patients with oral lichen planus. Oral Surg Oral Med Oral Pathol. 1987:63(4):429-432.

[Full text links] [PubMed] Google Scholar Scopus

43. Valter K, Boras WV, Buljan D, et al. The influence of psychological state on oral lichen planus. Acta Clin Croat. 2013;52(2):145-149. [Full text links] [PubMed] Google Scholar Scopus

44. Pippi R, Patini R, Ghiciuc CM, et al. Diurnal trajectories of salivary cortisol, salivary a-amylase and psychological profiles in oral lichen planus patients. J Biol Regul Homeost Agents. 2014;28(1):147-156.

[Full text links] [PubMed] Google Scholar Scopus

45. Chaudhary S. Psychosocial stressors in oral lichen planus. Aust Dent J. 2004;49(4):192-195. [CrossRef] [PubMed] Google Scholar Scopus

46. Carrozzo M, Thorpe RJ. Update on oral lichen planus. Expert Rev Dermatol. 2009;4(5):483-494.

[CrossRef] Google Scholar Scopus

47. Ivanovski K, Nakova M, Warburton G, et al. Psychological profile in oral lichen planus. J Clin Periodontol. 2005;32(10):1034-1040. [CrossRef] [PubMed] Google Scholar Scopus

48. Prolo P, Chiappelli F, Cajulis E, et al. Psychoneuroimmunology in oral biology and medicine: the model of oral lichen planus. Ann NY Acad Sci. 2002;966:429-440.

[CrossRef] [PubMed] Google Scholar Scopus

49. Romeo HE, Tio DL, Rahman SU, et al. The glossopharyngea nerve as a novel pathway in immune-to-brain communication: relevance to neuroimmune surveillance of the oral cavity. $J$

Neuroimmunol. 2001;115(1-2):91-100.

[CrossRef] [PubMed] Google Scholar Scopus

50. Burkhart NW, Burker EJ, Burkes EJ, et al. Assessing the Characteristics of Patients with Oral Lichen Planus. J Am Dent Assoc. 1996;127(5):648-662.

[CrossRef] [PubMed] Google Scholar Scopus

51. Lundqvist EN, Wahlin YB, Bergdahl M, et al. Psychological health in patients with genital and oral erosive lichen planus. J Eur Acad Dermatol Venereol. 2006;20(6):661-666.

[CrossRef] [PubMed] Google Scholar Scopus

52. HeY, Gong D, Shi C, et al. Dysbiosis of oral buccal mucosa microbiota in patients with oral lichen planus. Oral Dis. 2017;23(5):674-682

[CrossRef] [PubMed] Google Scholar Scopus

53. Bornstein MM, Hakimi B, Persson GR. Microbiological findings in subjects with asymptomatic oral lichen planus: a cross-sectional comparative study. J Periodontol. 2008;79(12):2347-2355. [CrossRef] [PubMed] Google Scholar Scopus

54. Baek K, Choi Y. The microbiology of oral lichen planus: Is microbial infection the cause of oral lichen planus? Mol Oral Microbiol. 2018;33(1):22-28.

[CrossRef] [PubMed] Google Scholar Scopus

55. Slebioda Z, Szponar E, Kowalska A. Etiopathogenesis of recurrent aphthous stomatitis and the role of immunologic aspects: literature review. Arch Immunol Ther Exp. (Warsz) 2014;62(3):205-215

[CrossRef] [PubMed] Google Scholar Scopus

56. Albanidou-Farmaki E, Poulopoulos AK, Epivatianos A, et al. Increased anxiety level and high salivary and serum cortiso concentrations in patients with recurrent aphthous stomatitis. Tohoku J Exp Med. 2008;214(4):291-296. [CrossRef] [PubMed] Google Scholar Scopus

57. Al-Omiri MK, Karasneh J, Lynch E. Psychological profiles in patients with recurrent aphthous ulcers. Int J Oral Maxillofac Surg. 2012;41(3):384-388. [CrossRef] [PubMed] Google Scholar Scopus

58. McCartan BE, Lamey PJ, Wallace AM. Salivary cortisol and anxiety in recurrent aphthous stomatitis. J Oral Pathol Med. 1996;25(7):357-359.

[CrossRef] [PubMed] Google Scholar Scopus

59. Huling LB, Baccaglini L, Choquette $L$, et al. Effect of stressful life events on the onset and duration of recurrent aphthous stomatitis. J Oral Pathol Med. 2012;41(2):149-152. [CrossRef] [PubMed] Google Scholar Scopus

60. Kumar MA, Ananthakrishnan V, Goturu J. Role of stress in recurrent aphthous stomatitis. Biomedicine. 2012;32(3):331-336. [Full text links] Google Scholar Scopus

61. Picek P, Buljan D, Rogulj AA, et al. Psychological status and recurrent aphthous ulceration. Coll Antropol. 2012;36(1):157-159. [Full text links] [PubMed] Google Scholar Scopus

62. Zwiri AM. Anxiety, Depression and Quality of Life among Patients with Recurrent Aphthous Ulcers. J Contemp Dent Pract. 2015;16(2):112-117.

[Full text links] [PubMed] Google Scholar Scopus

63. Lim PF, Maixner W, Khan AA. Temporomandibular disorder and comorbid pain conditions. J Am Dent Assoc. 2011;142(12):13651367.

[CrossRef] [PubMed] Google Scholar Scopus

64. Dworkin SF, Massoth DL. Temporomandibular disorders and chronic pain: disease or illness? J Prosthet Dent. 1994;72(1):29-38. [CrossRef] [PubMed] Google Scholar Scopus

65. Millan MJ. Descending control of pain. Prog Neurobiol. 2002;66(6):355-474

[CrossRef] [PubMed] Google Scholar Scopus

66. Gameiro GH, da Silva Andrade A, Nouer DF, et al. How may stressful experiences contribute to the development of temporomandibular disorders? Clin Oral Investig. 2006;10(4):261268.

[CrossRef] [PubMed] Google Scholar Scopus

67. Pergamalian A, Rudy TE, Zaki HS, et al. The association between wear facets, bruxism, and severity of facial pain in patients with temporomandibular disorders. J Prosthet Dent. 2003;90(2):194200. [CrossRef] [PubMed] Google Scholar Scopus

68. van Selms MK, Lobbezoo F Visscher CM et al Myofascial temporomandibular disorder pain, parafunctions and psychological stress. JOral Rehabil. 2008;35(1):45-52. [CrossRef] [PubMed] Google Scholar Scopus

69. Manfredini D, Bandettini di Poggio A Cantini E et al. Mood and anxiety psychopathology and temporomandibular disorder: a spectrum approach. J Oral Rehabil. 2004;31(10):933-940. [CrossRef] [PubMed] Google Scholar Scopus

70. Yap AU, Tan KB, Chua EK, et al. Depression and somatization in patients with temporomandibular disorders. J Prosthet Dent. 2002;88(5):479-484.

[CrossRef] [PubMed] Google Scholar Scopus

71. Glaros AG, Williams K, Lausten L. The role of parafunctions, emotions and stress in predicting facial pain. J Am Dent Assoc. 2005;136(4):451-458. 
[CrossRef] [PubMed] Google Scholar Scopus

72. Flor H, Birbaumer N, Schulte W, et al. Stress-related electromyographic responses in patients with chronic temporomandibular pain. Pain. 1991;46(2):145-152. [CrossRef] [PubMed] Google Scholar Scopus

73. Reissmann DR, John MT, Schierz O, et al. Stress-related adaptive versus maladaptive coping and temporomandibular disorder pain. J Orofac Pain. 2012;26(3):181-190. [Full text links] [PubMed] Google Scholar Scopus

74. Slade GD, Diatchenko L, Bhalang K, et al. Influence of psychological factors on risk of temporomandibular disorders. $J$ Dent Res. 2007;86(11):1120-1125.

[CrossRef] [PubMed] Google Scholar Scopus

75. Jones DA, Rollman GB, Brooke RI. The cortisol response to psychological stress in temporomandibular dysfunction. Pain. 1997;72(1-2):171-182.

[CrossRef] [PubMed] Google Scholar Scopus

76. Korszun A, Young EA, Singer K, et al. Basal circadian cortisol secretion in women with temporomandibular disorders. J Dent Res. 2002;81(4):279-283.

[CrossRef] [PubMed] Google Scholar Scopus

77. Smith MT, Wickwire EM, Grace EG, et al. Sleep disorders and their association with laboratory pain sensitivity in temporomandibular joint disorder. Sleep. 2009;32(6):779-790. [Full text links] [PubMed] Google Scholar Scopus

78. Camparis CM, Formigoni G, Teixeira MJ, et al. Sleep bruxism and temporomandibular disorder: Clinical and polysomnographic evaluation. Arch Oral Biol. 2006;51(9):721-728. [CrossRef] [PubMed] Google Scholar Scopus

79. Fernandes G, Franco AL, Siqueira JT, et al. Sleep bruxism increases the risk for painful temporomandibular disorder, depression and non-specific physical symptoms. J Oral Rehabil. 2012;39(7):538-544.

[CrossRef] [PubMed] Google Scholar Scopus

80. Fricton J, Look JO, Wright E, et al. Systematic review and metaanalysis of randomized controlled trials evaluating intraoral orthopedic appliances for temporomandibular disorders. $J$ Orofac Pain. 2010;24(3):237-254.

[Full text links] [PubMed] Google Scholar Scopus

81. Rollman GB, Gillespie JM. The role of psychosocial factors in temporomandibular disorders. Curr Rev Pain. 2000;4(1):71-81. [Full text links] [PubMed] Google Scholar Scopus

82. Liu HX, Liang QJ, Xiao P, et al. The effectiveness of cognitivebehavioural therapy for temporomandibular disorders: a systematic review. J Oral Rehabil. 2012;39(1):55-62. [CrossRef] [PubMed] Google Scholar Scopus

83. Logan HL, Lutgendorf S, Hartwig A, et al. Immune, stress, and mood markers related to recurrent oral herpes outbreaks. Ora Surg Oral Med Oral Pathol Oral Radiol Endod. 1998;86(1):48-54. [CrossRef] [PubMed] Google Scholar Scopus

84. Chida Y, Mao X. Does psychosocial stress predict symptomatic herpes simplex virus recurrence? A meta-analytic investigation on prospective studies. Brain Behav Immun. 2009;23(7):917-925. [CrossRef] [PubMed] Google Scholar Scopus

85. Sainz B, Loutsch JM, Marquart ME, et al. Stress-associated immunomodulation and herpes simplex virus infections. Med Hypotheses. 2001;56(3):348-356.

[CrossRef] [PubMed] Google Scholar Scopus

86. Halford WP, Gebhardt BM, Carr DJ. Mechanisms of herpes simplex virus type 1 reactivation. J Virol. 1996;70(8):5051-5060. [Full text links] [PubMed] Google Scholar Scopus

87. Kimyai-Asadi A, Usman A. The role of psychological stress in skin disease. J Cutan Med Surg. 2001;5(2):140-145. [CrossRef] [PubMed] Google Scholar Scopus

88. Boucher Y. Psycho-stomatodynia. Journal of Oral Medicine and Oral Surgery. 2019;25(1):2.

[CrossRef] Google Scholar

89. Galli F, Lodi G, Sardella A, et al. Role of psychological factors in burning mouth syndrome: A systematic review and metaanalysis. Cephalalgia. 2017;37(3):265-277.

[CrossRef] [PubMed] Google Scholar Scopus
90. Baad-Hansen L. Atypical odontalgia - pathophysiology and clinical management. JOral Rehabil. 2008;35(1):1-11. [CrossRef] [PubMed] Google Scholar Scopus

91. Kaye W. Neurobiology of anorexia and bulimia nervosa. Physiol Behav. 2008;94(1):121-135.

[CrossRef] [PubMed] Google Scholar Scopus

92. Lavender JM, Wonderlich SA, Engel SG, et al. Dimensions of emotion dysregulation in anorexia nervosa and bulimia nervosa: A conceptual review of the empirical literature. Clin Psychol Rev. 2015;40:111-122. [CrossRef] [PubMed] Google Scholar Scopus

93. Vaz-Leal FJ, Rodriguez-Santos L, Melero-Ruiz MJ, et al. Psychopathology and lymphocyte subsets in patients with bulimia nervosa. Nutr Neurosci. 2010;13(3):109-115. [CrossRef] [PubMed] Google Scholar Scopus

94. Ball K, Lee C. Relationships between psychological stress, coping and disordered eating: A review. Psychol Health. 2000;14(6):1007-1035.

[CrossRef] [PubMed] Google Scholar Scopus

95. Paszynska E Dmitrzak-Weglarz M Tyszkiewicz-Nwafor $M$ et al. Salivary alpha-amylase, secretory lgA and free cortiso as neurobiological components of the stress response in the acute phase of anorexia nervosa. World J Biol Psychiatry. 2016;17(4):266-273.

[Full text links] [PubMed] Google Scholar Scopus

96. Schlueter N, Ganss C, Potschke S, et al. Enzyme activities in the oral fluids of patients suffering from bulimia: a controlled clinical trial. Caries Res. 2012;46(2):130-139.

[CrossRef] [PubMed] Google Scholar Scopus

97. van de Wouw M, Schellekens H, Dinan TG, et al. Microbiota-GutBrain Axis: Modulator of Host Metabolism and Appetite. J Nutr. 2017;147(5):727-745.

[CrossRef] [PubMed] Google Scholar Scopus

98. Aas JA, Paster BJ, Stokes LN, et al. Defining the normal bacteria flora of the oral cavity. J Clin Microbiol. 2005;43(11):5721-5732. [CrossRef] [PubMed] Google Scholar Scopus

99. Dewhirst FE, Chen T, Izard J, et al. The human oral microbiome. J Bacteriol. 2010;192(19):5002-5017. [CrossRef] [PubMed] Google Scholar Scopus

100. Wade WG. Non-culturable bacteria in complex commensal populations. Adv Appl Microbiol. 2004;54:93-106. [CrossRef] [PubMed] Google Scholar Scopus

101. Abusleme L, Dupuy AK, Dutzan N, et al. The subgingival microbiome in health and periodontitis and its relationship with community biomass and inflammation. ISMEJ. 2013;7(5):10161025.

[CrossRef] [PubMed] Google Scholar Scopus

102. Hajishengallis G. Immunomicrobial pathogenesis of periodontitis: keystones, pathobionts, and host response. Trends Immunol. 2014;35(1):3-11.

[CrossRef] [PubMed] Google Scholar Scopus

103. Vollaard EJ, Clasener HA. Colonization resistance. Antimicrob Agents Chemother. 1994:38(3):409-414. [CrossRef] [PubMed] Google Scholar Scopus

104. Kapil V, Milsom AB, Okorie M, et al. Inorganic nitrate supplementation lowers blood pressure in humans: role for nitrite-derived NO. Hypertension. 2010;56(2):274-281. [CrossRef] [PubMed] Google Scholar Scopus

105. Meurman JH, Stamatova I. Probiotics: contributions to oral health. Oral Dis. 2007;13(5):443-451. CrossRef] [PubMed] Google Scholar Scopus

106. Stamatova I, Meurman JH. Probiotics and periodontal disease. Periodontol. 2000 2009;51:141-151. [CrossRef] [PubMed] Google Scholar Scopus

107. Bosch JA, Turkenburg M, Nazmi K, et al. Stress as a Determinan of Saliva-Mediated Adherence and Coadherence of Oral and Nonoral Microorganisms. Psychosom Med. 2003;65(4):604-612. [CrossRef] [PubMed] Google Scholar Scopus

\section{Matej PAR \\ DMD, PhD, Postdoctoral Researcher Department of Endodontics and Restorative Dentistry School of Dental Medicine, University of Zagreb \\ Zagreb, Croatia} C)

Mater Par, DMD, PhD is a postdoctoral researcher at the Department of Endodontics and Restorative Dentistry, School of Dental Medicine in Zagreb, Croatia. He is a young researcher who authored 26 original research articles and contributed to 2 textbook chapters. His primary areas of interest include dental biomaterials and the development of experimental remineralizing resin composites. 


\section{Orestions}

\section{Why should dental practitioners consider psycho-neuro-immune interactions in their daily practice?}

口a. Dental treatment may have a negative long-term effect on the psychological status in susceptible patients:

b. Certain oral diseases may be affected by psychological disturbances;

口c. Early signs of some psychiatric disorders can be recognized in the mouth;

$\square d$. Major modifications of dental treatment are needed in patients with some personality disorders.

\section{Which of the following is incorrect?}

a. Periodontitis can affect systemic health, and some systemic diseases can influence the course of periodontitis;

b. Severity of periodontitis can be affected by stress, depression, and coping behavior;

ac. Some forms of periodontitis can be successfully treated using psychotherapy, without the need for local periodontal treatment;

$\square$ d. Despite considerable amount of evidence, psychological factors cannot be yet regarded as definitive risk factors for the onset of periodontitis.

\section{Which of the following conditions usually does not present with painful symptoms?}

$\square$ a. Periodontitis and tooth caries;

b. Herpes labialis and recurrent aphthous stomatitis;

ac. Temporomandibular disorder;

ad. Burning mouth syndrome.

\section{Choose the correct statement:}

a. Oral microbiome consists of 500-1000 bacterial species; diseases such as caries and periodontitis occur in cases of imbalances in microbiome in which only one bacterial species becomes dominant over others;

ab. Exacerbations of periodontitis and oral lichen planus have been shown to correlate with certain psychological states but no association of these diseases with stress-related hormones such as cortisol was observed;

ac. Necrotizing ulcerative gingivitis and periodontitis are the only forms of periodontal disease which are not associated with psychological factors;

$\square$ d. Burning mouth syndrome and atypical odontalgia usually present with no clinical or radiological signs of organic pathology but the patients affected by these conditions often show some psychological disturbance.

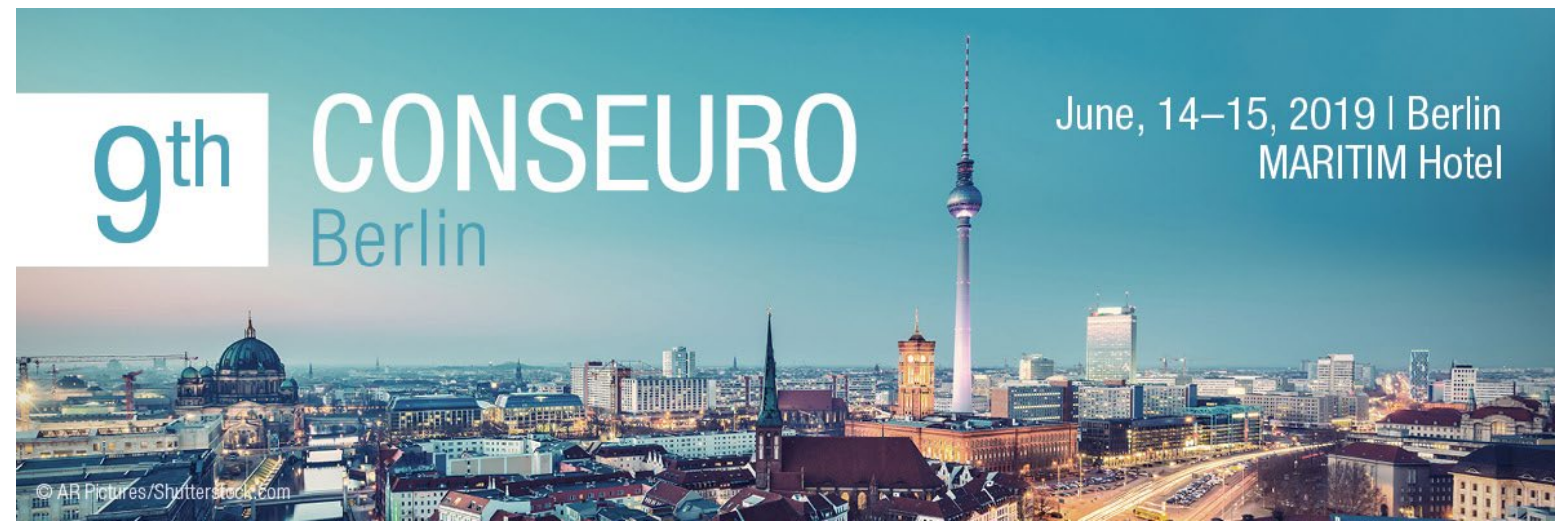

https://www.efcd.eu/conseuro-meeting/9th-conseuro-berlin-2019/ 


\section{ANKYLOS ${ }^{\circ}$}

ASTRA TECH IMPLANT SYSTEM ON XIVE

\section{Making the difference together}

Dentsply - Sirona Implants 
$26^{\text {th }}$ National Congress of the

College of University Teachers of

Odontostomatological Disciplines - CDUO

Date: 11 - 13 April 2019

Location: Naples, Italy

Event types: Conference, Exhibition

Visit event website: http://www.congressicduo.

it/images/2019/programma_cduo2019.pdf

International Women's Leadership

Conference VI - ADEA IWLC

Date: 23 - 25 April 2019

Location: Brescia, Italy

Event types: Conference, Workshop, Exhibition

Visit event website: http://

shapingdentaleducation.org/meetings/

brescia2019/programme.html

\section{$11^{\text {th }}$ EAPD Interim Seminar}

Date: 02 - 04 May 2019

Location: Chania, Crete, Greece

Event types: Conference, Workshop, Exhibition

Visit event website: https://pcoconvin.

eventsair.com/QuickEventWebsitePortal/

eapd/web/Extra-Content/

ContentSubPage?page $=2 \&$ subPage $=1$

New Orleans Dental Conference \& LDA

Annual Session

Date: 09 - 11 May 2019

Location: New Orleans, USA

Event types: Conference, Exhibition

Visit event website: http://www.nodc.org/ registration/mobile/index.html\#p=24

\section{$4^{\text {th }}$ Asia Pacific Dental Congress}

Date: 08 - 12 May 2019

Location: Manila, Philippines

Event types: Conference, Lectures, Exhibition

Visit event website: https://apdc2018.org/

scientific-information/scientific-program

\section{$38^{\text {th }}$ Asia Pacific Dental and Oral Health \\ Congress}

Date: 13-14 May 2019

Location: Osaka, Japan

Event types: Conference, Exhibition

Visit event website: https://www.

dentalcongress.com/asia-pacific/

InDent 2019 - International Dental

Exhibition and Conference

Date: 23-25 May 2019

Location: Brno, Czech Republic

Event types: Conference, Exhibition

Visit event website: https://www.dental-

tribune.com/event/indent-2019-international-

dentalexhibition-and-conference/
RDS 2019 - Congress of Romanian Dental

Society

Date: 23 - 25 May 2019

Location: Bucharest, Romania

Event types: Conference, Exhibition

Visit event website: https://sdr.info.

ro/2019/04/26/programul-congresului-sdr/

2019 Meeting of The Academy of

Prosthodontics

Date: 29 May - 01 June 2019

Location: Banff, Canada

Event types: Conference, Exhibition, Hands-on

Visit event website: https://

dentaleventscalendar.com/event/2019-

meeting-of-the-academyof-prosthodontics-

the-future-is-now/

\section{$1^{\text {st }}$ Bredent Group Days Russia}

Date: 31 May - 01 June 2019

Location: Saint Petersburg, Russia

Event types: Conference, Exhibition, Hands-on

Visit event website: https://bit.ly/2EEvDuz

$10^{\text {th }}$ AIO International Congress

Date: 13 - 15 June 2019

Location: Chia (Cagliari), Sardegna, Italy

Event types: Conference, Exhibition

Visit event website: http://congressaio.it/

$9^{\text {th }}$ CONSEURO Berlin 2019

Date: 14 - 15 June 2019

Location: Berlin, Germany

Event types: Conference, Exhibition

Visit event website: https://conseuro.berlin/

programm/

$4^{\text {th }}$ Annual Meeting on Pediatric Dentistry \& Dental Treatments

Date: 14 - 15 June 2019

Location: Montreal, Canada

Event types: Conference, Exhibition

Visit event website: https://pediatricdentistry. conferenceseries.com/scientific-program

\section{$25^{\text {th }}$ American Dental Research \& Future}

Dentistry

Date: 14 - 15 June 2019

Location: Montreal, Canada

Event types: Conference, Exhibition

Visit event website: http://kindcongress.com/ congress/future-dentistry-2019/

$4^{\text {th }}$ International Conference on Dental and Clinical Dentistry

Date: 08 - 09 July 2019

Location: Berlin, Germany

Event types: Conference, Exhibition

Visit event website: https://clinicaldentistry.

dentistryconferences.com/scientific-program 


\section{Neuromuscular Dentistry Powered by Myotronics}

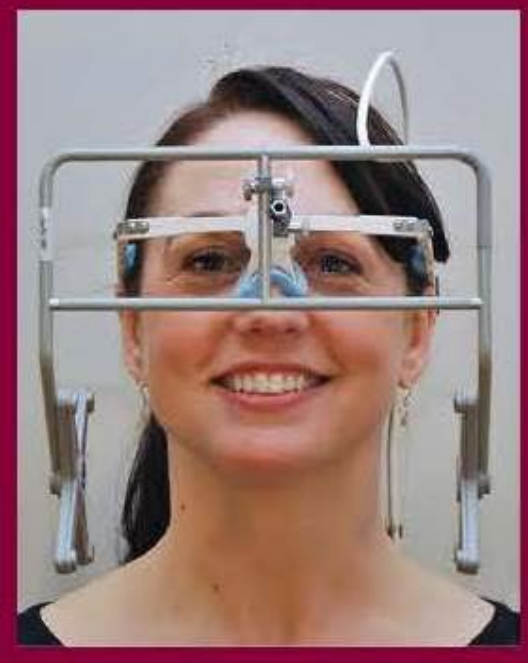

Dentists worldwide are discovering the science and the benefits of Neuromuscular Dentistry with Myotronics technology. Evaluate and successfully treat occlusal and restorative cases with reliable, reproducible clinical data never seen before.

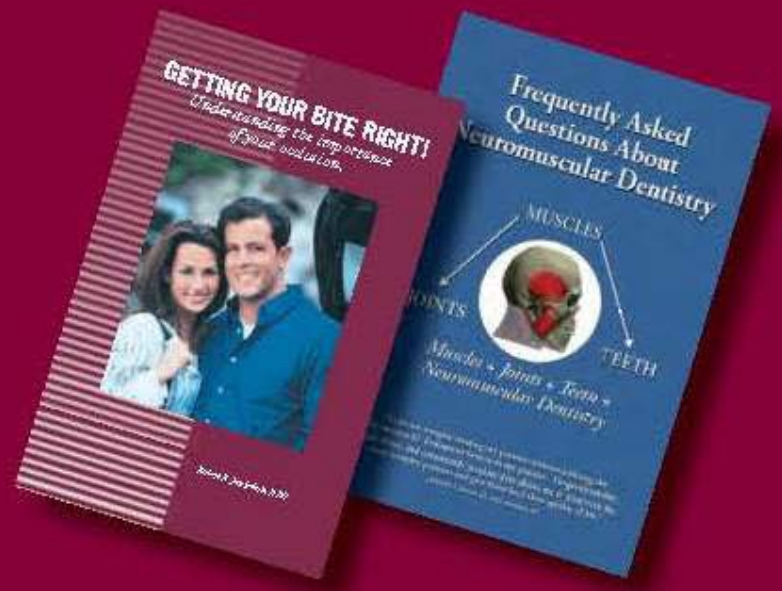

Contact Myotronics to receive information on upcoming CE courses and complimentary booklets on the benefits of Neuromuscular Dentistry. 800.426.0316 orinfo@myotronics.com.
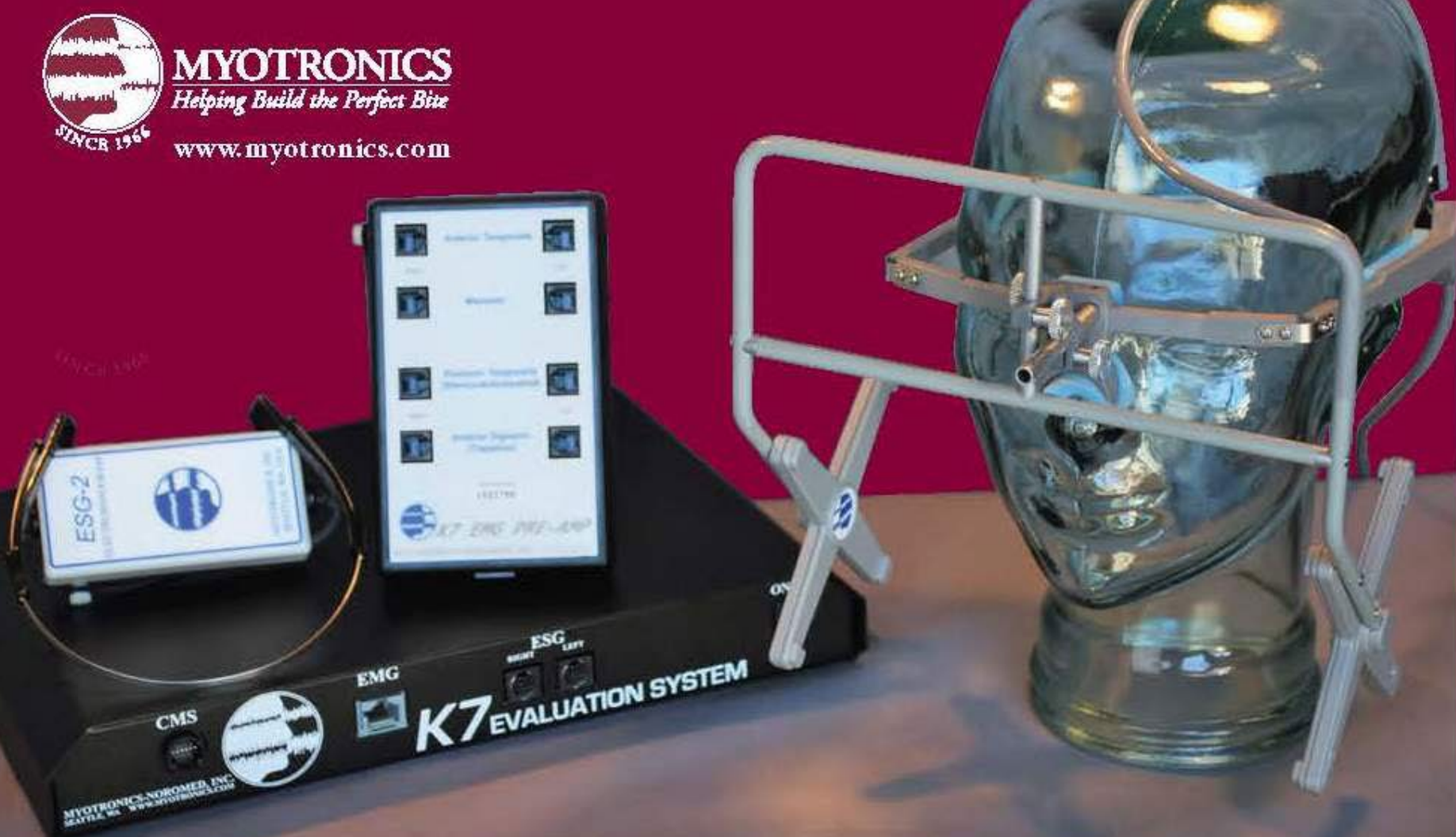


\section{Adviser of dental industry quality products: IDS 2019}

At the 38th International Dental Show (IDS), Cologne, Germany, over the five days (12-16 March, 2019), a total exposure area of $170,000 \mathrm{~m}^{2}$ was attended by 2,327 companies from 64 countries whose stands were visited by over 160,000 visitors from 166 countries.

The trade and the users mainly focused on innovative products and technologies, systems for improving digital workflows, additive production, new prophylaxis formulas for and filling materials, intraoral scanners, implant designs as well as flexible workflows for management of the laboratory.

As a first global oral hygiene innovation, the multifunctional device of Dr. Mark Wotherspoon from Australia, is an allin-one system that cleans, stores and protects all types of removable dental appliances called Dr. Mark's HyGenie ${ }^{\circledR}$. As an enthusiast of periodontal surgery, we prospered the market for additive manufacturers. At the UK company stand, EthOss Regeneration Ltd, I re-introduced the inventor of EthOss, Dr. Peter Fairbairn, and his team. EthOss $^{\oplus}$, a mixture of completely synthetic material, is a step forward in guided bone regeneration (GBR) and Bone Grafting technology. Personal experience over 2 years, the excellent results obtained and the use by oral implantologists around the world of this completely synthetic material, make me recommend you with all the warmth.

Following the introduction through the world of oral implant manufacturers, we have seen the presence of the established companies (Alpha-Bio Tec Ltd, B \& B Dental Ltd, Bicon Dental Implants, Implant Direct, MegaGen Implant Co., Ltd., Straumann Deutschland $\mathrm{GmbH}$ ) new models and some young producers. At IDS 2019, Straumann launched a new implant, BLX Implant, developed by Dr. Ophir Fromovich, a former graduate of "Carol Davila" University in Bucharest, Romania.

Reaching my constant passion for dental occlusion and instrumental occlusal analysis, I went to Dr. Jean Bausch $\mathrm{GmbH} \& \mathrm{Co}$. KG and Zebris Medical GmbH. The owner of Bausch, Dr. André Bausch and his daughter, presented to us and my father, the new OccluSense ${ }^{\circledast}$ BK 5000 system, which combines the traditional and digital recording of the pressure distribution of occlusal surfaces. Compared to the well-known T-Scan (Tekscan, Inc., South Boston, MA 02127, USA) whose 100 microns pressure sensor at OccluSense ${ }^{\circledast}$ is only 60 microns in color, it is red. Traditional color transfer on occlusal surfaces facilitates the allocation of recorded data. The data can be displayed in 2- and 3-dimensional graphs, including the digitally recorded masticatory distribution in 256 pressure levels.

Eng. Wolfgang Brunner, one of the owners of Zebris Medical $\mathrm{GmbH}$, presented us with the characteristic enthusiasm, the Optic Jaw Motion Analyzer. The new system extends Zebris' US JMA systems with state-of-theart optical sensor technology. The analyzer is made up of a handy stand-alone face with a lower jaw sensor, capable of recording the lower jaw movement range on all degrees of freedom with high precision. Its uses cover a wide range of applications, from the creation of functional dental

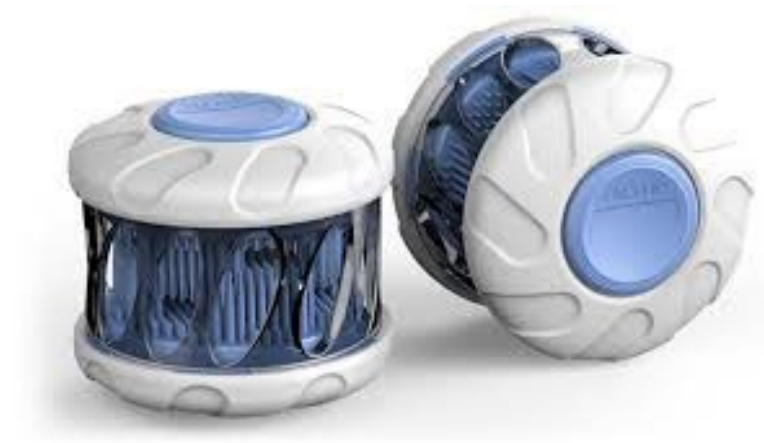

I Dr. Mark's HyGenie device (Dr. Mark's Hygenie Pty Ltd., Perth, Wa 6000, Australia) https://drmarkshygenie.com/.

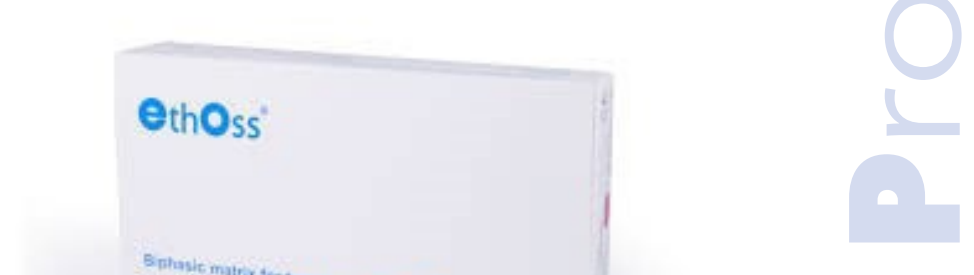

IEthOss ${ }^{\oplus}$ (Ethoss Regeneration Ltd., Silsden, BD20 0DL, UK) https://ethoss.dental//

restorations to planning, documentation and monitoring of oral rehabilitation. In addition to my IDS trip, I found that the Optic or US, JMA systems was developed by Zebris Medical $\mathrm{GmbH}$ for instrumental analysis of occlusion for 12 companies, including AXIOQUICK 3D Recorder for SAM-Dental, SICAT JMT + for SICAT GmbH \& Co. KG. KG, ARCUSdigma $^{\text {TM }}$ for KaVo Dental $\mathrm{GmbH}$.

Of course, I could continue listing the important products exhibited this year by the dental manufacturers present. I reserve for the following issues to provide you with other products of interest.

Florin - Eugen Constantinescu

DMD, PhD Student

Editorial Director, Product News

DOI: https://doi.org/10.25241/stomaeduj.2019.6(1).prodnews.1 
Office \& Showroom

98A Vulturilor Street, $3^{\text {rd }}$ District

RO-030857 Bucharest, Romania

Tel: +40 774074094

e-mail: office.romania@dentsplysirona.com

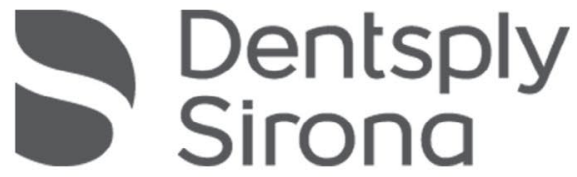

Intego

Performance you can rely on

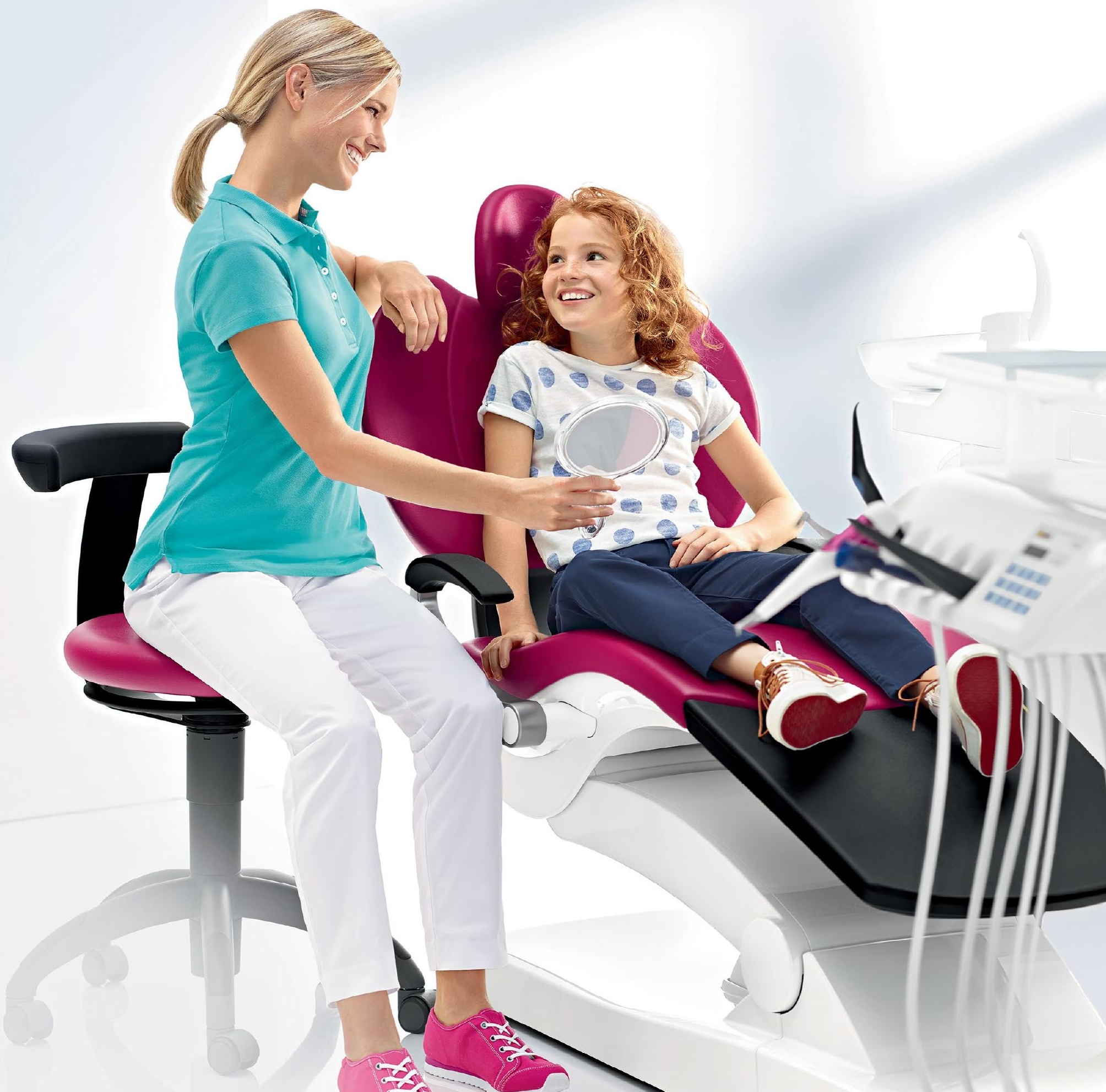




\section{Concepts in Oral Medicine - tractatio, concipio, documentatio Volume I, II, III}

Author: Rudolf Slavicek

Publisher: GAMMA medizinisch-wissenschaftliche Fortbildungs-GmbH, Austria Language: English / German

ISBN: 978-3-9501261-6-7

Edition: 1/e

Publish Year: 2015

Pages: 475, illustrated

Price: $498.00 €$

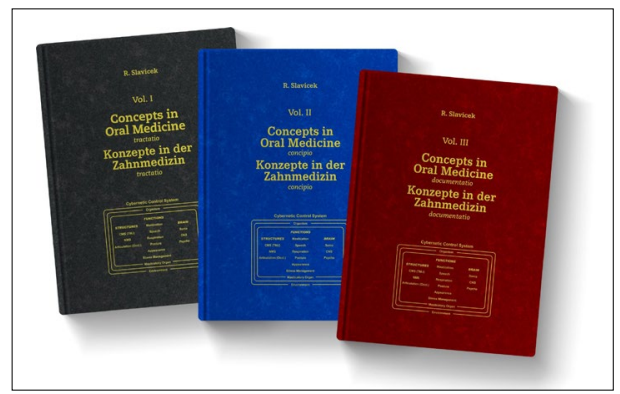

Professor Rudolf Slavicek, called his new book on the masticatory organ "Concepts in Oral Medicine" as it is the logical continuation and actualization of the book "The Masticatory Organ" (published in 2000).

The text book is divided into 3 volumes named "TRACTATIO", "CONCIPIO", and "DOCUMENTATIO".

The first volume, "TRACTATIO", is divided into 28 chapters. The author seeks to explain the meaning of the term "feedback control system" for medicine, starting with the hypothesis of the hominization evolution of the masticatory organ. Starting from the hypothesis of the dental crown morphology that functionally adapts to the neuromuscular system along the occlusion maturation in ontogenesis, it analyzes the human masticatory organ.

Moreover, the author assigns a special place to the analysis of lateral cephalometrics, the concept of dynamic lateral and frontal radiographic analysis, as well as the third dimension in cephalometry - CBCT and 3D landmarks as a necessary support in the treatment of the dysfunctional masticatory organ.

Professor Slavicek also presents clinical and instrumental functional analysis I, and clinical functional analysis II with the help of instruments (condylography).

The second volume entitled "CONCIPIO" focuses on the description of Orthoskelia, a term that represents man's correct vertical posture from the skeletal perspective, as well as complex suspension of the skull, coordinated by the neuromuscular and craniomandibular system vectors. The volume includes 14 chapters and a glossary.

After presenting the function of the human posture as an interdisciplinary dialogue, the author presents the analysis of the cyber feedback control system (CMS 1), of the cranial anatomy and the vectors.

There follows a presentation of aspects related to phylogenesis and the evolution of the masticatory organ and an analysis of he structures and functions of the ontogenesis period.

The book shows clearly and suggestively the structures of the masticatory system from the perspective of ontogenesis, principles of occlusion, TMJ, the spheres of the masticatory organ in the statics and dynamics of the wax-up technique for Class I, in the reflections on malocclusions, the idea of the vertical dimension, the lateral cephlogram, the CBCT in general diagnosis for a better correlation in the clinical function analysis. The presentation of the bipedal orthoskelia makes for a better understanding of the evolution of the whole body skeleton.

Volume 3, entitled "DOCUMENTATIO", contains 15 chapters. Each chapter contains the presentation of a clinical case treated by Professor Slavicek and his team, that is analyzed according to a well-established protocol of diagnosis, treatment objectives, treatment plan and epicrisis, all being clearly illustrated.

Professor Slavicek clarifies all the topics approached in his three volumes. Whoever is willing to refresh his basic notions on the masticatory organ must read these pages again.

Professor Rudolf Slavicek's latest book called "Concepts in Oral Medicine" comprises more than 1500 pages presenting facts and documentation on the treatment of patients along the principles of the Vienna School of Interdisciplinary Dentistry (VieSID).

DOI: https://doi.org/10.25241/stomaeduj.2019.6(1).bookreview.1

The Books Review is drafted in the reviewer's sole wording and illustrates his opinions. 


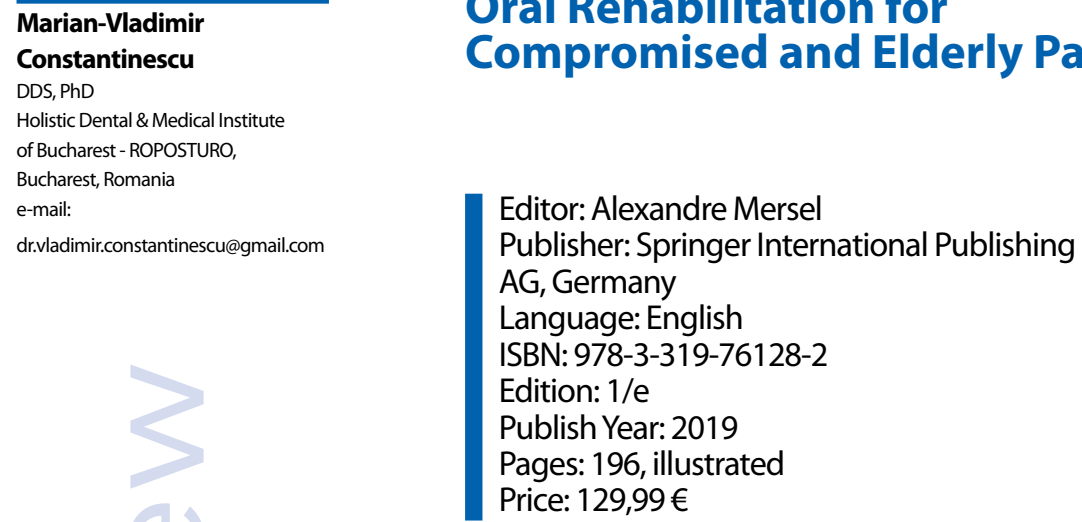

Editor: Alexandre Mersel

Publisher: Springer International Publishing

AG, Germany

Language: English

ISBN: 978-3-319-76128-2

Edition: $1 / \mathrm{e}$

Publish Year: 2019

Pages: 196, illustrated

Price: $129,99 €$

\section{Oral Rehabilitation for Compromised and Elderly Patients}

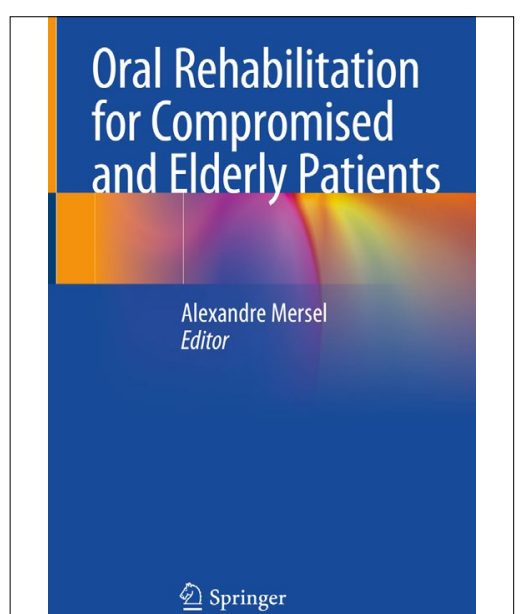

The World Health Organization (WHO) estimates that life expectancy will increase in the next 30 years and the cohort of elderly people will have an important impact on daily dental practice.

Professor Alexandre Mersel, renowned authority in geriatric dentistry, together with his 11 co-workers have drafted the book "Oral Rehabilitation for Compromised and Elderly Patients" to teach dentists how they can better provide evidence-based dental treatment for their aging patients.

This text is divided in 11 chapters. The first chapter talks about demography and aging. The correlation between systemic diseases and oral health is presented in chapter two. The third chapter explains treatment approaches for periodontal diseases and the modifiers which are linked to the biological changes due to age, chronic diseases, medications and socio-economical issues. An entire chapter provides a description of the physiological changes in endodontics, and how to decide and process a root canal treatment in elder patients. Chapter five presents some general concepts of TMD etiology, diagnosis and management. The following chapter speaks about the masticatory functions and nutritional status - considerations for an ageing population. Chapter seven and eight are dedicated to the caries destruction of the remaining teeth in the elder patients and minimalistic approach for conservative restorations such as the Minimal Invasive Treatment (MIT), infiltrations and the use of mesenchymal stem cells (MSCs) which may represent an autologous source of cells for tooth regenerative research. Chapter nine makes an evaluation of transitional or immediate complete dentures and should be specific because it has to cope with changes in the oral conditions initiated by ageing; and the last two chapters underline the limits of complete denture rehabilitation and the uniqueness of implant overdentures.

Because of the huge increase in the elderly population the general practitioner in dentistry is faced with important issues and this book with simple and easy procedures will help him overcome difficulties in these areas. Each general practitioner in dentistry who reads the book by Professor Alexandre Mersel and his renowned co-workers will find explanatory information on how to handle complex oral rehabilitation for compromised and elderly patients. 


\section{Esthetic and Restorative Dentistry Material Selection and Technique}

Authors: Douglas A. Terry, Willi Geller

Publisher: Quintessenz Verlags-GmbH, Germany

Language: English

ISBN: 978-0-86715-763-5

Edition: 3/e

Publish Year: 2018

Pages: 792, illustrated

Price: $348.00 €$

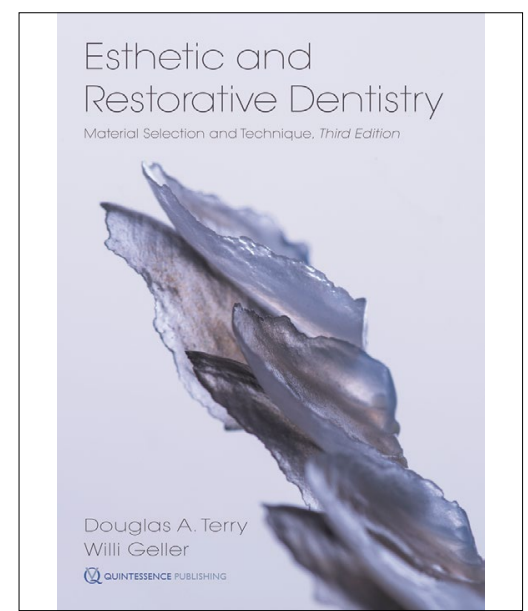

The intense and rapid development of research in dental materials and digital technologies, has made the development of new concepts for the realization of dental restorations possible.

Dr. Douglas A. Terry has become accustomed to writing high-level scientific books supplemented with clinical cases treated with the most modern aesthetic restoration methods based on an appropriate laboratory technology. His third edition of the book "Esthetic and Restorative Dentistry" is the most recent step in this evolution. The book is structured in 14 chapters and begins by establishing the diagnostic protocol based on digital photography, shade determination, diagnostic models, wax-up diagnostic and communication using eLABor_aid Concept. Further the principles of tooth preparation starting from evolution preparation design, clinical objectives of modern restorative dentistry, biomaterial selection, consideration for CAD/CAM technology and composite preparation for all five cavity classes, veneer preparation design, inlay/onlay, full coverage are presented through abundantly illustrated clinical cases. The properties and qualities of composite resins are also discussed addressing the integration, infrastructure, stress at the restorative-tooth interface, CAD/CAM resin ceramic restoration, current development in nanotechnology for each cavity class, and for diastema closure and anterior veneers. Ceramic materials also area topic of the book showing the properties, different classifications and methods. for the fabrication of a single-coping zirconia or FPD framework, and scanning methods. All ceramic crowns, feldspathic porcelain veneers, preparationless veneers, porcelain fused to metal crowns, color management of the implant supported single central incisor restorations, and balancing the esthetic zone are discussed in detail. An important stage is the impression process which is described and illustrated and includes material selection and impression techniques as well.

Mechanisms of adhesion, adhesive cements and modern interim restorative treatment concept are eloquently presented. Clinical objectives, requirements, and consideration, fabrication techniques, consideration factors in cement selection, laboratory fabrication of a composite resin FPD, direct fabrication of an anterior provisional crown, provisional veneer, indirect/direct fabrication of an implant provisional restoration and functional composite provisional are abundantly illustrated. Esthetic post systems such as direct fiber-reinforced post and core system and prefabricated fiber-reinforced post systems are discussed along this book. The authors highlight the importance of finishing and polishing esthetic restorative materials. Digital photography it is an important subject in modern dentistry and because of that an entire chapter is dedicated to this topic providing all the necessary informations like: camera system, reflective exposure measurement, guidelines for camera selection and application of digital camera systems. The end of the book brings us information about periodontal plastic surgery, including crown lengthening procedures and mucogingival surgical procedures, translating the gummy smile, and connective tissue grafting for various classes of recession type defects; interdisciplinary implantology diagnosis, assessment and treatment planning, implantation and placement and interdisciplinary surgical strategy; biomodification of tooth discoloration, based on extrinsic and intrinsic stains origin and conservative tooth correction treatment through vital and nonvital bleaching.

Dr. Douglas A. Terry, starting from the new esthetic and restorative dentistry philosophy shows us three principles for treating patients: prevention, preservation and perpetuation of longevity. He has succeeded, together with Maestro Willi Geller and his renowned referents, to accomplish an exhaustive volume through text and an exceptional over 2500 figures. This is useful book for every dentist who aims at restoring aesthetic at the highest scientific and technological level.

DOI: https://doi.org/10.25241/stomaeduj.2019.6(1).bookreview.3

The Books Review is drafted in the reviewer's sole wording and illustrates his opinions. 


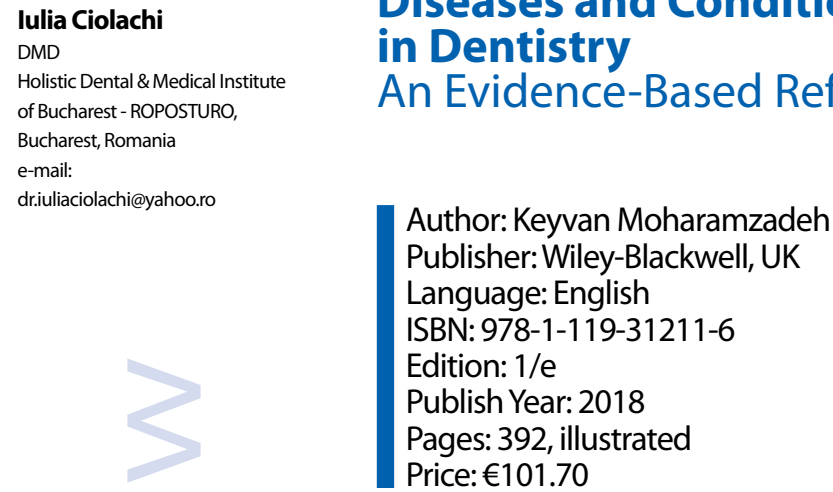

Author: Keyvan Moharamzadeh

Publisher:Wiley-Blackwell, UK

Language: English

ISBN: 978-1-119-31211-6

Edition: $1 / \mathrm{e}$

Publish Year: 2018

Pages: 392, illustrated

Price: $€ 101.70$

\section{Diseases and Conditions in Dentistry \\ An Evidence-Based Reference}

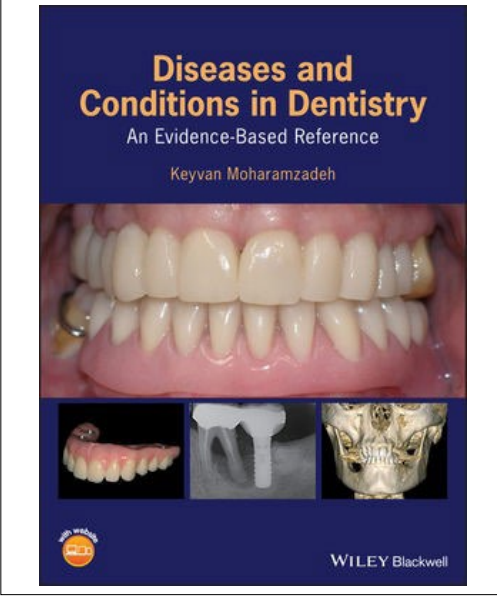

This reference book on dental diseases and conditions in endodontics, periodontics, prosthodontics and restorative dentistry, with detailed clinical cases and evidence-based discussions constitutes a guide for dentistry clinicians. It is the result of 7 years of hard work by Dr. Keyvan Moharamzadeh, Senior Clinical Lecturer and Honorary Consultant in Restorative Dentistry and Specialist in Prosthodontics, Periodontics, Endodontics and Restorative Dentistry, at the University of Sheffield, a book in which he gathered the essence of thousands of pages of relevant dental books and articles. The book is divided in 50 chapters and an index, containing over 100 hours of continuing professional development reading for GDPs and specialists. In order to make each chapter easier to read, the author uses the same format, including definitions, etiology, classifications, epidemiology, relevant history and special investigations, diagnosis, prognosis, treatment challenges, management options, maintenance issues, and relevant evidence from the literature.

To allow a better understanding the book is accompanied by a website with additional clinical photographs, radiographs, and case notes. Diseases and conditions in dentistry are presented in alphabetical order covering every issue that might be encountered during daily practice from amelogenesis imperfecta and chronic periodontitis to external root resorption, to temporomandibular disorders.

The book is an excellent guide for under- and post-graduate students, and for those preparing for the ORE, MFDS, MSc, MRD, ISFE, MClinDent, and DClinDent specialty exams.

DOI: https://doi.org/10.25241/stomaeduj.2019.6(1).bookreview.4

\section{Therapeutic Ultrasound in Dentistry \\ Applications for Dentofacial Repair, Regeneration, and Tissue Engineering}

Editors: Tarek El-Bialy, Eiji Tanaka, Dror

Aizenbud

Publisher: Springer International

Publishing AG, Germany

Language: English

ISBN: 978-3-319-66322-7

Edition: $1 / \mathrm{e}$

Publish Year: 2018

Pages: 96, illustrated

Price: $117,69 €$

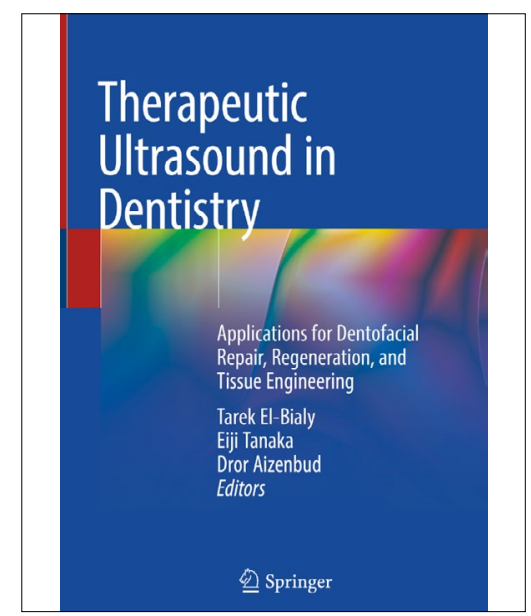

This book highlights a new possibility of dental treatment for some pathological conditions considered untreatable with conventional methods by the use of low-intensity pulsed ultrasound (LIPUS). The book is divided in 11 chapters. A series of information on LIPUS aspects, how to act and the biological mechanisms on dentofacial bioengineering are presented. The role of LIPUS for bone healing, skeletal muscles, periodontal tissue regeneration, temporomandibular joints and salivary glands is convincingly explained in a number of chapters. LIPUS application in orthodontics, dentofacial region, shockwave therapy in orthodontics, and pulp cell differentiation and future directions are the subjects of other chapters.

The authors, presenting and illustrating the latest discoveries and uses of ultrasound in dentistry, manage to attain their aim and write a particularly useful book for dental surgeons, orthodontists, periodontologists, and other practitioners. 


\section{Application of the Neutral Zone in Prosthodontics}

Authors: Joseph J. Massad, David R.

Cagna, Charles J. Goodacre, Russell A.

Wicks, Swati A. Ahuja

Publisher:Wiley-Blackwell, UK

Language: English

ISBN: 978-1-1191-5814-1

Edition: 1/e

Publish Year: 2017

Pages: 176, illustrated

Price: $71.50 £$

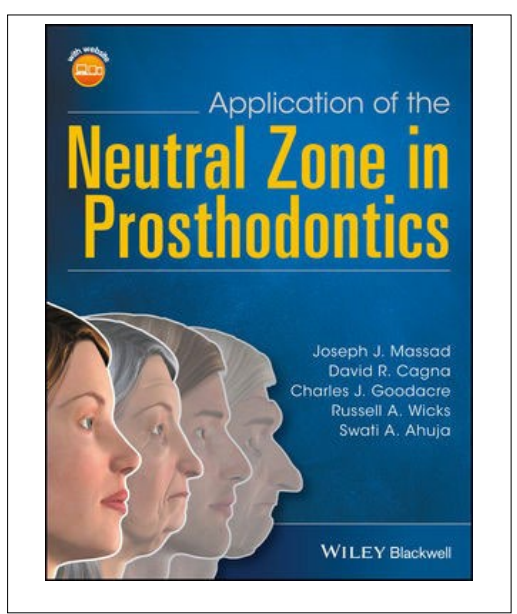

Marian-Vladimi

Constantinescu

DDS, PhD

Holistic Dental \& Medical Institute of Bucharest-ROPOSTURO

Bucharest, Romania

dr.vladimir.constantinescu@gmail.com

The success of the edentulous patients' treatment also involves understanding the importance of the neutral zone in prosthetic dentistry. Professor Joseph J. Massad, together with his colleagues, has sought to provide us with the methods and techniques in which the neutral zone must be incorporated.

The book entitled "Application of the Neutral Zone in Prosthodontics" contains 11 chapters and an index. The main objective of the book is to describe the current procedures in fabricating prostheses that include the neutral zone: implant-supported overdentures, fixed complete dentures and complete dentures.

The authors exemplify the evaluation of edentulous patients, starting with the interview, facial analysis, prosthetic factors, oral characteristics, and then moving on to conditioning the abused tissues and stabilizing the existing prosthesis, seeking re-establishing the orthopedic mandibular position.

There is an innovative, personal technique useful for each type of clinical prosthesis that simplifies fingerprinting, and reduces the number of clinical procedures.

After the production of the definitive models, it continues with the laboratory procedures, the production of record bases, occlusal rims and the mounting of a central bearing device (designed by Massad) indicated in the preparation of the clinical phase of recording the centric relation.

After adjusting the wax occlusal rim in alignment with the facial shape, mount the maxillary cast in the articulator to the transverse horizontal axis and then record the centric relation with the jaw recorder device. A separate chapter covers the recording of the physiological neutral zone for edentulous patients with an impression compound, and for a dentate patient with vinyl polysiloxane (VPS)impression material. Then there follows the selection and arrangement of the anterior teeth, maxillary and mandibular, and then the posterior, mandibular and maxillary teeth, depending on neutral zone registration. There follows the evaluation of wax trial dentures, firstly extra-oral evaluation, the teeth arrangement on the articulator, and then the intra-oral evaluation, esthetics, phonetics, OVD, CR position, and realization of external impressions through appropriate movements to physiologically mold the labial and buccal polished surfaces for one arch at a time.

The treatment is completed by a series of procedures necessary for definitive dentures integration. In the last chapter the book shows a detailed presentation of the use of CAD / CAM technology to record and fabricate neutral zone dentures.

The book is a valuable guide for students, general dentistry residents, prosthodontics, and practitioners who want to understand the neutral zone as a guarantee of the success of a prosthetic treatment.

DOI: https://doi.org/10.25241/stomaeduj.2019.6(1).bookreview.6

The Books Review is drafted in the reviewer's sole wording and illustrates his opinions. 


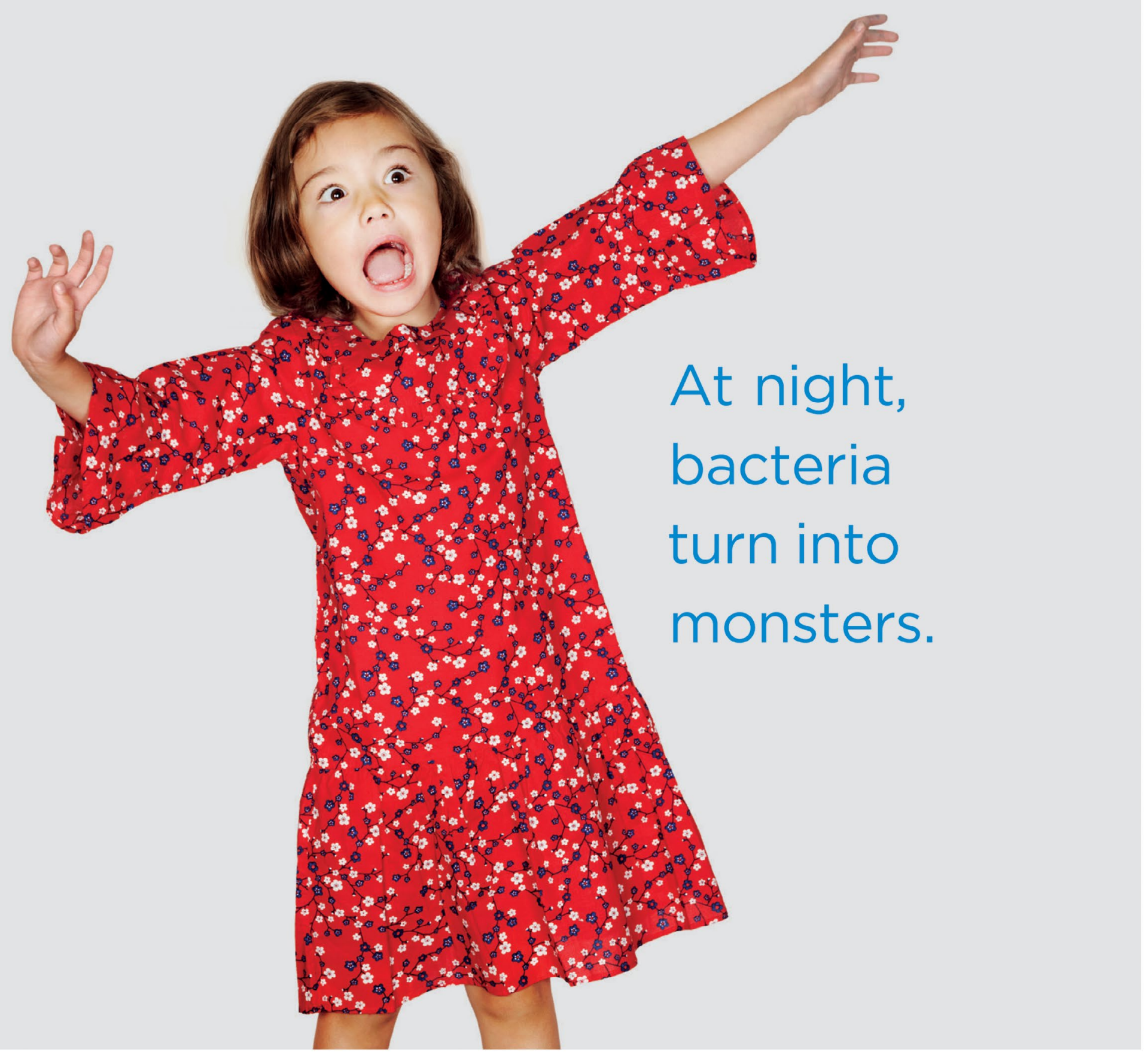

\section{We care. We protect you.}

... and there is a bit of truth in every cliché.

Over the course of a day, a total of eight billion bacteria form in your treatment center. They might not turn into monsters at night, but should not be underestimated. That means taking infection prevention seriously. And that's why an automatic cleaning system prevents infections and can save you up to 2.5 hours of your time per month.

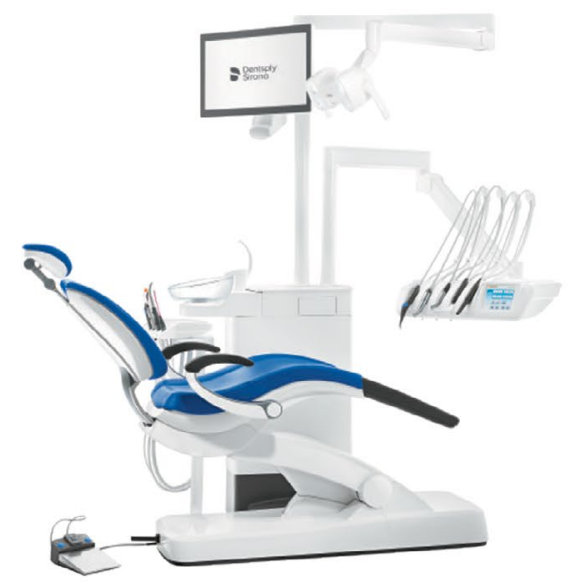


The Stomatology Edu Journal (Stoma Edu J) is a quarterly international journal, double blind peer-reviewed, open access journal to be database indexed, which accepts original articles for publication in all aspects of dental development and research. It addresses those interested in oral and maxillofacial sciences including students, graduates, postgraduates, educators, researchers, dental practitioners, those involved in dental industry and policy-makers relevant to the practice of dentistry.

\section{Submission Instructions}

The Stomatology Edu Journal (Stoma Edu J) publishes articles written only in English. All articles will be accompanied by the signed copyright form which can be returned by e-mail, fax (as scanned documents). All the responsibility for the originality of the material sent belongs to the author(s) alone. Each article will be evaluated by the peer-review committee composed of two independent peer-reviewers, in a blinded fashion, according to the peer-review protocol. All manuscripts must be original and exclusive. The Stomatology Edu Journal Editor will consider only articles that are original, have not been published elsewhere and have been submitted exclusively to the Stomatology Edu Journal. The manuscripts should be submitted online at www. ManuscriptManager.net/stom.

\section{Ethics in publishing}

The Stomatology Edu Journal (Stoma Edu J) and its editoria board fully adhere and comply to the policies and principles of Committee on Publication Ethics (COPE) (https:// publicationethics.org/files/2008 Code of Conduct.pdf). Your manuscript should not contain any information that has already been published. If you include already published figures or images, please obtain the necessary permission from the copyright holder to publish under the CC-BY license. Plagiarism, data fabrication and image manipulation are not tolerated. Plagiarism is not acceptable in the Stomatology Edu Journal (Stoma Edu J) submissions. Plagiarism includes copying text, ideas, images, or data from another source, even from your own publications, without giving any credit to the original source. Reuse of text that is copied from another source must be between quotes and the original source must be cited. If a study's design or the manuscript's structure or language has been inspired by previous works, these works must be explicitly cited.

If plagiarism is detected during the peer review process, the manuscript may be rejected. If plagiarism is detected after publication, we may publish a correction or retract the paper. Image files must not be manipulated or adjusted in any way that could lead to misinterpretation of the information provided by the original image. To verify the originality of content submitted to our journals, we use iThenticate (www.ithenticate. com) to check submissions against previous publications. All submitted manuscripts will be checked for any possible duplication or plagiarism with iThenticate (www.ithenticate. com). Nevertheless, corresponding authors are responsible for any fraud, intentional or unintentional malpractice.

\section{Articles sent for publishing}

The Stomatology Edu Journal (Stoma Edu J) publishes: original articles; reviews; case reports; technical procedures; consensus declaration coming from an association or from a group of specialists; letters to the editor. All articles must be up to 3,000 and 5,000 words for meta- analysis (the word count is for the manuscript text only). Letters to the editor must not exceed 400 words of text and have no more than 3 authors. Letters to the editor can be related to an article already published in the journal or it can represent original scientific contributions or events news/presentations etc. of interest for the reader.

\section{Permissions and Ethics}

For citations, tables, figures etc. which are not original, these must be accompanied by the written permission for their use and the full reference must be provided. Photographs of identifiable persons must be sent alongside the written permission of the person(s) and all regions that may allow the identification of the subject must be covered. The author must have obtained, for all studies including human subjects, the permission of the subjects to be part of the study whilst keeping their anonymity. By sending the article, the author declares that he obtained this permission from all his subjects. All studies must respect the Helsinki Declaration (1975). For human and animal studies, the authors must have obtained the approval of the ethics committee from the University/Institute/etc. where the study was done. Consent for publication is required for studies involving human subjects - ALL case reports, letters that describe cases and some original articles. Cohort studies are exempt; instead evidence of IRB approval (name of IRB, date of approval and approval code/reference number) must be provided.

\section{Manuscript preparation}

The article must be written in conformity with the general recommendations of the International Committee of Medical Journal Editors. http://www.icmje.org/icmjerecommendations.pdf

The Stomatology Edu Journal (Stoma Edu J) uses double-blind review, which means that both the reviewer and author name(s) are not allowed to be revealed to one another for a manuscript under review. The identities of the authors are concealed from the reviewers, and vice versa. To facilitate this, please include the following separately:

Title page (with author details): This should include the title, authors' names and affiliations, and a complete address for the corresponding author including an e-mail address, Author Contributions, Acknowledgements and Curriculum Vitae.

Blinded manuscript (no author details): The main body of the paper (including the references, figures, and tables) should not include any identifying information, such as the authors' names or affiliations.

The articles must be sent either as a Microsoft Word 2000 document $\left({ }^{*}\right.$.doc) or as a Microsoft Word 2003 document (*.docx). The article will be written using Times New Roman font, size 12 for the characters with one and half $(11 / 2)$ spaces between paragraphs. The manuscript must be sent in its final form. The pages will be numbered with the manuscript containing the following sections: title, authors, abstract, keywords, the text of article, contributions, acknowledgments, references, the figures and the tables legend.

A. The title of the manuscript will have a maximum of 100 characters without spaces, written in title case, centered capitals, and in 12 point bold Times New Roman font at the top of page. Abbreviations should be avoided within the title.

B. The author(s) will send their full name(s) and surname(s) the highest academic position, their full titles and their affiliations. All names are listed together and separated by commas. Provide exact and correct author names as these will be indexed in official archives. Affiliations should be keyed to the author's name with superscript numbers and be listed as follows: Laboratory, Department, Institute, Organization, City, State abbreviation (USA, Canada, Australia), and Country (without detailed address information such as city zip codes or street names).

The correspondent author will send his/her full name and surname, the highest academic position, his/her full title, his/ her affiliation, his/her institution address, his/ her telephone, fax and e-mail. The authors will send this information in the same format as that in the published articles.

\section{The Structured Abstract}

The abstract can have a maximum of 250 words. After the abstract, the author(s) must mention a maximum of 5 keywords. Keywords must be selected from Medline Mesh. Abbreviations are not accepted in the title or the abstract.

The abstract for Original Scientific Articles should be no more than 250 words using the following structure: Introduction; Methodology; Results; Conclusion.

The abstract for Review Articles should be no more than 250 words with the authors covering all the following information regarding the subject presented under the following subheadings: Background, Objective, Data Sources, Study Selection, Data Extraction, Data Synthesis.

The abstract for Case Reports should be no more than 250 words using the following structure: Aim, Summary and Key learning points: provide up to 5 short statements of the report The abstract for Clinical Articles should be no more than 250 words using the following structure: Aim, Methodology, Results and Conclusions. 


\section{The Article Text}

Headings and Sub-headings

Except for special names (e.g. GABAergic), capitalize only the first letter of headings and subheadings. Headings and subheadings need to be defined in Times New Roman, 12, bold. You may insert up to 5 heading levels into your manuscript (not more than for example: 3.2.2.1.2 Heading title).

For original articles:

1. Introduction - a presentation of the most important aspects in the studied domain without doing a review of the literature. The purpose of this part is to present and backup the hypothesis on which the study was based.

2. Material and Methods - this section will include all required information so that the reader can verify the validity of the study including, but not limited to, subjects, measurements, statistics and ethics. The methods used should be discussed (why the methods have been chosen, which the limitations/ advantages). A paragraph about the statistical analysis is required as well.

3. Results - the results of the study will be presented in a descending order of importance. An interpretation of the results will not be done in this section.

4. Discussion - the authors will present the way the results backup the original hypothesis, as well as the way in which the results are backed up or contradicted by the published literature. A paragraph must be dedicated to presenting the limitations of the study.

5. Conclusion - The conclusion presents the implications of this latest work. In addition, authors may consider discussing future plans or recommendations for future research etc. For all other types of articles, we recommend the use of a clear structure based on sections and sub-sections.

\section{E. Author Contributions}

The Author Contributions section is mandatory for all articles, including articles by sole authors. The Author Contributions statement must describe the contributions of individual authors and, in doing so, all authors agree to be accountable for the content of the work. Please list only 2 initials for each author, without periods, but separated by commas (e.g. AC, AS). In the case of two authors with the same initials, please use their middle initial to differentiate between them (e.g. AEC, ASC). Each author must be able to prove his active participation in the study by contributing to the concept, protocol, data gathering or analysis, their interpretation or by critically revising the manuscript.

\section{F. Acknowledgments}

Acknowledge persons who have made substantive contributions to the study. Specify grant or other financial support, citing the name of the supporting organization and grant number.

\section{G. References}

- The references will be written using the Vancouver style (https://www.imperial.ac.uk/media/imperial-college/ administration-and-support-services/library/public/vancouver. pdf). All references that are identified with DOI (Digital Object Identifier) must be mentioned.

- For each reference use active links to the full text (DOI link), free PMC article, PubMed, Google Scholar, and Scopus pages, were they exist:

- For all references identified with DOI the full-text link must be the CrossRef hyperlink

\section{Examples}

\section{Articles with DOI}

Singbartl G. Pre-operative autologous blood donation: clinical parameters and efficacy. Blood Transfus. 2011;9(1):10-18.

[CrossRef] [Free PMC Article] [PubMed] Google Scholar Scopus Articles without DOI

Mehta H, Shah S. Management of Buccal Gap and Resorption of Buccal Plate in Immediate Implant Placement: A Clinical Case Report. J Int Oral Health. 2015;7(Suppl 1):72-75.

\section{[Full text links] [PubMed] Google Scholar}

- The references will be numbered, in the order they appear in the text, in square brackets, as such: [3], [5,7-9].

- All sources found in the text must be present in the bibliography and all the papers mentioned in the bibliography must appear in the text.

- For references with more than 5 authors, list the first 3 authors followed by "et al."
- Full-page ranges should be given in expanded form (e.g.. 426429, not 426-9).

- If non-English-language titles are translated into English, bracketed indication of the original language should follow the title.

- All journals will be abbreviated and italicized names of journals according to the style in PubMed; refer to the National Library of Medicine (NLM) Journals Database (http://www.ncbi.nlm. nih.gov/nlmcatalog/journals) if needed. Journal names will be abbreviated according to the List of Title Word Abbreviations - Information obtained from sources which are not published yet, but accepted for publishing will include at the end of the reference the mention "in print" between round parentheses.

- If the cited results have not been published yet the mention will be "personal communication" written in the text of article between round parentheses.

- Only references read by the authors of the article will be cited.

- An original article will have at most 50 references, a review will have at most 100 references, a letter to the editor 5 references, whilst all other types of articles will have the minimum number of references required.

\section{Curriculum Vitae - Ultra Short version}

Please provide a brief presentation of the first author and his contribution in the field, of maximum 130 words (with a $3.5 \times 4.5$ $\mathrm{cm}$ color photo).

\section{Figures, Images, Tables}

All illustrations must be numbered and cited in the text in order of appearance.

Figures and Images will be drawn professionally and sent in separate file(s) as jpeg, tiff or png files. Illustrations should preferably fill single column width $(54 \mathrm{~mm})$ after reduction, although in some cases $113 \mathrm{~mm}$ (double column) and $171 \mathrm{~mm}$ (full page) widths will be accepted. See the Image quality specifications chart for details. Image files also must be cropped as close to the actual image as possible.

In the text, each figure must be represented by a number, a title and a description. The authors will indicate where should the figure be placed in the text. All images or figures must come from the author's personal collection or the author must have rights to publish the image or figure. All images must be at or above intended display size with the following image resolutions: Line Art $800 \mathrm{dpi}$, Combination (Line Art + Halftone) 600 dpi, Halftone 300 dpi. We do not accept images or figures taken from the Internet.

The Tooth Identification System used in manuscripts must conform to the FDI International System. Units used in manuscripts must conform to the Système Internationale d'Unités (SI).

Tables will be included in the text and each table will have a number and a short description if required.

\section{Ownership Rights}

By sending the article for publication the author(s):

- take full responsibility for the scientific content of the text and for the accuracy of the send data;

- become (co)author(s) of the manuscript (all further plagiarism accusation are addressed solely to the author(s) who signed the manuscript);

- declare they are the rightful owners of the images, figures and/or information sent for publishing and that they have the permission to publish all the materials for which they do not own the intellectual property rights;

- declare that the message/content of the manuscript is not influenced in anyway by commercial interests/previous engagements/ any sort of relations with other people or companies;

- transfer all rights for the manuscript to the Editorial Council for the Stomatology Edu Journal.

\section{Other}

Previously mentioned limitations can be ignored in special cases with the agreement of the chief-editor and/or the publisher. All published materials cannot be returned.

Not taking into consideration the recommen-dations mentioned before can lead to delay in publishing the materials or may lead to not publishing the article.

The Stomatology Edu Journal (Stoma Edu J) also helps authors measure the impact of their research through specialist partnerships with Kudos and Altmetric. 


\section{SUBSGRIPTION}

\section{I want to subscribe to stonacouj}

- 1 year Subscription (4 issues of the journal) - 280 RON (72 Euro for foreign subscribers)

- 2 years Subscription ( 8 issues of the journal) - 540 RON (136 Euro for foreign subscribers)

- Single Issue - 80 RON (20 Euro for foreign subscribers)

Please send the filled subscription at the following e-mail: roposturo@gmail.com.

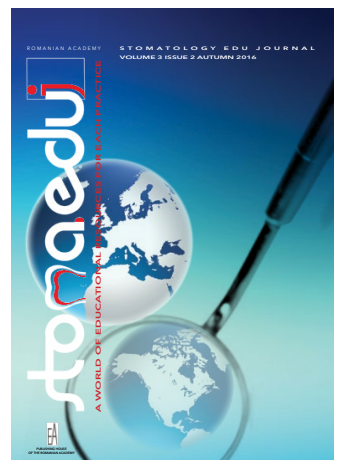

\section{PLEASE COMPLETE ALL THE SUBSCRIPTION FIELDS IN CAPITAL LETTERS!}

Name.......................................... Surname

Mrs. $\square$ Mr. $\square$ Ms. $\square$

Home Address

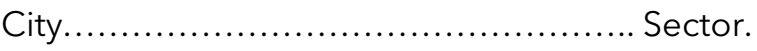

Mobile phone...

Post office code

E-mail:.

................ Web.

Student $\square$ Resident $\square$ Specialist doctor $\square$ Primary doctor

Competence.

Institution...

Activity domain: $\square$ Private $\square$ Public

Department....

Position.

Specialty

Institution address

City.

Sector

District.

Post office code

Phone.

E-mail:

Web.

CUI (Institution Unique Registration Code)

VAT Payer: $\square$ Yes $\square$ No

Invoice - please fill all the necessary details for invoice:

Name.

CNP (Personal Identification Number).

Or

Institution

CUI (Institution Unique Registration Code).

Date.

After filling the subscription, please send it together with the proof of payment to:

\section{ROMANIAN ACADEMY PUBLISHING HOUSE}

13, Calea 13 Septembrie, $5^{\text {th }}$ District

RO-050711 Bucharest, Romania

Tel: +4021318 81 46, 40213188106

Fax: +402131824 44

e-mail: edacad@ear.ro

www.ear.ro

\section{S.C. MANPRES DISTRIBUTION S.R.L.}

1, Piaţa Presei Libere, Corp B

3rd floor, room 301-302, $1^{\text {st }}$ District

RO-013701 Bucharest, Romania

Tel/Fax: +40213146339

e-mail: abonamente@manpres.ro

www.manpres.ro 


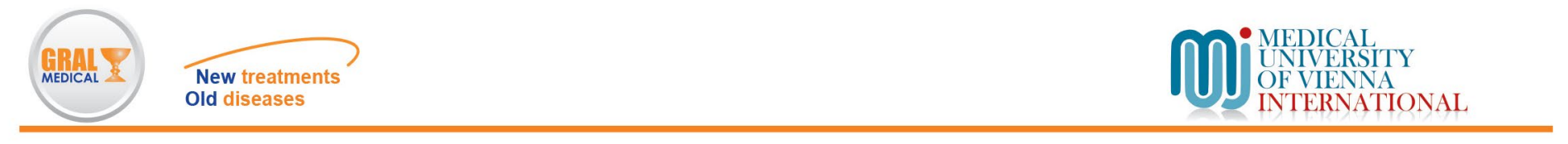

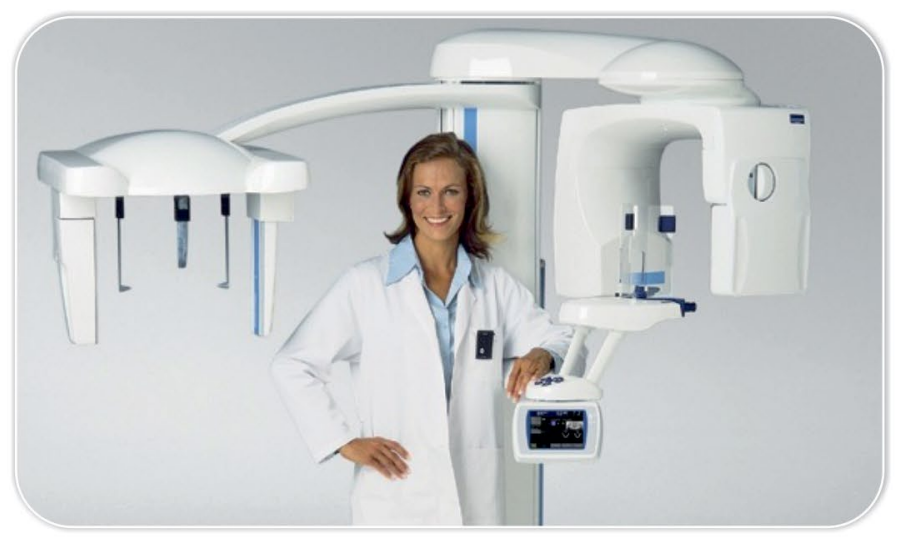

\section{ORTHODONTIC X-RAYS (RADIOGRAPHS)}

Profile (lateral) cephalometric views

Standard OPG (Orthopantomogram) for adults and children (magnification 1.3-1.6)

Orthodontic diagnostic photos

\section{X-RAYS (RADIOGRAPHS) FOR SPECIAL TREATMENTS} Standard OPG (Orthopantomogram) for adults and children (magnification 1.3-1.6)

Ortoradial orthopantogram for adults and

children (magnification 1.3-1.6)

Orthopantogram with reduced for adults and children

Combination for the same patient

(standard OPG +orthoradial+ reduced shadow)

Four-view TMJ- right to left joint

Anterior maxillary sinus panoramic radiographs

Posterior maxillary sinus panoramic radiographs

Salivary gland panoramic radiographs

Prophile (lateral) cephalometric radiographs

Orthodontic diagnostic photos

\section{D CT SCANS}

Full maxilla and mandible CT scan

Maxilla and maxillary sinus CT scan

Mandible and mandible

Mandible and mandibular canal CT scan

Partial maxillary and mandibular CT scan

TMJ CT scan

CT scan of included teeth

\section{MRI -CT}

Ortho-maxillofacial MRI

Ortho-maxillofacial CT

Examination of the throat using a special protocol for: cavum; oropharynx, oral cavity, tongue, soft palate, salivary glands, larynx and hypopharynx is conducted only at 79-91, Traian Popovici Street, $3^{\text {rd }}$ District,

RO-031422 Bucharest, ROMANIA

Tel: 021-323.00.00 | 0731-494.688
The Plevnei Gral Medical Dental Imaging Center provides dental imaging services dedicated to obtaining a quick and correct dental diagnostic in order to plan an adequate and efficient treatement.

Our state-of-the-art equipment provides dentists, implantologists or maxillofacial surgeons with accurate 2D and 3D images of the structures they will work upon, being of real service to the patients, by practically eliminating all major intervention-associated risks, both due to the use of very low radiation doses and the easy and comfortable positioning of the patient.
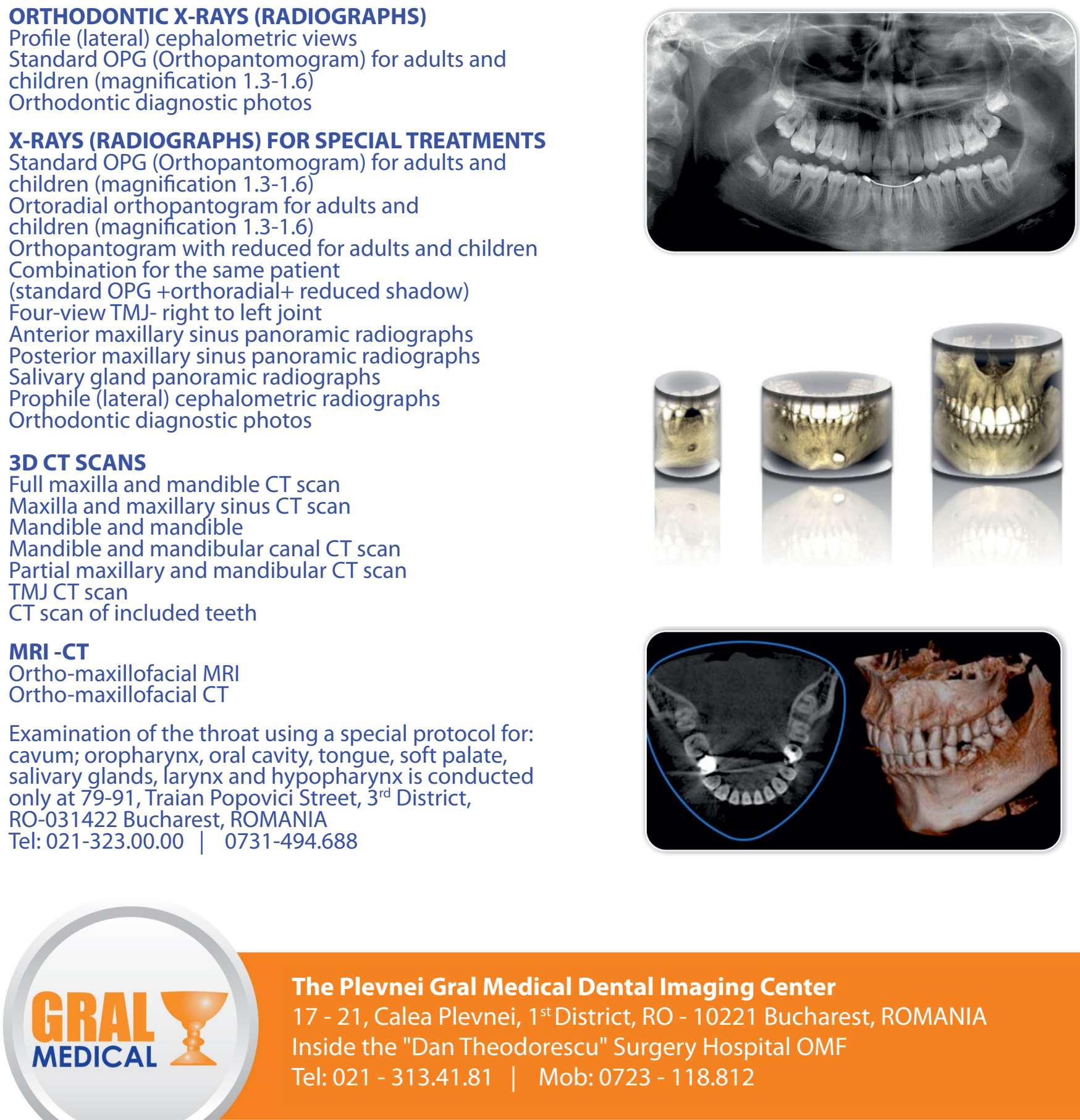


\section{Be a part of something extraordinary.}
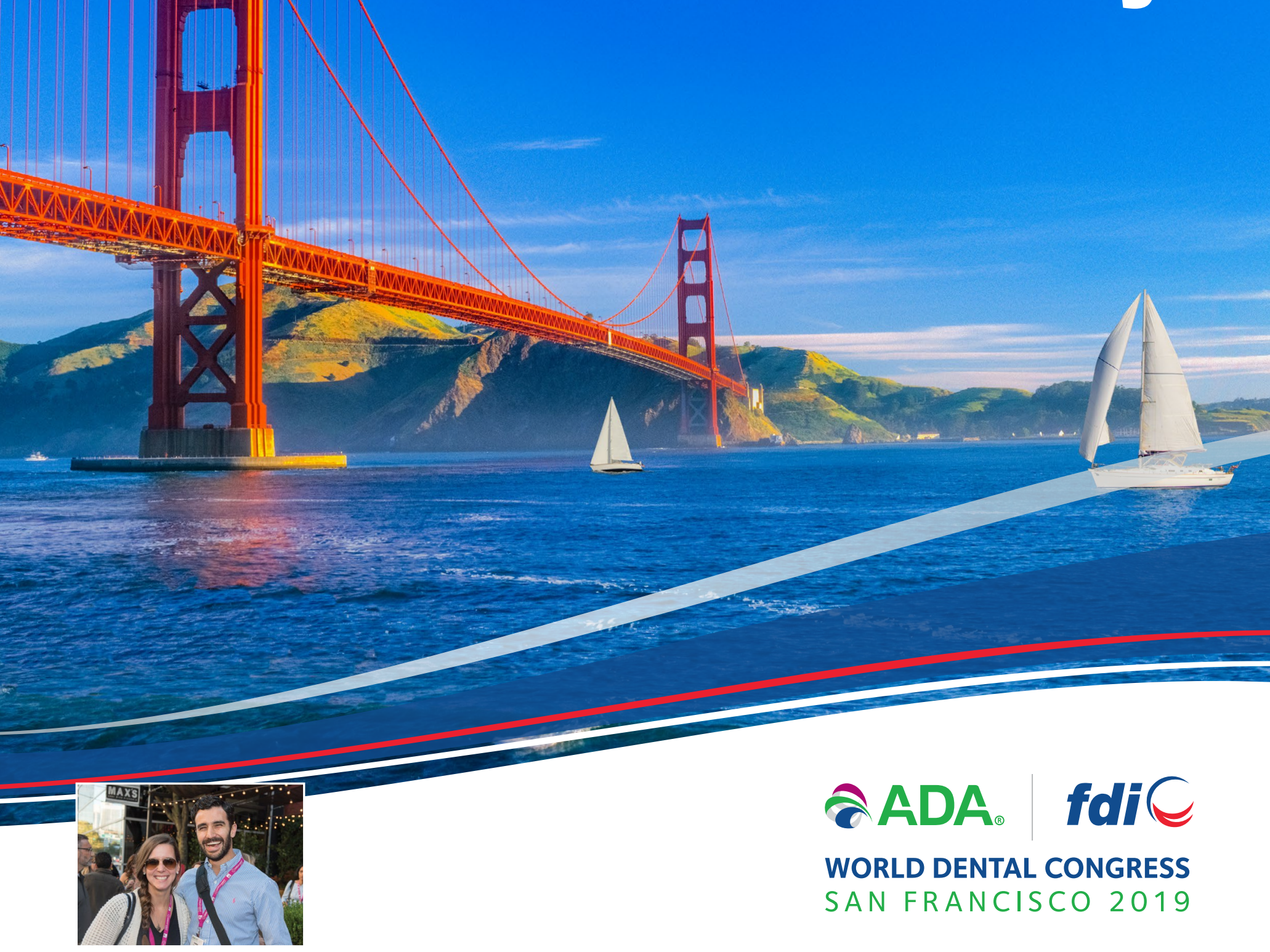

2ADA. fdiC

WORLD DENTAL CONGRESS

SAN FRANCISCO 2019

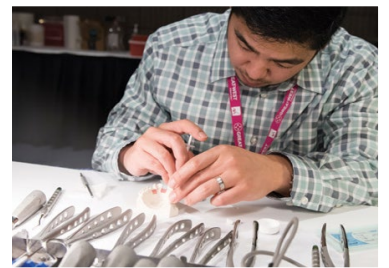

4-8 September 2019 Moscone Convention Center 3 DAYS OF EXHIBITION

5-7 SEPTEMBER

\section{SCIENTIFIC PROGRAMME}

2 HALF DAYS (4, 8 SEPT) \& 3 FULL DAYS (5-7 SEPT)

- MORE THAN 1,300 STANDS

- 200 WORLDWIDE SPEAKERS

- 40,000 M² OF EXHIBITION SPACE

- MORE THAN 30,000 PARTICIPANTS 